\title{
Interventions for visual field defects in people with stroke (Review)
}

Pollock A, Hazelton C, Rowe FJ, Jonuscheit S, Kernohan A, Angilley J, Henderson CA, Langhorne P, Campbell P

Pollock A, Hazelton C, Rowe FJ, Jonuscheit S, Kernohan A, Angilley J, Henderson CA, Langhorne P, Campbell P. Interventions for visual field defects in people with stroke.

Cochrane Database of Systematic Reviews 2019, Issue 5. Art. No.: CD008388.

DOI: 10.1002/14651858.CD008388.pub3. 
TABLE OF CONTENTS

HEADER 1

ABSTRACT

PLAIN LANGUAGE SUMMARY

SUMMARY OF FINDINGS

BACKGROUND

OBJECTIVES

METHODS

RESULTS

Figure 1.

Figure 2.

Figure 3.

DISCUSSION

AUTHORS' CONCLUSIONS

ACKNOWLEDGEMENTS

REFERENCES

CHARACTERISTICS OF STUDIES

DATA AND ANALYSES

Analysis 1.1. Comparison 1: Restitutive interventions versus control, placebo or no intervention, Outcome 1: Visual field ........

Analysis 1.2. Comparison 1: Restitutive interventions versus control, placebo or no intervention, Outcome 2: Quality of life ....

Analysis 2.1. Comparison 2: Compensative interventions versus control, placebo or no intervention, Outcome 1: Visual field ..

Analysis 2.2. Comparison 2: Compensative interventions versus control, placebo or no intervention, Outcome 2: Extended activities of daily living

Analysis 2.3. Comparison 2: Compensative interventions versus control, placebo or no intervention, Outcome 3: Reading ......

Analysis 2.4. Comparison 2: Compensative interventions versus control, placebo or no intervention, Outcome 4: Quality of life

Analysis 2.5. Comparison 2: Compensative interventions versus control, placebo or no intervention, Outcome 5: Scanning cancellation

Analysis 2.6. Comparison 2: Compensative interventions versus control, placebo or no intervention, Outcome 6: Adverse events

Analysis 3.1. Comparison 3: Substitutive interventions versus control, placebo or no intervention, Outcome 1: Functional Activities of Daily Living

Analysis 3.2. Comparison 3: Substitutive interventions versus control, placebo or no intervention, Outcome 2: Visual field ...... Analysis 3.3. Comparison 3: Substitutive interventions versus control, placebo or no intervention, Outcome 3: Extended activities of daily living

Analysis 3.4. Comparison 3: Substitutive interventions versus control, placebo or no intervention, Outcome 4: Reading ......... Analysis 3.5. Comparison 3: Substitutive interventions versus control, placebo or no intervention, Outcome 5: Falls ............... Analysis 3.6. Comparison 3: Substitutive interventions versus control, placebo or no intervention, Outcome 6: Quality of life .. Analysis 3.7. Comparison 3: Substitutive interventions versus control, placebo or no intervention, Outcome 7: Scanning cancellation

Analysis 3.8. Comparison 3: Substitutive interventions versus control, placebo or no intervention, Outcome 8: Adverse events .

Analysis 4.1. Comparison 4: Assessment or screening versus control, placebo or no intervention, Outcome 1: ADL ................. ADDITIONAL TABLES

APPENDICES

WHAT'S NEW

HISTORY

CONTRIBUTIONS OF AUTHORS

DECLARATIONS OF INTEREST

SOURCES OF SUPPORT

DIFFERENCES BETWEEN PROTOCOL AND REVIEW

INDEX TERMS 
[Intervention Review]

\section{Interventions for visual field defects in people with stroke}

Alex Pollock ${ }^{1}$, Christine Hazelton${ }^{1}$, Fiona J Rowe ${ }^{2}$, Sven Jonuscheit ${ }^{3}$, Ashleigh Kernohan ${ }^{4}$, Jayne Angilley ${ }^{5}$, Clair A Henderson 6 , Peter Langhorne?, Pauline Campbell1

${ }^{1}$ Nursing, Midwifery and Allied Health Professions Research Unit, Glasgow Caledonian University, Glasgow, UK. ${ }^{2}$ Department of Health Services Research, University of Liverpool, Liverpool, UK. ${ }^{3}$ Vision Sciences, Glasgow Caledonian University, Glasgow, UK. ${ }^{4}$ Population Health Sciences Institute, Newcastle University, Newcastle upon Tyne, UK. ${ }^{5}$ Cornwall \& Isles of Scilly Primary Care Trust, Newquay, UK. ${ }^{6}$ Police Division, The Scottish Government, Edinburgh, UK. ${ }^{7}$ Academic Section of Geriatric Medicine, ICAMS, University of Glasgow, Glasgow, UK

Contact address: Alex Pollock, alex.pollock@gcu.ac.uk.

Editorial group: Cochrane Stroke Group.

Publication status and date: Edited (no change to conclusions), published in Issue 9, 2020.

Citation: Pollock A, Hazelton C, Rowe FJ, Jonuscheit S, Kernohan A, Angilley J, Henderson CA, Langhorne P, Campbell P. Interventions for visual field defects in people with stroke. Cochrane Database of Systematic Reviews 2019, Issue 5. Art. No.: CD008388. DOI: 10.1002/14651858.CD008388.pub3.

Copyright () 2019 The Cochrane Collaboration. Published by John Wiley \& Sons, Ltd.

\section{A B S T R A C T}

\section{Background}

Visual field defects are estimated to affect $20 \%$ to $57 \%$ of people who have had a stroke. Visual field defects can affect functional ability in activities of daily living (commonly affecting mobility, reading and driving), quality of life, ability to participate in rehabilitation, and depression and anxiety following stroke. There are many interventions for visual field defects, which are proposed to work by restoring the visual field (restitution); compensating for the visual field defect by changing behaviour or activity (compensation); substituting for the visual field defect by using a device or extraneous modification (substitution); or ensuring appropriate diagnosis, referral and treatment prescription through standardised assessment or screening, or both.

\section{Objectives}

To determine the effects of interventions for people with visual field defects after stroke.

\section{Search methods}

We searched the Cochrane Stroke Group Trials Register, the Cochrane Eyes and Vision Group Trials Register, CENTRAL, MEDLINE, Embase, CINAHL, AMED, PsycINFO, and PDQT Databse, and clinical trials databases, including ClinicalTrials.gov and WHO Clinical Trials Registry, to May 2018. We also searched reference lists and trials registers, handsearched journals and conference proceedings, and contacted experts.

\section{Selection criteria}

Randomised trials in adults after stroke, where the intervention was specifically targeted at improving the visual field defect or improving the ability of the participant to cope with the visual field loss. The primary outcome was functional ability in activities of daily living and secondary outcomes included functional ability in extended activities of daily living, reading ability, visual field measures, balance, falls, depression and anxiety, discharge destination or residence after stroke, quality of life and social isolation, visual scanning, adverse events, and death.

\section{Data collection and analysis}

Two review authors independently screened abstracts, extracted data and appraised trials. We undertook an assessment of methodological quality for allocation concealment, blinding of outcome assessors, method of dealing with missing data, and other potential sources of bias. We assessed the quality of evidence for each outcome using the GRADE approach. 


\section{Main results}

Twenty studies (732 randomised participants, with data for 547 participants with stroke) met the inclusion criteria for this review. However, only 10 of these studies compared the effect of an intervention with a placebo, control, or no treatment group, and eight had data which could be included in meta-analyses. Only two of these eight studies presented data relating to our primary outcome of functional abilities in activities of daily living. One study reported evidence relating to adverse events.

Three studies (88 participants) compared a restitutive intervention with a control, but data were only available for one study (19 participants). There was very low-quality evidence that visual restitution therapy had no effect on visual field outcomes, and a statistically significant effect on quality of life, but limitations with these data mean that there is insufficient evidence to draw any conclusions about the effectiveness of restitutive interventions as compared to control.

Four studies (193 participants) compared the effect of scanning (compensatory) training with a control or placebo intervention. There was low-quality evidence that scanning training was more beneficial than control or placebo on quality of life, measured using the Visual Function Questionnaire (VFQ-25) (two studies, 96 participants, mean difference (MD) 9.36, 95\% confidence interval (CI) 3.10 to 15.62). However, there was low or very-low quality evidence of no effect on measures of visual field, extended activities of daily living, reading, and scanning ability. There was low-quality evidence of no significant increase in adverse events in people doing scanning training, as compared to no treatment.

Three studies (166 participants) compared a substitutive intervention (a type of prism) with a control. There was low or very-low quality evidence that prisms did not have an effect on measures of activities of daily living, extended activities of daily living, reading, falls, or quality of life, and very low-quality evidence that they may have an effect on scanning ability (one study, 39 participants, $\mathrm{MD} 9.80,95 \% \mathrm{Cl}$ 1.91 to 17.69). There was low-quality evidence of an increased odds of an adverse event (primarily headache) in people wearing prisms, as compared to no treatment.

One study (39 participants) compared the effect of assessment by an orthoptist to standard care (no assessment) and found very lowquality evidence that there was no effect on measures of activities of daily living.

Due to the quality and quantity of evidence, we remain uncertain about the benefits of assessment interventions.

\section{Authors' conclusions}

There is a lack of evidence relating to the effect of interventions on our primary outcome of functional ability in activities of daily living. There is limited low-quality evidence that compensatory scanning training may be more beneficial than placebo or control at improving quality of life, but not other outcomes. There is insufficient evidence to reach any generalised conclusions about the effect of restitutive interventions or substitutive interventions (prisms) as compared to placebo, control, or no treatment. There is low-quality evidence that prisms may cause minor adverse events.

\section{PLAIN LANGUAGE SUMMARY}

\section{Interventions for visual field defects in people with stroke}

\section{Review question}

Are there effective treatments for people who have visual field defects after stroke?

\section{Background}

Stroke can cause some people ( $20 \%$ to $57 \%$ of people with stroke) to lose the ability to see the entire space in front of them - often one complete half of the normal field of vision is lost. These problems with seeing are called visual field defects. Visual field defects can make it difficult for people to function normally - especially moving about freely, avoiding obstacles, reading, driving, and taking part in rehabilitation for other stroke-related problems.

We wanted to see whether treatments for visual field defects could improve stroke survivors' abilities in activities of daily living (our primary outcome of interest), or other (secondary) outcomes. Secondary outcomes that we were interested in included the size of the visual field defect, independence (in functional abilities), quality of life, ability to scan/search for objects, reading ability, balance and falls, depression and anxiety, and adverse events.

\section{Study characteristics}

We included 20 studies (involving 547 stroke participants) that investigated the effect of treatments for visual field defects. However, only 10 of these studies compared the effect of a particular treatment with no treatment. Three of these studies investigated a type of eye movement training designed to improve the lost visual field (a 'restitutive' intervention). Four of the included studies investigated the effect of scanning training, which involves training people to 'scan' across the space in front of them and into the 'lost' visual field, in order to better cope with their lost vision (a 'compensatory' intervention). Three of the included studies investigated the effect of wearing a special 
prism on a pair of glasses, which increases the amount a person can see on their affected side (a 'substitutive' intervention). One of the studies investigated the effect of specialised assessment by an orthoptist (a hospital-based vision specialist), compared to standard care.

\section{Search date}

We searched for studies up to May 2018.

\section{Key results}

Only two studies presented data relating to how treatment can improve stroke survivors' abilities in activities of daily living, and there was a lack of consistency across studies that limited our ability to draw clear conclusions. There was insufficient evidence to draw any conclusions about the effectiveness of restitutive interventions as compared to control. There was low or very low-quality evidence that scanning training may help improve quality of life, but may have no effect on other outcomes (including adverse events). There was low or very-low quality evidence that prisms may have an effect on ability to scan (look) for objects, but may cause a range of minor adverse events (particularly headache) and may have no effect on other outcomes. Limitations with the evidence meant that we could not draw any conclusions about the benefits of assessment interventions.

\section{Quality of the evidence}

The quality of the evidence was low to very low, and in general was insufficient to reach conclusions about the effects of interventions for people with visual field defects. 
SUMMARY OF FINDINGS

\section{Summary of findings 1. Summary of findings: Restitutive interventions versus control}

\section{Restitutive interventions compared with control for visual field defects in patients with stroke}

Patient or population: stroke survivors with visual field defects

Settings: any rehabilitation setting

Intervention: restitutive interventions

Comparison: control, placebo, or no intervention

\begin{tabular}{|c|c|c|c|c|}
\hline Outcomes & $\begin{array}{l}\text { Relative effect } \\
(95 \% \mathrm{Cl})\end{array}$ & $\begin{array}{l}\text { No of Participants } \\
\text { (studies) }\end{array}$ & $\begin{array}{l}\text { Quality of the } \\
\text { evidence } \\
\text { (GRADE) }\end{array}$ & Comments \\
\hline $\begin{array}{l}\text { Functional ability } \\
\text { in activities of dai- } \\
\text { ly living }\end{array}$ & (no data) & No studies & $\begin{array}{l}\text { Insufficient evi- } \\
\text { dence }\end{array}$ & \\
\hline $\begin{array}{l}\text { Visual field } \\
\text { (TAP border posi- } \\
\text { tion in degrees of } \\
\text { visual angle from } \\
\text { zero vertical merid- } \\
\text { ian) } \\
\text { After intervention }\end{array}$ & $\begin{array}{l}\text { MD } 1.02(-1.37 \text { to } \\
3.41)\end{array}$ & $\begin{array}{l}19 \\
\text { (1 study, Kasten 1998) }\end{array}$ & $\begin{array}{l}\oplus \ominus \odot \ominus \\
\text { very low }\end{array}$ & $\begin{array}{l}\text { Reasons for downgrades: } \\
\text { - Risk of bias - study had high ROB for } \\
\text { 'other bias' (relating to potential finan- } \\
\text { cial interest in the intervention), study } \\
\text { had uncertain ROB for allocation con- } \\
\text { cealment and incomplete outcome da- } \\
\text { ta } \\
\text { - Indirectness - included participants } \\
\text { with diagnoses other than stroke } \\
\text { - Imprecision - very small study popula- } \\
\text { tion ( } \mathrm{n}=19)\end{array}$ \\
\hline $\begin{array}{l}\text { Extended activi- } \\
\text { ties of daily living }\end{array}$ & (no data) & No studies & $\begin{array}{l}\text { Insufficient evi- } \\
\text { dence }\end{array}$ & \\
\hline Reading ability & (no data) & No studies & $\begin{array}{l}\text { Insufficient evi- } \\
\text { dence }\end{array}$ & \\
\hline Falls & (no data) & No studies & $\begin{array}{l}\text { Insufficient evi- } \\
\text { dence }\end{array}$ & \\
\hline $\begin{array}{l}\text { Quality of life } \\
\text { (improved or not } \\
\text { improved - derived } \\
\text { from percentage of } \\
\text { those who reported } \\
\text { subjective improve- } \\
\text { ments of vision) }\end{array}$ & $\begin{array}{l}\text { OR } 13.00 \text { (2.07 to } \\
81.48)\end{array}$ & $\begin{array}{l}30^{*} \\
\text { (1 study, Kasten 1998) } \\
{ }^{*} \text { The data used in this } \\
\text { analysis were derived } \\
\text { from } 30 \text { of the original } \\
38 \text { participants, which } \\
\text { included data from an } \\
\text { additional } 19 \text { partici- } \\
\text { pants with optic nerve } \\
\text { injury who had also } \\
\text { received the same in- } \\
\text { terventions in a sepa- } \\
\text { rate (but parallel) tri- } \\
\text { al. Participants with op- }\end{array}$ & $\begin{array}{l}\oplus \ominus \odot \ominus \\
\text { very low }\end{array}$ & $\begin{array}{l}\text { Reasons for downgrades: } \\
\text { - Risk of bias - study had high ROB for } \\
\text { 'other bias' (relating to potential finan- } \\
\text { cial interest in the intervention), study } \\
\text { had uncertain ROB for allocation con- } \\
\text { cealment and incomplete outcome da- } \\
\text { ta } \\
\text { - Indirectness - analysis contained data } \\
\text { from a subset of participants from a } \\
\text { separate trial, who were not relevant to } \\
\text { this review } \\
\text { - Indirectness - included participants } \\
\text { with diagnoses other than stroke } \\
\text { - Imprecision - very small study popula- } \\
\text { tion (n=19) }\end{array}$ \\
\hline
\end{tabular}


tic nerve injury do not meet the inclusion criteria for this review.

\begin{tabular}{lll}
\hline $\begin{array}{l}\text { Scanning - cancel- } \\
\text { lation }\end{array}$ & (no data) No studies & $\begin{array}{l}\text { Insufficient evi- } \\
\text { dence }\end{array}$ \\
\hline
\end{tabular}

GRADE Working Group grades of evidence

High quality: Further research is very unlikely to change our confidence in the estimate of effect.

Moderate quality: Further research is likely to have an important impact on our confidence in the estimate of effect and may change the estimate.

Low quality: Further research is very likely to have an important impact on our confidence in the estimate of effect and is likely to

change the estimate.

Very low quality: We are very uncertain about the estimate.

$\mathrm{Cl}$ : confidence interval

MD: mean difference

n: number

OR: odds ratio

ROB: risk of bias

TAP: Tuebingen Automated Perimeter

Summary of findings 2. Summary of findings: Compensative interventions versus control

Compensative interventions compared with control for visual field defects in patients with stroke

Patient or population: stroke survivors with visual field defects

Settings: any rehabilitation setting

Intervention: compensative interventions

Comparison: control, placebo, or no intervention

\begin{tabular}{|c|c|c|c|c|}
\hline Outcomes & $\begin{array}{l}\text { Relative effect } \\
(95 \% \mathrm{Cl})\end{array}$ & $\begin{array}{l}\text { No of Partici- } \\
\text { pants } \\
\text { (studies) }\end{array}$ & $\begin{array}{l}\text { Quality of the } \\
\text { evidence } \\
\text { (GRADE) }\end{array}$ & Comments \\
\hline $\begin{array}{l}\text { Functional ability in } \\
\text { activities of daily liv- } \\
\text { ing }\end{array}$ & (no data) & No studies & $\begin{array}{l}\text { Insufficient evi- } \\
\text { dence }\end{array}$ & \\
\hline $\begin{array}{l}\text { Visual field } \\
\text { (Functional field score } \\
\text { and relative change in } \\
\text { visual field score, com- } \\
\text { bined) } \\
\text { After intervention }\end{array}$ & $\begin{array}{l}\text { SMD }-0.11(-0.92 \\
\text { to } 0.70 \\
\text { (no significant ef- } \\
\text { fect) }\end{array}$ & $\begin{array}{l}95 \\
\text { (2 studies, De } \\
\text { Haan 2015; Rowe } \\
\text { 2010) }\end{array}$ & $\begin{array}{l}\oplus \Theta \Theta \Theta \\
\text { very low }\end{array}$ & $\begin{array}{l}\text { Reasons for downgrades: } \\
\text { - Risk of bias - one study judged as high risk } \\
\text { of bias for at least one domain } \\
\text { - Inconsistency - one study had baseline dif- } \\
\text { ferences } \\
\text { - Inconsistency - }\left.\right|^{2}=75 \% \\
\text { - Indirectness - studies explored very differ- } \\
\text { ent compensatory interventions }\end{array}$ \\
\hline $\begin{array}{l}\text { Extended activities of } \\
\text { daily living } \\
\text { (Mobility questionnaire } \\
\text { and change in Notting- } \\
\text { ham EADL, combined) }\end{array}$ & $\begin{array}{l}\text { SMD } 0.49(-0.01 \\
\text { to } 0.99) \\
\text { (no significant ef- } \\
\text { fect) }\end{array}$ & $\begin{array}{l}97 \\
\text { (2 studies, De } \\
\text { Haan 2015; Rowe } \\
\text { 2010) }\end{array}$ & $\begin{array}{l}\oplus \odot \odot \odot \\
\text { very low }\end{array}$ & $\begin{array}{l}\text { Reasons for downgrades: } \\
\text { - Risk of bias - one study judged as high risk } \\
\text { of bias for at least one domain } \\
\text { - Indirectness - outcome measures were } \\
\text { very different; for one study outcome was }\end{array}$ \\
\hline
\end{tabular}


After intervention a mobility measure, rather than a general measure of EADL

- Indirectness - studies explored very different compensatory intervention

$\mathrm{S}$

\begin{tabular}{|c|c|c|c|c|}
\hline $\begin{array}{l}\text { Reading ability } \\
\text { (Reading speed; various } \\
\text { tests) } \\
\text { After intervention }\end{array}$ & $\begin{array}{l}\text { SMD } 0.26(-0.05 \\
\text { to } 0.58) \\
\text { (no significant ef- } \\
\text { fect) }\end{array}$ & $\begin{array}{l}162 \\
\text { (4 studies, Aimo- } \\
\text { la 2011; De Haan } \\
\text { 2015; Rowe 2010; } \\
\text { Spitzyna 2007) }\end{array}$ & $\begin{array}{l}\oplus \oplus \Theta \Theta \\
\text { low }\end{array}$ & $\begin{array}{l}\text { Reasons for downgrades: } \\
\text { - Risk of bias - three studies judged as high } \\
\text { risk of bias for at least one domain } \\
\text { - Indirectness - studies explored very differ- } \\
\text { ent compensatory intervention }\end{array}$ \\
\hline Falls & (no data) & No studies & $\begin{array}{l}\text { Insufficient evi- } \\
\text { dence }\end{array}$ & \\
\hline $\begin{array}{l}\text { Quality of life } \\
\text { (National Eye Institute } \\
\text { Visual Function Ques- } \\
\text { tionnaire (NEI - VFQ-25) } \\
\text { total score) } \\
\text { After intervention }\end{array}$ & $\begin{array}{l}\text { MD } 9.36 \text { ( } 3.10 \text { to } \\
15.62 \text { ) } \\
\text { (favours com- } \\
\text { pensatory) }\end{array}$ & $\begin{array}{l}96 \\
\text { (2 studies, De } \\
\text { Haan 2015; Rowe } \\
\text { 2010) }\end{array}$ & $\begin{array}{l}\oplus \oplus \ominus \ominus \\
\text { low }\end{array}$ & $\begin{array}{l}\text { Reasons for downgrades: } \\
\text { - Risk of bias - two studies judged as high } \\
\text { risk of bias for at least one domain } \\
\text { - Indirectness - studies explored very differ- } \\
\text { ent compensatory interventions }\end{array}$ \\
\hline $\begin{array}{l}\text { Scanning - cancella- } \\
\text { tion } \\
\text { (cancellation tests - } \\
\text { time to complete) } \\
\text { After intervention }\end{array}$ & $\begin{array}{l}\text { SMD }-0.01(-0.40 \\
\text { to } 0.39) \\
\text { (no significant ef- } \\
\text { fect) }\end{array}$ & $\begin{array}{l}97 \\
\text { (2 studies, Aimo- } \\
\text { la 2011; De Haan } \\
\text { 2015) }\end{array}$ & $\begin{array}{l}\oplus \oplus \ominus \ominus \\
\text { low }\end{array}$ & $\begin{array}{l}\text { Reasons for downgrades: } \\
\text { - Risk of bias - two studies judged as high } \\
\text { risk of bias for at least one domain } \\
\text { - Indirectness - studies explored very differ- } \\
\text { ent compensatory interventions }\end{array}$ \\
\hline $\begin{array}{l}\text { Adverse events } \\
\text { (number of participants } \\
\text { with reported events } \\
\text { during intervention pe- } \\
\text { riod) }\end{array}$ & $\begin{array}{l}\text { OR } 5.18 \text { ( } 0.24 \text { to } \\
112.57 \\
\text { (favours control) }\end{array}$ & $\begin{array}{l}108 \\
\text { (2 studies, De } \\
\text { Haan 2015; Rowe } \\
\text { 2010) } \\
\text { (NB. no events } \\
\text { recorded in } \\
\text { De Haan 2015, } \\
\text { which did not } \\
\text { explicitly report } \\
\text { adverse events } \\
\text { as an outcome } \\
\text { measure) }\end{array}$ & $\begin{array}{l}\oplus \oplus \oplus \ominus \\
\text { low }\end{array}$ & $\begin{array}{l}\text { Reason for downgrades: } \\
\text { - Inconsistency - no events from one study, } \\
\text { means pooled result was not estimable for } \\
\text { that study; large confidence intervals } \\
\text { - Indirectness - studies explored very differ- } \\
\text { ent compensatory interventions }\end{array}$ \\
\hline
\end{tabular}

GRADE Working Group grades of evidence

High quality: Further research is very unlikely to change our confidence in the estimate of effect.

Moderate quality: Further research is likely to have an important impact on our confidence in the estimate of effect and may change the estimate.

Low quality: Further research is very likely to have an important impact on our confidence in the estimate of effect and is likely to change the estimate.

Very low quality: We are very uncertain about the estimate.

\section{$\mathrm{Cl}$ : confidence intervals}

EADL: extended activities of daily living

MD: mean difference

NEI-VFQ-25: National Eye Institute Visual Function Questionnaire 
OR: odds ratio

SMD: standardised mean difference

\section{Summary of findings 3. Summary of findings: Substitutive interventions versus control}

\section{Substitutive interventions compared with control for visual field defects in patients with stroke}

Patient or population: stroke survivors with visual field defects

Settings: any rehabilitation setting

Intervention: compensative interventions

Comparison: control, placebo, or no intervention

\begin{tabular}{|c|c|c|c|c|}
\hline Outcomes & $\begin{array}{l}\text { Relative effect } \\
(95 \% \mathrm{Cl})\end{array}$ & $\begin{array}{l}\text { No of Partici- } \\
\text { pants } \\
\text { (studies) }\end{array}$ & $\begin{array}{l}\text { Quality of the } \\
\text { evidence } \\
\text { (GRADE) }\end{array}$ & Comments \\
\hline $\begin{array}{l}\text { Functional ability } \\
\text { in activities of dai- } \\
\text { ly living } \\
\text { (Barthel Index) } \\
\text { After } 4 \text { weeks of } \\
\text { treatment }\end{array}$ & $\begin{array}{l}\text { Wearing prisms } \\
\text { MD }-4.00 \text { (-17.86 to } \\
9.86 \text { ) } \\
\text { (no significant ef- } \\
\text { fect) }\end{array}$ & $\begin{array}{l}39 \\
(1 \text { study, Rossi } \\
1990)\end{array}$ & $\begin{array}{l}\oplus \odot \Theta \odot \\
\text { very low }\end{array}$ & $\begin{array}{l}\text { Reasons for downgrades: } \\
\text { - Risk of bias - study judged as high risk of bias } \\
\text { for at least one domain } \\
\text { - Indirectness - included data from partici- } \\
\text { pants with neglect } \\
\text { - Imprecision - small study population }(n=39)\end{array}$ \\
\hline $\begin{array}{l}\text { Visual field } \\
\text { (change in visual } \\
\text { field area \& change } \\
\text { in error scores, from } \\
\text { baseline) } \\
\text { After intervention }\end{array}$ & $\begin{array}{l}\text { Not wearing } \\
\text { prisms } \\
\text { SMD } 0.12(-0.46 \text { to } \\
0.70) \\
\text { Wearing prisms } \\
\text { SMD } 1.12 \text { ( } 0.44 \text { to } \\
1.80)\end{array}$ & $\begin{array}{l}85 \\
\text { (2 studies, Rossi } \\
\text { 1990; Rowe 2010) }\end{array}$ & $\begin{array}{l}\oplus \ominus \Theta \odot \\
\text { very low }\end{array}$ & $\begin{array}{l}\text { Reasons for downgrades: } \\
\text { - Risk of bias - one study judged as high risk of } \\
\text { bias for at least one domain } \\
\text { - Indirectness - included data from partici- } \\
\text { pants with neglect } \\
\text { - Indirectness - studies cannot be combined } \\
\text { due to differences in testing (wearing/not } \\
\text { wearing prisms) }\end{array}$ \\
\hline $\begin{array}{l}\text { Extended activi- } \\
\text { ties of daily living } \\
\text { (Change in EADL } \\
\text { from baseline; mo- } \\
\text { bility improvement } \\
\text { scores, in Logits) } \\
\text { After intervention }\end{array}$ & $\begin{array}{l}\text { Not wearing } \\
\text { prisms } \\
\text { SMD } 0.20(-0.44 \text { to } \\
0.85) \\
\text { Wearing prisms } \\
\text { SMD } 0.24(-0.26 \text { to } \\
0.75)\end{array}$ & $\begin{array}{l}99 \\
\text { (2 studies, Bow- } \\
\text { ers 2014; Rowe } \\
\text { 2010) }\end{array}$ & $\begin{array}{l}\oplus \ominus \ominus \ominus \\
\text { very low }\end{array}$ & $\begin{array}{l}\text { Reasons for downgrades: } \\
\text { - Risk of bias - one study judged as high risk of } \\
\text { bias for at least one domain } \\
\text { - Indirectness - one study outcome was a mo- } \\
\text { bility measure, rather than a general mea- } \\
\text { sure of EADL } \\
\text { - Indirectness - included participants with di- } \\
\text { agnoses other than stroke } \\
\text { - Indirectness - studies cannot be combined } \\
\text { due to differences in testing (wearing/not } \\
\text { wearing prisms) }\end{array}$ \\
\hline Reading ability & $\begin{array}{l}\text { Not wearing } \\
\text { prisms } \\
\text { MD } 2.80 \text { (-7.13 to } \\
12.73 \text { ) } \\
\text { (no significant ef- } \\
\text { fect) }\end{array}$ & $\begin{array}{l}45 \\
\text { (1 study, Rowe } \\
2010)\end{array}$ & $\begin{array}{l}\oplus \oplus \Theta \Theta \\
\text { Low }\end{array}$ & $\begin{array}{l}\text { Reasons for downgrades: } \\
\text { - Imprecision - small study population }(n=45) \\
\text { - Imprecision - wide confidence intervals }\end{array}$ \\
\hline
\end{tabular}




\begin{tabular}{|c|c|c|c|c|}
\hline $\begin{array}{l}\text { Falls } \\
\text { (number of falls) } \\
\text { After intervention }\end{array}$ & $\begin{array}{l}\text { Wearing prisms } \\
\text { OR } 1.21,(0.26 \text { to } \\
5.76) \\
\text { (no significant dif- } \\
\text { ference) }\end{array}$ & $\begin{array}{l}39 \\
(1 \text { study, Rossi } \\
1990)\end{array}$ & $\begin{array}{l}\oplus \ominus \ominus \ominus \\
\text { very low }\end{array}$ & $\begin{array}{l}\text { Reasons for downgrades: } \\
\text { - Risk of bias - study judged as high risk of bias } \\
\text { for at least one domain } \\
\text { - Indirectness - included data from partici- } \\
\text { pants with neglect } \\
\text { - Imprecision - small study population }(n=39)\end{array}$ \\
\hline $\begin{array}{l}\text { Quality of life } \\
\text { (Visual Function } \\
\text { Questionnaire } \\
\text { (VFQ-25)) } \\
\text { After intervention }\end{array}$ & $\begin{array}{l}\text { Not wearing } \\
\text { prisms } \\
\text { MD } 8.40 \text { (- } 4.18 \text { to } \\
20.98 \text { ) } \\
\text { (no significant ef- } \\
\text { fect) }\end{array}$ & $\begin{array}{l}43 \\
\text { (1 study, Rowe } \\
2010)\end{array}$ & $\begin{array}{l}\oplus \oplus \oplus \ominus \\
\text { Low }\end{array}$ & $\begin{array}{l}\text { Reasons for downgrades: } \\
\text { - Imprecision - small study population }(n=43) \\
\text { - Imprecision - wide confidence intervals }\end{array}$ \\
\hline $\begin{array}{l}\text { Scanning - cancel- } \\
\text { lation } \\
\text { (line cancellation } \\
\text { errors) } \\
\text { After intervention }\end{array}$ & $\begin{array}{l}\text { Wearing prisms } \\
\text { MD } 9.80 \text { ( } 1.91 \text { to } \\
17.69 \text { ) } \\
\text { (favours substitu- } \\
\text { tive) }\end{array}$ & $\begin{array}{l}39 \\
(1 \text { study, Rossi } \\
1990)\end{array}$ & $\begin{array}{l}\oplus \ominus \ominus \ominus \\
\text { very low }\end{array}$ & $\begin{array}{l}\text { Reasons for downgrades: } \\
\text { - Risk of bias - study judged as high risk of bias } \\
\text { for at least one domain } \\
\text { - Indirectness - included data from partici- } \\
\text { pants with neglect } \\
\text { - Imprecision - small study population }(n=39) \\
\text { - Imprecision - wide confidence intervals }\end{array}$ \\
\hline $\begin{array}{l}\text { Adverse events } \\
\text { (number of partici- } \\
\text { pants with reported } \\
\text { events during inter- } \\
\text { vention period) }\end{array}$ & $\begin{array}{l}\text { OR } 87.32 \text { ( } 4.87 \text { to } \\
1564.66 \text { ) } \\
\text { (favours control) }\end{array}$ & $\begin{array}{l}59 \\
\text { (1 study, Rowe } \\
2010)\end{array}$ & $\begin{array}{l}\oplus \oplus \ominus \ominus \\
\text { Low }\end{array}$ & $\begin{array}{l}\text { Reason for downgrades: } \\
\text { - Inconsistency - large confidence intervals } \\
\text { - Imprecision - data from only one study }\end{array}$ \\
\hline
\end{tabular}

GRADE Working Group grades of evidence

High quality: Further research is very unlikely to change our confidence in the estimate of effect.

Moderate quality: Further research is likely to have an important impact on our confidence in the estimate of effect and may change the estimate.

Low quality: Further research is very likely to have an important impact on our confidence in the estimate of effect and is likely to change the estimate.

Very low quality: We are very uncertain about the estimate.

EADL: extended activities of daily living

MD: mean difference

OR: odds ratio

SMD: standardised mean difference

VFQ-25: Visual function questionnaire

\section{Summary of findings 4. Summary of findings: Assessment/screening interventions versus control}

\section{Assessment/screening interventions compared with control for visual field defects in patients with stroke}

Patient or population: stroke survivors with visual field defects

Settings: any rehabilitation setting

Intervention: assessment/screening interventions

Comparison: control, placebo, or no intervention 


\begin{tabular}{|c|c|c|c|c|}
\hline Outcomes & $\begin{array}{l}\text { Relative effect } \\
(95 \% \mathrm{CI})\end{array}$ & $\begin{array}{l}\text { No of Partici- } \\
\text { pants } \\
\text { (studies) }\end{array}$ & $\begin{array}{l}\text { Quality of the evidence } \\
\text { (GRADE) }\end{array}$ & Comments \\
\hline $\begin{array}{l}\text { Functional ability in activi- } \\
\text { ties of daily living } \\
\text { (FIM) } \\
\text { After intervention }\end{array}$ & $\begin{array}{l}\text { MD }-6.97(-23.78 \\
\text { to } 9.84) \\
\text { (no significant ef- } \\
\text { fect) }\end{array}$ & $\begin{array}{l}37 \\
\text { (1 study, Jarvis } \\
2012 \text { ) }\end{array}$ & $\begin{array}{l}\oplus \Theta \Theta \odot \\
\text { very low }\end{array}$ & $\begin{array}{l}\text { Reasons for downgrades: } \\
\text { - Risk of bias - study judged } \\
\text { as high risk of bias for at } \\
\text { least one domain } \\
\text { - Imprecision - small study } \\
\text { population ( } \mathrm{n}=37 \text { ) } \\
\text { - Imprecision - wide confi- } \\
\text { dence intervals }\end{array}$ \\
\hline Visual field & (no data) & No studies & Insufficient evidence & \\
\hline $\begin{array}{l}\text { Extended activities of daily } \\
\text { living }\end{array}$ & (no data) & No studies & Insufficient evidence & \\
\hline Reading ability & (no data) & No studies & Insufficient evidence & \\
\hline Falls & (no data) & No studies & Insufficient evidence & \\
\hline Quality of life & (no data) & No studies & Insufficient evidence & \\
\hline Scanning - cancellation & (no data) & No studies & Insufficient evidence & \\
\hline
\end{tabular}

GRADE Working Group grades of evidence

High quality: Further research is very unlikely to change our confidence in the estimate of effect.

Moderate quality: Further research is likely to have an important impact on our confidence in the estimate of effect and may change the estimate.

Low quality: Further research is very likely to have an important impact on our confidence in the estimate of effect and is likely to change the estimate.

Very low quality: We are very uncertain about the estimate.

FIM: Functional Independence Measure

MD: mean difference 


\section{B A C K G R O U N D}

\section{Description of the condition}

Following stroke, a common visual problem is loss of one-half of the visual field in both eyes; this is called hemianopia or hemianopsia. As it affects the same side in both eyes, it is termed a homonymous hemianopia. For example, left hemisphere stroke causes the loss of the nasal field of the left eye and temporal (outer field) of the right eye, resulting in an inability to see to the right of the centre of the field of view. Visual field defects are common following stroke; the prevalence has been reported as being between $20 \%$ and $57 \%$ of people (Ali 2013; Rowe 2007; Rowe 2009). The extent of the loss within the visual field may vary, from the loss of the entire half of the visual field to the loss of only a portion of the affected half. It has been reported that $70 \%$ of those with visual field loss will maintain a small area of central vision (macular sparing) (Kerkhoff 1999).

The association between visual impairment and disability in activities of daily living has been well-established (Wolter 2006). Visual field defects can affect functional ability and quality of life following stroke (Dombovy 1986; Jongbloed 1986). Studies have demonstrated that people with visual field defects have an increased risk of falling (Ramrattan 2001), and that visual field loss is a predictor of poor functional status at discharge from a stroke unit (Kaplan 1982). People report walking into objects, tripping and falling, feeling unsafe, getting lost, and experiencing panic when in crowded or unfamiliar areas (Windsor 2008). Stroke survivors may struggle with reading, and with accomplishing everyday tasks such as shopping and handling their finances (Warren 2009), and they report severe difficulty returning to work, and marked loss of selfconfidence (Rowe 2017).

Visual field loss may also impact on a person's ability to participate in rehabilitation, to live in their own home, and on depression, anxiety, social isolation, and quality of life following stroke (Hepworth 2016; Jones 2006). Visual field defects often co-exist with visual neglect or other perceptual problems. Differentiation between visual field defects and visual neglect can be difficult (Jones 2006).

\section{Description of the intervention}

There are many different treatment and management approaches available for people with visual field defects. This review considered any intervention that is specifically targeted at improving the visual field defect or improving the ability of the person to cope with the visual field loss.

Treatments for visual field defects can be described as restitution, compensation or substitution (Hämäläinen 2004; Kerkhoff 2000). In addition to these types of treatments, this review also considered assessment and screening interventions that are specifically targeted at people with visual field defects.

These interventions may include, but are not limited to, the following.

- Restitutive interventions: visual field training, contrast sensitivity training, fusional (binocular vision) training.

- Compensatory interventions: saccadic (fast, simultaneous) eye movement training, training in visual search strategies, training eye movements for reading, use of eye blinks or colour cues, training in activities of daily living.
- Substitutive interventions: prisms (Peli 2000; Rossi 1990), eye patches, adapted lighting, magnification, environmental modification.

- Assessment and screening interventions: standardised visual assessment, screening and referral for visual assessment and intervention.

These are all complex interventions and, therefore, there can be substantial variations, even within interventions of the same type. For example, there can be differences between interventions in relation to the mode of delivery (e.g. therapist-delivered, selfdirected, or computer-based), personnel involved in delivery (e.g. vision specialists, such as orthoptists; stroke-care rehabilitation professionals, such as occupational therapists), and in the dose of the intervention (amount of training per day, or per week, and length of intervention period).

\section{How the intervention might work}

Interventions for visual field defects are proposed to work by either restoring the visual field (restitution); compensating (adapting) for the visual field defect by changing behaviour or activity (compensation); substituting for the visual field defect by using a device or extraneous modification (substitution); or ensuring appropriate diagnosis, referral and treatment prescription through standardised assessment or screening, or both.

\section{Restitution}

This includes the biochemical events that help restore functional neural (nervous system) tissue, for example, the reduction of oedema, absorption of blood, restoration of normal neuronal physiology and restoration of axon (part of a nerve cell) transport. In the past, researchers thought that restitutive approaches would have limited effect in visual rehabilitation (Kerkhoff 2000). However, in the last decade, reports have suggested that expansion of the visual field can be achieved with specific interventions after brain or optic nerve injury (Romano 2008; Sabel 2000; Sahraie 2006). Restitutive interventions include those where there is direct training of the impaired function or repetitive stimulation of the visual field. Commercially available treatments, including NovaVision ${ }^{\circledR}$ Visual Restorative Therapy, give people repeated exposure to stimuli targeting a vision deficit in a direct attempt to help activate the brain to restore vision (NovaVision 2009).

\section{Compensation}

Compensation aims to improve the mismatch between the skills of those affected and the demands placed on them by their environment by teaching them to compensate using a spared or intact function (Kerkhoff 1999; Kerkhoff 2000; Peli 2000). Interventions include teaching people compensatory visual search or scanning techniques, varying from simple training strategies to interventions using computerised scanning schedules and specially-developed commercially available tools (such as NVT 2009). When describing interventions for visual field defects, the term compensation may be used synonymously with the term adaptation, but we use the term compensation throughout this review.

\section{Substitution}

Substitution involves adaptation of visual components that have been lost or disrupted through the use of optical devices or 
environmental modifications (Kerkhoff 1999; Kerkhoff 2000; Peli 2000). Optical devices can include prisms, which shift the image received into an area that can be perceived, and typoscopes, which provide a guide for eye movements when reading.

\section{Assessment and screening interventions}

These may work by ensuring that the visual field defect is appropriately diagnosed, enabling other interventions to be prescribed. In those who have co-existing visual field defects and visual neglect; determining the action of an effective intervention can be difficult. The co-existence of visual neglect could prevent interventions aimed at the visual field defect from working effectively. For example, teaching scanning techniques to people with visual field defects may help them learn to compensate by scanning to the affected field but may not be as effective in people with co-existing visual neglect.

\section{Why it is important to do this review}

The services available to people with visual problems following stroke are presently inconsistent. There are various treatment and management approaches that are available for people with visual field defects. However, these are used to varying degrees in clinical practice (Rowe 2014), and clinicians lack research-based guidance on the choice of treatment (Hanna 2017). There is a recognised need to identify the evidence base for treatments for visual problems following stroke.There is considerable controversy and debate about the effectiveness of restitutive interventions (Horton 2005a; Horton 2005b; Reinhard 2005; Sabel 2006). There are a number of published reviews of the literature relating to interventions for visual problems following stroke. Barrett 2009 and Riggs 2007 provided reviews of visual problems, which included a small section relating to visual field problems after stroke; both of these reviews were limited in their scope and methodological quality. Bouwmeester 2007 completed a systematic review of the effect of one intervention (visual training) on visual field defects in people with brain damage, including stroke. Lane 2008 provided a narrative review of evidence for interventions for visual field loss. Das 2010 provided a narrative review with an emphasis on restitutive interventions, and primarily discussed a range of cohort studies that used localised, repetitive perceptual training aimed at reversing visual field loss induced by cortical damage. Hanna 2017 provided a narrative review of evidence for visual impairments, including visual field defect, summarising evidence from earlier versions of this review and evidence from non-randomised studies. There is agreement amongst these reviews that there is a need for high-quality studies of the effectiveness of interventions for visual field defects. In order to determine the current evidence for the effectiveness of any treatment or management approaches for stroke patients with visual field defects, and to enable appropriate planning and prioritisation of future primary research, it is essential that there is an up-to-date high-quality systematic review of the existing evidence base.

\section{O B JECT I VES}

The key objective of this review was to determine the effects of interventions for people with visual field defects after stroke.

\section{Research questions}

- Do interventions for visual field defects improve functional ability following stroke?
- Are interventions for visual field defects more effective at improving functional ability in people with a visual field defect only than in those both with a co-existing visual field defect and visual perceptual problems?

\section{Specific objectives}

- To determine if in 1) all participants with visual field defects following stroke (with or without visual perceptual problems), 2) those with visual field defects and no visual perceptual problems, and 3) those with co-existing visual field defects and visual perceptual problems:

* restitutive interventions are more effective than control, placebo, or no intervention at improving functional ability in activities of daily living;

* compensative interventions are more effective than control, placebo, or no intervention at improving functional ability in activities of daily living;

* substitutive interventions are more effective than control, placebo, or no intervention at improving functional ability in activities of daily living;

* assessment and screening interventions are more effective than control, placebo, or no intervention at improving functional ability in activities of daily living;

* any one active intervention is more effective than any other active intervention at improving functional ability in activities of daily living.

- To determine if in 1) all participants with visual field defects following stroke (with or without visual perceptual problems), 2) those with visual field defects and no visual perceptual problems, and 3) those with co-existing visual field defects and visual perceptual problems:

* restitutive interventions are more effective than control, placebo, or no intervention at improving secondary outcomes;

* compensatory interventions are more effective than control, placebo, or no intervention at improving secondary outcomes;

* substitutive interventions are more effective than control, placebo, or no intervention at improving secondary outcomes;

* assessment and screening interventions are more effective than control, placebo, or no intervention at improving secondary outcomes;

* any one active intervention is more effective than any other active intervention at improving secondary outcomes.

- To explore the relationship between participant characteristics and the effect of interventions aimed at improving functional abilities in activities of daily living using subgroup analysis.

- To make specific recommendations for future research into the effectiveness of interventions for visual field defects based on a knowledge of the existing evidence base.

\section{METHODS}

\section{Criteria for considering studies for this review}

\section{Types of studies}

Randomised controlled trials (RCTs) and randomised controlled cross-over trials (the first phase analysed as a parallel-group trial). 


\section{Types of participants}

Adult participants (over 18 years of age) after stroke (using the World Health Organization (WHO) definition of stroke, or a clinical definition if not specifically stated; that is, signs and symptoms persisting longer than 24 hours) who have been diagnosed as having a visual field defect.

Where studies included participants with visual field defects due to reasons other than stroke (e.g. traumatic brain injury), in addition to participants with visual field defects due to stroke, we included these studies. We documented the number of participants with each clinical diagnosis, and planned to use this information when exploring heterogeneity.

We defined a visual field defect as a homonymous loss of vision contralateral to the side of the lesion. We accepted a clinical diagnosis of visual field defect. We documented the method of diagnosing a visual field defect.

We excluded participants with monocular visual field defects due to retinal stroke.

\section{Types of interventions}

We included any intervention that was specifically targeted at improving the visual field defect or improving the ability of the participant to cope with the visual field loss. We classified interventions as either restitution, compensation, substitution, or assessment and screening (see Description of the intervention).

We compared interventions with no treatment, placebo, and control, within four specific preplanned comparisons:

- restitutive interventions versus no treatment, placebo, or control;

- compensatory interventions versus no treatment, placebo, or control;

- substitutive interventions versus no treatment, placebo, or control;

- assessment and screening interventions versus standard care.

We considered studies which compared one active intervention with another active intervention within a narrative synthesis. We did not plan to conduct any meta-analyses comparing one active intervention with another active intervention as we anticipated that there would be substantial variation in the interventions, and that it would not make sense to combine the results.

Two review authors ( $\mathrm{CH}, \mathrm{AP})$ independently classified the types of interventions in each included trial as either restitution, compensation, substitution, or assessment and screening. We anticipated that we might experience some difficulties in the classification of some interventions, in particular, the classification of interventions as either restitutory or compensatory, and had planned to reach consensus through discussion, involving a third review author when necessary. If there was uncertainty about the action of a particular intervention, we planned to carry out sensitivity analyses to explore the effect of removing and including the relevant trial(s). However, the two independent review authors agreed on all classifications and did not require further discussion with a third review author.

\section{Types of outcome measures}

Where possible, we assessed the outcome at the end of the intervention period and at a follow-up point (ideally six months after the intervention had finished, but we accepted any follow-up point after the intervention period had finished, documenting the time point).

\section{Primary outcomes}

\section{Functional ability in activities of daily living (ADL)}

We included the following validated scales: Barthel Activities of Daily Living Index (Mahoney 1965), Functional Independence Measure (FIM) (Smith 1990), modified Rankin Scale (mRS) (Wilson 2002), Katz Index of Activities of Daily Living (Katz 1963), and Rehabilitation Activities Profile (Van Bennekom 1995). If more than one of these functional ability scales was reported, we used the scale appearing earliest in our list.

\section{Secondary outcomes}

We included the following secondary outcomes. We prestated outcome measurement tools/scales which we anticipated, and planned that if more than one of the scales or measures was reported, we would use the scale appearing earliest in our list. If additional tools/scales were reported, but none from our prestated list, we included these.

- Functional ability in extended activities of daily living (EADL): Nottingham Extended Activities of Daily Living scale (Nouri 1987), Lawton Instrumental Activities of Daily Living (Lawton 1969), Frenchay Activities Index (Holbrook 1983), Rivermead Activities of Daily Living (ADL) score (Lincoln 1990).

- Reading - reading ability: reading speed (text reading time), reading accuracy (Wide Range Achievement Test (WRAT) (Wilkinson 2006), Gray Oral Reading test (Bryant 2011).

- Visual field: visual field outcomes subdivided into 1) gross visual screening: confrontation tests, Harrington Flocks Visual Screener; 2) kinetic perimetry: Goldmann perimetry, Tangent Screen measures; 3) static perimetry: Humphrey Automated Perimetry, Tubinger Automated Perimetry (TAP), High resolution perimetry (HRP). For perimetry outcomes: when more than one measure had been taken with the same instrument we reported border position for the intact visual field and used it for analysis in preference to hit or detection rate.

- Balance: Berg Balance Scale (Berg 1989), Functional Reach (Duncan 1990), Get-Up and Go test (Mathias 1986), Standing Balance test, Step Test, or other standardised balance measure. We did not include measures of weight distribution or postural sway during standing as the relationship between ability to maintain balance and these outcomes is not established.

- Falls: number of reported falls, Falls Efficacy Scale (Tinetti 1990).

- Depression and anxiety: Hospital Anxiety and Depression scale (Zigmond 1983), Beck Depressive Inventory (Beck 1987), General Health Questionnaire (Goldberg 1979), Geriatric Depression Scale (Cinnamon 2011).

- Discharge destination or residence after stroke: dichotomous variable - discharged to previous place of residence (i.e. place of residence prior to stroke) or discharged to alternative destination. 
- Quality of life and social isolation: EQ5D (Rabin 2001), Healthrelated quality of life scale (Williams 1999), Quality of Well Being scale (Kaplan 1993), SF36 (Garrett 1993).

- Visual scanning: cancellation techniques.

- Adverse events: any reported adverse events, excluding falls, death.

- Death.

\section{Search methods for identification of studies}

See the methods for the Cochrane Stroke Group Specialised register. We searched for trials in all languages and arranged for the translation of trials where necessary.

\section{Electronic searches}

We searched the Cochrane Stroke Group Trials Register (May 2018), the Cochrane Eyes and Vision Group Trials Register (May 2018) and the following electronic bibliographic databases:

- Cochrane Central Register of Controlled Trials (CENTRAL; 2015, Issue 1) in the Cochrane Library (accessed May 2018) (Appendix 1);

- MEDLINE Ovid (1950 to 16 May 2018) (Appendix 2);

- Embase Ovid (1980 to 16 May 2018) (Appendix 3);

- CINAHL EBSCO (Cumulative Index to Nursing and Allied Health Literature; 1982 to 16 May 2018) (Appendix 4);

- AMED Ovid (Allied and Complementary Medicine; 1985 to 16 May 2018) (Appendix 5);

- PsycINFO (1967 to 16 May 2018) (Appendix 6);

- ProQuest Dissertations \& Theses (PQDT) database (1861 to 22 March 2015) (Appendix 7).

\section{Searching other resources}

In an effort to identify further published, unpublished and ongoing trials we:

- searched the following registers of ongoing trials:

- US National Institutes of Health Ongoing Trials Register ClinicalTrials.gov (www.clinicaltrials.gov; May 2018) (Appendix 8);

- World Health Organization International Clinical Trials Registry Platform (apps.who.int/trialsearch; May 2018) (Appendix 8);

- ISRCTN Registry (www.isrctn.org) (formerly known as the Current Controlled Trials; www.controlled-trials.com) (March 2015);

- Health Service Research Projects in Progress (wwwcf.nlm.nih.gov/hsr_project/home_proj.cfm) (March 2015);

- National Eye Institute Clinical Studies Database (clinicalstudies.info.nih.gov/cgi/protinstitute.cgi? NEl.0.html) (March 2015);

- Stroke Trials Registry (www.strokecenter.org/trials/) (March 2015);

- handsearched the following journals and conference proceedings:

- Australian Orthoptic Journal (1959 to August 2018);
- British Orthoptic Journal (1939 to August 2003);

- British and Irish Orthoptic Journal (2004 to August 2018);

- International Orthoptic Association (www.liverpool.ac.uk/orthoptics/research/search.htm) (1967 to August 2018);

- International Strabismological Association (ISA) (1966 to August 2018);

- Proceedings of the European Strabismological Association (ESA) (1969 to August 2018).

We searched the reference lists of included trials and review articles about vision after stroke and contacted experts in the field.

\section{Data collection and analysis}

One review author ( $\mathrm{CH}$ or $\mathrm{PC})$ ran all the electronic searches, downloaded references into bibliographic software, and removed duplicates. One review author excluded any titles which were obviously not related to stroke and vision (one of $\mathrm{CH}, \mathrm{PC}$, or $\mathrm{AP}$ ). We obtained the abstracts for remaining references and two review authors (two of $\mathrm{CH}, \mathrm{AP}, \mathrm{PC}, \mathrm{SJ}, \mathrm{AK}$ ) independently considered each of these abstracts, excluded any studies that were clearly not RCTs or cross-over trials, and excluded any studies where the intervention was not specifically aimed at improving the visual field defect or the participant's ability to cope with the visual field defect. The review authors resolved any disagreements through discussion, involving a third review author where necessary. We obtained the full papers for any studies included at this stage.

\section{Selection of studies}

Two review authors independently applied the selection criteria by considering and documenting the type of studies, type of participants, intervention, comparison intervention, and the outcome measures (two of AP, CH, SJ, AK). Each review author classified studies as 'include' or 'exclude'. If there was disagreement between these two review authors, they reached consensus through discussions involving a third review author.

We listed any excluded studies that included participants with visual field defects in the Characteristics of excluded studies table and provided the reason for exclusion. We did not list studies that were excluded because they included participants who did not have visual field defects (i.e. visual neglect, eye-movement disorders, age-related visual problems) in the Characteristics of excluded studies table unless the two review authors agreed that there was a clear reason to do so.

\section{Data extraction and management}

We used a pre-designed data extraction form to extract data from the included studies. Two review authors (two of AP, CH, SJ) independently documented the following.

- Methods: study design, method of randomisation.

- Participants: number of participants, inclusion criteria, time since stroke, type, nature and location of lesion. We documented the method of diagnosing the visual field defect and the type and extent of the visual field loss; the presence or absence of visual perceptual problems, and the method of diagnosis; and the country of origin of participants. We documented whether the included participants had visual field defects only (no visual neglect), co-existing visual field defects and visual neglect, or 
whether the participants were a mixed group (some with and some without visual neglect). If there was a mixed group of participants, we documented whether data were available for the visual field defect-only group and the group with co-existent visual field and visual neglect. Where information was available, we documented the presence or absence of eye movement disorders or low vision, accepting a clinical diagnosis of these.

- Interventions: description of interventions given to each treatment group including, if relevant, the duration, intensity, frequency and dose. We classified the type of intervention as restitution, compensation, substitution, or assessment and screening; and the type of control as no treatment, placebo, control, or standard care. We documented the professional background of the person providing the intervention (e.g. occupational therapist, orthoptist).

- Outcomes: we documented the primary and secondary outcomes relevant to this review. If a study used a number of different methods of measuring the same outcome, we noted the outcome to be used for any subsequent analysis.

- Notes: we noted any important confounding variables. If more than two intervention groups were included in the study, we noted the method of including these groups in any subsequent analysis.

In addition, the review authors independently documented, if data allowed, the following demographics of the included participants: age, gender, place of residence, type of stroke, side of stroke, time since stroke, initial visual field defect, and initial functional ability. The review authors resolved any data extraction discrepancies through discussion.

\section{Assessment of risk of bias in included studies}

Two independent authors (two of AP, $\mathrm{CH}, \mathrm{SJ}$ ) assessed risk of bias by grading the following domains as 'low risk', 'high risk' or 'unclear risk' of bias for each included study. We documented this within the 'Risk of bias' tables.

\section{Allocation concealment}

Studies with adequate concealment included those that used central randomisation at a site remote from the study, computerised allocation in which records were in a locked readable file that could be assessed only after entering participant details, or the drawing of opaque envelopes. Studies with inadequate concealment included those using an open list or table of random numbers, open computer systems, or drawing of non-opaque envelopes. Studies with unclear concealment included those with no or inadequate information in the report.

\section{Blinding}

Adequate concealment included studies which stated that a masked outcome assessor was used, and that had masking of participants and key study personnel and did not identify any 'unmasking'. Inadequate concealment included studies that did not use masking of the outcome assessor, personnel, or participants, where there was incomplete masking, or where the report clearly identified that 'unmasking' occurred during the study. We documented concealment as unclear if a study did not state, or if there was insufficient information to judge, whether or not personnel, participants, and outcome assessors were masked. We acknowledged that for some (but not all) interventions for visual field defects, masking of personnel or participants, or both, is not possible, and considered the potential for any lack of blinding of personnel or participants, or both, to introduce bias.

\section{Incomplete outcome data}

Studies adequately addressing incomplete outcome data either had: no missing outcome data; missing outcome data that were unlikely to be related to true outcome; missing outcome data that were balanced in numbers across intervention groups, with similar reasons for missing data across groups; a reported effect size (difference in means or standardised difference in means) among missing outcomes that were not enough to have a clinically relevant impact on observed effect size; or missing data that had been imputed using appropriate methods. Studies inadequately addressing incomplete outcome data either had: missing outcome data that were likely to be related to true outcome, with either imbalance in numbers or reasons for missing data across intervention groups; a reported effect size (difference in means or standardised difference in means) among missing outcomes enough to induce clinically relevant bias in the observed effect size; as-treated analysis done with substantial departure of the intervention received from that assigned at randomisation. We documented addressing of incomplete outcome data as unclear if there was insufficient reporting to allow this to be assessed, or if this was not addressed in the report.

\section{Other bias}

We assessed a study not to be free of other bias if it was assessed to have at least one important risk of bias, such as: a potential source of bias related to the specific study design used, an extreme baseline imbalance, a claim to have been fraudulent, financial association with the intervention, or some other problem. If there was insufficient information, or the information provided was unclear, we documented the risk of other bias as unclear.

We produced a 'Risk of bias' summary figure to illustrate the potential biases within each of the included studies.

\section{Measures of treatment effect}

We used the Review Manager software RevMan 5.3 (RevMan 2014) to carry out statistical analyses to determine the treatment effect of:

- restitutive interventions (compared to no treatment, control, placebo, or standard care);

- compensatory interventions (compared to no treatment, control, placebo, or standard care);

- substitutive interventions (compared to no treatment, control, placebo, or standard care);

- assessment and screening interventions (compared to standard care).

We used a random-effects model for all statistical analyses. For dichotomous, variables we calculated and reported Peto odds ratios (ORs) with $95 \%$ confidence intervals (Cls). For continuous data, we calculated the treatment effect using standardised mean differences (SMDs) and 95\% Cls where studies used different scales for the assessment of the same outcome, and using mean differences (MDs) and 95\% Cls where all studies used the same method of measuring an outcome. 
The primary outcome of functional ability in activities of daily living, and secondary outcomes of functional ability in extended activities of daily living, visual field data, balance, depression and anxiety, and quality of life and social isolation comprise either ordinal data from measurement scales, or continuous data. We analysed these as continuous variables.

Where reported outcomes had a measurement scale where a lower value is indicative of a better outcome (e.g. depression and anxiety scales) we multiplied the reported values by -1 so that in all analyses a higher value was indicative of a better outcome.

If studies reported change values and the baseline value was available, we calculated the value at follow-up (change value baseline value). If studies reported change values and the baseline value was not available, we used these data in meta-analyses but planned sensitivity analyses to investigate the effect of including the data.

We planned to analyse falls, discharge destination, adverse events, and deaths as dichotomous variables.

\section{Unit of analysis issues}

We anticipated that the majority of trials would have a parallelgroup design in which each individual participant was randomised to one of two, or more, treatment groups. Where studies had two or more active intervention groups eligible for inclusion within the same comparison (against a control, placebo, or no treatment group), we intended to 'share' the control group data between the multiple pair-wise comparisons in order to avoid double counting of participants within an analysis.

If studies used a randomised controlled cross-over design, we planned to analyse data from the first phase only. We did not anticipate that any studies would use a cluster-randomised design.

\section{Dealing with missing data}

If an included study did not report a particular outcome, we did not include that study in the analysis of that outcome.

If an included study had missing data (e.g. reported means but not standard deviations for the follow-up data), we took logical steps to enter an assumed value. Such steps included estimating a standard deviation (SD) based on a reported standard error and estimating a follow-up SD based on a baseline value. We performed calculations of SDs from standard errors and $P$ values using methods described in section 7.7.3.3 of the Cochrane Handbook for Systematic Reviews of Interventions (Higgins 2011). We planned to do sensitivity analyses to investigate the effect of entering assumed values. We also contacted authors in an attempt to obtain missing data.

\section{Assessment of heterogeneity}

We visually assessed heterogeneity by looking at the extent of overlap of the $\mathrm{Cls}$ on the forest plots. We considered the $P$ value, considering that with $P<0.1$ there was likely to be heterogeneity. We considered the $1^{2}$ statistic. We considered $1^{2}$ $>50 \%$ as substantial heterogeneity. If $12>50 \%$, we explored the individual trial characteristics to identify potential sources of heterogeneity.

\section{Assessment of reporting biases}

We attempted to avoid reporting biases by using a comprehensive search strategy that included searching for unpublished studies and searching trials registers. We planned to carry out sensitivity analyses to explore the effect of publication type.

\section{Data synthesis}

Two review authors (AP, $\mathrm{CH}$, or $\mathrm{SJ}$ ) independently extracted data from the included trials. One review author (AP) entered the data into RevMan 5.3 (RevMan 2014), and the other review author checked the entries. They resolved any disagreements through discussion, with reference to the original report.

\section{Subgroup analysis and investigation of heterogeneity}

We intended to explore heterogeneity by subgroup analyses to investigate the effect of:

- time after stroke (zero to three months, three to six months, more than six months);

- type of visual field defect (homonymous hemianopia, other) (We anticipated that the majority of the participants would have homonymous hemianopia. However, we documented the type of visual field defect and planned subgroup analyses to investigate the effect of including participants with types other than homonymous hemianopia);

- extent of visual field loss if homonymous (complete hemianopia, partial hemianopia, quadrantanopia);

- presence or absence of visual neglect (no visual neglect, all participants with co-existing visual field defects and visual neglect, mixed group of participants some with and some without visual neglect);

- macular sparing, macular splitting field loss;

- type of treatment (e.g. for compensatory interventions: saccadic eye movement, activities of daily living training; for substitutive interventions: prisms, patches, environmental modifications; for assessment and screening: by orthoptist, occupational therapist, doctor).

We planned to use an established method for subgroup analyses (Deeks 2001). We planned to carry out these subgroup analyses when there were six or more studies included in a single analysis, all with sufficient information to determine the subgroups.

\section{Sensitivity analysis}

We planned to carry out sensitivity analysis to explore the effect of the following methodological features.

- Allocation concealment: we planned to re-analyse data, excluding trials with inadequate or unclear allocation concealment.

- Masking of outcome assessor: we planned to re-analyse data, excluding trials without or with unclear masking of outcome assessor.

- Missing outcome data: we planned to re-analyse the data, excluding trials with inadequate or unclear methods of dealing with missing outcome data.

- Other bias: we planned to re-analyse the data, excluding trials assessed to have other bias, or unclear as to whether they had other bias. 
- Type of intervention: we planned to re-analyse data, excluding trials where the classification of the type of intervention was uncertain.

- Publication type (peer-reviewed journal, conference abstract or proceedings, doctoral dissertation): we planned to re-analyse data including only those trials from peer-reviewed journals.

We planned to carry out these planned sensitivity analyses when there are six or more studies included in a single analysis.

\section{GRADE assessment and 'Summary of findings' tables}

We presented the results of the main preplanned comparisons of the review in 'Summary of findings' tables;

- restitutive interventions (compared to no treatment, control, placebo, or standard care): Summary of findings 1;

- compensatory interventions (compared to no treatment, control, placebo, or standard care): Summary of findings 2;

- substitutive interventions (compared to no treatment, control, placebo, or standard care): Summary of findings 3;

- assessment and screening interventions (compared to standard care): Summary of findings 4.

Within each 'Summary of findings' table, we summarised data for the primary outcome of interest (functional ability in activities of daily living), the six secondary outcomes for which we had identified the greatest volume of evidence in previous versions of this review (visual field, extended activities of daily living, reading ability, falls, quality of life, scanning - cancellation), and any data related to adverse events.

For each of the preplanned comparisons, we assessed quality of the evidence using the GRADE approach (Guyatt 2011a), considering each of the following criteria.

- Risk of bias due to flawed design or conduct of studies (Guyatt 2011b).

- Imprecision (e.g. when confidence intervals for treatment effect are wide) (Guyatt 2011d).

- Inconsistency (e.g. when point estimates vary widely, $\mathrm{I}^{2}$ is large) (Guyatt 2011e).

- Indirectness (e.g. variations in participants, interventions, comparisons, and outcomes) (Guyatt 2011f).

- Publication bias (may be explored with the use of funnel plots and classed as not suspected, suspected, strongly suspected or very strongly suspected) (Guyatt 2011c).
We documented identified concerns relating to any of the above criteria, and downgraded the level of evidence accordingly (one downgrade for each concern, and a maximum of two downgrades for each of the listed criteria). If there were no downgrades the level of evidence was high quality, if there was one downgrade the level of evidence was moderate quality, if there were two downgrades the level of evidence was low quality, and if there were more than two downgrades the level of evidence was very low quality. We used the following definitions of evidence.

- High quality: when further research is very unlikely to change our confidence in the estimate of effect.

- Moderate quality: when further research is likely to have an important impact on our confidence in the estimate of effect and may change the estimate.

- Low quality: when further research is very likely to have an important impact on our confidence in the estimate of effect and is likely to change the estimate.

- Very low quality: when we are very uncertain about the estimate.

One review author (AP) assessed quality of evidence, reported identified concerns, and applied downgrades. Other review authors checked agreement with these judgements and resolved any disagreements through discussion.

\section{RES U L T S}

\section{Description of studies}

See: Characteristics of included studies; Characteristics of excluded studies; Characteristics of ongoing studies, Characteristics of studies awaiting classification.

\section{Results of the search}

Results of the search are shown in Figure 1. Our search strategy identified 17,224 records from the main electronic databases, and we identified a further eight studies through our wider search. One review author (AP, $\mathrm{CH}$ or $\mathrm{PC}$ ) eliminated 15,658 titles that were clearly irrelevant, and two review authors (AP, $\mathrm{CH}$ ) applied the inclusion criteria to the remaining 1574 abstracts, identifying 178 to be considered at full text. Of these, we identified a total of 20 studies for inclusion. In addition, we identified seven ongoing studies (see Characteristics of ongoing studies), and two studies that require further assessment (see Characteristics of studies awaiting classification). 
Figure 1. Study flow diagram.

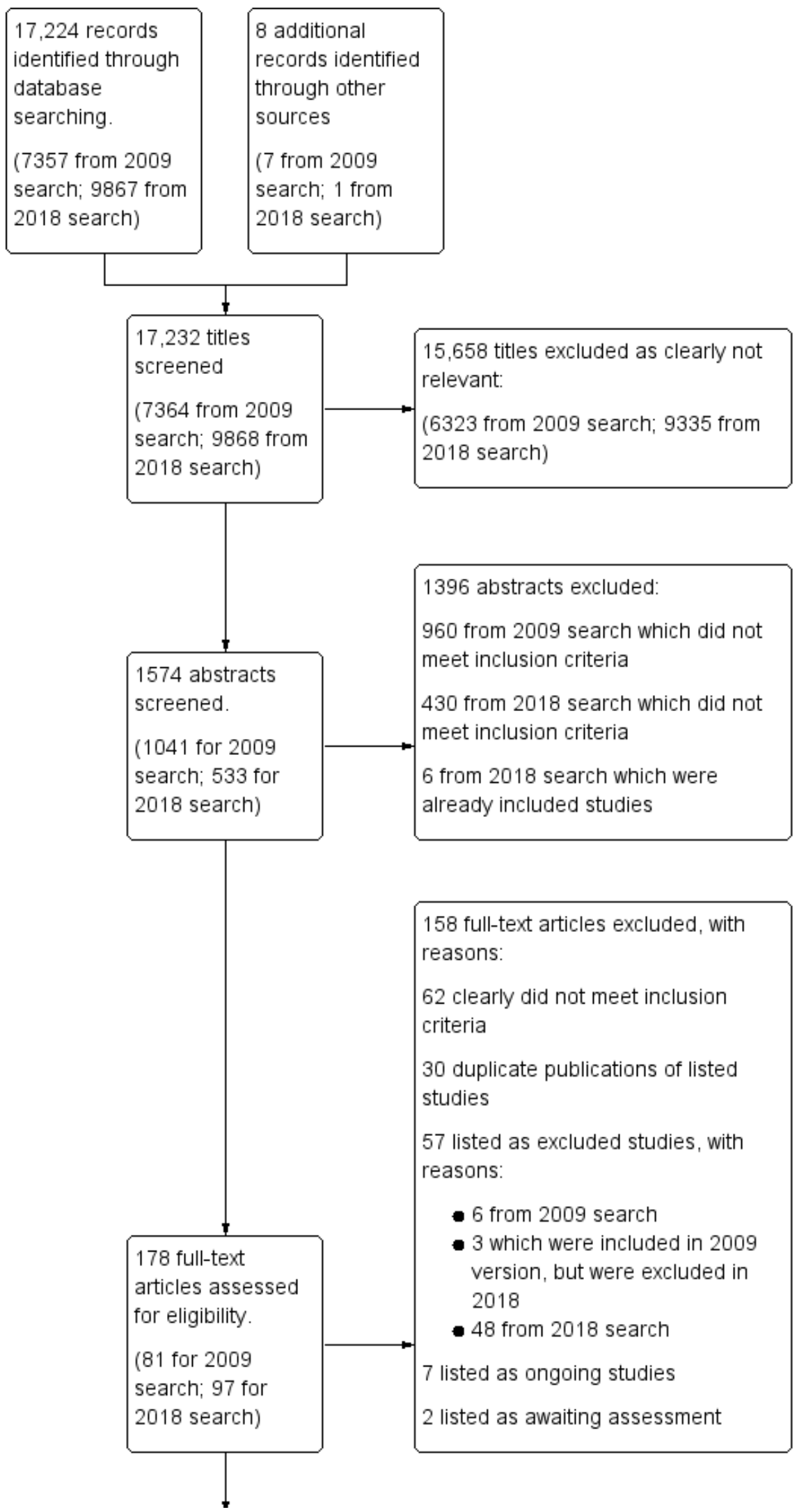


Figure 1. (Continued)

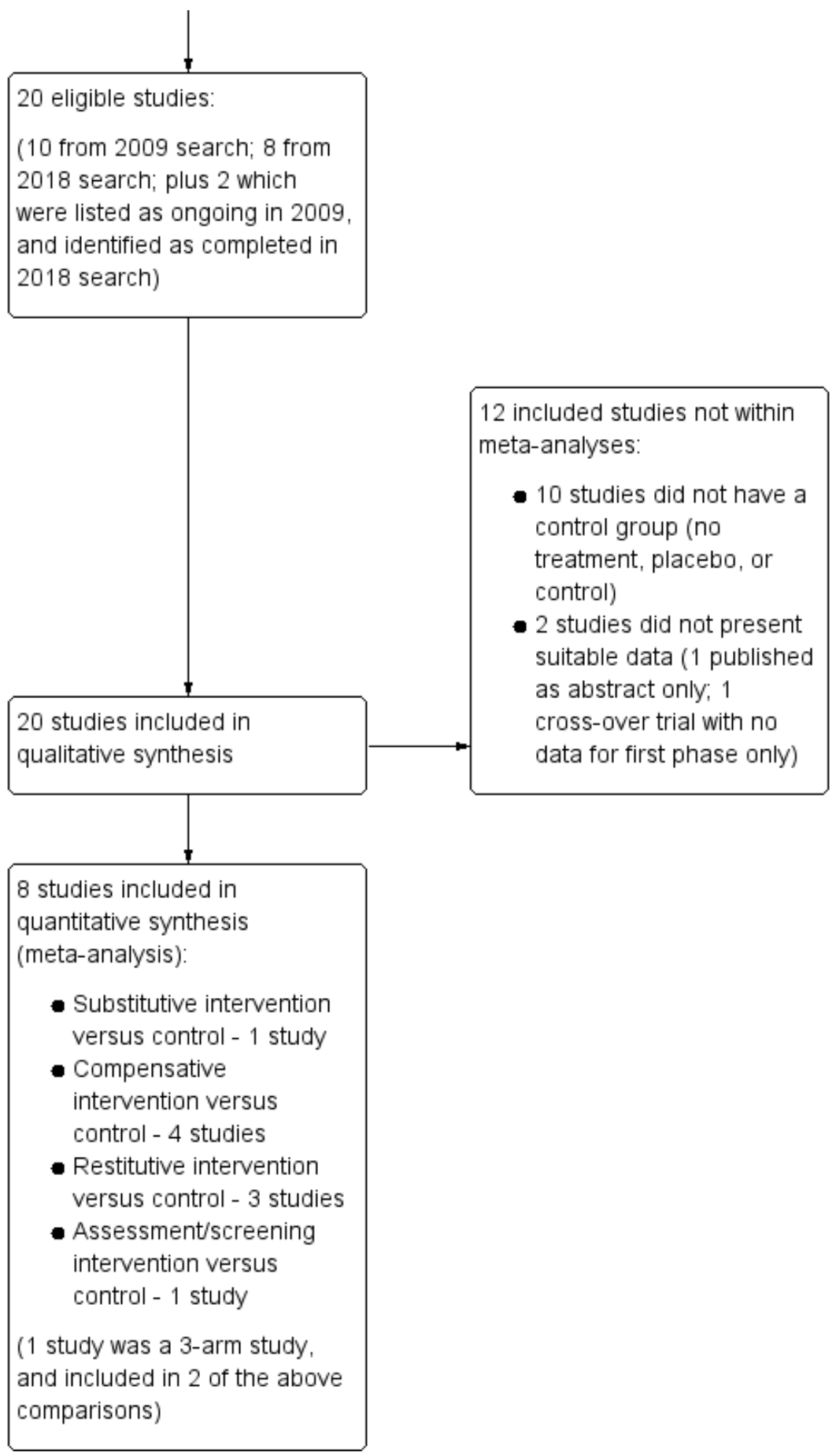

\section{Included studies}

The previous version of this review included 13 studies (344

We included 20 studies (732 randomised participants, with data available for 638, of whom 547 (85\%) had a diagnosis of ischaemic or haemorrhagic stroke) in this updated review (Aimola 2011; Bainbridge 1994; Bowers 2014; De Haan 2015; Elshout 2016; Gall 2013; Jarvis 2012; Jobke 2009; Kasten 1998; Kasten 2007; Keller 2010; Modden 2012; Plow 2010; Poggel 2004; Rossi 1990; Roth 2009; Rowe 2010; Schuett 2012; Spitzyna 2007; Szlyk 2005). randomised participants, 285 of whom were participants with stroke) (Bainbridge 1994; Carter 1983; Jobke 2009; Kasten 1998; Kasten 2007; Plow 2010; Poggel 2004; Rossi 1990; Roth 2009; Spitzyna 2007; Szlyk 2005; Weinberg 1977; Weinberg 1979). However, we have excluded three of these studies from this update (Carter 1983, Weinberg 1977; Weinberg 1979: see Excluded studies for reason for these exclusions). 
There were only abstracts available for Bainbridge 1994 and Gall 2013. In the previous version, Plow 2010 was based on data from a conference abstract and ongoing trials register data only; however, for this update a full paper was available.

We present a brief overview of the studies below. Full descriptions of the included studies can be found in the Characteristics of included studies table and in Table 1 (Demographics of included studies: settings of included studies), Table 2 (Demographics of included studies: demographics of included participants), Table 3 (Demographics of included studies: visual problems of included participants), and Table 4 (Outcome measures within included studies).

\section{Study design}

Fifteen of the included studies were parallel-group randomised controlled trials (RCTs), and five were randomised cross-over studies (Bowers 2014; Elshout 2016; Jobke 2009; Schuett 2012; Szlyk 2005)

Sixteen of the included studies randomised participants to one of two treatment groups; three had three treatment groups (Kasten 2007; Modden 2012; Rowe 2010); and one was a cross-over AB/BA design, where $A$ was an active treatment and $B$ a placebo; however participants were also randomised to receive one of two different active treatments, each of which had a related sham treatment meaning that there were effectively four different treatment groups (active 1, active 2, sham 1 and sham 2) (Bowers 2014).

\section{Comparison versus control}

Ten of the 20 included studies had a control (no treatment, standard care, or placebo) group, comparing 10 active treatments with control (Rowe 2010 had two active treatment groups):

- three compared a restitutive intervention with control (Gall 2013; Elshout 2016; Kasten 1998);

- four compared a compensatory intervention with control (Aimola 2011; De Haan 2015; Rowe 2010; Spitzyna 2007);

- three compared a substitutive intervention with control (Bowers 2014; Rossi 1990; Rowe 2010);

- one compared assessment/screening with control (Jarvis 2012).

In Rowe 2010, the two active treatment groups (compensatory and substitutive interventions) were compared with each other.

Ten of the 20 included studies did not have a control group. Nine compared two different active treatments, and one had three active treatment groups (Modden 2012):

- four compared different restitutive interventions (Jobke 2009; Kasten 2007; Plow 2010; Poggel 2004);

- three compared different compensatory interventions (Keller 2010; Modden 2012; Schuett 2012);

- two compared different substitutive interventions (Bainbridge 1994; Szlyk 2005);

- two compared compensatory and restitutive interventions (Modden 2012; Roth 2009).

\section{Interventions studied}

\section{Restitutive interventions}

Nine studies (239 randomised participants) investigated the effect of restitutive interventions.

In eight of these studies, the restitutive intervention studied was a form of computer-based vision restoration therapy:

- Kasten 1998 and Elshout 2016 compared visual restitution therapy with a placebo intervention;

- Jobke 2009 and Kasten 2007 compared the effectiveness of two (or more) types of visual restitution therapy;

- Plow 2010 explored the effect of adding transcranial direct current stimulation (tDCS) to visual restitution therapy;

- Poggel 2004 explored the effect of adding attentional cueing to visual restitution therapy;

- Modden 2012 compared computerised restitution therapy with two different compensatory interventions;

- Roth 2009 compared 'flicker-stimulation training', which the authors described as a "potential" restitutive intervention, with a compensatory intervention.

In one of these nine included studies, the restitutive intervention studied was a form of non-invasive brain stimulation using alternating current stimulation. This was compared with a placebo intervention (Gall 2013).

\section{Compensatory interventions}

Eight studies (347 randomised participants) investigated the effect of compensatory interventions:

- Aimola 2011 compared computer-based compensatory training with a control;

- Spitzyna 2007 compared computer-based reading training ("optokinetic nystagmus inducing reading therapy", involving reading scrolling right to left text) with a control;

- De Haan 2015 compared a compensatory scanning training programme with a control;

- Rowe 2010 compared paper-based visual scanning training with a control (and with a substitutive intervention);

- Keller 2010 compared two types of compensatory training audiovisual exploratory training and visual exploration training;

- Schuett 2012 compared two types of compensatory training visual exploration training and reading training;

- Modden 2012 compared computerised scanning training, an occupational therapy compensatory training program, and a computerised restitutive therapy;

- Roth 2009 compared computer-based scanning training with restitutive training.

\section{Substitutive interventions}

Five studies (227 randomised participants) investigated the effect of substitutive interventions. In all five studies, the substitutive intervention studied was a type of prism:

- Rossi 1990 compared 15 diopter Fresnel prisms with no prisms;

- Rowe 2010 compared 40 diopter Fresnel prisms with no treatment, and with a compensatory intervention; 
- Bowers 2014 compared 57 diopter oblique prism glasses and horizontal prism glasses with five diopter sham prism glasses;

- Bainbridge 1994 compared full-field 15 diopter Fresnel prisms with hemi-field 15 diopter Fresnel prisms;

- Szlyk 2005 compared 20 diopter Fresnel prisms with 18.5 dioptre Gottlieb VFAS (Visual Field Awareness System) prisms.

\section{Assessment and screening interventions}

One study (64 randomised participants) investigated the effectiveness of an assessment and screening intervention on relevant outcomes:

- Jarvis 2012 compared the effect of providing therapy staff with information from an orthoptic assessment with no intervention.

\section{Populations studied}

The reported diagnoses of the participants within the 20 included studies were as follows:

- 14 studies recruited participants with mixed diagnoses including stroke, trauma, surgery, and infections;

- five studies included participants with stroke only; and

- one study - the cause of the lesion was unclear.

(See details in Characteristics of included studies and Table 2). Despite the high number of studies including participants with mixed diagnoses, the majority of participants in the studies in this review did have stroke (across all studies, $85 \%$ (520/611) of participants with data reported had a diagnosis of stroke).

Fourteen of the 20 included studies included participants with visual field defects only (no visual neglect); seven of 14 studies clearly stated the method of diagnosis of visual neglect (Bowers 2014; De Haan 2015; Elshout 2016; Keller 2010; Roth 2009; Rowe 2010; Schuett 2012), four of the 14 studies stated that participants with neglect were excluded but did not state the method of diagnosis of visual neglect (Kasten 1998; Kasten 2007; Modden 2012; Poggel 2004), and in the three remaining studies it was assumed (but not clearly stated) that participants with visual field defects only were included (Jobke 2009; Spitzyna 2007; Szlyk 2005). Four of the included studies included participants who had visual neglect in addition to, or instead of, visual field defects (Aimola 2011; Bainbridge 1994; Jarvis 2012; Rossi 1990). In two studies, it was unclear whether the participants had visual neglect or not (Gall 2013; Plow 2010). See Table 3.

\section{Visual field measurement}

All 20 included studies reported a measurement of the visual field in order to inform participant inclusion or provide baseline information relating to visual field defect, or both. Seven reported one visual field measure (De Haan 2015; Gall 2013; Jarvis 2012; Modden 2012; Plow 2010; Schuett 2012; Szlyk 2005), 11 reported two visual field measures (Aimola 2011; Bainbridge 1994; Bowers 2014; Elshout 2016; Jobke 2009; Kasten 1998; Keller 2010; Rossi 1990; Roth 2009; Rowe 2010; Spitzyna 2007), and two reported three visual field measures (Kasten 2007; Poggel 2004). Spitzyna 2007 reported a second measure only where the first perimetric results had poor reliability.

In three studies, the perimetry equipment was unclear (Aimola 2011; Gall 2013; Jobke 2009), and in Rowe 2010, either of two types of perimetry was reported (Esterman static programme or Goldmann kinetic).

Visual field measurements were categorised as:

- gross visual screening: five studies reported gross visual screening; two using the Harrington Flocks visual screener (Bainbridge 1994; Rossi 1990), two using a confrontation method (Bainbridge 1994; Jarvis 2012), one reporting the visual field assessment from the Test Battery of Attentional Performance (Modden 2012), and one a subjective topographic measure of perceived visual field defect (Plow 2010);

- kinetic perimetry: 10 studies reported measures of kinetic perimetry; seven used Goldmann perimetry (Bowers 2014; De Haan 2015; Elshout 2016; Keller 2010; Rowe 2010; Spitzyna 2007; Szlyk 2005), one used Tubingen kinetic perimetry (Schuett 2012), one used tangent screen measures (Rossi 1990), and one used an unspecified kinetic perimeter (Aimola 2011);

- static threshold perimetry: eight studies reported static perimetry measures; two used standard automated perimetry (Gall 2013; Jobke 2009), four used Tubinger automated perimetry (TAP) (Kasten 1998; Kasten 2007; Poggel 2004; Roth 2009), and two used Humphrey automated perimetry (Elshout 2016; Spitzyna 2007);

- static suprathreshold (inclusive of full field 120, Esterman, campimetry, tangent screen): five studies reported static suprathreshold measures; two reported Esterman measures (Aimola 2011; Rowe 2010), one reported Humphrey full field 120 (Bowers 2014), one reported suprathreshold checks on a Goldmann perimeter (Keller 2010), and one reported high resolution campimetry (Poggel 2004);

- resolution perimetry: six studies reported resolution perimetry measures; five used high resolution perimetry (HRP) (Jobke 2009; Kasten 1998; Kasten 2007; Plow 2010; Poggel 2004), and one used scanning laser ophthalmoscopy (Roth 2009).

\section{Sample size}

On average, included studies randomised 36 participants (standard deviation, 22 participants) into the trial prior to attrition. This ranged from just 10 participants (Szlyk 2005), to 87 participants (Rowe 2010). Only five of 19 studies recruited more than 50 participants: Aimola $2011(n=70)$, Bowers $2014(n=73)$, De Haan $2015(n=54)$, Jarvis $2012(n=64)$, and Rowe $2010(n=87)$. A total of 732 participants were recruited across the 20 included studies, with data available for 638 participants, of whom 547 were stroke patients. See Table 2 for recruitment numbers across all included studies.

\section{Outcome measures}

Table 4 summarises the outcome measures within the included studies, and highlights which studies had data which was suitable for inclusion in meta-analyses within this review.

\section{Primary outcome}

- Functional ability in activities of daily living. Three studies included a measure of functional ability: Rossi 1990 reported the Barthel Index, Jarvis 2012 reported the FIM, and Modden 2012 reported the extended Barthel Index (German version). 


\section{Secondary outcomes}

- Visual field. As reported above, all 20 included studies used at least one measure of visual field at inclusion/baseline. However, two of the studies did not measure visual field as an outcome (i.e. measured following treatment) (Bowers 2014; Jarvis 2012); in one cross-over study, while it was measured as an outcome, no measurement was taken immediately after the cross-over (Schuett 2012); while in Aimola 2011 it was unclear whether this was measured as an outcome or just at baseline. The methods of assessing visual field as a study outcome are summarised in Table 4. Visual field outcomes of potential relevance to our meta-analyses included measures of: 1 ) gross visual screening: four studies (Bainbridge 1994; Rossi 1990, Modden 2012, Plow 2010); 2) kinetic perimetry: seven studies (Aimola 2011; De Haan 2015; Elshout 2016; Keller 2010; Rowe 2010; Spitzyna 2007; Szlyk 2005); 3) static threshold perimetry: eight studies (Jobke 2009; Kasten 1998; Kasten 2007; Elshout 2016; Gall 2013; Poggel 2004, Roth 2009, Spitzyna 2007); 4) static superthreshold perimetry: four studies (Keller 2010; Poggel 2004; Rossi 1990; Rowe 2010); and 5) resolution perimetry; six studies (Jobke 2009; Kasten 1998; Kasten 2007; Plow 2010; Poggel 2004; Roth 2009).

- Extended activities of daily living. Three studies reported a measure of extended activities of daily living (other than a measure of reading ability). Two were measures of functional mobility: Bowers 2014 quantified "Perceived difficulties with mobility" using "a 5-point rating scale (no difficulty to extreme difficulty) for seven situations (items) relevant to homonymous hemianopia, including at home, in stores, outdoors, in unfamiliar areas, in familiar areas, in crowded areas, and noticing objects off to the side when walking"; and De Haan 2015 used an independent mobility questionnaire. Rowe 2010 reported the Nottingham Extended Activities of Daily Living index.

- Reading. Ten studies reported measures of reading ability (Aimola 2011; De Haan 2015; Elshout 2016; Jobke 2009; Keller 2010; Modden 2012; Roth 2009; Rowe 2010; Schuett 2012; Spitzyna 2007). The measures used were the Radner reading test in three studies (De Haan 2015; Jobke 2009; Rowe 2010), tests of reading speed in seven studies (Aimola 2011; De Haan 2015; Elshout 2016; Keller 2010; Roth 2009; Schuett 2012; Spitzyna 2007), and measures linked to the correctness of reading in four studies (De Haan 2015; Jobke 2009; Modden 2012; Schuett 2012). Text reading time data were displayed graphically by Spitzyna 2007 but actual data were confirmed by correspondence with the author.

- Falls. One trial reported the number of falls (Rossi 1990).

- Quality of life. Ten trials reported measures of quality of life (Aimola 2011; De Haan 2015; Gall 2013; Jobke 2009; Kasten 1998; Kasten 2007; Keller 2010; Plow 2010; Roth 2009; Rowe 2010), with several reporting more than one type of measure. The National Eye Institute Visual Functioning Questionnaire (NEIVFQ) was used by five studies (Aimola 2011; De Haan 2015; Gall 2013; Jobke 2009; Rowe 2010), the Short-Form 12 (SF-12) by two studies (Gall 2013; Rowe 2010), the World Health Organization Quality of Life Bref (WHOQOL-Bref) by one (Roth 2009), the Impact of Visual Impairment profile (IVI) and Veterans Affairs Low Vision Visual Function Quaestion (LV-LFQ) by one (Plow 2010), and the EQ-5D (standardised EuroQol health-related quality of life instrument) by one (Rowe 2010). A number of different, often self-designed, questionnaires of satisfaction, improvement and visual ability levels were also used (see Table 4). The quality of life data from Kasten 1998 were included as a dichotomous variable as the data presented in the published paper were a percentage of those who reported subjective improvements of vision; the results were for both the pre- and post-chiasmal group, with 30 of the 38 participants responding.

- Visual scanning. Eight trials reported measures of visual scanning as assessed by a range of scanning and cancellation techniques (Aimola 2011; Bainbridge 1994; De Haan 2015; Keller 2010; Modden 2012; Rossi 1990; Roth 2009; Schuett 2012). In addition, one reported the visual scan test from the Test Battery of Attentional Performance (Modden 2012), and one also used a video eye tracker (Roth 2009). Reported data included scanning/search time and number of errors or omissions (see Table 4). Where a study reported a range of scanning outcomes, we prioritised measures of scanning time for meta-analyses. De Haan 2015 used three different visual scanning tests, and reported a range of different data; we used the results of the "parallel search test" for all trials (target present and target absent), but explored the impact of using alternative data.

\section{Excluded studies}

We excluded 158 papers after assessment of the full paper (see Figure 1). Sixty-two of the 158 clearly did not meet the inclusion criteria, and 30 of the 158 were duplicate publications of excluded studies. Fifty-seven of the 158 papers required more in-depth appraisal prior to exclusion; we have provided our reasons for exclusion of these studies in the Characteristics of excluded studies table. We excluded the majority of these because the intervention was not specifically targeted at the ability of the participant to cope with visual field loss (32/57), or because the study was not randomised (22/57). We found one study did not include participants with stroke, one was focused on central alexia, and one was exploring agreement using a visual screening tool.

We included three studies in the previous (2011) version of this review (Carter 1983, Weinberg 1977 and Weinberg 1979), but they have been excluded in this update: in the 2011 version, we included studies that investigated the effectiveness of visual scanning training and techniques even if the population of participants had not been clearly defined as having visual field defects. Carter 1983, Weinberg 1977and Weinberg 1979 included populations of participants with 'visual scanning' problems, who may have had either visual field defects or visual neglect, or both. For this latest update, we reconsidered and reversed this decision: we have excluded populations of participants with 'visual scanning problems', but no confirmed visual field defect, to ensure that all included studies are focused on stroke survivors with confirmed visual field defects.

\section{Studies awaiting classification}

Two studies are awaiting classification (Ghandehari 2011; Sand 2017). Ghandehari 2011 compared two different pharmacological interventions (Neuroaid and Piracetam) without a control group. The selection criteria, which were prestated for this review, did not clearly state whether pharmacological interventions were relevant for inclusion, but discussion amongst review authors supports the conclusion that it would be appropriate to include any trials of pharmacological interventions if they are specifically focused on improving outcomes in participants with visual field defects. However, it remains unclear whether this study is a randomised controlled trial or not, as there is inconsistent reporting of the study 
design, and we await clarification from the study authors. Prior to any future updates of this review, we will clarify the selection criteria and methods to ensure that the inclusion (or exclusion) of pharmacological interventions is addressed. Sand 2017 is an ongoing study; however, it was not possible to determine from available information whether this was a randomised controlled trial or not.

\section{Ongoing studies}

Seven studies are listed as ongoing studies. Two ongoing studies compare a form of visual restitutive training with control (Feldon 2017; NCT02886663); one is comparing a form of transcranial electrical stimulation with control (Gall 2015); one is comparing a pharmacological intervention focused on restitution of the visual field with a placebo (NCT02737930); and one is comparing two different modes of delivery of computer-based compensatory scanning interventions with a control (ISRCTN16023965). Two of these studies, listed as ongoing in the previous version of this review, are now complete (Hayes 2010; Komm 2009), but we have been unable to obtain results from the authors. If results are not available at the time of the next update, we will exclude these studies.

\section{Risk of bias in included studies}

We have described the assessment of risk of bias for individual studies in the 'Risk of bias' tables in Characteristics of included studies, summarised in Figure 2. 
Figure 2. Risk of bias summary: review authors' judgements about each risk of bias item for each included study.

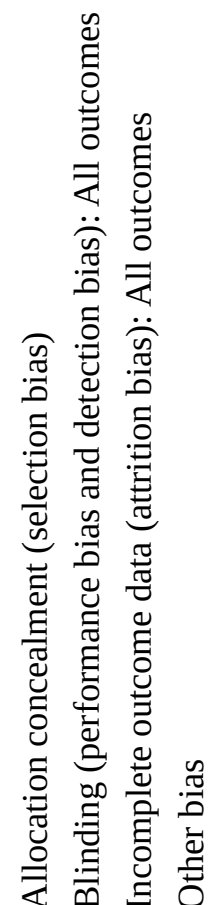

\begin{tabular}{|c|c|c|c|c|}
\hline 11 & + & ? & & \\
\hline bri & ? & ? & ? & ? \\
\hline Bowers 2014 & + & \pm & & \\
\hline e Haan 2015 & + & \pm & & \\
\hline Elshout 2016 & + & $\mathrm{E}$ & $?$ & + \\
\hline Gall 2013 & $?$ & $?$ & $?$ & ? \\
\hline Jarvis 2012 & + & E & ? & 5 \\
\hline Jobke 2009 & $?$ & $?$ & ? & \\
\hline Kasten 1998 & $?$ & + & ? & \\
\hline Kaste & $?$ & + & & \\
\hline Keller 2010 & 巨 & $?$ & ? & + \\
\hline Modd & & & & \\
\hline Plow 2010 & + & + & + & + \\
\hline Poggel 2004 & $?$ & & $?$ & \\
\hline Rossi 1990 & ? & - & ? & + \\
\hline Roth 2009 & $?$ & $?$ & & \\
\hline Rowe 2010 & \pm & + & & + \\
\hline Schuett 2012 & $?$ & $?$ & $?$ & + \\
\hline pitzyna 2007 & + & & & \\
\hline Szlyk 2005 & $?$ & $?$ & $?$ & + \\
\hline
\end{tabular}




\section{Allocation}

Although all 20 included studies were described as randomised controlled trials, only 10 of them reported sufficient information on the method of randomisation to assess whether the randomisation and allocation concealment methods were adequate, and, in two of these studies, we judged them to be at high risk of bias: in Keller 2010 some of the allocation appeared to have been alternate, rather than random, and, in Modden 2012, randomisation was through throwing of a dice, with no allocation concealment.

\section{Blinding}

In the majority of included studies, the nature of the intervention meant that it was not possible to mask (blind) participants or people involved in their care. We judged blinding as low risk of bias if there was evidence that the outcome assessor was masked to the treatment allocation of the participants - six of the 20 studies clearly reported having a masked outcome assessor. In eight of the 20 studies this information was unclear, and in six of the 20 studies we judged that there was a high risk of bias as the outcome assessor was not masked.

\section{Incomplete outcome data}

Lack of information about the management of incomplete outcome data, and whether or not there had been dropouts or participants excluded from the studies, made it difficult to assess risk of bias relating to incomplete outcome data for all the studies. In four of the 20 studies, we considered that adequate reasons for dropouts were provided, numbers of dropouts were even between groups, or intention-to-treat analysis was carried out. However, in five of the 20 studies where we felt that incomplete outcome data were not adequately addressed, and that dropouts were either unbalanced or might be related to the intervention studied (e.g. because people dropped out or were excluded because of low compliance), we judged risk of bias to be high. For the remaining 11 studies, we were unclear as to whether or not incomplete outcome data were adequately addressed.

\section{Other potential sources of bias}

Lack of information and details of methodology within the included studies generally made it difficult for us to assess the potential risk due to other biases. However, four of the studies of visual restitution therapy were carried out by researchers who have acknowledged a financial interest in this intervention (as stated in Poggel 2004) (Jobke 2009; Kasten 1998; Kasten 2007; Poggel 2004), and Bowers 2014 declared a financial conflict of interest relating to the prisms that were being investigated. We assessed this to potentially introduce a source of bias. We identified concerns that the increased attention given to the treatment group, as opposed to the control group, in De Haan 2015 may create a high risk of bias. For two of the studies, only abstracts were available and there was insufficient information on which to assess bias (Bainbridge 1994; Gall 2013). We judged the remaining 12 studies as unlikely to be at risk of other potential sources of bias, but based this assessment on the absence of information suggesting bias rather than the presence of information indicating that the study was free from bias.

\section{Studies included in meta-analyses within this review}

From the 20 studies included in this review, there are only eight studies included in meta-analyses within this review (Aimola 2011;
Bowers 2014; De Haan 2015; Jarvis 2012; Kasten 1998; Rossi 1990; Rowe 2010; Spitzyna 2007). These eight studies randomised 428 participants. The studies relevant to our prestated comparisons (see Objectives), and included within the planned meta-analyses are:

\section{Restitutive interventions versus no treatment, placebo, or control}

- Kasten 1998 (visual restitution therapy versus placebo, $n=19$ ). We have included data from this study in relevant analyses.

\section{Compensatory interventions versus no treatment, placebo, or control}

- Aimola 2011 ( $n=52)$, De Haan 2015 ( $n=49)$, Rowe 2010 ( $n=$ 70), and Spitzyna $2007(\mathrm{n}=22)$ are all relevant and have data included in relevant analyses.

\section{Substitutive interventions versus no treatment, placebo, or control}

- Rossi 1990 (prisms versus no treatment, $\mathrm{n}=39$ ) and Rowe 2010 (prisms versus control, $n=59$ ). We have included data from these studies in relevant analyses.

- Bowers 2014 (prisms versus placebo, $n=67$ ). This is a crossover study and data were principally presented after the crossover; however, there were data for one outcome (extended activities of daily living) presented before the cross-over, with data suitable for inclusion in analysis.

\section{Assessment or screening versus no treatment, placebo, or control}

- Jarvis 2012 (assessment versus control, $\mathrm{n}=39$ ). We have included data from this study in relevant analyses.

\section{Studies not included in meta-analyses}

Ten of the studies included in this review did not have a control group and are therefore not included in meta-analyses.

These 10 studies each compared one active intervention with another active intervention:

- Jobke 2009, Kasten 2007, Modden 2012, Plow 2010, Poggel 2004, and Roth 2009 all investigated restitutive interventions, and did not include a no-treatment, placebo, or control group.

- Keller 2010, Modden 2012, Roth 2009, and Schuett 2012 all investigated compensatory interventions, and did not include a no-treatment, placebo, or control group.

- Bainbridge 1994 and Szlyk 2005 both investigated substitutive interventions, and did not include a no-treatment, placebo, or control group.

The results from relevant outcomes from these studies are summarised in Table 5 and Table 6 and in a narrative synthesis below.

One study did have a relevant control group (alternating current stimulation versus placebo, $n=39$ ) but was published as an abstract only and we have been unable to identify data suitable for inclusion (Gall 2013).

One study did have a relevant control group (visual restitution training versus placebo, $\mathrm{n}=30$ ) but was a randomised cross-over 
trial and we have been unable to obtain data from the first phase only, in order to include data in meta-analyses (Elshout 2016).

\section{Effects of interventions}

See: Summary of findings 1 Summary of findings: Restitutive interventions versus control; Summary of findings 2 Summary of findings: Compensative interventions versus control; Summary of findings 3 Summary of findings: Substitutive interventions versus control; Summary of findings 4 Summary of findings: Assessment/ screening interventions versus control

\section{Restitutive interventions versus no treatment, placebo, or control}

There was one included study: Kasten 1998 (see Summary of findings 1). Data were available for visual field and quality of life outcomes, but not for any other outcomes of interest to this review. Stroke survivors with visual neglect were not included in Kasten 1998 , therefore these analyses relate to participants with visual field defects only (no co-existing visual neglect).

\section{Visual field}

See Analysis 1.1. Data from Kasten 1998 (19 participants) showed that there was no statistically significant effect of a restitutive intervention as compared to control (MD 1.02, 95\% Cl -1.37 to 3.41) for the visual field outcome (confrontation). We judged this evidence to be of very low quality.

\section{Quality of life}

See Analysis 1.2. Data from Kasten 1998 showed that there was a statistically significant effect of a restitutive intervention as compared to control (OR $13.00,95 \% \mathrm{Cl} 2.07$ to 81.48$)$. The data used in this analysis were derived from 30 randomised participants, and included data from participants with optic nerve injury who had also received the same interventions in a separate (but parallel) trial. A total of 38 participants were randomised, of whom 19 had stroke and 19 had optic nerve injury; data were only available for 30 of 38 of these participants for this outcome. Separate data were not available for participants with stroke only. We judged this evidence to be of very low quality.

\section{Compensatory interventions versus no treatment, placebo, or control}

Included studies: Aimola 2011; De Haan 2015; Rowe 2010; Spitzyna 2007 (see Summary of findings 2). Stroke survivors with visual neglect were not included in De Haan 2015; Rowe 2010; Spitzyna 2007, while participants in Aimola 2011 could have co-existing neglect: data are presented in subgroups relating to the inclusion of participants with neglect.

\section{Visual field}

See Analysis 2.1. Data from two studies (95 participants) showed that there was no statistically significant effect of compensatory interventions compared with control (SMD $-0.11,95 \% \mathrm{Cl}-0.92$ to 0.70, heterogeneity: $\mathrm{I}^{2}=75 \%$ ) (De Haan 2015; Rowe 2010). We judged this evidence to be of very low quality. Several factors could contribute to the substantial heterogeneity, including different inclusion criteria (e.g. participants had to be $<26$ weeks post stroke in Rowe 2010) and very different interventions (see Characteristics of included studies). However a key factor to note, which limits confidence in these findings, is that there was a significant difference in baseline assessment between groups in De Haan 2015).

\section{Extended activities of daily living}

See Analysis 2.2. Data from two studies (97 participants) showed that there was no statistically significant benefit in favour of compensatory interventions compared with control (SMD 0.49, $95 \% \mathrm{Cl}-0.01$ to 0.99 , heterogeneity: $I^{2}=25 \%$ ) (De Haan 2015, Rowe 2010). We judged this evidence be of very low quality.

\section{Reading}

See Analysis 2.3. Data from four studies (162 participants) showed that there was no statistical significant effect of compensatory interventions compared with control (SMD $0.26,95 \% \mathrm{Cl}-0.05$ to 0.58, heterogeneity: $I^{2}=0 \%$ ) (Aimola 2011; De Haan 2015; Rowe 2010; Spitzyna 2007). We judged this evidence to be of low quality. Although some of the participants in Aimola 2011 may have had neglect, there was no downgrade for indirectness as the test for subgroup differences demonstrated no significant differences between the studies including or not including participants with neglect $(P=0.43)$.

\section{Quality of life}

See Analysis 2.4. Data from two studies (96 participants) showed that there was a statistically significant effect of compensatory interventions compared with control (MD 9.36, 95\% Cl 3.10 to $15.62)$, with minimal heterogeneity $\left(I^{2}=0 \%\right)$, based on the results for the total score for the VFQ-25 assessment (De Haan 2015; Rowe 2010). We judged this evidence to be of low quality.

\section{Scanning - cancellation}

See Analysis 2.5. Data from two studies (97 participants) showed that there was no statistically significant effect of compensatory interventions compared with control (SMD $-0.01,95 \% \mathrm{Cl}-0.40$ to 0.39 ), with minimal heterogeneity $\left(\mathrm{I}^{2}=0 \%\right.$ ) (Aimola 2011; De Haan 2015). We judged this evidence to be of low quality. Although some of the participants in Aimola 2011 may have had neglect, there was no downgrade for indirectness as the test for subgroup differences demonstrated no significant differences between the studies including or not including participants with neglect $(P=$ 0.55). Substituting the De Haan 2015 'parallel search test' data for 'all trials' with other presented data, including the 'serial search test' data and 'dot counting test', or substituting the 'target present' data for the 'all trials' data, did not change the non-significant result.

\section{Adverse events}

See Analysis 2.6. Rowe 2010 collected and reported data relating to adverse events, stating that: "Two patients $(6.7 \%)$ in the visual search training arm experienced seven adverse events (six fatigue and one headache). No adverse events were recorded for the standard care arm". De Haan 2015 did not report adverse events as an outcome measure, but stated that: "No important harms caused by the training or the assessments were encountered, nor reported by the participants". Data from Rowe 2010 (see Analysis 2.6), showed that there was no difference in the odds of a participant having an adverse event with compensatory scanning training, when compared to control (OR 15.18, $95 \% \mathrm{Cl} 0.24$ to 112.57). We judged this evidence to be of low quality. 
Substitutive interventions versus no treatment, placebo, or control

Included studies: Bowers 2014; Rossi 1990; Rowe 2010 (see Summary of findings 3). Stroke survivors with visual neglect were not included in Bowers 2014 and Rowe 2010, while participants in Rossi 1990 could have co-existing neglect. Substitutive prisms were worn during the outcome assessment by participants in Bowers 2014 and Rossi 1990, but were not worn during outcome assessment by participants in Rowe 2010. As the wearing of the substitutive intervention during outcome assessment should theoretically expand the size of the visual field, the data arising from these different approaches (wearing or not wearing prisms) were presented as subgroups, and no pooled total was calculated.

\section{Functional activities of daily living (primary outcome)}

See Analysis 3.1. Data from one study (39 participants, wearing prisms during assessment; participants may have co-existing neglect) showed that there was no statistically significant effect of a substitutive intervention compared with control for the primary outcome of functional activities of daily living (MD $-4.00,95 \% \mathrm{Cl}$ -17.86 to 9.86) (Rossi 1990). We judged this evidence to be of very low quality.

\section{Visual field}

See Analysis 3.2. Data from one study (46 participants; no neglect) showed that there was no statistically significant effect of a substitutive intervention compared with control when the substitutive intervention (prism) was not being worn (SMD 0.12, $95 \% \mathrm{Cl}-0.46$ to 0.70 ) (Rowe 2010). Data from one study (39 participants; possibly co-existing neglect) showed that there was a statistically significant effect of a substitutive intervention compared with control when the substitutive intervention (prism) was being worn (SMD 1.12, 95\% Cl 0.44 to 1.80) (Rossi 1990). There was a statistically significant difference between the subgroups in which participants did and did not wear prisms during assessment $(P=0.03)$. We judged this evidence to be of very low quality.

\section{Extended activities of daily living.}

See Analysis 3.3. Data from one study (48 participants, no neglect) showed that there was no statistically significant effect of a substitutive intervention compared with control when the substitutive intervention (prism) was not being worn (SMD 0.20, $95 \% \mathrm{Cl}-0.44$ to 0.85 ) (Rowe 2010). Data from one study (61 participants, no neglect) showed that there was no statistically significant effect of a substitutive intervention compared with control for measures of extended activities of daily living, using a mobility score (SMD $0.24,95 \% \mathrm{Cl}-0.26$ to 0.75 ) (Bowers 2014). There was no statistically significant difference between the subgroups that did and did not wear prisms during assessment $(P=0.92)$. We judged this evidence to be of very low quality.

\section{Reading}

See Analysis 3.4. Data from one study (45 participants, no neglect) showed that there was no statistically significant effect of a substitutive intervention compared with control when the substitutive intervention (prism) was not being worn (MD 2.80, 95\% $\mathrm{Cl}-7.13$ to 12.73) (Rowe 2010). We judged this evidence to be of low quality.

\section{Falls}

See Analysis 3.5. Data from one study (39 participants, possible coexisting neglect) showed that there was no statistically significant effect of a substitutive intervention compared with control for the risk of falls (OR 1.21, 95\% Cl 0.26 to 5.76) (Rossi 1990). We judged this evidence to be of very low quality.

\section{Quality of Life}

See Analysis 3.6. Data from one study (43 participants, assessed not wearing prisms; no neglect) showed that there was no statistically significant effect of a substitutive intervention compared with control for a measure of quality of life (MD $8.40,95 \% \mathrm{Cl}-4.18$ to 20.98) (Rowe 2010). We judged this evidence to be of low quality.

\section{Scanning (cancellation)}

See Analysis 3.7. Data from one study (39 participants, assessed wearing prisms; possibly co-existing neglect) showed that there was a statistically significant effect of a substitutive intervention compared with control for measures of scanning (MD 9.80, 95\% Cl 1.91 to 17.69) (Rossi 1990). We judged this evidence to be of very low quality.

\section{Adverse events}

Rowe 2010 collected and reported data relating to adverse events, stating that "Eighteen patients (69.2\%) in the Fresnel prisms arm experienced a total of 42 adverse events of which 28 were classified as headache. No adverse events were recorded in the standard care arm". The reported adverse events in the group wearing prisms were: headache (28 events in six participants); diplopia (five events in five participants); visual confusion (four events in three participants); difficulty with navigation (two events in two participants); dizziness (two events in one participant); optical glare/aberrations (one event in one participant). Analysis 3.8 shows that there was an increased odds of a participant having an adverse event if they were wearing prisms (OR $87.32,95 \% \mathrm{Cl} 4.87$ to 1564.66). We judged this evidence to be of low quality.

\section{Assessment or screening interventions versus no treatment, placebo, or control}

Included study - Jarvis 2012 (see Summary of findings 4).

\section{Functional activities of daily living (primary outcome)}

See Analysis 4.1. Data from Jarvis 2012 (37 participants) showed that there was no statistically significant effect of an assessment intervention compared with control for measures of functional activities of daily living (MD $-6.97,95 \% \mathrm{Cl}-23.78$ to 9.84 ). We judged this evidence to be of very low quality.

\section{Subgroup and sensitivity analyses}

As there were no more than six trials in any single meta-analysis, as prestated in our protocol, we did not carry out the planned subgroup or sensitivity analyses. There were two exceptions to this:

- we carried out subgroup analysis to explore the effect of including studies in which participants may have had neglect in addition to visual field defects. This decision was made as there was one study in which some of the participants may have had neglect (Aimola 2011), and we considered the implications for including this group of participants of key clinical importance. Results of these analyses are reported above; 
- we carried out subgroup analyses to explore different ways of doing assessment in studies investigating the use of prisms (i.e. assessment wearing or not wearing prisms). This was considered central to the clinical relevance of the pooled result. Results of these analyses are reported above.

\section{One active intervention versus another active intervention (narrative synthesis)}

As planned, no meta-analyses have been carried out to pool data from studies that compared one active intervention with another active intervention. A summary of results for relevant outcomes for these comparisons is provided in Table 5 and Table 6, and a brief narrative summary below.

\section{Studies comparing two similar active interventions}

(See Table 5)

\section{One restitutive intervention versus another restitutive intervention}

We found two studies that compared the effectiveness of two (or more) types of visual restitution therapy (Jobke 2009; Kasten 2007). Jobke 2009 compared extrastriate visual restitution therapy with conventional visual restitution therapy in a cross-over study including 18 participants. After the first phase of the study, the extrastriate visual restitution therapy group had improved in measures of visual field (detection performance in HRP) by $5.9 \%$ and the conventional visual restitution therapy group had improved by $2.9 \%$. No significant changes were found for either group for Radner reading scores. Kasten 2007 compared three treatment groups: 1) standard visual restitution therapy with single stimulation, 2) visual restitution therapy with parallel co-stimulation, and 3) visual restitution therapy with moving co-stimulation. We found no statistically significant differences between groups for measures of the visual field (perimetry).

We found two studies that investigated the addition of another intervention to visual restitution therapy (Plow 2010; Poggel
2004). Plow 2010 investigated the effect of adding transcranial direct current stimulation (tDCS) to visual restitution therapy and reported a greater increase in detection accuracy (perimetry) in the group receiving tDCS $(9.37 \%$ increase compared to $5.55 \%$ increase in control group). Poggel 2004 compared standard visual restitution therapy with visual restitution therapy plus attentional cueing in 19 participants; results were primarily presented graphically and as whole-group data: the authors concluded that the visual field border increased significantly more in the participants in the attentional cueing group.

\section{One compensative intervention versus another compensative intervention}

We found three studies that compared different compensative interventions (Keller 2010; Modden 2012; Schuett 2012). Keller 2010 compared audiovisual training and visual exploration training in 10 participants, reporting that audiovisual training was better than visual exploration training for outcomes of activities of daily living, reading, and visual scanning. Schuett 2012 compared reading training and visual exploration training in 36 participants within a cross-over study. We used data reported from before the cross-over period to calculate effect sizes for Schuett 2012 (see Figure 3); this demonstrated that visual exploration training was significantly more beneficial than reading training at improving scanning outcomes, and there was a trend towards reading training improving reading outcomes more significantly than visual exploration training. Modden 2012 compared 45 participants within three groups; one receiving computer-based restitution therapy, one computer-based compensation therapy, and one standard occupational therapy. We judged the occupational therapy intervention to be a compensatory intervention. We found no differences between the groups receiving the computer-based compensatory therapy and occupational therapy interventions for measures of visual field enlargement, reading, or visual scanning.

Figure 3. One compensatory intervention versus another compensatory intervention. Effect sizes for Schuett 2012 (see Table 5)

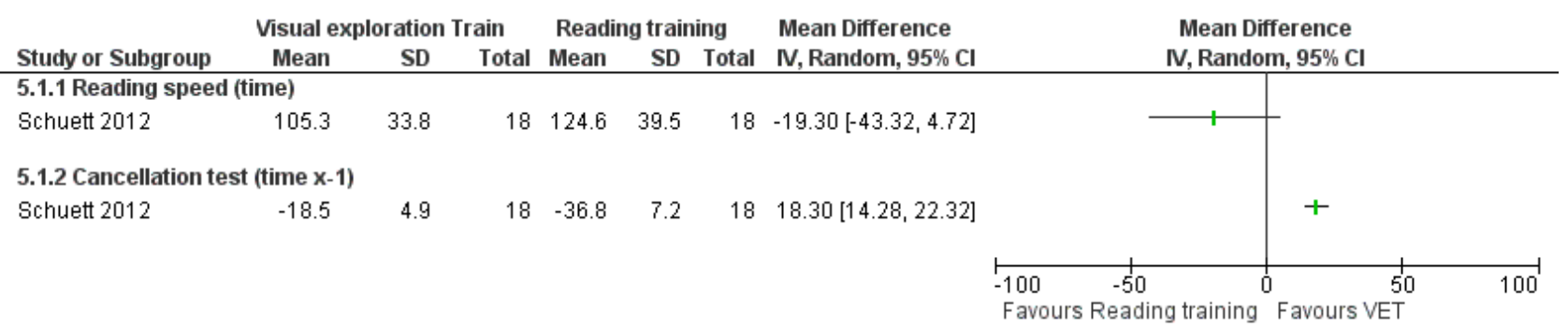

One substitutive intervention versus another substitutive intervention

We found two studies that compared the effectiveness of two types of prism (Bainbridge 1994; Szlyk 2005). Bainbridge 1994 compared the effect of full-field and hemi-field prisms in 18 participants, and reported a significant effect in favour of full-field prisms for the cancellation test and Harrington Flocks Visual Field score. Szlyk 2005 compared Fresnel prisms and the Gottlieb Visual Field Awareness System in 10 participants and found no statically significant differences in outcomes between the two groups, although this was a cross-over study with no data presented for the period of time before the cross-over.

\section{Studies comparing two different types of active intervention}

(see Table 6)

\section{Compensation intervention versus restitutive intervention}

Two studies compared the effectiveness of a compensation intervention and a restitutive intervention (Modden 2012; Roth 2009). Roth 2009 compared explorative scanning training (a 
compensation intervention) with flicker stimulation training (a restitution intervention) in 29 participants, finding no significant differences between groups for key outcomes (although there were differences between groups at baseline for some outcomes). Modden 2012 compared 45 participants within three groups; one receiving computer-based restitution therapy, one computerbased compensation therapy, and one standard occupational therapy. In Table 6, we compared the results of the groups receiving computer-based training. There were no significant differences reported for these groups for measures of visual field enlargement, activities of daily living, reading, or visual scanning.

\section{Compensation intervention versus substitution intervention}

One study compared the effectiveness of a compensative intervention (paper-based visual search training) and a substitutive intervention (Fresnel prisms) (Rowe 2010). This was a three-armed study, with a control (standard care) treatment; data from the active treatment arms compared to the control treatment have been included in meta-analyses within this review. We found no significant differences between the compensative and substitutive intervention for measures of visual field, extended activities of daily living, and reading. We found a statistically significant difference in favour of the compensative intervention for the measure of quality of life (using the VFQ-25).

\section{DISCUSSION}

\section{Summary of main results}

We found 20 studies (732 randomised participants, with data for 638 participants, 547 of whom were participants with stroke) that investigated interventions for visual field defects in people with stroke. However, only 10 of these studies compared the effect of an intervention with a placebo, control, or no treatment group, which were the comparisons of interest to the review question, and only eight had data suitable for inclusion within meta-analyses. Only two of these eight studies presented data relating to our primary outcome of functional abilities in activities of daily living, and there was a lack of consistency in outcome measures used across studies, which limited our ability to draw generalised conclusions.

\section{Effect of restitutive interventions}

Three studies (88 participants) compared a restitutive intervention with a control, but data were only available for one (19 participants). There was very low-quality evidence that visual restitution therapy had no effect on visual field outcomes, and a statistically significant positive effect on quality of life. However, the data relating to the quality of life outcome must be interpreted with caution as the data used for analysis combined the population of interest with an additional 19 participants with optic nerve injury who had been included in a separate (but parallel) trial. These participants had damage to the anterior visual pathway, a population which was specifically excluded from this review, and in none of the participants was the optic nerve damage due to stroke. We, therefore, do not believe that the findings based on data from this population are applicable to the population of patients with visual field loss due to post-chiasmal stroke. There is, therefore, insufficient evidence to draw any conclusions about the effectiveness of visual restitution therapy as compared to placebo, control, or no treatment. There was also some very limited evidence from two small studies which compared different types of restitutive interventions that there may be some benefits to adding either attentional cueing or tDCS to visual restitutive therapy, while a further two small studies found no difference in different modes of delivering visual restitution therapy.

\section{Effect of compensatory interventions}

Four studies (193 participants) compared a compensatory intervention with a control. There was low-quality evidence of a beneficial effect on measures of quality of life. However, there was low- or very low-quality evidence of no effect on measures of visual field, extended activities of daily living, reading, and scanning ability. Findings from a small study comparing two different types of compensatory therapy conflicts with the evidence of no effect on scanning outcome, demonstrating a beneficial effect of visual exploration therapy on scanning outcomes when compared to reading training. There is, therefore, some limited low-quality evidence that compensatory scanning training may improve an important outcome (quality of life) in people with visual field defects following stroke, but further research is very likely to have an important impact on our confidence in the estimate of effect and is likely to change the estimate. Studies comparing different active interventions provide some very limited evidence that there may be benefits associated with audiovisual training, rather than visual exploration training alone, and suggest that compensatory training, as delivered during standard clinical practice, may be as effective as computer-based training interventions.

\section{Effect of substitutive interventions}

Three studies (166 participants) compared a substitutive intervention (a type of prism) with a control. There was low- or very low-quality evidence that prisms did not have an effect on measures of activities of daily living, extended activities of daily living reading, falls, or quality of life, but that they may have an effect on scanning ability. Evidence from one study indicates that people using prisms may have a higher odds of adverse events, particularly headache. However, it is important to note a fundamental difference between these studies in that, in two of the studies, participants in the treatment group wore prisms during the outcome assessments (Bowers 2014; Rossi 1990), while in one study none of the participants wore prisms during outcome assessment by participants (Rowe 2010). Evidence relating to measures of visual field demonstrated a significant difference between studies that measured outcome whilst wearing or not wearing the substitutive device, with a beneficial effect when the prisms were worn during testing but not without. However, due to the quality and quantity of evidence, we remain uncertain about the benefits of prisms.

\section{Effect of screening/assessment interventions}

One study (39 participants) compared the effect of assessment by an orthoptist to standard care (no assessment) and found very low-quality evidence that there was no effect on measures of activities of daily living. However, due to the quality and quantity of evidence, we remain uncertain about the benefits of assessment interventions.

Ten studies compared the effect of two of more different active interventions and did not include a control group.

In summary, this review has identified:

- a lack of evidence relating to the effect of interventions on our primary outcome (functional ability in activities of daily living); 
- low-quality evidence that compensatory scanning training is more beneficial than placebo or control at improving quality of life, but not other outcomes;

- insufficient evidence to reach any generalised conclusions about the effect of restitutive interventions, substitutive interventions (prisms), or screening/assessment interventions as compared to placebo, control or no treatment;

- low-quality evidence that prisms may result in an increase in the number of people experiencing adverse events (particularly headache).

\section{Overall completeness and applicability of evidence}

\section{Studies with control, placebo, or no treatment group}

Although we identified 20 studies that investigated the effect of interventions for visual field defects after stroke, only 10 of these studies (and only eight with data) compared the effect of an intervention with a control, placebo, or no treatment group, which was the question of interest to this review. The remaining 10 studies compared different types of interventions, with nine of these studies comparing interventions of the same 'type' (i.e. comparing two substitutive interventions or two restitutive interventions); arguably, comparisons of different active interventions have little merit until such time as the benefits (and harms) of active interventions, as compared to control, placebo, or no treatment have been established. Three studies did compare the relative effects of two different types of intervention (i.e. compensatory versus restitutive, or compensative versus substitutive). Thus, although we made the decision to include all the studies which investigated the effectiveness of interventions for visual field defects, in fact only nine of these studies included comparisons that were directly relevant to the review question, focusing on a comparison with a control, placebo, or no treatment group. Five of the 20 included studies, including two of the 10 studies with a control/placebo comparison, were cross-over studies. The reporting of data from after the cross-over in studies with this design limited our ability to incorporate data within meta-analyses in this review, and there is a risk that outcomes from after the crossover are affected by the treatments administered prior to the crossover.

\section{Restitutive interventions versus no treatment, placebo, or control}

Kasten 1998 was the one study comparing a restitutive intervention with a control or placebo, with data suitable for inclusion in our meta-analyses. This study included 19 participants, only 10 of whom had stroke. The study did not measure our primary outcome of interest (functional ability in activities of daily living). There was an uneven distribution of stroke patients between the two groups (with two stroke patients out of the nine participants in the treatment group and eight stroke patients out of 10 participants in the control group). This uneven distribution means that only two patients with stroke received an active intervention, providing evidence from which it would be inappropriate to generalise. Furthermore, for quality of life outcome data, the 19 participants in this study had been combined with the results of 19 participants in another similar study. However, the additional 19 participants all had optic nerve injury rather than post-chiasmal injury. Due to the nature of the participants included in this study, it would not be appropriate to make generalisations from this evidence to the population of stroke patients with visual field defects after stroke. Our confidence in the findings from this evidence is very low.

\section{Compensatory interventions versus no treatment, placebo, or control}

We were able to combine data from four studies (162 participants) comparing compensatory (scanning) interventions with control or placebo in meta-analysis. None of these studies measured our primary outcome of interest (functional ability in activities of daily living). Visual field defects in the participants included in these studies were confirmed using perimetry (see Table 3). Three of the studies included participants with visual field defects and no co-existing visual neglect; two of these studies excluded participants with neglect based on clinical testing (De Haan 2015; Rowe 2010), while one only included participants with a leftsided cerebrovascular accident where patients rarely experience persistent neglect (Spitzyna 2007). One study included participants who had visual field defects but possibly also co-existing visual neglect (Aimola 2011); clinical testing confirmed that only three of the 52 participants had confirmed neglect. Participants included those from a mixed population (i.e. stroke and other neurological conditions) for three of the four studies; 41 of the 49 participants had stroke in De Haan 2015, 39 of 52 had stroke in Aimola 2011, and 13 of 22 had stroke in Spitzyna 2007. All participants had stroke in Rowe 2010. The majority of participants in these studies, therefore, had visual field defects following stroke and did not have co-existing neglect (as confirmed by clinical testing); therefore, it would be appropriate to generalise from these results to the population of stroke survivors with visual field defects and no neglect.

The nature of the scanning training in the four studies combined within the meta-analyses varied considerably; two investigated computer-based scanning training, one focused on visual exploration training (Aimola 2011), one on reading training using scrolling horizontal text (Spitzyna 2007), one was a training programme, primarily delivered face-to-face by an occupational therapist (De Haan 2015), and one was a self-delivered paperbased scanning exercise (Rowe 2010). It is likely that the nature of these interventions will result in varied scanning movements of the eye. As well as differences in the mode of delivery of the scanning training, there were also differences in the amount of training. These differences in the compensatory interventions reduce confidence in any findings, and limit ability to generalise from these findings. During the GRADE assessment of quality of evidence, we applied a downgrade to each comparison combining results from these studies due to the variations in the interventions studied. We, therefore, have low- to very-low confidence in the findings from this evidence.

\section{Substitutive interventions versus no treatment, placebo, or control}

Two studies compared a substitutive intervention (prisms) with a no treatment control (Rossi 1990; Rowe 2010). Rossi 1990 measured our primary outcome of interest (functional ability in activities of daily living). Both studies only included participants with stroke, but Rossi 1990 included participants with visual neglect in additional to visual field defect. The studies both investigated the effect of Fresnel prisms. There was a fundamental difference between these studies relating to the assessment of outcome: Rossi 1990 measured outcomes whilst participants in the intervention 
group wore the assigned prisms, whilst Rowe 2010 measured outcomes while participants were not wearing any assigned prisms. It has been argued that the rationale for prisms is that they provide visual field expansion when in use, and that consequently outcomes from clinical trials exploring the effectiveness of prisms should be measured with participants wearing the prisms (Bowers 2014). In contrast, Rowe 2010 measured outcomes without use of assigned prisms in order to preserve blinding of outcome assessor and enable direct comparison of study treatment groups. It was, therefore, not appropriate to pool data from these different studies of prisms, as the wearing of prisms during assessment in one study but not the other makes the results incomparable. This is an important issue which must be appropriately considered in future trials. Due to the methodological limitations of these studies, and the inability to combine results, we have low to very low confidence relating to this evidence.

\section{Assessment/screening intervention versus control}

One study explored the effect of implementing a full visual assessment by an orthoptist and sharing the results with hospital staff (Jarvis 2012). This study measured our primary outcome of interest (functional ability in activities of daily living). The evidence was judged to be very low quality, limiting our confidence in the findings from this study.

\section{Quality of the evidence}

For this updated review, we judged the quality of evidence using the GRADE approach. We judged all evidence included within metaanalyses to be of low or very low quality. Key factors contributing to downgrading of the evidence within these comparisons included:

\section{Risk of bias}

We identified concerns about the methodology for the majority of included studies, and there were often insufficient details available from incomplete reporting of methodological details. We judged only eight of the 20 studies to be at low risk of bias for allocation concealment, six of the 20 for blinding of outcome assessment, and four of the 20 for incomplete outcome assessment. Furthermore, five of the studies were carried out by researchers who have acknowledged a financial interest in intervention (Bowers 2014; Jobke 2009; Kasten 1998; Kasten 2007; Poggel 2004); we assessed this as potentially introducing a source of bias.

\section{Imprecision}

The number of participants within the included studies was small, ranging from 10 to 87 participants, with only five of the 20 studies including more than 50 participants. While there were a total of 732 randomised participants, variations in studies made it inappropriate for the majority of study data to be combined within analyses, and the maximum number of participants with data combined in a single analysis was 162 (Analysis 2.3). The small number of participants within the included studies and suitable for combination within meta-analyses limits the conclusions that can be drawn from this evidence.

\section{Indirectness}

A number of factors contributed to indirectness of the data included within meta-analyses. In particular:
- population: there was considerable heterogeneity between the populations recruited to individual studies. In addition to stroke-related differences, such as time post-stroke, initial impairment, and the presence of other strokerelated impairments (e.g. communication, mobility), this was confounded by the inclusion of participants with conditions other than stroke, and in opposing the decision to either include or exclude participants with visual neglect. The variations in populations contributed to decisions to downgrade the quality of evidence, as this reduced our certainty in the reported findings;

- interventions: this review aimed to synthesise evidence relating to a wide range of different interventions for visual field defects following stroke and preplanned categories to support appropriate combination of evidence. However, we found substantial variations in the interventions within these different categories in relation to the details of the delivered interventions. In particular, the compensative interventions had considerable variation in the mode of delivery, with interventions varying from computer-based scanning training and reading training, paper-based scanning training, to face-toface scanning and mobility training. What is being delivered in terms of the eye movements being trained with these different interventions is likely to vary considerably, and - while data from these 'scanning' interventions have been combined - the variations in interventions limit our ability to be confident about the pooled result;

- outcomes: as is highlighted in Table 4, there was a lack of consistency in the outcomes assessed by individual studies, and in the assessment tools used to do this. While there is an argument that outcome measures should be carefully selected according to the anticipated action of, or scientific rationale for, the intervention (Bowers 2017), the variations in interventions do not fully explain the lack of consistency between the outcome measures. Within the studies of prisms, the difference in choice of outcome measure was further confounded by opposing decisions relating to whether outcomes were assessed wearing or not wearing the prisms. The variations in outcome measures limited the ability to pool data from individual studies in a meaningful way, and where measures have been pooled, limited our certainty in the result.

In summary, we judged the quality of the evidence synthesised within this review to be low to very low, and this limits our confidence in the results. Future research needs to address the factors which contribute to this level of evidence, in order to produce results which are useful and meaningful.

\section{Potential biases in the review process}

\section{Publication bias}

Through a thorough searching process we are quite confident that we should have identified all relevant published studies. However, at the peer review stage of this review update, we were alerted to the fact that we had erroneously excluded a relevant study (Elshout 2016): while this was corrected prior to publication, it does highlight the potential for human error in our process of screening titles. A limitation of our search strategy for this update is that we have not searched a number of trials databases beyond March 2015 (Current Controlled Trials, Health Service Research Projects in Progress, National Eye Institute Clinical Studies Database, Stroke Trials Registry); this may have limited our ability to identify ongoing trials, 
but ought not to have impacted on our identification of completed trials. It must be acknowledged that there is a small possibility that there are additional studies (published and unpublished) that we did not identify. We had planned to explore the effect of publication type using sensitivity analyses; however, all data included in metaanalyses were from peer-reviewed journals.

\section{Categorisation of interventions}

Although we anticipated that we may experience difficulty in categorising the interventions studied into our predefined categories of restitutive, compensative, and substitutive interventions, this was not the case and the categorisation process was a clear and unambiguous process. This was because the studies we identified were primarily visual restitution therapy (restitutive), compensatory scanning training (compensative), or prisms (substitutive). We are, therefore, confident that our categorisation of interventions has not introduced bias into the review process. However, we did find substantial differences between the interventions within each category (see discussion above), and decisions to combine data from varied interventions may reduce applicability of these results. Future updates of this review should, therefore, consider and preplan which interventions it is clinically relevant to combine. Involvement of key stakeholders to inform this decision making for future updates would be an advantage.

\section{Inclusion criteria: participants}

In the previous version of this review, we reported that the inclusion criterion that was judged as most difficult to assess by the independent review authors was the participants. The particular difficulty encountered was with studies that did not appear to include the diagnosis of visual field defects as an inclusion criterion. In the previous version, we identified and included several studies that either used a clinical assessment of 'scanning' as an inclusion criterion without formally assessing or diagnosing either visual field defects or visual neglect, or which included participants with a right-sided cerebrovascular accident, making the assumption that these participants would have visual neglect (and possibly also visual field defects). For this update of the review, we addressed this difficulty by only including studies that reported a method for diagnosing visual field defects at the recruitment stage. This led to the exclusion of a number of studies that had previously been included, but in which the participants did not have confirmed visual field defects (Carter 1983; Weinberg 1977; Weinberg 1979). We made this change between the previous version and this updated version of the review in order to reduce potential bias in the review process; however, we acknowledge that this may have led to the exclusion of studies in which some participants had visual field defects that were not confirmed through clinical diagnosis (e.g. instead manifesting as a scanning problem).

\section{Outcomes}

Categorisation of some reported outcome assessments into our predefined outcomes of interest was difficult in some cases. For this update of the review, we added a table to report our categorisation of outcomes to ensure transparency in this process (Table 4). We also reconsidered categorisation of all outcomes from trials included in the previous version of the review, and made a number of changes through a process of consensus. For example, Plow 2010 reported the Veterans Affairs Low Vision-Visual Functional Questionnaire (LV-VFQ) which "assesses an individual's visual ability to perform ADLs across 4 domains, including reading, mobility, visual motor function, and visual processing". This measure arguably relates to both extended activities of daily living and quality of life. In the first version of this review, this was listed as a measure of EADL: however, this was changed to being listed as a measure of QoL outcome for subsequent updates, following consensus discussion between review authors.

The primary outcome for this review was functional ability in activities of daily living, measured using standardised scales. It has been argued that measurement of effectiveness in rehabilitation ought to take into account patients' individual goals (Turner-Stokes 2009). There is growing evidence that goal attainment scaling (a standardised method of scoring performance of patient-specific tasks) may provide a valid, reliable, sensitive method of evaluating outcomes that are of greatest importance to individual patients (Krasny-Pacini 2016). This scale was not considered for inclusion within this review, and could be considered for future updates.

As has been discussed under Quality of the evidence, variations in outcomes and outcomes assessment tools between included studies created challenges for the synthesis of evidence within this review. The need to make judgements and decisions relating to categorisation and pooling of outcomes created potential for the introduction of bias into the review process. We have aimed for transparency in our decision making and reporting in an attempt to avoid the introduction of bias. However, to support the creation of meaningful evidence syntheses and meta-analyses, there is a need for consensus between stroke survivors, their families and carers, health professionals, and researchers in relation to core outcomes for trials relating to interventions for visual field defects after stroke as recommended by the COMET Initiative.

\section{Agreements and disagreements with other studies or reviews}

\section{Agreements and disagreements between this updated version and previous version}

In the previous 2011 version of this review, we stated the key conclusions and implications for practice arising from the evidence as follows.

- There is limited evidence which supports the use of compensatory scanning training for patients with visual field defects (and possibly co-existing visual neglect) to improve visual field, scanning, and reading outcomes.

- There is insufficient evidence to reach a conclusion about the impact of compensatory scanning training on functional activities of daily living.

- There is also insufficient evidence to reach generalised conclusions about the benefits of visual restitution therapy (restitutive intervention) or prisms (substitutive intervention) for patients with visual field defects after stroke.

Key changes in the methods between different versions of this review include:

- updated searches in this updated version, increasing the number of included studies;

- amended inclusion criteria, leading to the exclusion of studies in which participants did not have confirmed visual field defects; 
- the use of the GRADE approach to systematically assess quality of evidence in this updated version.

These changes have highlighted further uncertainty around previous limited evidence supporting the use of compensatory interventions and have introduced evidence relating to adverse events associated with substitutive interventions, but have not resulted in any changes in conclusions relating to restitutive or substitutive interventions.

- There is limited low-quality evidence that compensatory scanning training may improve an important outcome (quality of life) in patients with visual field defects following stroke, but further research is very likely to have an important impact on our confidence in the estimate of effect and is likely to change the estimate. There is insufficient evidence to reach a conclusion about the impact of compensatory scanning training on other outcomes.

- There remains insufficient evidence to reach generalised conclusions about the benefits of visual restitution therapy (restitutive intervention) or prisms (substitutive intervention), and there is insufficient evidence to reach conclusions about the effect of screening or assessment interventions for patients with visual field defects after stroke.

- There is now some low-quality evidence from one study that prisms may result in an increased number of adverse events, particularly headache.

\section{Agreements and disagreements with other published reviews}

The Royal College of Physicians updated the evidence included in the earlier version of this review, concluding that there is "insufficient evidence regarding the effectiveness of interventions aimed at improving function in people with visual field defects" (ISWP 2016). This updated review is in agreement with the conclusions drawn from the evidence in the guideline.

The Scottish Intercollegiate Guideline Network (SIGN) guidelines for stroke rehabilitation state that there is "limited poor quality evidence suggesting that visual scanning compensatory training techniques may be effective in improving functional outcomes after stroke" (SIGN 2011). This SIGN guideline (updated in 2010 ) is based on a number of other reviews (Barrett 2009; Bouwmeester 2007; Jones 2006). While the previous version of our review was in agreement with the recommendations made by the Royal College of Physicians and SIGN guidelines, our updated review has highlighted further uncertainty relating to the effect of compensatory interventions. The National Institute for Clinical Excellence (NICE) stroke guidelines recommends that "eye movement therapy" is provided to "people who have persisting hemianopia after stroke and who are aware of the condition" (NICE 2013): our updated review does not directly support this recommendation.

Our review is in agreement with the conclusions in other reviews that the evidence relating to the effectiveness of visual restoration therapy is inconsistent and of poor quality (Barrett 2009; Bouwmeester 2007), and that few studies have assessed functional ability in activities of daily living as an outcome.

Our review is in agreement with narrative reviews of evidence for interventions for visual problems after stroke (Lane 2008, Hanna
2017), which have concluded that there is a need for high-quality studies of the effectiveness of interventions for visual field defects.

\section{AUTHORS' CONCLUSIONS}

\section{Implications for practice}

There is limited low-quality evidence that compensatory scanning training may improve an important outcome (quality of life) in patients with visual field defects following stroke, but further research is very likely to have an important impact on our confidence in the estimate of effect and is likely to change the estimate. There is insufficient evidence to reach a conclusion about the impact of compensatory scanning training on other outcomes.

There is insufficient evidence to reach generalised conclusions about the benefits of visual restitution therapy (restitutive intervention), prisms (substitutive intervention), or assessment or screening interventions for patients with visual field defects after stroke. Prisms may cause a range of adverse events, particularly headache.

\section{Implications for research}

Specific implications for research, based on the findings of this review, are outlined below.

\section{Are further randomised controlled trials (RCTs) required?}

RCTs are required to determine the effect of:

- compensatory scanning training compared to no treatment, placebo, or usual care;

- restitutive interventions compared to no treatment, control, or placebo;

- substitutive interventions compared to no treatment, control, or placebo;

- assessment or screening interventions compared to standard care.

\section{Such RCTs must:}

- have adequate power (i.e. with an appropriate power calculation undertaken based on existing trial evidence);

- have adequate allocation concealment, blinding of outcome assessor, and intention-to-treat analysis;

- clearly define trial participants, with particular care relating to the diagnosis and inclusion of patients with visual field defects or visual neglect, or both;

- consider the severity of the visual field defect and plan subgroup analyses, where appropriate;

- include measures of functional ability in activities of daily living

- collect and report data relating to adverse events;

- report clear and usable data.

We recommend that future RCTs concentrate on answering the specific question relating to the effectiveness of interventions compared to control, placebo, no treatment, or usual care rather than comparisons with variations of the same 'type' or category of intervention, or comparisons of different doses, adjuncts to treatment, or modes of delivery. We believe that until such time as the benefits of interventions for visual field defects compared to control, placebo, no treatment, or usual care have been established 
(or refuted), it is not beneficial to compare the relative effects of different interventions. We recommend that future RCTs should include outcomes that are of importance to people affected by this problem, such as quality of life, confidence, and participation in social activities and relationships. We recommend that consensus is reached relating to the important outcome measures which all future trials of interventions for visual field defects in people with stroke should assess (i.e. a core outcome set), and that stroke survivors, carers, health professionals, and researchers are involved in developing this core outcome set.

A number of RCTs are currently ongoing. Once they are completed it will be important to update this review and to re-evaluate the need for further RCTs of interventions for visual field defects.

\section{Are other primary research studies required?}

We do not recommend other study designs aimed at investigating the effects of visual restitution therapy or prisms, although development or pilot studies may be justified to support the design of a full trial if such work has not previously been completed. Given the variation in compensatory interventions included in this review, we do recommend that other primary research studies are considered to explore an optimal scanning training intervention. Such studies may consider the evaluation of computerised as well as non-computerised interventions, the effective dosage, and the role of reading-specific training. However, this work ought to be done as a prequel to a well-designed RCT of the scanning intervention. Studies evaluating different types of scanning training should provide clear details of the treatment parameters, including the eye movements which are being trained by the intervention.

There is a need for further research to identify optimal outcome measures for use within future RCTs in this area. Such research may consider the relationship between functional measures of activities of daily living (ADL), measures of vision-related extended $A D L$ (such as reading, driving, navigating within an environment), and laboratory measures of the visual field.

\section{Are further systematic reviews required?}

We do not recommend any further systematic reviews aimed at addressing the effectiveness of interventions for visual field defects after stroke. We do recommend that this review is updated when the ongoing RCTs are completed.

\section{Summary of findings}

- The quality of evidence summarised in this review is judged to be low to very low.

- Methodological quality of studies is, in general, poor or poorly reported, providing insufficient high-quality evidence on which to reach generalisable conclusions.

- Limited low-quality evidence suggests compensatory interventions may improve an important outcome (quality of life) in patients with visual field defects following stroke, but further research is very likely to have an important impact on our confidence in the estimate of effect and is likely to change the estimate. There is insufficient evidence to reach a conclusion about the impact of compensatory scanning training on functional activities of daily living, or other outcomes.

- There is insufficient evidence to reach generalised conclusions about the benefits of vision restoration therapy for patients with visual field defects after stroke.

- There is insufficient evidence to reach generalised conclusions about the benefits of prisms for patients with visual field defects after stroke; there is some low-quality evidence that prisms may cause adverse events.

- High-quality RCTs are needed to compare compensatory, restitutive, substitutive, and assessment interventions with placebo, control, no treatment, or usual care.

\section{ACK N O WLEDGEMENTS}

Baljean Dhillon, Heather Orr, Katrina Livingstone, Frank A Munro, and Uma Shahani were authors on the 2009 version. They contributed to discussions that led to the development of the review protocol, provided content expertise, and read and commented on final drafts.

Joshua Cheyne for help in running the 2018 searches. Brenda Thomas and Marion Kelt for their help in developing the 2009 search strategy.

All the authors who responded to our requests for information. For the 2009 version: Dr Alex Bowers, Dr Michael Crossland, Professor Leonard Diller, Dr Francesca Frasinetti, Allison Hayes, Sandra Jobke, Dr Peter Klavora, Professor Alexander Leff, Dr Lotfi Merabet, Professor Berhard Sabel, and Professor Susanne Trauzettel-Klosinski. For this latest version: Professor Fiona Rowe and Dr Gera de Haan. 


\section{R E F E R E N C E S}

\section{References to studies included in this review}

Aimola 2011 \{published data only\}

* Aimola L, Lane AR, Smith DT, Kerkhoff G, Ford GA, Schenk T. Efficacy and feasibility of home-based training for individuals with homonymous visual field defects. Neurorehabilitation and Neural Repair 2014;28(3):207-18.

Schenk T, Aimola L, Lane AR, Smith DT, Kerkhoff G, Ford G. Efficacy and feasibility of a home-based computer training for individuals with homonymous visual field defects. Behavioural Neurology 2013;27(3):316.

Bainbridge 1994 \{published data only (unpublished sought but not used)\}

Bainbridge W, Reding M. Full-field prisms for hemi-field visual impairments following stroke: a controlled trial. Neurology 1994;44 Suppl 2:A312-13.

Bowers 2014 \{published and unpublished data\}

* Bowers AR, Keeney K, Peli E. Randomized crossover clinical trial of real and sham peripheral prism glasses for hemianopia. JAMA Ophthalmology 2014;132(2):214-22.

NCT00494676. Clinical trial of peripheral prism glasses for hemianopia. clinicaltrials.gov/ct2/show/NCT00494676 (first received 2 July 2007).

\section{De Haan 2015 \{published data only\}}

* De Haan GA, Melis-Dankers BJM, Brouwer WH, Tucha O, Heutink J. The effects of compensatory scanning training on mobility in patients with homonymous visual field defects: a randomized controlled trial. PLOS One 2015;10(8):e0134459.

De Haan GA. Homonymous Hemianopia. Impact on Daily Life and the Effects of Scanning Training on Mobility [PhD Thesis]. Rijksuniversiteit, Groningen, 2016.

ISRCTN16833414. The effects of scanning compensatory therapy for patients with homonymous visual field defects: a randomised controlled trial [The effects of scanning training for patients with hemianopia (visual field defects)]. www.isrctn.com/ISRCTN16833414 (first received 13 February 2015).

\section{Elshout 2016 \{published data only\}}

Elshout JA, Van Asten F, Hoyng CB, Bergsma DP, Van den Berg AV. Visual rehabilitation in chronic cerebral blindness: a randomized controlled crossover study. Frontiers in Neurology 2016;7(92):10.3389/fneur.2016.00092.

\section{Gall 2013 \{published data only\}}

Gall C, Rossini PM, Tatlisumak T, Waleszczyk W, Broesel D, Sabel BA. Non-invasive alternating current stimulation to improve visual impairment after post-chiasmatic lesions. Clinical Neurophysiology 2014;125:S36.

* Gall C, Rossini PM, Tatlisumak T, Waleszczyk W, Speck O, $\mathrm{He} \mathrm{H}$, et al. REVIS: Restoration of vision after stroke using non- invasive alternating and direct current stimulation. Journal of the Neurological Sciences 2013;333:e550.

Sabel BA, Brosel D, Krohn F, Schlaug C, Rossini PM, Tatlisumak T, et al. REVIS-network: Restoration of vision after stroke with noninvasive alternating current stimulation to improve visual impairment. Brain Injury 2014;28(5-6):764.

\section{Jarvis 2012 \{published data only\}}

Jarvis K, Grant E, Rowe F, Evans J, Cristino-Amenos M. Impact of visual impairment assessment on functional recovery in stroke patients: a pilot randomized controlled trial. International Journal of Therapy and Rehabilitation 2012;19(1):11-20.

\section{Jobke 2009 \{published and unpublished data\}}

Jobke S, Kasten E, Sabel BA. Vision restoration through extrastriate stimulation in patients with visual field defects: a double-blind and randomized experimental study. Neurorehabilitation and Neural Repair 2009;23(3):246-55.

Kasten 1998 \{published and unpublished data\}

Kasten E, Wurst S, Behrens-Bauman W, Sabel BA. Computerbased training for the treatment of partial blindness. Nature Medicine 1998;4(9):1083-7.

Kasten 2007 \{published and unpublished data\}

Kasten E, Bunzenthal U, Muller-Oehring EM, Mueller I, Sabel BA. Vision restoration does not benefit from costimulation: a pilot study. Journal of Clinical and Experimental Neuropsychology 2007;29(6):569-84.

\section{Keller 2010 \{published data only\}}

Keller I, Lefin-Rank G. Improvement of visual search after audiovisual exploration training in hemianopic patients. Neurorehabilitation and Neural Repair 2010;24(7):666-73.

\section{Modden 2012 \{published data only\}}

Modden C, Behrens M, Damke I, Eilers N, Kastrup A, Hildebrandt $\mathrm{H}$. A randomized controlled trial comparing 2 interventions for visual field loss with standard occupational therapy during inpatient stroke rehabilitation. Neurorehabilitation and Neural Repair 2012;26(5):463-9.

\section{Plow 2010 \{published and unpublished data\}}

NCT00921427. The use of transcranial direct current stimulation (tDCS) to enhance rehabilitative effect of vision restoration therapy. clinicaltrials.gov/ct2/show/NCT00921427 (first received 16 June 2009).

* Plow EB, Obretenova SN, Fregni F, Pascual-Leone A, Merabet LB. Comparison of visual field training for hemianopia with active versus sham transcranial direct cortical stimulation. Neurorehabilitation and Neural Repair 2012;26(6):616-26.

Plow EB, Obretenova SN, Halko MA, Jackson ML, PascualLeone A, Merabet LB. Combining non-invasive cortical stimulation with vision rehabilitation to improve visual function in post-stroke hemianopia. In: American Academy of Neurology (AAN) Meeting; April 2010; Toronto. 2010. 
Plow EB, Obretenova SN, Jackson ML, Merabet LB. Temporal profile of functional visual rehabilitative outcomes modulated by transcranial direct current stimulation. Neuromodulation 2012;15(4):367-73.

\section{Poggel 2004 \{published and unpublished data\}}

Poggel DA, Kasten E, Sabel BA. Attentional cueing improves vision restoration therapy in patients with visual field defects. Neurology 2004;63:2069-76.

\section{Rossi 1990 \{published data only\}}

Rossi P, Khefyets S, Reding MJ. Fresnel prisms improve visual perception in stroke patients with homonymous hemianopia or unilateral visual neglect. Neurology 1990;40(10):1597-9.

\section{Roth 2009 \{published data only\}}

Roth T, Sokolov AN, Messias A, Roth P, Weller M, TrauzettelKlosinski S. Comparing explorative saccade and flicker training in hemianopia. Neurology 2009;72:324-31.

\section{Rowe 2010 \{published and unpublished data\}}

ISRCTN05956042. Visual impairment in stroke: intervention or not (VISION) [Visual impairment in stroke: intervention or not (VISION) - a randomised controlled trial to investigate whether prism glasses or visual search training are more effective than information only (standard care) in patients with a homonymous hemianopia follow stroke]. www.isrctn.com/ ISRCTN05956042 (first received 8 April 2011). [ISRCTN05956042]

ISRCTN05956042. Visual impairment in stroke: intervention or not (VISION). www.ukctg.nihr.ac.uk/trials/trial-details/trialdetails?trialld=4710 (date first received 8 April 2011).

Rowe FJ, Barton PG, Bedson E, Breen R, Conroy EJ, Cwiklinski E, et al. A randomised controlled trial to compare the clinical and cost-effectiveness of prism glasses, visual search training and standard care in patients with hemianopia following stroke: a protocol. BMJ Open 2014;4(7):e005885.

Rowe FJ, Conroy EJ, Barton PG, Bedson E, Cwiklinski E, Dodridge $\mathrm{C}$, et al. A randomised controlled trial of treatment for post-stroke homonymous hemianopia: screening and recruitment. Neuro-Ophthalmology 2016;40(1):1-10.

* Rowe FJ, Conroy J, Bedson E, Cwiklinski E, Drummond A, García-Fiñana M, et al. A pilot randomized controlled trial comparing effectiveness of prism glasses, visual search training and standard care in hemianopia. Acta Neurologica Scandinavica 2017;136:310-21. [DOI: 10.1111/ane.12725]

\section{Schuett 2012 \{published data only\}}

Schuett S, Heywood CA, Kentridge RW, Dauner R, Zihl J. Rehabilitation of reading and visual exploration in visual field disorders: transfer or specificity? Brain 2012;135(Part 3):912-21.

\section{Spitzyna 2007 \{published and unpublished data\}}

Spitzyna GA, Wise RJS, McDonald SA, Plant GT, Kidd D, Crewes $\mathrm{H}$, et al. Optokinetic therapy improves test reading in patients with hemianopic alexia. Neurology 2007;68:1922-30.

\section{Szlyk 2005 \{published data only\}}

Szlyk JP, Seiple W, Stelmack J, McMahon T. Use of prisms for navigation and driving in hemianopic patients. Ophthalmic and Physiological Optics 2005;25:128-35.

\section{References to studies excluded from this review}

Akinwuntan 2005 \{published data only\}

Akinwuntan AE, De Weerdt W, Feys H, Pauwels J, Baten G, Arno $P$, et al. Effect of simulator training on driving after stroke. a randomized controlled trial. Neurology 2005;65:843-50.

\section{Akinwuntan 2010 \{published data only\}}

Akinwuntan A, Devos H, Nieuwboer A, Feys H, Tant M, Baten G, et al. Short and long term effects of driving training after stroke. International Journal of Stroke 2010;5:66.

* Akinwuntan AE, Devos H, Verheyden G, Baten G, Kiekens C, Feys $\mathrm{H}$, et al. Retraining moderately impaired stroke survivors in driving-related visual attention skills. Topics in Stroke Rehabilitation 2010;17(5):328-36.

Akinwuntan AE. Driving after a neurologic condition. Neurorehabilitation and Neural Repair 2012;26(6):676-7.

Devos H, Akinwuntan AE, Nieuwboer A, Ringoot I, Van Berghen $\mathrm{K}$, Tant $\mathrm{M}$, et al. Effect of simulator training on fitnessto-drive after stroke: a 5-year follow-up of a randomized controlled trial. Neurorehabilitation and Neural Repair 2010;24(9):843-50.

\section{Akinwuntan 2012 \{published data only\}}

Akinwuntan AE. Driving after a neurologic condition Neurorehabilitation and Neural Repair 2012;26(6):654-94.

\section{Alber 2015 \{published data only\}}

Alber R, Moser H, Sabel BA, Gall C. Boosting recovery of vision loss in post-acute stroke with tDCS - a pilot study. Brain Stimulation 2015;8(2):382.

Balconi 2013 \{published data only\}

Balconi M, Amenta S, Sozzi M, Cannata AP, Pisani L. Eye movement and online bisection task in unilateral patients with neglect: a new look to the 'gradient effect'. Brain Injury 2013;27(3):310-7.

\section{Beasley 2013 \{published data only\}}

Beasley IG, Davies LN. The effect of spectral filters on visual search in stroke patients. Perception 2013;42(4):401-12.

Bowers 2012 \{published data only\}

Bowers AR, Ananyev E, Mandel AJ, Goldstein RB, Peli E. Driving with hemianopia: IV. head scanning and detection at intersections in a simulator. Investigative Ophthalmology and Visual Science 2014;55(3):1540-8.

* Bowers AR, Tant M, Peli E. A pilot evaluation of on-road detection performance by drivers with hemianopia using oblique peripheral prisms. Stroke Research and Treatment 2012;article ID 176806:10 pages. [DOI: 10.1155/2012/176806.] 
Braga 2018 \{published data only\}

Braga MM, Nickel R, Lange M, Piovesan EJ. Driving and visual deficits in stroke patients. Arquivos de Neuro-Psiquiatria 2018;76(2):85-88. [dx.doi.org/10.1590/0004-282x20170184]

\section{Brandt 2009 \{published data only\}}

Brandt SA, Rohmel J, Kraft A, Olma M. Transcranial brain stimulation and post-stroke recovery of visual field defects. Journal of the Neurological Sciences 2009;285:S178-9.

\section{Brigui 2014 \{published data only\}}

Brigui M, Chauvet D, Clarencon F, Degos V, Sourour NA, Nouet A, et al. Recovery from oculomotor nerve palsy due to posterior communicating artery aneurysms: results after clipping versus coiling in a single-center series. Acta Neurochirurgica 2014;156(5):879-84.

\section{Cameirao 2012 \{published data only\}}

Cameirao MS, Badia SB, Duarte E, Frisoli A, Verschure PF. The combined impact of virtual reality neurorehabilitation and its interfaces on upper extremity functional recovery in patients with chronic stroke. Stroke 2012;43(10):2720-8.

Carter 1983 \{published data only (unpublished sought but not used)\}

Carter LT, Howard BE, O'Neil WA. Effectiveness of cognitive skill remediation in acute stroke patients. American Journal of Occupational Therapy 1983;3(5):320-7.

Carter 1988 \{published data only (unpublished sought but not used)\}

Carter LT, Oliveira DO, Duponte J, Lynch SV. The relationship of cognitive skills performance to activities of daily living in stroke patients. American Journal of Occupational Therapy 1988;42:449-55.

\section{Chen 2013 \{published data only\}}

Chen XM, Han DC, Wei XD, Zhou Y, Li WG. Clinical research for the treatment of anterior ischemic optic neuropathy by periglomerular injection of dexamethasone. International Eye Science 2013;13(3):470-3.

\section{ChicTR-00N-15006688 \{published data only\}}

ChiCTR-OON-15006688. Effects of inhibitory visual training on post-stroke hemianopia and its neural mechanisms. www.chictr.org.cn/showprojen.aspx?proj=1136 (first received 3 July 2015).

\section{Cho 2015 \{published data only\}}

Cho H-Y, Kim K, Lee B, Jung J. The effect of neurofeedback on a brain wave and visual perception in stroke: a randomized control trial. Journal of Physical Therapy Science 2015;27(3):673-6.

\section{Courtney-Harris 2015 \{published data only\}}

Courtney-Harris M, Jolly N. The use of a tool to detect the presence of vision defects in patients diagnosed with stroke: phase 1 validation of the vision screening tool. Sydney; University of Technology; 2015. Report to Agency for Clinical Innovation:1-29.

\section{Crotty 2009 \{published data only\}}

Crotty M, George S. Retraining visual processing skills to improve driving ability after stroke. Archives of Physical Medicine and Rehabilitation 2009;90(12):2096-102.

\section{Cutfield 2011 \{published data only\}}

Cutfield NJ, Cousins S, Seemungal BM, Gresty MA, Bronstein AM. Vestibular perceptual thresholds to angular rotation in acute unilateral vestibular paresis and with galvanic stimulation. Annals of the New York Academy of Sciences 2011;1233(1):256-62.

\section{Dai 2014 \{published data only\}}

Dai CY, Liu WM, Chen SW, Yang CA, Tung YC, Chou LW, et al. Anosognosia, neglect and quality of life of right hemisphere stroke survivors. European Journal of Neurology 2014;21(5):797-801.

\section{Dargie 2012 \{published data only\}}

* Dargie R, Olma M, Behrens J, Kraft A, Irlbacher K, Fahle M, et al. Serial anodal tDCS over V1 induces long-term effects on colour discrimination in V4 measured in the unimpaired hemifield of patients with occipital stroke. Clinical Neurophysiology 2013;124(10):e138.

Dargie RA, Olma MC. Serial transcranial direct current stimulation in the treatment of homonymous visual field defects: a double-blind placebo-controlled study. Klinische Neurophysiologie 2012;43:1.

Olma MC, Dargie RA, Behrens JR, Kraft A, Irlbacher K, Fahle M, et al. Long-term effects of serial anodal tDCS on motion perception in subjects with occipital stroke measured in the unaffected visual hemifield. Frontiers in Human Neuroscience 2013;7:314.

\section{Davis 2009 \{published data only\}}

Davis SM, Martinelli D, Braxton B, Kutrovac K, Crocco T. The impact of the extended parallel process model on stroke awareness: pilot results from a novel study. Stroke 2009;40(12):3857-63.

\section{Fedorov 2010 \{published data only\}}

Fedorov A, Chibisova Y, Szymaszek A, Alexandrov M, Gall C, Sabel A. Non-invasive alternating current stimulation induces recovery from stroke. Restorative Neurology and Neuroscience 2010;28(6):825-33.

\section{Ginsberg 2013 \{published data only\}}

Ginsberg MD, Palesch YY, Hill MD, Martin RH, Moy CS, Barsan WG, et al. The albumin in acute stroke (alias) part 2 clinical trial - a randomized multicenter investigation of albuminneuroprotection for acute ischemic stroke. 2: primary and secondary efficacy outcomes. Cerebrovascular Diseases 2013;35:107.

\section{Gordon 1985 \{published data only\}}

Gordon WA, Hibbard MR, Egelko S. Perceptual remediation in patients with right brain damage: a comprehensive program. Archives of Physical Medicine and Rehabilitation 1985;66:353-9. 
Hamel 2012 \{published data only\}

Hamel J, Kraft A, OhI S, De Beukelaer S, Audebert HJ, Brandt SA. Driving simulation in the clinic: testing visual exploratory behavior in daily life activities in patients with visual field defects. Journal of Visualized Experiments 2012;67:e4427.

\section{Hazelton 2013 \{published data only\}}

Hazelton C, Pollock A, Brady M, Walsh G. The "what, who and how" of scanning training for visual field loss after stroke: a comprehensive mixed methods systematic literature review. Cerebrovascular Diseases 2013;35:826.

Hollands 2013 \{published data only\}

Hollands KL, Pelton T, Wimperis A, Whitham D, Jowett S, Sackley $C$, et al. Visual cue training to improve walking and turning after stroke: a study protocol for a multi-centre, single blind randomised pilot trial. Trials 2013;14(1):276.

\section{Jo 2012 \{published data only\}}

Jo K, Yu J, Jung J. Effects of virtual reality-based rehabilitation on upper extremity function and visual perception in stroke patients: a randomized control trial. Journal of Physical Therapy Science 2012;24(11):1205-8.

Kang 2009 \{published data only\}

Kang SH, Kim DK, Seo KM, Choi KN, Yoo JY, Sung SY, et al. A computerized visual perception rehabilitation programme with interactive computer interface using motion tracking technology - a randomized controlled, single-blinded, pilot clinical trial study. Clinical Rehabilitation 2009;23(5):434-44.

\section{Kerkhoff 2013 \{published data only\}}

* Kerkhoff G, Reinhart S, Ziegler W, Artinger F, Marquardt C, Keller I. Smooth pursuit eye movement training promotes recovery from auditory and visual neglect: a randomized controlled study. Neurorehabilitation and Neural Repair 2013;27(9):789-98.

Kerkhoff G, Reinhart S, Ziegler W, Artinger F, Volzke V, Brasse M, et al. Smooth pursuit eye movement training accelerates recovery from auditory/visual neglect and reduces disability and unawareness: 2 randomized controlled trials. Journal of the Neurological Sciences 2013;333:e570.

\section{Kerry 2017 \{published data only\}}

Kerry SJ, Woodhead ZVJ, Aguilar OM, Ong Hoon Y, Hogan JS, Pappa K, et al. Transcranial direct current stimulation facilitates reading training in participants with post-stroke central alexia. Brain Stimulation 2017;10(2):364.

\section{Ko 2011 \{published data only\}}

Ko JH, Kim YJ. Oculomotor nerve palsy caused by posterior communicating artery aneurysm: evaluation of symptoms after endovascular treatment. Interventional Neuroradiology 2011;17(4):415-9.

\section{Lane 2010 \{published data only\}}

Lane AR, Smith DT, Ellison A, Schenk T. Visual exploration training is no better than attention training for treating hemianopia. Brain 2010;133(6):1717-28.

\section{Lee 2013a $\{$ published data only\}}

Lee JK, Lee KL, Lee YB. Prism adaptation simulation program for the treatment of hemispatial neglect. Stroke 2013;44:AWP313.

Lee 2013b \{published data only\}

Lee MS. Literature commentary on: Bowers AR, Tant M, Peli E. A pilot evaluation of onroad detection performance by drivers with hemianopia using oblique peripheral prisms, in Stroke Research and Treatment, 2012. Journal of Neuro-Ophthalmology 2013;33(2):199.

\section{Loverro 1988 \{published data only\}}

Loverro J, Reding M. Bed orientation and rehabilitation outcome for patients with stroke and hemianopia or visual neglect. Journal of Neurological Rehabilitation 1988;2:147-50.

\section{Machner 2012 \{published data only\}}

* Machner B, Könemund I, Sprenger A, Von der Gablentz J, Helmchen C. Randomized controlled trial on hemifield eye patching and optokinetic stimulation in acute spatial neglect. Stroke 2014;45:2465-8.

NCT01617343. The HEP-OKS study - hemifield eye patching and optokinetic stimulation to treat hemispatial neglect in stroke patients. clinicaltrials.gov/ct2/show/NCT01617343 (first received 12 June 2012)

\section{Mancuso 2012 \{published data only\}}

Mancuso M, Pacini M, Gemignani P, Bartalini B, Agostini B, Ferroni L, et al. Clinical application of prismatic lenses in the rehabilitation of neglect patients. A randomized controlled trial. European Journal of Physical and Rehabilitation Medicine 2012;48(2):197-208.

\section{Markowitz 2010 \{published data only\}}

Markowitz SN. Visual training of cerebral blindness patients gradually enlarges the visual field. Evidence-Based Ophthalmology 2010;11(3):154-5.

\section{NTR5637 \{published data only\}}

NTR5637. Neuroplasticitiy in homonymous hemianopia: functional and structural brain changes underlying residual and compensatory perceptual behaviour. trialregister.nl/trial/5637 (first received 17 February 2016).

Olma 2013 \{published data only\}

Olma MC, Dargie RA, Behrens JR, Kraft A, Irlbacher K, Fahle M, et al. Long-term effects of serial anodal tDCS on motion perception in subjects with occipital stroke measured in the unaffected visual hemifield. Frontiers in Human Neuroscience 2013;7:314

\section{Opolka 2013 \{published data only\}}

Opolka M, Harvey M, Kerkhoff G, Niemann H. Comparing the effectiveness of visuo-motor training and optokinetic stimulation with standardized exploration training in patients with hemispatial neglect. Behavioural Neurology 2013;27(3):405 
Padula 2009 \{published data only\}

Padula WV, Nelson CA, Padula WV, Benabib R, Yilmz T, Krevisky S. Modifying postural adaptation following a CVA through prismatic shift of visuo-spatial egocenter. Brain Injury 2009;23(6):566-76.

* Padula WV, Nelson CA, Padula WV, Benabib R, Yilmz T, Krevisky S. Modifying postural adaptation following a CVA through prismatic shift of visuo-spatial egocenter. Brain Injury 2010;24(3):123-4.

\section{Park 2013 \{published data only\}}

Park SH, Koh EJ, Choi HY, Ko MH. A double-blind, shamcontrolled, pilot study to assess the effects of the concomitant use of transcranial direct current stimulation with the computer assisted cognitive rehabilitation to the prefrontal cortex on cognitive functions in patients with stroke. Journal of Korean Neurosurgical Society 2013;54(6):484-8.

\section{Rosenberg 2011 \{published data only\}}

Rosenberg G, Bornstein N, Diener HC, Gorelick PB, Shuaib A, Lees K, MACSI investigators. The Membrane-Activated Chelator Stroke Intervention (MACSI) trial of DP-b99 in acute ischemic stroke: a randomized, double-blind, placebo-controlled, multinational pivotal phase III study. International Journal of Stroke 2011;6(4):362-7.

\section{Sabel 2009 \{published and unpublished data\}}

Sabel BA, Fedorov AB, Dettler N, Ernst L, Borrmann A, Herrmann $C$, et al. Non-invasive alternating current stimulation for the treatment of visual field defects in optic neuropathy a single-centre trial. In: European Federation of Neurological Science; 2009 Sept; Florence (Italy). 2009.

\section{Saposnik 2013 \{published data only\}}

NCT01836159. iPad Technology for HOME Rehabilitation in Patients After Stroke: iHOME Acute/Chronic. clinicaltrials.gov/ ct2/show/NCT01836159 (first received 19 April 2013).

* Saposnik G, Chow CM, Gladstone D, Cheung D, Brawer E, Thorpe KE, et al. iPad technology for home rehabilitation after stroke (iHOME): a proof-of-concept randomized trial. International Journal of Stroke 2014;9(7):956-62.

\section{Scholomov 2010 \{published data only\}}

Sholomov II, Cherevashchenko LA, Suprunov OV, Raigorodskii YM. The potential of transcranial magnetotherapy in color and rhythm therapy in the rehabilitation of ischemic stroke. Neuroscience and Behavioral Physiology 2010;40(8):920-5.

\section{Taylor 2011 \{published data only\}}

Taylor L, Poland F, Harrison P, Stephenson R. A quasiexperimental feasibility study to determine the effect of a systematic treatment programme on the scores of the Nottingham Adjustment Scale of individuals with visual field deficits following stroke. Clinical Rehabilitation 2011;25(1):43-50.

\section{Teasell 2011 \{published data only\}}

Teasell R, Salter K, Bitensky J, Bhogal S, Foley N, Menon A, et al. Perceptual disorders. www.ebrsr.com/ (accessed prior to 4 May 2019):1-70.

\section{Thurtell 2010 \{published data only\}}

Thurtell MJ, Joshi S, Stahl JS, Leigh RJ. Double-blind cross-over trial of gabapentin versus memantine for treatment of acquired nystagmus. Annals of Neurology 2010;67(5):676-80.

\section{Van Wyk 2011 \{published data only\}}

Van Wyk A, Eksteen C. Effect of visual scanning exercises integrated into task-specific activities on the functional ability in patients with visual perceptual disorders post-stroke. In: World Congress of Physical Therapy; 2011 June 21-24; Amsterdam (Netherlands). 2011.

* Van Wyk A, Eksteen CA, Rheeder P. The effect of visual scanning exercises integrated into physiotherapy in patients with unilateral spatial neglect poststroke: a matched-pair randomized control trial. Neurorehabilitation and Neural Repair 2014;28(9):856-73.

Van Wyk A. Effect of saccadic eye movement training with visual scanning exercises integrated into task-specific activities on unilateral spatial neglect post stroke. In: 8th World Stroke Congress; 2012; Brasilia. 2012.

\section{Van Wyk 2016 \{published data only\}}

Van Wyk A, Eksteen CA, Becker PJ, Heinze BM. A cross-sectional survey and cross-sectional clinical trial to determine the prevalence and management of eye movement disorders and vestibular dysfunction in post-stroke patients in the sub-acute phase: protocol. Frontiers in Neurology 2016;7:140.

Weinberg 1977 \{published data only (unpublished sought but not used)\}

Weinberg J, Diller L, Gordo WA, Gerstman LJ, Lieberman A, Lakin $P$, et al. Visual scanning training effect on reading-related tasks in acquired right brain damage. Archives of Physical Medicine and Rehabilitation 1977;58:479-86.

Weinberg 1979 \{published data only (unpublished sought but not used)\}

Weinberg J, Diller L, Gordon WA, Gerstman LJ, Lieberman A, Lakin P, et al. Training sensory awareness and spatial organization in people with right brain damage. Archives of Physical Medicine and Rehabilitation 1979;60:491-6.

\section{White 2010 \{published data only\}}

White $\mathrm{H}$, Jamieson DG. RE of the ESPRIT Study: aspirin plus dipyridamole versus aspirin alone for prevention of vascular events after a noncardioembolic, mild-to-moderate ischemic stroke or transient ischemic attack. Postgraduate Medicine 2010;122(6):227-9.

\section{References to studies awaiting assessment}

Ghandehari 2011 \{published data only\}

Ghandehari K, Mood ZI, Ebrahimzadeh S, Picard D, Zhang Y. NeuroAid (MLC601) versus piracetam in the recovery of post- 
infarct homonymous hemianopsia. Neural Regeneration Research 2011;6(6):418-22.

\section{Sand 2017 \{published data only\}}

NCT02307981. Norwegian occipital ischemic stroke study (NOROCCIP). clinicaltrials.gov/ct2/show/NCT02307981 (first received 4 December 2014).

* Sand KK, Thomassen L, Taraldsen AR, Wilhelmsen G, Midelfart A, Rodahl E, et al. Management and outcome of visual field defects in occipital ischemic stroke (nor-occip) a multi-center prospective study. European Stroke Journal 2017;2(1):375.

\section{References to ongoing studies}

Feldon 2017 \{published data only\}

NCT03350919. Visual restoration for hemianopia. clinicaltrials.gov/ct2/show/NCT03350919 (first received 22 November 2017).

\section{Gall 2015 \{published data only\}}

DRKS00005949. Electrical stimulation for restoration of vision after stroke (REVIS) in the damaged visual field after stroke. www.drks.de/DRKS00005949 (first received 6 January 2016).

* Gall C, Silvennoinen K, Granata G, De Rossi F, Vecchio F, Brösel D, et al. Non-invasive electric current stimulation for restoration of vision after unilateral occipital stroke. Contemporary Clinical Trials 2015;43:231-6.

NCT02405143. Restoration of vision after stroke (REVIS). clinicaltrials.gov/ct2/show/NCT02405143 (first received 1 April 2015).

\section{Hayes 2010 \{published data only (unpublished sought but not used)\}}

ACTRN12610000494033. Retraining following hemianopia in acquired brain injury following stroke. www.anzctr.org.au/Trial/ Registration/TrialReview.aspx?ACTRN=12610000494033 (first registered 16-06-2010).

* George S, Hayes A, Chen C, Crotty M. The effect of static scanning and mobility training on mobility in people with hemianopia after stroke: a randomized controlled trial comparing standardized versus non-standardized treatment protocols. BMC Neurology 2011;11:87.

\section{ISRCTN16023965 \{published data only\}}

ISRCTN16023965. Home-training for hemianopia (partial blindness). www.isrctn.com/ISRCTN16023965 (first received 15 May 2015).

\section{Komm 2009 \{published data only (unpublished sought but not} used)\}

Komm DU, Kasten E, Sabel BA, Gall C. Rehabilitation outcome in chronic neglect patients with associated visual field loss: results of a blinded randomized cross-over study. European Journal of Neurology 2009;16 Suppl 3:456.
NCT02737930 \{published data only\}

NCT02737930. Fluoxetine for visual recovery after ischemic stroke (FLUORESCE). clinicaltrials.gov/ct2/show/NCT02737930 (first received 14 April 2016).

\section{NCT02886663 \{published data only\}}

NCT02886663. Visual field restoration in patients with poststroke homonymous hemianopsia (REVOIR). clinicaltrials.gov/ ct2/show/NCT02886663 (first received 1 September 2016).

\section{Additional references}

\section{Ali 2013}

Ali M, Hazelton C, Lyden P, Pollock A, Brady M, VISTA Collaboration. Recovery from poststroke visual impairment: evidence from a clinical trials resource. Neurorehabilitation and Neural Repair 2013;27(2):133-41.

\section{Bailey 1976}

Bailey IL, Lovie SE. New design principles for visualacuity letter charts. American Journal of Optometry and Physiological Optics 1976;53(11):740-5.

\section{Barrett 2009}

Barrett BT. A critical evaluation of the evidence supporting the practice of behavioural vision therapy. Ophthalmic and Physiological Optics 2009;29:4-25.

\section{Beck 1987}

Beck AT, Steer RA. Manual for the Beck Depression Inventory. 1993 edition. San Antonio (TX): The Psychological Corporation, 1987.

\section{Berg 1989}

Berg KO, Wood-Dauphinee S, Williams JI, Gayton D. Measuring balance in the elderly: preliminary development of an instrument. Physiotherapy Canada 1989;41:304-11.

\section{Bouwmeester 2007}

Bouwmeester L, Heutink J, Lucas C. The effect of visual training for patients with visual field defects due to brain damage: a systematic review. Journal of Neurology, Neurosurgery, and Psychiatry 2007;78:555-64.

\section{Bowers 2017}

Bowers AR, Dickinson C, Peli E. Comments about outcome measures for clinical trials of interventions for post-stroke patients with hemianopia. Acta Neurologica Scandinavica 2017;136:548-50.

\section{Bryant 2011}

Bryant BR, Wiederholt JL. Gray Oral Reading Tests (GORT-5). Vol. 5. Austin, Texas: Pearson Clinical Assessments, 2011.

\section{Cassidy 2001}

Cassidy TP, Bruce DW, Gray CS. Visual field loss after stroke: confrontation and perimetry in the assessment of recovery. Journal of Stroke and Cerebrovascular Diseases 2001;10(3):113-7. 


\section{Cinnamon 2011}

Cinamon JS, Finch L, Miller S, Higgins J, Mayo N. Preliminary evidence for the development of a stroke specific geriatric depression scale. International Journal of Geriatric Psychiatry 2011;26(2):188-98.

\section{COMET Initiative}

COMET Initiative. www.comet-initiative.org/ (accessed 27 September 2018).

\section{Das 2010}

Das A, Huxlin KR. New approaches to visual rehabilitation for cortical blindness: outcomes and putative mechanisms. Neuroscientist 2010;16(4):374-87.

\section{Deeks 2001}

Deeks JJ, Altman DG, Bradburn MJ. Statistical methods for examining heterogeneity and combining results from several studies in meta-analysis. In: Egger M, Davey Smith G, Altman DG, editors(s). Systematic Reviews in Health Care. 2nd edition. London, UK: BMJ Books, 2001:200.

\section{Dombovy 1986}

Dombovy ML, Sandok BA, Basford JR. Rehabilitation for stroke: a review. Stroke 1986;17(3):363-7.

\section{Duncan 1990}

Duncan PW, Weiner DK, Chandler J, Studenski S. Functional reach: a new clinical measure of balance. Journal of Gerontology 1990;45(6):M192-7.

\section{Garrett 1993}

Garratt AM, Ruta DA, Abdalla MI, Buckingham JK, Russell IT. The SF-36 health survey questionnaire: an outcome measure suitable for routine use within the NHS? BMJ 1993;306:1440-4.

\section{Goldberg 1979}

Goldberg DP, Hillier VF. A scaled version of the General Health Questionnaire. Psychological Medicine 1979;9:139-45.

\section{Guyatt 2011a}

Guyatt GH, Oxman AD, Schünemann HJ, Tugwell P, Knotterus A. GRADE guidelines: a new series of articles in the Journal of Clinical Epidemiology. Journal of Clinical Epidemiology 2011;64(4):380-2.

\section{Guyatt 2011b}

Guyatt GH, Oxman AD, Vist G, Kunz R, Brozek J, Alonso-Coello P, et al. GRADE guidelines: 4. rating the quality of evidence - risk of bias. Journal of Clinical Epidemiology 2011;64(4):407-15.

\section{Guyatt 2011c}

Guyatt GH, Oxman AD, Montori V, Vist G, Kunz R, Brozek J, et al. GRADE guidelines: 5 . rating the quality of evidence - publication bias. Journal of Clinical Epidemiology 2011;64(12):1277-82.

\section{Guyatt 2011d}

Guyatt G, Oxman AD, Kunz R, Brozek J, Alonso-Coello P, Rind D, et al. GRADE guidelines: 6 . Rating the quality of evidence imprecision. Journal of Clinical Epidemiology 2011;12:1283-93.

\section{Guyatt 2011e}

Guyatt GH, Oxman AD, Kunz R, Woodcock J, Brozek J, Helfand M, et al, The GRADE Working Group. GRADE guidelines:

7. Rating the quality of evidence - inconsistency. Journal of Clinical Epidemiology 2011;64(12):1294-302.

\section{Guyatt $2011 f$}

Guyatt GH, Oxman AD, Kunz R, Woodcock J, Brozek J, Helfand M, et al, The GRADE Working Group. GRADE guidelines: 8. Rating the quality of evidence - indirectness. Journal of Clinical Epidemiology 2011;64(12):1303-10.

\section{Halligan 1991}

Halligan PW, Cockburn J, Wilson BA. The behavioural assessment of visual neglect. Neuropsychological Rehabilitation 1991;1:5-32.

\section{Hanna 2017}

Hanna KL, Hepworth LR, Rowe FJ. The treatment methods for post-stroke visual impairment: a systematic review. Brain and Behavior 2017;7(5):e00682.

\section{Hepworth 2016}

Hepworth LR, Rowe FJ. Visual impairment following stroke - the impact on quality of life: a systematic review. Ophthalmology Research 2016;5(2):1-16.

\section{Higgins 2011}

Higgins JPT, Green S, (editors). Cochrane Handbook for Systematic Reviews of Interventions Version 5.1.0 [updated March 2011]. The Cochrane Collaboration, 2011. Available from handbook.cochrane.org.

\section{Holbrook 1983}

Holbrook M, Skilbeck CE. An activities index for use with stroke patients. Age and Ageing 1983;12:166-70.

\section{Holmes 2001}

Holmes JM, Hohberger GG, Leske DA. Photographic and clinical techniques for outcome assessment in sixth nerve palsy. Ophthalmology 2001;108(7):1300-7.

\section{Horton 2005a}

Horton JC. Disappointing results from Nova Vision's visual restoration therapy. British Journal of Ophthalmology 2005;89(1):1-2.

\section{Horton 2005b}

Horton JC. Vision restoration therapy: confounded by eye movements. British Journal of Ophthalmology 2005;89:792-4.

\section{Hämäläinen 2004}

Hämäläinen HA, Julkunen LAM. Treatment of visual field defects after stroke. Advances in Clinical Neuroscience and Rehabilitation 2004;3(6):17-8.

\section{ISWP 2016}

Intercollegiate Stroke Working Party. National Clinical Guideline for Stroke. 5th edition. London: Royal College of Physicians, 2016. 


\section{Jones 2006}

Jones SA, Shinton RA. Improving outcome in stroke patients with visual problems. Age and Ageing 2006;35:560-5.

\section{Jongbloed 1986}

Jongbloed L. Prediction of function after stroke: a critical review. Stroke 1986;17(4):765-76.

\section{Kaplan 1982}

Kaplan J, Hier DB. Visuospatial deficits after right hemisphere stroke. American Journal of Occupational Therapy 1982;36:314-21.

\section{Kaplan 1993}

Kaplan RM, Anderson JP, Ganiats TG. The Quality of Well-being Scale: rationale for a single quality of life index. In: Walker SR, Rosser RM, editors(s). Quality of Life Assessment: Key Issues in the 1990s. London: Kluwer Academic Publishers, 1993:65-94.

\section{Kasten 1998b}

Kasten E, Wuest S, Sabel BA. Partial residual vision in transition zones in patients with cerebral blindness. Journal of Clinical and Experimental Neuropsychology 1998;20:581-98.

\section{Kasten 2001}

Kasten E, Muller-Oehring E, Sabel BA. Stability of visual field enlargements following computer-based restitution training - results of a follow-up. Journal of Clinical and Experimental Neuropsychology 2001;23(3):297-305.

\section{Katz 1963}

Katz S, Ford AB. Studies of illness in the aged. The Index of ADL: a standardised measure of biological and psychosocial function. JAMA 1963;185:914-9.

\section{Kerkhoff 1999}

Kerkhoff G. Restorative and compensatory therapy approaches in cerebral blindness: a review. Restorative Neurology and Neuroscience 1999;15:255-71.

\section{Kerkhoff 2000}

Kerkhoff G. Neurovisual rehabilitation: recent developments and future directions. Journal of Neurology, Neurosurgery, and Psychiatry 2000;68:691-706.

\section{Krasny-Pacini 2016}

Krasny-Pacini A, Evans J, Sohlberg MM, Chevignard M. Proposed criteria for appraising goal attainment scales used as outcome measures in rehabilitation research. Archives of Physical Medicine and Rehabilitation 2016;97(1):157-70.

\section{Lane 2008}

Lane AR, Smith DT, Schenk T. Clinical treatment options for patients with homonymous visual field defects. Clinical Ophthalmology 2008;2(1):93-102.

\section{Lawton 1969}

Lawton MP, Brody EM. Assessment of older people: selfmaintaining and instrumental activities of daily living. Gerontologist 1969;9:179-86.

\section{Lincoln 1990}

Lincoln NB, Edmans JA. A re-validation of the Rivermead ADL Scale for elderly patients with stroke. Age and Ageing 1990;19:19-24.

\section{Mahoney 1965}

Mahoney FI, Barthel DW. Functional evaluation: the Barthel Index. Maryland State Medical Journal 1965;Feb 14:61-5.

\section{Mathias 1986}

Mathias S, Nayak U, Isaacs B. Balance in elderly patients: the "Get-up and Go" test. Archives of Physical Medicine and Rehabilitation 1986;67:387-9.

\section{NICE 2013}

National Institute for Health and Care Excellence. Stroke Rehabilitation in Adults. Clinical Guideline CG162. Manchester: NICE, 2013

\section{Nouri 1987}

Nouri F, Lincoln NB. An extended activities of daily living scale for stroke patients. Clinical Rehabilitation 1987;1:233-8.

\section{NovaVision 2009}

Vision restoration therapy: addressing vision loss after stroke and traumatic brain injury (TBI). www.novavision.com (last accessed 28 August 2009).

\section{NVT 2009}

Neuro Vision Technology (NVT). www.neurovisiontech.com.au/ (last accessed 28 August 2009).

\section{Pediatric Eye Disease Investigator Group 2009}

Pediatric Eye Disease Investigator Group. Interobserver reliability of the prism and alternate cover test in children with esotropia. Archives of of Ophthalmology 2009;127(1):59-65.

\section{Peli 2000}

Peli E. Field expansion for homonymous hemianopia by optically induced peripheral exotropia. Optometry Vision Science 2000;77:453-64.

\section{Rabin 2001}

Rabin R, De Charro F. EQ-5D: a measure of health status from the EuroQoL Group. Annals of Medicine 2001;33:337-43.

\section{Ramrattan 2001}

Ramrattan RS, Wolfs RC, Panda-Jones S. Prevalence and causes of visual field loss in the elderly and associations with impairment in daily functioning: the Rotterdam Study. Archives of Ophthalmology 2001;119:1788-94.

\section{Reinhard 2005}

Reinhard J, Schreiber A, Schiefer U. Does visual restitution training change absolute homonymous visual field defects? A fundus controlled study. British Journal of Ophthalmology 2005;89:30-5. 


\section{RevMan 2014 [Computer program]}

Nordic Cochrane Centre, The Cochrane Collaboration Review Manager 5 (RevMan 5). Version 5.3. Copenhagen: Nordic Cochrane Centre, The Cochrane Collaboration, 2014.

\section{Riggs 2007}

Riggs RV, Andrews K, Roberts P, Gilewski M. Visual deficit interventions in adult stroke and brain injury. American Journal of Physical Medicine and Rehabilitation 2007;86:853-60.

\section{Romano 2008}

Romano JG, Schulz P, Kenkel S, Todd DP. Visual field changes after a rehabilitation intervention: vision restoration therapy. Journal of the Neurological Sciences 2008;273(1-2):70-4. [DOI: 10.1016/j.jns.2008.06.026]

\section{Rosner 1984}

Rosner J, Clift GD. The validity of the frisby stereotest as a measure of precise stereoacuity. Journal of the American Optometric Association 1984;55(7):505-6.

\section{Rowe 2007}

Rowe F. Visual consequences of stroke and their impact on driving ability. In: 2nd UK Stroke Forum; 2007 December 6, Harrogate. 2007.

\section{Rowe 2009}

Rowe F, Brand D, Jackson CA, Price A, Walker L, Harrison S, et al. Visual impairment following stroke: do stroke patients require vision assessment? Age and Ageing 2009;38:188-93.

\section{Rowe 2014}

Rowe FJ, Walker M, Rockliffe J, Pollock A, Noonan C, Howard C, et al. Care provision for poststroke visual impairment. Journal of Stroke and Cerebrovascular Diseases 2015;24(6):1131-44.

\section{Rowe 2017}

Rowe, FJ. Stroke survivors' views and experiences on impact of visual impairment. Brain and Behavior 2017;7(9):e00778.

\section{Sabel 2000}

Sabel BA, Kasten E. Restoration of vision by training of residual functions. Current Opinion in Ophthalmology 2000;11:430-6.

\section{Sabel 2006}

Sabel BA. Vision restoration therapy and raising red flags too early. British Journal of Ophthalmology 2006;90:659-60.

\section{Sahraie 2006}

Sahraie A, Trevethan CT, MacLeod M-J, Murray AD, Olson JA, Weiskrantz L. Increased sensitivity following repeated stimulation in Blindsight. Proceeding of National Academy of Sciences of the United States of America 2006;103(40):14971-6.

\section{Schuett 2008}

Schuett S, Heywood CA, Kentridge RW, Zihl J. Rehabilitation of hemianopic dyslexia: are words necessary for re-learning oculomotor control? Brain 2008;131:3156-68.

\section{SIGN 2011}

Scottish Intercollegiate Guidelines Network. Sign Guideline 118. Management of patients with stroke: rehabilitation, prevention and management of complications, and discharge planning: a national clinical guideline. www.sign.ac.uk/guidelines/ fulltext/118/index.html (accessed prior to 4 May 2019).

\section{Smith 1990}

Smith P, Hamilton BB, Granger CV. The fone FIM. Buffalo (New York): Research Foundation of the State University of New York; 1990.

\section{Tinetti 1990}

Tinetti ME, Richman D, Powell L. Falls efficacy as a measure of falling. Journal of Gerontology 1990;45(6):239-43.

\section{Turner-Stokes 2009}

Turner-Stokes L. Goal attainment scaling (GAS) in rehabilitation: a practical guide. Clinical Rehabilitation 2009;23:362-70.

\section{Van Bennekom 1995}

Van Bennekom CAM, Jelles F, Lankhorst GJ. Rehabilitation activities profile: the ICIDH as a framework for a problemoriented assessment method in rehabilitation medicine. Disability and Rehabilitation 1995;17:169-75.

\section{Warren 2009}

Warren M. Pilot study on activities of daily living limitations in adults with hemianopsia. American Journal of Occupational Therapy 2009;63(5):626-33.

\section{Wilkinson 2006}

Wilkinson GS, Robertson GJ. Wide Range Achievement Test. In: Psychological Assessment Resources. 4th edition. Florida: Lutz, 2006.

\section{Williams 1999}

Williams LS, Weinberger M, Harris LE, Clark DO, Biller J. Development of a stroke-specific quality of life scale. Stroke 1999;30(7):1362-9.

\section{Wilson 2002}

Wilson LJT, Harendran A, Grant M, Baird T, Schultz UGR, Muir KW, et al. Improving the assessment of outcomes in stroke: use of a structured interview to assign grades on the Modified Rankin Scale. Stroke 2002;33:2243-6.

\section{Windsor 2008}

Windsor RL, Windsor LK. Hemianopsia: loss of half of the visual field after stroke or traumatic brain injury. www.lowvision.org/ understanding\%20hemianopsia1.htm (last accessed 11 June 2008).

\section{Wolter 2006}

Wolter M, Shannon P. Visual deficits following stroke: maximising participation in rehabilitation. Topics in Stroke Rehabilitation 2006;13(3):12-21.

\section{Zigmond 1983}

Zigmond AS, Snaith RP. The Hospital Anxiety and Depression Scale. Acta Psychiatrica Scandinavica 1983;67:361-70. 


\section{Zihl 1995}

Zihl J. Eye movement patterns in hemianopic dyslexia. Brain 1995;118:891-912.

\section{Zihl 2011}

Zihl J. Rehabilitation of Visual Disorders after Brain Injury. 2nd edition. Hove, UK: Psychology Press, 2011.

\section{References to other published versions of this review \\ Pollock 2010 \\ Pollock A, Hazelton C, Henderson CA, Angilley J, Dhillon B, Langhorne P, et al. Interventions for visual field}

\section{CHARACTERISTICS OF STUDIES}

Characteristics of included studies [ordered by study ID] defects in patients with stroke. Cochrane Database of Systematic Reviews 2010, Issue 3. Art. No: CD008388. [DOI: 10.1002/14651858.CD008388]

\section{Pollock 2011}

Pollock A, Hazelton C, Henderson CA, Angilley J, Dhillon B, Langhorne $P$, et al. Interventions for visual field defects in patients with stroke. Cochrane Database of Systematic Reviews 2011, Issue 10. Art. No: CD008388. [DOI: 10.1002/14651858.CD008388.pub2]

* Indicates the major publication for the study

Aimola 2011

\section{Study characteristics}

Methods Compensative intervention versus control, placebo, or no intervention

Design: "A randomized, controlled, parallel-group design was used."

\section{Stratification: no}

Randomisation sequence: "participants were randomized equally to 2 groups ... using parallel trial allocation software"

Comparisons: 2 groups: intervention versus control

Allocation concealment: "Participants were informed about the training types but did not know to which group they were assigned."

Blinding: not stated if outcome assessor was blinded

Power calculation: no (feasibility study)

Intention-to-treat analysis: no

Other recruitment details: "recruited from local hospitals or as self-referrals"

Patient and public involvement: not stated

Participants

Total study population: randomised 70; "final sample included in analyses consisted of 52 participants; 28 intervention and 24 control"

Withdrawals: 18 "dropped out during the intervention period because of health problems $(n=7)$, death $(n=2)$, or low motivation $(n=9)$ ".

Method of diagnosing VFD: monocular automatic perimetry

Characteristics of population: "chronic hemi-VFDs resulted from any post-chiastmatic lesion." Participant details are listed in Table 2.

Type and severity of visual problems: participant details are listed in Table 3.

Inclusion criteria: at least 18 years old, no previous access to any formal hemi-VFD rehabilitation (restoration, substitution or compensation)

Exclusion criteria: "medical instability, inability to provide informed consent, visual loss as a consequence of prechiasmatic damage or a progressive condition, photosensitive epilepsy, oculomotor dis- 
Aimola 2011 (Continued)

orders, and severe cognitive impairment. Participants were not enrolled until at least 3 months after onset to minimize confounding by spontaneous recovery (range = 3-276 months)".

Baseline comparison of treatment groups: no differences noted at baseline

This study included participants with diagnoses other than stroke.

This study included participants with visual field defects and co-existing visual neglect.

Method of diagnosing visual perceptual problems: Bells test

Interventions

Group 1: home-based compensatory training $(n=28)$

Intervention: "the experimental training consisted of reading and exploration components; patients completed components sequentially with order randomized."

Intervention type: compensation. Materials: computer-based: Where can materials be accessed? not stated. Procedures: "In the visual exploration tasks patients had to find a target defined by a specific feature (color, shape, size) among an array containing distractors (i.e. a red letter among blue ones). In the reading task, patients had to detect a nonword target (ie, vowels) among a varying number of words (i.e. accent), presented in a single central horizontal line. In both task types participants responded to target presence using an appropriate computer-mouse press. Computer feedback on speed and accuracy of responses, and overall progress to date (i.e. difficulty level achieved and number of training sessions completed), was provided at the end of each block of trials." Provided by: "at the start of the intervention period the experimenter demonstrated the training, during which the computer was set up ... Participants were encouraged to train in a similar manner, though adherence cannot be guaranteed" .Delivery: home-based (Table 1). Regimen: "Patients could perform a maximum of 14 blocks per day. Each block contained 120 trials. They completed 294 exploration and 196 reading blocks." Tailoring: "For both training components difficulty level was dynamically adjusted based on both accuracy and speed of previous performance. If patients were $\geq 90 \%$ accurate then difficulty would increase to the next level, whereas with accuracy $<75 \%$ difficulty would drop to an easier level. In exploration tasks difficulty was increased by enlarging the spatial zone within which a target could appear and by making targets and distractors more similar. For the reading task the word length and number of distractor words increased (up to a maximum of 7). For both tasks, presentation time was directly related to previous response times, that is, the faster the participant, the shorter the successive presentation time". Modification: see tailoring. Adherence: "There were 18 withdrawals, 9 due to low motivation. A total of $89 \%$ of the low-motivation withdrawals were in the control group. Recommended training duration was 5 weeks. However, only 3 patients met this requirement; the mean completion time for the experimental training was 9.3 weeks $(S D=6.0) . "$

Group 2: control $(n=24)$

Intervention: "This training consisted of a number of tasks requiring visual attention but no systematic exploration or large horizontal eye movements." Intervention type: placebo/attention control. Materials: computer-based. Where can materials be accessed? not stated. Procedures: "The randomly presented tasks included a Go/No-Go task, centrally presented sequential search, Sternberg task, and a "rabbit hunting" task." Provided by: "at the start of the intervention period the experimenter demonstrated the training, during which the computer was set up ... Participants were encouraged to train in a similar manner, though adherence cannot be guaranteed". Delivery: home-based (Table 1). Regimen: "Patients were instructed to complete 10 blocks per day in approximately 1 hour, with a total of 350 blocks." Tailoring: "Difficulty was adjusted dynamically depending on performance by reducing presentation time or increasing attentional load." Modification: see tailoring. Adherence: "There were 18 withdrawals, 9 due to low motivation. A total of $89 \%$ of the low-motivation withdrawals were in the control group. Recommended training duration was 5 weeks. However, only 3 patients met this requirement; the mean completion time for the experimental training was 9.3 weeks (SD =6.0)."

$\begin{array}{ll}\text { Outcomes } & \text { See Table } 4 \\ & \text { Perimetry (Esterman) } \\ & \text { Visual search (find the number) } \\ & \text { Reading (corrected reading speed) }\end{array}$


Aimola 2011 (Continued)

Tasks simulating ADL: 1) driving hazard perception (mean score per hazard), 2) obstacle avoidance (completion time), 3) visuomotor search (time)

Attention tasks: 1) sustained attention to response (mean percentage error score), 2) test of everyday attention

Subjective questionnaires: Visual Functioning Questionnaire (VFQ-25), Subjective Reasons Questionnaire

Time points when outcomes were assessed: before and after intervention

\section{Notes}

\section{Risk of bias}

\begin{tabular}{|c|c|c|}
\hline Bias & Authors' judgement & Support for judgement \\
\hline $\begin{array}{l}\text { Allocation concealment } \\
\text { (selection bias) }\end{array}$ & Low risk & Stated "using parallel trial allocation software" \\
\hline $\begin{array}{l}\text { Blinding (performance } \\
\text { bias and detection bias) } \\
\text { All outcomes }\end{array}$ & Unclear risk & $\begin{array}{l}\text { "Participants were informed about the training types but did not know to } \\
\text { which group they were assigned." Not stated if outcome assessor was blinded. }\end{array}$ \\
\hline $\begin{array}{l}\text { Incomplete outcome data } \\
\text { (attrition bias) } \\
\text { All outcomes }\end{array}$ & High risk & "There were 18 withdrawals, 9 due to low motivation." \\
\hline Other bias & Low risk & No other issues noted \\
\hline
\end{tabular}

Bainbridge 1994

\section{Study characteristics}

\begin{tabular}{ll}
\hline Methods & Substitutive intervention versus substitutive intervention \\
Design: parallel RCT & Stratification: not stated \\
Randomisation sequence: not stated \\
Comparisons: Full Field plastic press-on 15-diopter Fresnel prisms (base towards the deficit) versus \\
Half Field prisms cut to cover the respective homonymous field \\
Allocation concealment: not stated \\
Blinding: not stated \\
Power calculation: not stated \\
Intention-to-treat analysis: not stated \\
Other recruitment details: not stated \\
Patient and public involvement: not stated \\
Total study population: 18 (stroke only) participants who had hemianopsia or visual neglect, or both \\
Withdrawals: none
\end{tabular}


Bainbridge 1994 (Continued)

Method of diagnosing VFD: confrontation; method of diagnosing visual perceptual problems: confrontation

Characteristics of population: participant details are listed in Table 2

Type and severity of visual problems: participant details are listed in Table 3

Inclusion criteria: not stated

Exclusion criteria: not stated

Baseline comparison of treatment groups: not stated

\section{Group 1: Full field prism $(n=10)$}

Intervention type: substitution. Materials: Full field prism. Where can materials be accessed? not stated. Procedures: 15 dioptre full-field plastic press-on Fresnel prisms (base towards the deficit). Provided by: not stated. Delivery: face-to-face, individual, location not stated (Table 1). Regimen: used the prisms while awake for 4 weeks. Tailoring: not stated. Modification: not stated. Adherence: not stated

\section{Group 2: Hemi-field prism $(n=8)$}

Intervention type: substitution. Materials: Hemi-field 15 diopter Fresnel prism. Where can materials be accessed? not stated. Procedures: Hemi-field prisms cut to cover the respective field. Provided by: not stated. Delivery: face-to-face, individual, location not stated (Table 1). Regimen: used the prisms while awake for 4 weeks. Tailoring: not stated. Modification: not stated. Adherence: not stated

\begin{tabular}{|c|c|c|}
\hline \multirow[t]{7}{*}{ Outcomes } & \multicolumn{2}{|l|}{ See Table 4} \\
\hline & \multicolumn{2}{|c|}{ Motor visual perception score } \\
\hline & \multicolumn{2}{|l|}{ Line Bisection Test } \\
\hline & \multicolumn{2}{|l|}{ Line Cancellation test } \\
\hline & \multicolumn{2}{|c|}{ Harrington-Flocks Visual Field score } \\
\hline & \multicolumn{2}{|c|}{ Time points when outcomes were assessed: baseline and at 4 weeks } \\
\hline & \multicolumn{2}{|c|}{ Adverse events? not stated } \\
\hline Notes & \multicolumn{2}{|c|}{ Insufficient information to assess for any confounding variables (abstract) } \\
\hline \multicolumn{3}{|l|}{ Risk of bias } \\
\hline Bias & Authors' judgement & Support for judgement \\
\hline $\begin{array}{l}\text { Allocation concealment } \\
\text { (selection bias) }\end{array}$ & Unclear risk & $\begin{array}{l}\text { Quote "patients were randomized". Insufficient information available in the } \\
\text { abstract }\end{array}$ \\
\hline $\begin{array}{l}\text { Blinding (performance } \\
\text { bias and detection bias) } \\
\text { All outcomes }\end{array}$ & Unclear risk & Insufficient information available in the abstract \\
\hline $\begin{array}{l}\text { Incomplete outcome data } \\
\text { (attrition bias) } \\
\text { All outcomes }\end{array}$ & Unclear risk & Insufficient information available in the abstract \\
\hline Other bias & Unclear risk & Insufficient information available in the abstract \\
\hline
\end{tabular}




\section{Substitutive intervention versus control, placebo or no intervention}

Design: RCT (cross-over, with a "counterbalanced $A B / B A$ design ( $A B=$ real first, $B A=$ sham first)". The "real" prisms could be either "oblique" or "horizontal" peripheral prism glasses, meaning that there were 4 possible treatment allocations for each participant).

Stratification: see below (minimisation)

Randomisation sequence: participants were assigned using minimisation. "The first participant was assigned randomly, with each subsequent participant assigned in such a way as to minimize imbalances among the 4 treatment allocations. We could realistically balance for only 2 factors. Study site was the primary factor (because continuation rates varied significantly across sites in our first multicenter study) and side of hemianopia (right or left) was the second factor (because the side of the lesion could potentially affect performance with the prism glasses). We did not balance for age because it was not a significant factor affecting continuation rates in our previous study."

Comparisons: oblique peripheral prism glasses, horizontal peripheral prism glasses, sham prism glasses

\section{Allocation concealment: yes}

Blinding: "Double-masking was used, with participants and data collectors being masked as far as possible. In addition, the principal investigator who conducted data analyses was masked. However, it was impossible to mask all study personnel; there was an unmasked practitioner at each site who fitted the prism glasses and dealt with clinical aspects of patient care."

Power calculation: yes (data from previous trial used to calculate minimum sample size; led to "plan to enrol at least 68 participants")

\section{Intention-to-treat analysis: no}

Other recruitment details: "Data were collected at 13 study sites, including the Peli laboratory at Schepens, 11 vision rehabilitation clinics in the United States, and 1 in the United Kingdom. The clinics included university, hospital, and private practice clinics. Each site recruited a median of 7 participants (range, 3-12). Participants were recruited by practitioners at each study site."

Patient and public involvement: not stated

Withdrawals: 6 (before the start of the cross-over)

Method of diagnosing VFD: visual field mapping extended to at least $50^{\circ}$ from fixation in all directions and was performed using Goldmann perimetry (V4e target), a Humphrey Field Analyzer 120-point fullfield screening test, or similar tests, depending on the equipment available at each clinic.

Characteristics of population: participant details are listed in Table 2.

Type and severity of visual problems: participant details are listed in Table 3

Inclusion criteria: "Complete homonymous hemianopia of greater than 3 months' duration, no visual neglect (Bells test and Schenkenberg Line Bisection test), and no history of having worn peripheral prism glasses. In addition, participants had corrected monocular visual acuity of at least 20/50 in each eye, refractive error within the -5 diopter (D) to $+5 \mathrm{D}$ range, no strabismus, no significant cognitive decline (Short Portable Mental Status Questionnaire), and no balance problems or other deficits that could impair ability to walk or use the prism glasses. To ensure that study inclusion criteria were uniformly applied, screening data were sent to the principal investigator (A.R.B.), who determined eligibility".

Exclusion criteria: none listed 
Intervention type: substitution. Materials: peripheral prism glasses of 57 prism dioptres (intervention) versus 5 prism dioptres (sham). Where can materials be accessed? From vision specialists; for the study these were manufactured by "Chadwick Optical, Inc. (White River Junction, Vermont)". Procedures: participant fitted and provided with prism glasses to be worn for the following 4 weeks. "Training in how to use the prism glasses was conducted by the practitioner." "Participants were taught to view through the central prism-free area of the spectacle lens at all times and to turn the head and eyes to fixate objects of interest that were initially detected from the prism image in peripheral vision. A simple "reach and touch" training exercise was used to familiarize participants with the relationship between the apparent and real positions of objects detected from the prism image; this exercise was also encouraged for home-training. Participants were given verbal and written instructions about how to use the prism glasses and were encouraged to wear them as much as possible each day. They were advised not to use the peripheral prism glasses for driving or prolonged reading." Provided by: "practitioner". Delivery: face-to-face, individual, clinic appointment to be provided with the glasses, then to be worn by participant (Table 1). Regimen: first pair of prisms glasses 4 weeks; then crossover and use of second pair of prism glasses for another 4 weeks (see procedures). Tailoring: not stated. Modification: not stated. Adherence: not stated

\section{Group 2: Sham prism glasses (total $\mathbf{n}=36$ )}

\section{2a. Sham oblique prism glasses $(n=17)$}

\section{2b. Sham horizontal prism glasses $(n=19)$}

Intervention: control. Intervention type: placebo control. Materials: sham prism glasses. Where can materials be accessed? For the study these were manufactured by "Chadwick Optical, Inc. (White River Junction, Vermont)". Procedures: as for real prisms. Provided by: "practitioner". Delivery: face-toface, individual, clinic appointment to be provided with the glasses, then to be worn by participant (Table 1). Regimen: first pair of prisms glasses 4 weeks; then cross-over and use of second pair of prism glasses for another 4 weeks (see procedures). Tailoring: not stated. Modification: not stated. Adherence: not stated

The proportion of participants fitted with each type of prism glasses for whom the decision is to continue using the glasses

Difference in perceived mobility (i.e. rating of how helpful each type of prism glasses are in avoidance of obstacles when walking)

Time points when outcomes were assessed: at the end of each cross-over period

Notes
Data presented for the first phase (i.e. before the cross-over) is presented for "real" versus "sham"
significant differences between the oblique and horizontal groups for any of the outcome measures ...
therefore, data were pooled across the 2 groups for the main analyses".

\begin{tabular}{lll}
\hline Risk of bias & & \\
\hline Bias & Authors' judgement & Support for judgement \\
\hline $\begin{array}{ll}\text { Allocation concealment } \\
\text { (selection bias) }\end{array}$ & Low risk & $\begin{array}{l}\text { "The clinical coordinator at Schepens assigned participants to } 1 \text { of } 4 \text { possible } \\
\text { treatment allocations (real oblique AB/BA and real horizontal AB/BA) using } \\
\text { minimization". Allocation was done by central clinical co-ordinator. }\end{array}$ \\
\hline
\end{tabular}


Bowers 2014 (Continued)

Blinding (performance bias and detection bias) All outcomes
Low risk

Outcome assessor was blinded. The personnel fitting the prism were not blind ed: "Double-masking was used,with participants and data collectors being masked as far as possible. In addition, the principal investigator who conducted data analyses was masked. However, it was impossible to mask all study personnel; there was an unmasked practitioner at each site who fitted the prism glasses and dealt with clinical aspects of patient care". In the debriefing, $61 \%(37 / 61)$ of participants reported that they thought that one pair of glasses might have been a sham; of these, $92 \%$ (34/37) correctly identified the sham.
Incomplete outcome data Low risk

(attrition bias)

All outcomes
Reasons for dropouts were reported and were balanced across the groups.

Other bias High risk

Authors have disclosed conflicts of interest: "Dr Peli has financial interest in a patent related to the peripheral prism glasses (assigned to Schepens Eye Research Institute). Ms Keeney has licensed that patent for Chadwick Optical, Inc. Chadwick Optical, Inc funded the study in part from National Institutes of Health (NIH) grant EY014723 through a subcontract with Schepens Eye Research Institute. Dr Peli was a paid consultant to Chadwick Optical, Inc on the design of the permanent prisms. No other financial interests were reported."

\section{Study characteristics}

Methods

\section{Compensative intervention versus control, placebo or no intervention}

Design: RCT

Stratification: minimisation ("minimised regarding gender, side of field defect (left or right), side of field defect (hemianopia versus quadrantanopia), age (younger versus older than 55), and time since onset (shorter versus longer than 12 months - because time since onset was assumed less important than the other variables, this variable was weighted less heavily than the others)

Randomisation sequence: randomisation software

Comparisons: 2 groups, training group and control group

Allocation concealment: no, "author GH entered the characteristics of the patient into the randomisation software ... which resulted in allocation to the training group or the waiting list control group"

Blinding: "Assessors were blinded to participants' group allocation".

Power calculation: yes

Intention-to-treat analysis: no; some participant data excluded from analysis due to deviations from study protocol ("too low compliance with training protocol", "time period between T1 and T2 longer than acceptable")

Other recruitment details: patients were recruited at Royal Dutch Visio and Bartiméus, the two centers of expertise for blind and partially sighted people in the Netherlands.

Patient and public involvement: not described

Participants

Total study population: 54 randomised; training group $(n=30)$, control group $(n=24)$

Withdrawals: at follow-up immediately after training; training group $(n=28)$, control group $(n=24)$. Additional participants excluded from analysis, so in analysis: training group $(n=26)$, control group $(n=$ 23). 
Method of diagnosing VFD: specific method not clear: "patients underwent extensive and standardized ophthalmological and neuropsychological assessments at the centers mentioned above prior to participation in the study."

Characteristics of population: participant details are listed in Table 2.

Type and severity of visual problems: participant details are listed in Table 3.

Inclusion criteria: "The main inclusion criterion was presence of a hemi-VFD, at least a quadrantanopia, restricted to one half of the visual field, due to acquired postchiasmatic brain injury ... To be included, patients required a minimum binocular visual acuity of Snellen 0.5 (6/12 or 20/40, LogMAR 0.3), a stable neurological and ophthalmological condition, non-disturbed eye and head motility, ability to walk at least 50 meters, and a Mini Mental State Examination (MMSE) score 24 out of 30."

Exclusion criteria: "Exclusion criteria were ocular diseases affecting the visual field or binocular visual acuity, signs of severe physical impairments or (neuro)psychological disorders. Neglect was excluded based on the Balloons, Drawings, Line Bisection and Rey Complex Figure Test."

Baseline comparison of treatment groups: yes

Intervention type: compensation. Materials: "The full training protocol is available at Visio and Bartimeus for occupational therapists trained for applying the protocol". Electronic software was needed: "software was needed in order to implement the exercises ... this software was developed by the faculty of Behavioural and Social Science at the University of Groningen".Procedures: "The aim of the IH-CST is to teach patients with HVFD to compensate for their visual field defect during a wide range of mobility-related activities... The compensation strategy taught in the IH-CST is to apply a scanning rhythm consisting of a triad of saccades. First a large saccade towards the blind side is made in order to receive information from the periphery. This is followed by a second saccade back towards the seeing side to prevent overcompensation. Third, a small saccade is made back to the starting point of looking straight forward ... The training program consists of exercises for improving awareness of the visual field defect and its consequences for daily life, exercises to learn the scanning rhythm, and practice of the scanning rhythm in daily life mobility situations".Provided by: occupational therapists: "Thirty occupational therapists ... experienced in working with brain injured patients were schooled in providing the IH-CST ... ". Delivery: "Training according to the protocol was provided in Dutch at nine locations of Royal Dutch Visio and one location of Bartimeus in the Netherlands." "Homework assignments are included in the training protocol". (Table 1). Regimen: 15 individual sessions of 60 to 90 minutes each, 18.5 hours of face-to-face training in total during a period of 10 weeks. Tailoring: yes (stated "not applicable" in author's checklist, but stated that "... the patient proceeds to the next exercise once the predefined targets or an exercise are accomplished. This creates flexibility for individual needs and progress and can cause the training to take more or less than 15 sessions"). Modification: no. Adherence: "patients are asked to keep a diary of their practice at home and the therapist asks about the progress of the homework assignment at the beginning of every training session".

Group 2: Wait-list control $(n=23)$

Intervention type: control. Materials: none. Where can materials be accessed? NA. Procedures: NA. Provided by: NA. Delivery: NA. (Table 1) Regimen: NA. Tailoring: NA. Modification: NA. Adherence: NA.

See Table 4
Tests for visual functions (Goldman perimetry)
Reading tests
Basic scanning tests
Hazard perception test
Tracking task


De Haan 2015 (Continued)

Obstacle course

Questionnaires for activity and participation

Time points when outcomes were assessed: participants in the training group were assessed the week before training (T1) and the week after training (T2); participants in the control group were assessed at the same time points ( $\mathrm{T} 1$ and $\mathrm{T} 2$ ).

Notes Trial registration details: ISRCTN Registry (ID ISRCTN16833414); Central Committee on Research Involving Human Subjects (CCMO; registration number NL31718.042.10)

\section{Risk of bias}

\begin{tabular}{lll}
\hline Bias & Authors' judgement & Support for judgement \\
\hline $\begin{array}{l}\text { Allocation concealment } \\
\text { (selection bias) }\end{array}$ & Low risk & $\begin{array}{l}\text { Random allocation, using randomisation software. Researcher (GH) was aware } \\
\text { of allocation, but was not involved in providing treatment or assessment }\end{array}$ \\
\hline $\begin{array}{l}\text { Blinding (performance } \\
\text { bias and detection bias) } \\
\text { All outcomes }\end{array}$ & Low risk & $\begin{array}{l}\text { Outcome assessors were blinded. Personnel providing training and partici- } \\
\text { pants could not be blinded. }\end{array}$ \\
\hline
\end{tabular}

\begin{tabular}{lll}
\hline $\begin{array}{l}\text { Incomplete outcome data } \\
\text { (attrition bias) } \\
\text { All outcomes }\end{array}$ & High risk & $\begin{array}{l}\text { No intention-to-treat analysis. Final analysis completed only on those who } \\
\text { completed training, and who complied with the training programme. }\end{array}$ \\
\hline Other bias & High risk & $\begin{array}{l}\text { Control group received no treatment or contact with personnel. Therefore, } \\
\text { high risk of bias due to attention received by training group. }\end{array}$ \\
\hline
\end{tabular}

\section{Elshout 2016}

\section{Study characteristics}

\section{Restitutive intervention versus control, placebo or no intervention}

Design: randomised cross-over trial

Stratification: not stated

Randomisation sequence: "For each cohort of 10 patients, numbers (J01-J40), the training stimuli (FloworPoint), and the order of training rounds [Test (defect) round first or Control (intact) round first] were randomly assigned to a patient number ... The patients were included in order of registration on our website. Thus, the assignment of a patient to a patient number (with corresponding training scheme: stimulus type and the training order) was determined prior to the first inclusion, completely random and not based on selection."

Comparisons: 2 groups: "(1) test (high contrast training of the affected field) and (2) control (low-contrast training of the intact visual field)"

\section{Allocation concealment: see randomisation sequence}

Blinding: "We applied both Humphrey (blinded) and Goldmann perimetry (not blinded, because of insufficient staffing)." Not stated for reading tests

\section{Power calculation: not stated}

Intention-to-treat analysis: no. "Three patients dropped out during the first training round for personal reasons and were excluded from analyses". 
Other recruitment details: "This study was part of a larger project ... Forty stroke patients with visual field defects due to post-chiasmatic stroke were included following written informed consent. Patients throughout the Netherlands could signup for our study voluntarily by filling in a form on our website." However after 3 cohorts of 10 patients, the training procedure was modified "because in some patients the control training reversed the increase of the visual field of the preceding defect training". This study therefore only reported the first 3 cohorts of participants.

Patient and public involvement: not stated

\begin{abstract}
Participants
Total study population: 30 patients with post-chiasmatic lesions

Withdrawals: 3 patients dropped out "for personal reasons". They were excluded from analyses.

Method of diagnosing VFD: Goldmann perimetry measurement

Characteristics of population: participant details are listed in Table 2.

Type and severity of visual problems: participant details are listed in Table 3.

Inclusion criteria: "Patients in the chronic phase of stroke (> 10 months post CVA) were included if they showed no signs of visual neglect (line bisection test). Patient age was between 18 and 75 years, and they were able to undergo (f)MRI scanning."
\end{abstract}

Exclusion criteria: visual neglect (see above)

Baseline comparison of treatment groups: not stated

Interventions

Group 1: defect training (high contrast stimuli offered within the field defect along its border) $(n=15$ for first phase, before cross-over)

Intervention type: restitution - high-contrast stimuli in affected hemifield. Materials: "Each patient received a training unit at home to create a controlled training environment. This unit consists of a container, to be placed on a table, with a top cover and side covers to present a dark visual surround for the training stimuli with the exclusion of stray light. Mini Mac computer, keyboard, and mouse, a support with 24" LED monitor, webcam, and chin/headrest were positioned inside the matte black container". Where can materials be accessed? not stated. Procedures: "Viewing distance was fixed at 40 $\mathrm{cm}$. The subject's face was indirectly lighted with a TL light for eyetracking with the webcam. The computer was prepared with eyetracking software, and training programs that were adjusted to the particular visual field defect of the patient." "For both stimuli, the patient maintained fixation binocularly on a ring (diameter $=0.5^{\circ}$ ) at the center of the screen. During stimulus presentation (7s),patients shifted attention covertly (i.e. without shifting eye fixation) toward the stimulus and responded using the keyboard. Only the fixation point was shown during the intertrial interval of $2 \mathrm{~s}$ ". "To cue the stimulated target location and to perform a discrimination task, a line was presented simultaneously with the point extending from the fixation target into the trained hemifield. The meridional angle of the line differed by $10^{\circ}$ from the training point.The patient made a forced-choice response whether the point stimulus was presented clockwise or counterclockwise relative to the presented line". Provided by: Not stated. Delivery: In patients home. (Table 1). Regimen: " 1 h a day, 5 days a week during 8 weeks to complete at least $40 \mathrm{~h}$ of training per hemifield". "The length of one training session was on average $12 \mathrm{~min}$ (depending on the number of trials set per session and amount of fixation errors). The number of trials in a session ranged between 60 and 100, depending on the shape and quality of the visual field defect. The stimuli were randomly presented for each session". Tailoring: The number of trials depended on the shape and quality of the visual field defect. "Point size was at least $0.2^{\circ}$ in diameter (at $1^{\circ}$ eccentricity) and was scaled with eccentricity: scale $(E)=(0: 0006 \mathrm{E} \wedge 2+0: 0448 \mathrm{E}+0: 092)=0: 1374$ ". Modification: not stated. Adherence: was monitored: "Throughout the training, fixation was monitored via a low-cost commercial webcam and eyetracking software available in the public domain (www.inference.phy.cam.ac.uk/opengazer/) that was adapted to supply eye position data to the training program".

Group 2. Control (intact training) (stimuli presented in the intact field about the same eccentricities as for defect training) ( $n=15$ for first phase, before cross-over)

Intervention type: placebo/control. Although paper stated: "Following three cohorts of 10 patients, we modified the training procedure, because in some patients the control training reversed the in- 
Elshout 2016 (Continued)

crease of the visual field of the preceding defect training". Materials: as above. Where can materials be accessed? not stated. Procedures: similar to above defect training: "During intact training, stimuli were presented within the intact field at about the same eccentricities as for the patient's defect training ... To offer a challenging training during the intact training, the stimulus contrast was reduced $(C<$ $0.15)$ ". "Within the entire visual field, a pattern of flow was shown that contracted on to a training location within the visual field (white points on a dark screen). The stimulus to be discriminated was placed on a black disk that covered the center of the contraction pattern, the diameter of which was eccentricity scaled with the same factor as for the point target. We used a minimal disk size of $1.7^{\circ}$ at $1^{\circ}$ eccentricity. The origin of the contraction pattern was the location cue for the flow discontinuity that had to be detected. The discontinuity stimulus (on the disk) was a flow pattern rotating clockwise or counterclockwise about the training location. The patient had to indicate the direction of rotation".Provided by: not stated.Delivery: in participant's home (Table 1). Regimen: as above. Tailoring: stimuli were presented at the same eccentricities as for the defect training, which depended on the shape and quality of the visual field defect. Modification: not stated. Adherence: as above

\begin{tabular}{|c|c|c|}
\hline \multirow[t]{3}{*}{ Outcomes } & \multicolumn{2}{|l|}{ See Table 4} \\
\hline & \multicolumn{2}{|c|}{ Perimetry: Humphrey (blinded) and Goldmann perimetry (not blinded because of insufficient staffing) } \\
\hline & \multicolumn{2}{|c|}{ Reading tests: reading speed } \\
\hline Notes & \multicolumn{2}{|c|}{$\begin{array}{l}\text { Supplementary material referred to within published paper, but not accessible via weblink. Requested } \\
\text { from authors February } 2019\end{array}$} \\
\hline \multicolumn{3}{|l|}{ Risk of bias } \\
\hline Bias & Authors' judgement & Support for judgement \\
\hline $\begin{array}{l}\text { Allocation concealment } \\
\text { (selection bias) }\end{array}$ & Low risk & $\begin{array}{l}\text { Patients were included in the order in which they registered on the website. } \\
\text { Order of treatment phases was randomly assigned, and allocated to patient } \\
\text { number prior to patient registrations. }\end{array}$ \\
\hline $\begin{array}{l}\text { Blinding (performance } \\
\text { bias and detection bias) } \\
\text { All outcomes }\end{array}$ & High risk & $\begin{array}{l}\text { No blinding for Goldmann Perimetry ("because of insufficient staffing"). } \\
\text { Humphrey perimetry was blinded. Not stated for reading tests. Unclear who } \\
\text { delivered the intervention and whether they were blind to the treatment } \\
\text { phase. }\end{array}$ \\
\hline $\begin{array}{l}\text { Incomplete outcome data } \\
\text { (attrition bias) } \\
\text { All outcomes }\end{array}$ & Unclear risk & $\begin{array}{l}\text { No intention-to-treat analysis. } 3 \text { dropouts during first phase "for personal rea- } \\
\text { sons", but unclear which treatment group they were in. }\end{array}$ \\
\hline Other bias & Low risk & No other issues noted \\
\hline
\end{tabular}

\section{Gall 2013}

\section{Study characteristics}

Methods Restitutive intervention versus control, placebo or no intervention

Design: RCT

Stratification: not stated

Randomisation sequence: not stated

Comparisons: 2 groups

Allocation concealment: not stated 
Gall 2013 (Continued)

Blinding: stated "blinded"

Power calculation: not stated

Intention-to-treat analysis: not stated

Other recruitment details: not stated

Patient and public involvement: not stated

Total study population: 29 patients with post-chiasmatic lesions
Withdrawals: not stated
Method of diagnosing VFD: not stated
Characteristics of population: participant details are listed in Table 2.
Type and severity of visual problems: participant details are listed in Table 3.
Inclusion criteria: not stated
Exclusion criteria: not stated
Baseline comparison of treatment groups: not stated

Interventions

Group 1: non-invasive brain stimulation using alternating current stimulation (ACS) $(n=15)$

Intervention type: restitution - alternating current stimulation. Materials: not stated. Where can materials be accessed? not stated. Procedures: not stated. Provided by: not stated. Delivery: face-toface, individual, location unclear (Table 1). Regimen: 10 days. No other details reported. Tailoring: not stated. Modification: not stated. Adherence: not stated

Group 2: sham stimulation $(n=14)$

Intervention type: placebo/control. Materials: not stated.Where can materials be accessed? not stated. Procedures: not stated.Provided by: not stated.Delivery: face-to-face, individual, location unclear (Table 1). Regimen: 10 days. No other details reported. Tailoring: not stated. Modification: not stated. Adherence: not stated

\begin{tabular}{|c|c|c|}
\hline \multirow[t]{5}{*}{ Outcomes } & \multicolumn{2}{|l|}{ See Table 4} \\
\hline & \multicolumn{2}{|c|}{ Perimetric thresholds within areas of residual vision } \\
\hline & \multicolumn{2}{|c|}{$\begin{array}{l}\text { Subjectively perceived visual functioning/vision-related quality of life (composite score of National Eye } \\
\text { Institute Visual Function Questionnaire 39) }\end{array}$} \\
\hline & \multicolumn{2}{|c|}{ Health-related quality of life (Short Form Health Survey SF-12) } \\
\hline & \multicolumn{2}{|c|}{ Time points when outcomes were assessed: baseline and post-intervention (time point not stated) } \\
\hline Notes & \multicolumn{2}{|c|}{ Insufficient information to assess for any confounding variables (abstract) } \\
\hline \multicolumn{3}{|l|}{ Risk of bias } \\
\hline Bias & Authors' judgement & Support for judgement \\
\hline $\begin{array}{l}\text { Allocation concealment } \\
\text { (selection bias) }\end{array}$ & Unclear risk & Insufficient information available in the abstract \\
\hline $\begin{array}{l}\text { Blinding (performance } \\
\text { bias and detection bias) } \\
\text { All outcomes }\end{array}$ & Unclear risk & Insufficient information available in the abstract \\
\hline
\end{tabular}


Gall 2013 (Continued)

Incomplete outcome data Unclear risk Insufficient information available in the abstract (attrition bias)

All outcomes

Other bias Unclear risk Insufficient information available in the abstract

Jarvis 2012

\section{Study characteristics}

Methods

Assessment or screening intervention versus control, placebo or no intervention

Design: pilot RCT

Stratification: none

Randomisation sequence: "randomized into one of two groups using a computer-generated randomization table"

Comparisons: 2 groups: Group A (control) and Group B (experimental)

Allocation concealment: not stated ("randomization process was administered by a researcher at the University of Liverpool, who was not involved in data collection but was involved in the later data analysis")

Blinding: participants were blinded ("participants were masked to group allocation"), "assessors were not masked" ("findings from the visual assessment were withheld from the therapy staff in group A (control group). In comparison the visual assessment details were made available to the therapy staff for participants in group B (experimental group)".

Power calculation: feasibility study ("prospective observation cohort study in the UK suggested that of all stroke patients referred with suspected visual impairment, $85 \%$ were found to have an identifiable visual impairment (Rowe 2007). On the basis of this preliminary data, this pilot study aimed to screen 100 patients in order to recruit a minimum of 70 participants").

Intention-to-treat analysis: no ("All data analysis was conducted based on the recruited patients to each group with full FIM data collection for both baseline and 6-week follow-up assessment").

Other recruitment details: "Participants were prospectively recruited between February 2008 and July 2009". "Specified members of the health care team (nurses, stroke physicians, physiotherapists and occupational therapists) on the stroke unit were required to screen patients against these criteria to identify potential participants. Staff used a screening form with questions to identify visual signs (head turning, strabismus, ptosis) and symptoms (diplopia, loss of vision, field loss). This was adapted from the screening form used in the Visual In Stroke (VIS) study (Rowe 2010)"."If visual impairment was noted, the screening form was sent to the orthoptist and hence, it doubled as a referral form". "Where necessary, for example when a potential participant had communication difficulties, adaptations were made to the consent process".

Patient and public involvement: not stated

Withdrawals: 13 died before full baseline assessment (Group A: 4; Group B: 9). Another 10 cases ( Group A: 6, Group B: 4) withdrew (death, early discharge, no follow-up or DNA follow-up) at follow-up assessment.

Method of diagnosing VFD: full visual assessment undertaken by orthoptist. Battery of routine tests used as part of a previous study (Rowe 2009). It comprised tests of visual acuity - logMAR (Bailey 1976), ocular alignment - cover test (Pediatric Eye Disease Investigator Group 2009), ocular motility - saccadic, smooth pursuit and vergence assessment (Holmes 2001), stereopsis - Frisby test (Rosner 1984), visual 
field - confrontation (Cassidy 2001) and visual inattention - line bisection, star cancellation, and clock drawing. "The orthoptist did not suggest possible adaptive strategies to be undertaken, the focus was on alterations made by the therapists based only on the visual assessment information".

Characteristics of population: participant details are listed in Table 2.

Type and severity of visual problems: participant details are listed in Table 3.

Inclusion criteria: "stroke within 2-6 weeks of being recruited, had a decreased functional ability compared to pre-stroke functioning, had a post-stroke visual impairment, and were able to understand the research process"

Exclusion criteria: "unable to consent due to cognitive impairment or communication difficulties, or if they had a visual field impairment pre-existing their stroke"

Baseline comparison of treatment groups: "no significant difference in the composition of both groups ( $x^{2}$ test $)$ for gender $(P=0.846)$, age $(P=0.113)$, stroke type $(P=0.564)$, stroke area $(P=0.499)$, stroke laterality $(P=0.396)$ and handedness $(P=0.268) "$

Interventions

\section{Group 1: experimental ( $n=24$ full baseline assessment; $n=20$ at follow-up assessment)}

Intervention type: assessment or screening. Materials: modified screening form. Where can materials be accessed? Screening form (modified) available from the Visual In Stroke (VIS) study (Rowe 2010). Procedures: "all participants underwent a full visual assessment by an orthoptist. The findings from the visual assessment were ... made available to the therapy staff for participants in group B (experimental group)". "participants in both groups received occupational therapy and physiotherapy". "Therapy routinely included working to regain motor activity and increase ability to achieve valued functional tasks. The therapists used strategies such as visual scanning and cueing to the affected side as part of their practice". Treatment in the experimental group was informed by the results of the visual assessment. Provided by: orthoptists. No details provided about their training. Delivery: face-to-face, location Inpatient, stroke unit (Table 1). Regimen: not stated. Tailoring: yes. Details not supplied. Modification: not stated. Adherence: not stated

\section{Group 2: control ( $n=27$ full baseline assessment; $n=19$ at follow-up assessment)}

Intervention type: control/standard care. Materials: NA. Where can materials be accessed? NA. Procedures: described above. Treatment in the control group was not informed by results of the visual assessment ("all participants underwent a full visual assessment by an orthoptist. The findings from the visual assessment were withheld from the therapy staff in group A (control group)"). Provided by: OT, physiotherapy. No details provided about their training. Delivery: face-to-face, individual, location inpatient (Table 1). Regimen: NA. Tailoring: NA. Modification: NA Adherence: NA

See Table 4

Functional independence measure (FIM)

Timed $10 \mathrm{~m}$ walk

Non-validated questionnaire ("Therapist with the most contact with each participant was asked to complete a non-validated questionnaire giving qualitative information about their treatment approach." "Two versions of this questionnaire. The group A questionnaire asked the therapist to justify their treatment approach. The group B questionnaire required the therapist to comment on whether their treatment approach had been influenced by the visual assessment").

Time points when outcomes were assessed: "baseline and at 6 weeks after baseline (or on discharge if this occurred earlier)" 
Jarvis 2012 (Continued)

Allocation concealment Low risk "computer generated randomization table. The randomization process was (selection bias) administered by a researcher at the University of Liverpool, who was not involved in data collection but was involved in the later data analysis. Participants were masked to group allocation, but the assessors were not masked in this trial".

Blinding (performance bias and detection bias) All outcomes
High risk

"Participants were masked to group allocation, but the assessors were not masked in this trial."

"The qualitative study indicated an inherent bias had been introduced to this trial, due to the inability to blind carers, and assessors to group allocation. The health care team perceived that the presence of a full baseline vision assessment enhanced their awareness of the effect of visual deficits following stroke. This was regardless of whether or not the full visual assessment details were available."

No intention-to-treat analysis. Dropouts were clearly reported, but reason for not attending was not clear and could be related to the intervention.

Unclear risk

(attrition bias)

All outcomes

Other bias Low risk No other concerns noted

Jobke 2009

\section{Study characteristics}

Methods

Restitutive intervention versus restitutive intervention

Design: RCT (cross-over)

Stratification: no

Randomisation sequence: no details reported ("randomly assigned them into 2 groups")

Comparisons: 2 groups, extrastriate vision restoration therapy versus conventional vision restoration therapy

Allocation concealment: not stated

Blinding: "double-blind"

Power calculation: no

Intention-to-treat analysis: no

Other recruitment details: none

Patient and public involvement: no

Participants

Total study population: 21 (mixed population) participants, with visual field defects, lesions over 1 year old

Group 1: 8 participants, Group 2: 10 participants. The study included a mixed population.

Withdrawals: "Three patients had to be excluded from the analysis. One male patient (patient 19) used another vision therapy program not included in this study. Another patient (patient 20) was excluded because he discontinued the training for more than 4 weeks during the trial and a female patient (patient 21 ) showed poor fixation performance (70\% rather than the minimally required $90 \%) . "$

Method of diagnosing VFD: high-resolution perimetry and "common static perimetry diagnosis at their own ophthalmologists office". Method of diagnosing visual perceptual problems: not stated 
Type and severity of visual problems: participant details are listed in Table 3.

Inclusion criteria: at least 6 months prior experience of vision restoration therapy

Exclusion criteria: none listed

Baseline comparison of treatment groups: yes

\section{Group 1: extrastriate vision restoration therapy (VRT) $(n=8)$}

Intervention type: restitution. Materials: extrastriate vision restoration therapy - not stated where this could be accessed/acquired

Procedures: stimulation of the "entire blind area with a massive moving spiral", plus standard VRT in areas of residual vision. "The spiral consisted of concentric circles which moved with a frequency of $2.5 \mathrm{~Hz}$, and increased in width to generate the perception of motion". "Additionally, areas of residual vision (relative defects) were stimulated by standard VRT, i.e. the common single-point stimulation paradigm. Just like in standard VRT, the patient had to respond to the white target stimuli presented at random locations in areas of residual vision." Provided by: not stated. Delivery: training carried out at home by participants (Table 1). Regimen: extrastriate VRT, 1/2 hour daily for 90 days Tailoring: Yes. "The size of the training area varied from patient to patient according to the size of the visual field defect". Modification: Yes: "Every week the patients completed a self-administered diagnostic test at home and sent their data to the institute for updating the training region if necessary. Adherence: "Training breaks of longer than 2 weeks led to exclusion of the patient."

\section{Group 2: conventional vision restoration therapy (VRT) $(n=10)$}

Intervention type: restitution. Materials: standard visual restoration therapy - not stated where this could be accessed/acquired. Procedures: standard vision restoration therapy consisted of single white target stimuli, presented at random in areas of residual vision. The participant had to respond to the white target stimuli presented at random locations in areas of residual vision. Provided by: not stated. Delivery: training carried out at home by participants (Table 1). Regimen: conventional vision restoration therapy, $1 / 2$ hour daily for 90 days. Tailoring: see above. Modification: see above. Adherence: see above

Outcomes
See Table 4
High-resolution perimetry
Perimetry: common static perimetric diagnosis at own ophthalmologist
Near visual acuity: Radner reading test
NEI-VFQ
Zahlen-Verbindungs test: speed of connecting numbers in a paper-pencil test
Time points when outcomes were assessed: before and after each cross-over period
1. "All patients had used VRT for at least 6 months (range from 6-36 months) prior to study entry and
were therefore experienced participants. We were aware that this might reduce the power of the ther-
apy because of a possible 'ceiling effect'. To eliminate training bias, no patient carried out VRT during
the 6 months preceding the study". But this also means that this was potentially a very selective group
of patients, i.e. those who were motivated to continue using VRT after an initial experience. Therefore,
it may be inappropriate to generalise from this study to the general population of patients with visual
function defects. There was no data on the type or length of each participant's previous VRT (just the
range of 6 to 36 months), and if there were previous changes in the functions measured in this test. In
his previous paper on VRT, (Kasten 2001) concluded that patients can be split into 3 main types after
scanning training: 1 ) those whose field increases both during and after training, 2) those whose field in-
creases during training, but decrease afterwards, and 3) those who show no change at all. If true, this
would impact on the results of this study, as types 1 ) and 3 ) do not benefit from further training.


Jobke 2009 (Continued)

2. Participants did not use their glasses for treatment and measurements. Measurements included a measure of near visual acuity; given the age of patients, most will be presbyopes, so will struggle with this task, dependent on age and prescription.

\title{
Risk of bias
}

\begin{tabular}{lll}
\hline Bias & Authors' judgement & Support for judgement \\
\hline $\begin{array}{l}\text { Allocation concealment } \\
\text { (selection bias) }\end{array}$ & Unclear risk & Quote "random assignment", no further details given \\
\hline $\begin{array}{l}\text { Blinding (performance } \\
\text { bias and detection bias) } \\
\begin{array}{l}\text { All outcomes } \\
\hline\end{array}\end{array}$ & Unclear risk & $\begin{array}{l}\text { "Double-blind" was in the title, but no further information appeared in the pa- } \\
\text { per }\end{array}$ \\
\hline
\end{tabular}

Incomplete outcome data Unclear risk (attrition bias)

All outcomes

\begin{abstract}
3 participants excluded from analysis and not included in demographic details. "One patient used another vision therapy program not included in this study. Another patient was excluded because he discontinued the training for more than 4 weeks during the trial and a patient showed poor fixation performance ( $70 \%$ rather than the minimally required $90 \%)$." Some of these dropouts may have occurred because of an issue directly associated with the intervention studied
\end{abstract}

Also, missing data for standard perimetry measures

Other bias High risk

Researchers may have had financial interest in intervention being investigated. Poggel 2004 stated "BA Sabel and E Kasten are inventors. BA Sabel is a consultant and shareholder of NovaVision Inc, and has equity in excess of $\$ 10,000$."

Kasten 1998

\section{Study characteristics}

Methods

\section{Restitutive intervention versus control, placebo or no intervention}

Design: RCT

Stratification: not stated

Randomisation sequence: not stated; correspondence with author did not provide any further detail

Comparisons: visual restitution training (computer-based training) versus placebo (fixation training program)

Allocation concealment: stated "randomly assigned (double-blind)"; no further details

Blinding: "double-blind"

Power calculation: no

Intention-to-treat analysis: no (1 dropout from placebo group)

Other recruitment details: not stated

Patient and public involvement: not stated 
Withdrawals: 1 ("one patient from the placebo group failed to meet the requirement to train for $150 \mathrm{~h}$. This patient dropped out of the study").

Method of diagnosing VFD: high-resolution perimetry and Tubinger automated perimetry

Characteristics of population: participant details are listed in Table 2.

Type and severity of visual problems: participant details are listed in Table 3.

Inclusion criteria: "patients had to have both a visual-field defect and post-chiasmatic or optic nerve damage as shown by CT, MRI, surgical records or ophthalmoscopic documentation of optic nerve atrophy".

Exclusion criteria: insufficient fixation ability, neglect, non-optic nerve heteronymous visual field defect, disorders of the eye, no residual vision, no visual deficit, age $>75$ years, age $<18$ years, died, lesion age $<12$ months, epilepsy or photosensitivity, cognitive deficits, not willing to participate in trial, no shows after initial screening

Baseline comparison of treatment groups: baseline comparison was presented for combined groups of 19 post-chiasmatic injury participants and 19 participants with optic nerve injury (see notes below).

Interventions

Group 1: visual restitution therapy $(n=9)$

Intervention type: restitution. Materials: computer-based training. Procedures: during vision restoration therapy, the participant maintained fixation on a central fixation spot, with their "visual border zone" stimulated by repetitive stationary stimuli of varying luminance presented in a random location within this border zone. Provided by: not stated. Delivery: training was carried out on a personal computer placed in a darkened room at home. (Table 1). Regimen: 1 hour per day, 6 days per week for 6 months (a total of 150 hours required). Tailoring: yes "compliance checks and adjustments of training difficulty level were done monthy". Modification: yes "we used an individually adapted training protocol, which was determined by the characteristics of the transition zone". Adherence: a total of 150 hours was required (compliance checks done monthly).

Group 2: placebo (fixation training) $(n=10)$

Intervention type: placebo.Materials: computer-based training.Procedures: the fixation training program required "eye movements to stimuli near the foveal region for a comparable amount of time". Provided by: not stated.Delivery: training was carried out on a personal computer placed in a darkened room at home. (Table 1). Regimen: 1 hour per day, 6 days per week for 6 months (a total of 150 hours required).Tailoring: not stated. Modification: not stated. Adherence: a total of 150 hours was required (compliance checks done monthly).

$\begin{array}{ll}\text { Outcomes } & \text { See Table } 4 \\ & \text { Visual field: high-resolution perimetry } \\ & \text { Visual field: Tubinger automated perimetry } \\ & \text { Visual acuity: Landolt ring to give minimum angle of resolution } \\ & \text { Quality of life questionnaire }\end{array}$

Notes

1. Reports of this trial combined data from the trial of 19 post-chiasmatic injury participants with data from a trial of 19 participants with optic nerve injury. However, within the paper it did state "The data reported here are from two independent clinical trials each with an experimental and a control group. In the first trial, two groups of optic nerve injury patients ... In the second trial, patients with post chiasmatic injury were randomly assigned ...". It is the second trial which is included in this review. However, baseline characteristics (age, gender, size of visual field deficit) were only available for the 2 trials combined ... i.e. from 38 participants, 19 of whom had optic nerve injuries and who were not relevant to this trial/review. 
Kasten 1998 (Continued)

2. This study included a mixed population of patients and there was no separate data for stroke. There was an uneven distribution of stroke patients between the groups, with only 2/9 in Group 1 and 8/10 in Group 2.

\section{Risk of bias}

\begin{tabular}{lll}
\hline Bias & Authors' judgement & Support for judgement \\
\hline $\begin{array}{l}\text { Allocation concealment } \\
\text { (selection bias) }\end{array}$ & Unclear risk & $\begin{array}{l}\text { Stated that participants were randomly assigned (double-blind). No further } \\
\text { details of method of randomisation. Correspondence with the author gave } \\
\text { the further detail that while participating in the study the participants did not } \\
\text { know which of the treatments were expected to produce effects. }\end{array}$ \\
\end{tabular}

\begin{tabular}{|c|c|c|}
\hline $\begin{array}{l}\text { Blinding (performance } \\
\text { bias and detection bias) } \\
\text { All outcomes }\end{array}$ & Low risk & $\begin{array}{l}\text { Stated "(double-blind)", but no further information provided in the paper. Cor- } \\
\text { respondence with the author stated that it was a different person performing } \\
\text { the tests than the person who gave the training }\end{array}$ \\
\hline
\end{tabular}

Incomplete outcome data Unclear risk

(attrition bias)

"One patient who failed to meet the requirement to training for a total of 150

All outcomes hours. This patient dropped out from the study". Data for this participant appeared to be included in baseline data but did not say if included in final assessment data; the implication was no. Visual acuity reported to be performed but no data were presented.

Other bias High risk

Researchers may have financial interest in intervention being investigated. Poggel 2004 stated "BA Sabel and E Kasten are inventors. BA Sabel is a consultant and shareholder of NovaVision Inc, and has equity in excess of $\$ 10,000 "$.

\section{Study characteristics}

Methods Restitutive intervention versus restitutive intervention

Design: RCT

\section{Stratification: not stated}

Randomisation sequence: "Patients were assigned randomly to one of 3 groups", method of randomisation not stated. Correspondence with author did not provide any further detail.

Comparisons: "Three experimental groups: Group I: parallel co-stimulation ( $n=7)$; Group II: moving co-stimulation ( $n=7)$; and Group III: single stimulation $(n=9)$ ".

Allocation concealment: not stated: ("Patients were informed that the effectiveness of three different programs for visual field training was being studied and that there was no placebo group".

Blinding: not clear: Correspondence with the author stated that it was a different person performing the tests than the person who gave the training.

\section{Power calculation: no}

Intention-to-treat analysis: no ("A total of 5 patients had to be excluded after baseline examinations for one or more of the following reasons: fixation deficits, noncompliance to the training procedure, other treatments that may have had influenced their training, or illness during the trial.")

Other recruitment details: not stated

Patient and public involvement: no 
Kasten 2007 (Continued)

Participants
Total study population: 28 considered; data available for 23

Withdrawals: "A total of 5 patients had to be excluded after baseline examinations for one or more of the following reasons: fixation deficits, noncompliance to the training procedure, other treatments that may have had influenced their training, or illness during the trial."

Method of diagnosing VFD: high-resolution perimetry and Tubinger automated perimetry

Characteristics of population: participant details are listed in Table 2.

Type and severity of visual problems: participant details are listed in Table 3

Inclusion criteria: patients aged 18 to 75 years with a stable homonymous visual field defect resulting from CNS lesion, of greater than 6 months. Visual fields had to have matching deficits of both eyes on monocular perimetry plus structural damage of post-chiasmic visual system as documented by MRI/CT or medical reports.

Exclusion criteria: total blindness, central scotomata, lesions of the optic nerve or chiasma, insufficient fixation, other visual diseases, visual neglect, motor disturbances, cognitive deficits, psychotic episodes, or epilepsy. Method of diagnosing visual perceptual problems: "Zahlen-Verbbinbungd test" and "alters-Konzentrationstest"

Baseline comparison of treatment groups: 23 causes of lesions were: 14 with vascular disease, stroke, cerebral haemorrhage or ischaemia; 8 with trauma; 1 with inflammation.
Interventions
Group 1: parallel co-stimulation $(n=7)$

Intervention type: restitution (2 stimuli presented simultaneously). Materials: training programs ran on commercially available personal computers. Procedures: "visual field training was completed at home after initial examinations and instruction sessions were carried out in our laboratory". Provided by: not stated. Delivery: "All three training conditions had the following features in common: While the patient had to watch a fixation control, a target stimulus (adjustable between about $0.5^{\circ}$ and $1.5^{\circ}$ diameter, $100 \mathrm{~cd} / \mathrm{m}^{2}$ ) was presented repeatedly in a predetermined intact part of the border region of the dark screen (adjustable between $<1 \mathrm{~cd} / \mathrm{m}^{2}$ up to $50 \mathrm{~cd} / \mathrm{m}^{2}$ ). Upon detection of the target stimulus, the patient was required to respond as soon as possible by pressing the spacebar of the computer keyboard. Then the stimulus moved some degrees towards the blind area. If the patient still perceived the stimulus, this had to be acknowledged by pressing the spacebar again; the stimulus then moved again some degrees into the direction of the blind area and so forth. This procedure was repeated until the patient was unable to see the stimulus in the absolute blind field. At this "blind" position the stimulus was then presented 10 times. Thereafter, stimulation started at another predetermined position of the border region (see also "transition zone", Kasten 1998b), and the stepwise stimulation process moving from intact to blind visual field regions was repeated. Standardized variables throughout training procedures in all patients were size and luminance of stimuli and background luminance." (Table 1). Regimen: 30 minutes twice per day for three months. Tailoring: yes. "the trained area was individually adjusted to the patient's visual field border". "Other variables were adjusted individually according to the visual defect - for example, the location of fixation control, the location to start stimulation, the direction of stimulation, the frequency of fixation controls, and whether feedback upon responding was accompanied by a tone. Accordingly, training parameters were adjusted to the individual pattern of residual vision."

Modification: yes "Each month (if necessary even more often), results stored on the disc were analyzed, and the training area was readjusted, based on the progress of the patients". Adherence: "After each session, data were saved automatically on a disk to control compliance".

Group 2: moving co-stimulation $(n=7)$

Intervention: restitution ( 2 stimuli presented, with 1 nearer the blind area "running" continually between intact and lost field). All other intervention details as Group 1

Group 3: single stimulus $(n=9)$ 
Intervention: Restitution (only a single stimulus was presented). All other intervention details as Group 1

See Table 4
Visual field: high-resolution perimetry (number of hits, learning effects, fixation ability, false hits)
Visual field: Tubinger automated perimetry at 30 and 90 degrees (no of hits, fixation ability)
Eye movements: "Chronos Vision Eye Tracker"
Visual acuity
Subjective visual ability questionnaire
Attention: "Zahlen-Verbindungs Test" of visuo-spatial attention
"Alters-Konzentrationstest" attention test for older people
"testbatterie zur Aufmerksamkeitspruefung" ability to improve attention

Notes

1. This study included a mixed population of patients and there was no separate data for stroke.

2. Visual acuity at $40 \mathrm{~cm}$ was measured without glasses.

\section{Risk of bias}

\begin{tabular}{|c|c|c|}
\hline Bias & Authors' judgement & Support for judgement \\
\hline $\begin{array}{l}\text { Allocation concealment } \\
\text { (selection bias) }\end{array}$ & Unclear risk & $\begin{array}{l}\text { Quote "participants were randomly assigned to one of three experimental } \\
\text { groups", no further information on method given. Correspondence with the } \\
\text { author gave the further detail that participating the patients did not know } \\
\text { which of the treatments were expected to produce effects. }\end{array}$ \\
\hline $\begin{array}{l}\text { Blinding (performance } \\
\text { bias and detection bias) } \\
\text { All outcomes }\end{array}$ & Low risk & $\begin{array}{l}\text { Correspondence with the author stated that it was a different person perform- } \\
\text { ing the tests than the person who gave the training. }\end{array}$ \\
\hline $\begin{array}{l}\text { Incomplete outcome data } \\
\text { (attrition bias) } \\
\text { All outcomes }\end{array}$ & High risk & $\begin{array}{l}\text { "A total of } 5 \text { patients had to be excluded after baseline examinations for one or } \\
\text { more of the following reasons: fixation deficits, non-compliance to the training } \\
\text { procedure, other treatments that may influence training, illness during the tri- } \\
\text { al". No data were provided for these participants. }\end{array}$ \\
\hline Other bias & High risk & $\begin{array}{l}\text { Researchers may have had financial interests in intervention being investi- } \\
\text { gated. Poggel } 2004 \text { stated " BA Sabel and E Kasten are inventors. BA Sabel is } \\
\text { a consultant and shareholder of NovaVision Inc, and has equity in excess of } \\
\$ 10,000 \text { ". }\end{array}$ \\
\hline
\end{tabular}

Keller 2010

\section{Study characteristics}

Methods Compensative intervention versus compensative intervention

Design: parallel-group RCT

Stratification: "To achieve a nearly balanced number of patients with quadrantanopia in each group, the assignment of quadrantanopic patients between treatment groups was alternated, resulting in 3 patients in the AVT group and 4 patients in the VST group". 
Randomisation sequence: random number algorithm

Comparisons: 2 groups, audiovisual stimulation training (AVT) versus visual stimulation training (VST)

Allocation concealment: not stated

Blinding: no detail provided about blinding of patients, caregivers or assessors

Power calculation: not stated

Intention-to-treat analysis: not stated

Other recruitment details: not stated

Patient and public involvement: not stated

Participants

Total study population: 20 with unilateral lesions of the occipital lobe confirmed by MRI. Not all participants had VFD as a result of stroke. $18 / 20$ stroke; $1 / 20$ tumour and $1 / 20$ TBI

Withdrawals: none

Method of diagnosing VFD: Goldmann perimeter examination. Visual field assessment was done using the kinetic method with suprathreshold checks. Measured before and after training. "Pre-post comparisons of visual field defects were classified as stable in all patients".

Characteristics of population: participant details are listed in Table 2.

Type and severity of visual problems: participant details are listed in Table 3.

Inclusion criteria: "left- or right-sided visual field deficits primarily caused by stroke" (as confirmed by MRI). Normal bilateral hearing measured by audiometry with no asymmetry between ears, normal or corrected binocular visual acuity.

Exclusion criteria: visual neglect or signs of aphasia ("Patients were initially tested with 3 different neglect tests (line bisection, Mesulam test, draw a clock face test) and the token test")

Baseline comparison of treatment groups: "Both groups were comparable with regard to demographic and clinical variables before treatment".

Interventions

Group 1: audiovisual exploration training (AVT) $(n=10)$

Intervention type: compensation. Materials: red light-emitting diodes (LEDs), piezoelectric loudspeakers, white-noise generator, laptop computer using a custom-made software for this purpose. Where can materials be accessed? not stated.Procedures: "training sessions were conducted in a dimly illuminated room. The patients sat in chairs $60 \mathrm{~cm}$ in front of the apparatus, with their eyes adjusted to the center of the apparatus. Stimuli to the blind visual field and intact visual field were presented in random sequence. Patients were instructed to detect the presence of visual targets by pressing a response button as fast as possible. To prevent patients from reacting to false positives, $20 \%$ catch trials with solely acoustic stimulation were implemented in each training session. Whenever patients responded to a catch trial, a computer-generated 'nickering' of a horse sounded. Patients were explicitly instructed to execute eye movements with their head held straight forward. Training was carried out under binocular conditions". Provided by: not stated. Delivery: face-to-face, individual, location inpatient (Table 1). Regimen: 20 therapy sessions (each session lasting 30 minutes) over 3 weeks. Tailoring: yes. Based on type of VFD ("For patients with homonymous hemianopia, $70 \%$ of all stimuli were presented in the blind visual field. For patients with quadrantanopia, $70 \%$ of the stimuli were presented in the 2 upper or 2 lower rows of the affected side"). Modification: yes, "whenever a patient complained of tiredness, the training was interrupted for 1 minute". Adherence: not stated

\section{Group 2: visual exploration training (VET) $(n=10)$}

Intervention type: compensation. Materials: as described for AVT. Where can materials be accessed? not stated. Procedures: "settings of stimuli presentation were identical as for the AVT, with the exception that the sound was turned off during all training sessions and catch trials were not needed". Provided by: not stated. Delivery: face-to-face, individual, location inpatient (Table 1). Regimen: 20 ther- 
Keller 2010 (Continued)

apy sessions (each session lasting 30 minutes) over 3 weeks. Tailoring: yes. Based on type of VFD ("For patients with homonymous hemianopia, $70 \%$ of all stimuli were presented in the blind visual field. For patients with quadrantanopia, $70 \%$ of the stimuli were presented in the 2 upper or 2 lower rows of the affected side"). Modification: yes, "whenever a patient complained of tiredness, the training was interrupted for 1 minute". Adherence: not stated

\begin{tabular}{ll}
\hline Outcomes & See Table 4 \\
& Visual field: Perimetry - Goldmann kinetic and suprathreshold \\
& Visual exploration test \\
& Reading test \\
& Search task \\
Evaluation of ADL \\
Electro-oculography
\end{tabular}

Time points when outcomes were assessed: before and after treatment

Definitions relevant to outcomes: "Changes in visual fields defects were established by comparing the pretraining visual field with the post-training visual field. Changes were classified as better, stable, or worse. Better or worse were defined by differences of more than $5^{\circ}$ horizontally or vertically".

Notes

Risk of bias

\begin{tabular}{|c|c|c|}
\hline Bias & Authors' judgement & Support for judgement \\
\hline $\begin{array}{l}\text { Allocation concealment } \\
\text { (selection bias) }\end{array}$ & High risk & $\begin{array}{l}\text { Random number algorithm used to assign participants. However, it was also } \\
\text { stated that "To achieve a nearly balanced number of patients with quadran- } \\
\text { tanopia in each group, the assignment of quadrantanopic patients between } \\
\text { treatment groups was alternated, resulting in } 3 \text { patients in the AVT group and } \\
4 \text { patients in the VT group". This suggests that allocation was not concealed for } \\
\text { these participants. }\end{array}$ \\
\hline
\end{tabular}

\begin{tabular}{|c|c|c|}
\hline $\begin{array}{l}\text { Blinding (performance } \\
\text { bias and detection bias) }\end{array}$ & Unclear risk & $\begin{array}{l}\text { No information was given on blinding of participants, or outcome assessors. It } \\
\text { is unlikely that personnel could be blinded. }\end{array}$ \\
\hline
\end{tabular}

All outcomes

Incomplete outcome data Unclear risk No mention of any dropouts

(attrition bias)

All outcomes

Other bias Low risk No other concerns noted

Modden 2012

\section{Study characteristics}

Methods Restitutive intervention versus compensative intervention

Design: prospective randomised controlled, single-blind, single-center treatment study

Stratification: no 
Randomisation sequence: "Patients were randomly assigned to receive either CT, RT, or OT. Randomization by throwing dice and allocation took place before starting with the initial assessment of neuropsychological tests".

Comparisons: compensatory therapy (CT) versus restorative computerised training (RT) versus standard occupational therapy (OT)

\section{Allocation concealment: no}

Blinding: no ("All patients were recruited and assigned to treatment groups by a neuropsychologist. The same neuropsychologist also tested the patients before (time point T1) and after (time point T2) the treatment and was not blinded to the type of training. The training itself was performed by a psychological assistant or by the occupational therapists not involved in the study, and they provided the test results at $\mathrm{T} 1$ and $\mathrm{T} 2 . "$

\section{Power calculation: yes}

Intention-to-treat analysis: no dropouts

Patient and public involvement: not stated

Participants

Total study population: 45 patients randomised

Withdrawals: 0

Method of diagnosing VFD: "a perimetry test from the Test Battery of Attentional Performance, the latter having a sensitivity and specificity for visual field defects similar to the Goldmann perimetry."

Characteristics of population: participant details are listed in Table 2.

Type and severity of visual problems: participant details are listed in Table 3.

Inclusion criteria: homonymous hemianopia with a posterior cerebral artery stroke

Exclusion criteria: visual neglect, eye-movement disorders, neuropsychological disorders like aphasia, dysexecutive syndromes, memory deficits, or higher order motor impairments like apraxia

Baseline comparison of treatment groups: "At baseline, the 3 groups did not differ in demographic and neuropsychological measures".

Interventions

Group 1: restitution therapy $(\mathrm{RT})(\mathrm{n}=15)$

Intervention: RT - computer-based stimulation of visual field

Intervention type: restitutive. Materials: computer-based restitution therapy: "A therapy-integrated perimeter program (provided by Teltra company)". Procedures: "A therapy-integrated perimeter program (provided by Teltra company) created the exact measurement of the individual visual field border. Using that measurement, a series of colored targets appeared on a blue screen anywhere at 1 of 10 positions on the border line. A randomly presented first fixation target (a rotating arrow) announced the second stimulus target in the hemianopic border zone (basic principle of covert attention shift). The patients were instructed to respond (by pressing a key) to each stimulus target (colored and flickering frames, beams, and spots) as soon it was perceived. The program contained no adaptive difficulty levels. Eye movements were not allowed, and this was controlled by the assistant". Provided by: "The training itself was performed by a psychological assistant or by the occupational therapists not involved in the study". Delivery: face-to-face, individual, location rehabilitation centre: "The participants in both PC-based therapy groups were seated $60 \mathrm{~cm}$ away from the screen (19-inch monitor) and had to perform the tasks binocularly. As during testing, the head was fixed by a chin rest, the sessions were always controlled by the assistant to make sure that the instructions were followed." (Table 1). Regimen: 30 minutes/day for 15 sessions. Tailoring: no: "The program contained no adaptive difficulty levels." Modification: no. Adherence: stated "no-one dropped out because of problems with compliance".

Group 2: compensatory therapy $(\mathrm{CT})(\mathrm{n}=15)$

Intervention: CT - computer-based stimulation of visual field 
Intervention type: compensatory. Materials: computer-based: "The 'Exploration' task (from RehaCom, provided by HASOMED GmbH, Magdeburg, Germany)". Procedures: "The "Exploration" task.......... was adapted individually according to the side of the hemianopia. On a dark background, different bright stimuli arranged in rows and columns were presented. A ring (diameter of 2 $\mathrm{cm}$ ) moved line by line (interlaced) on a matrix unit over the field. The participant was instructed to follow the ring (starting point to an outmost fixation in the blind side) by eye movements and to identify a critical targeted icon. The targets were not always distributed homogeneously but were clustered in the blind side. Thus, the exploration in the hemianopic field was further promoted. The patients had to respond (by pressing a key) when the targeted icon was perceived in the circle. Provided by: "The training itself was performed by a psychological assistant or by the occupational therapists not involved in the study". Delivery: face-to-face, individual, location rehabilitation centre: "The participants in both PC-based therapy groups were seated $60 \mathrm{~cm}$ away from the screen (19-inch monitor) and had to perform the tasks binocularly. As during testing, the head was fixed by a chin rest. The sessions were always controlled by the assistant to make sure that the instructions were followed." (Table 1). Regimen: 30 minutes/day for 15 sessions. Tailoring: yes: "The program contained several difficulty levels. In levels 1 to 20 , all lines were completely filled with symbols, whereas there were omissions in the rows of symbols in levels 21 to 30 to increase the difficulty." Modification: not clear. Adherence: stated "noone dropped out because of problems with compliance".

Group 3. occupation therapy $(\mathrm{OT})(\mathrm{n}=15)$

Intervention: OT - standard occupational therapy

Intervention type: compensatory. Procedures: "After a standardized assessment of daily living activities, the therapy consisted of individually adapted stimulation of daily activity tasks to compensate via eye-, head-, and body movements. These compensation strategies included aspects of spatial and body perception, searching or arranging objects, pen and paper searching task, reading maps or newspapers, and self-care activities. The participant was instructed to perform systematic eye movements toward the lost visual field. The interventions were carried out in the treatment rooms, on the wards, in a kitchen or a bathroom, outside in the park, or in a supermarket." Provided by: occupational therapist. Delivery: face-to-face, individual, location rehabilitation centre: (Table 1). Regimen: 30 minutes/day for 15 sessions. Tailoring: yes: "After a standardized assessment of daily living activities, the therapy consisted of individually adapted stimulation of daily activity tasks". Modification: not clear. Adherence: stated "no-one dropped out because of problems with compliance".

Note: "Patients receiving RT and CT did not receive OT in the context of their standard rehabilitation treatment."

\begin{tabular}{|c|c|}
\hline \multirow[t]{5}{*}{ Outcomes } & See Table 4 \\
\hline & Visual field expansion - test battery of attentional performance visual field assessment \\
\hline & Visual search performance - cancellation \\
\hline & Reading performance - Weschler memory tests \\
\hline & ADL - Extended Barthel Index \\
\hline
\end{tabular}

Time points when outcomes were assessed: after completion of training

\section{Risk of bias}

\begin{tabular}{|c|c|c|}
\hline Bias & Authors' judgement & Support for judgement \\
\hline $\begin{array}{l}\text { Allocation concealment } \\
\text { (selection bias) }\end{array}$ & High risk & Randomisation was by throwing a dice: no allocation concealment. \\
\hline $\begin{array}{l}\text { Blinding (performance } \\
\text { bias and detection bias) } \\
\text { All outcomes }\end{array}$ & High risk & $\begin{array}{l}\text { No blinding: "All patients were recruited and assigned to treatment groups by } \\
\text { a neuropsychologist. The same neuropsychologist also tested the patients be- } \\
\text { fore (time point } t \text { ) and after (time point } t 2 \text { ) the treatment and was not blind- }\end{array}$ \\
\hline
\end{tabular}




Incomplete outcome data Low risk No dropouts
(attrition bias)
All outcomes

\begin{tabular}{lll}
\hline Other bias $\quad$ Low risk other concerns noted & No
\end{tabular}

Plow 2010

\title{
Study characteristics
}

Methods

\author{
Restitutive intervention versus restitutive intervention \\ Design: "Randomised controlled, double-blind pilot trial"
}

\section{Stratification: no}

Randomisation sequence: "Participants were randomly assigned using a predetermined enrollment sequence to 1 of 2 arms". Method of randomisation not stated. Correspondence with the author provided the information that "as subjects were admitted, they were randomly assigned to one of two groups based on an a priori generated randomization strategy."

Comparisons: 2 groups: vision restoration therapy with active transcranial direct current stimulation $(V R T+t D C S)$ and vision restoration therapy with sham transcranial direct current stimulation (VRT + sham)

Allocation concealment: yes: "Participants and investigators analyzing visual field outcomes were blinded to the tDCS mode (active versus sham)."

Blinding: yes: "Participants and investigators analyzing visual field outcomes were blinded to the tDCS mode (active versus sham)."

Power calculation: not stated

Intention-to-treat analysis: no

Other recruitment details: "A total of 150 potential participants were screened. Following comprehensive neurological and ophthalmological screening, 12 patients ... were enrolled".

Patient and public involvement: not stated

Participants

Total study population: 12

Withdrawals: 4

Method of diagnosing VFD: high-resolution perimetry

Characteristics of population: participant details are listed in Table 2.

Type and severity of visual problems: participant details are listed in Table 3.

Inclusion criteria: "Patients with unilateral postchiasmal visual field loss following stroke or brain damage, who were in the chronic phase of recovery (> 3 months post-lesion)". Participants were "aged over 18, with deep hemianopic field loss as defined and confirmed by monocular perimetry along with established structural damage of the post-charismatic visual system as documented by standard neuroimaging techniques (CT or MRI), medical reports, or a combination of these. Participants also had cognitive, language and motor function sufficient to understand the experiments and follow instruc- 
Plow 2010 (Continued)

tions, had given informed written consent to participate in the study and had motivation to participate in the VRT program."

Exclusion criteria: "Any ocular visual pathology or contraindication to noninvasive brain stimulation and tDCS. Specific criteria drawn from safety guidelines pertaining to the use of noninvasive cortical stimulation include 1) the presence of any metallic, mechanical, or magnetic implant in the head or implantable device (e.g. cardiac pacemaker); 2) prior history of seizure or familial history of seizure disorder in a first degree relative, and 3) chronic use of neuroactive medication (e.g. neurostimulants, anticonvulsants, or antidepressants)."

Baseline comparison of treatment groups: not stated. Baseline data were provided, but no statistical comparison. Time since stroke did not appear to be comparable, with the VRT + tDCS group mean, 20.8 months (SD 26.6, range 3 to 72 months), and VRT + sham group mean, 58.7 months (SD 72.9, range 10 to 192 months).

This study appeared to include participants with visual field defects only (no visual neglect), although the method of ensuring no visual neglect was unclear

Method of diagnosing visual field defect: "monocular perimetry", no further details of method

Method of diagnosing visual perceptual problems: not stated

Interventions

Group 1: visual restoration therapy + transcranial Direct Current Stimulation (VRT + tDCS) $(n=6$; data available for $n=4$ )

Intervention: computer-based stimulation of the visual field with active transcranial direct current stimulation, 30-minute sessions twice per day, 3 times per week for 3 months of vision restoration therapy and concurrent transcranial direct current stimulation of $2 \mathrm{~mA} /$ minute

Intervention type: restorative. Materials: computer-based restitution therapy: "Vision Restoration Therapy (VRT; Novavision Inc, Boca Raton, Florida)", transcranial Direct Current Stimulation: "tDCS was applied using two $5 \times 7 \mathrm{~cm}^{2}$ saline-soaked sponge electrodes connected to a 9-V battery-driven stimulator (IOMED Inc. Salt Lake City, Utah)". Procedures: vision restoration therapy: "Briefly, participants were seated in front of a computer screen at a constant viewing distance and instructed to detect (signaled by a key press) the presence of a flashed light stimulus while maintaining fixation on a central target. Built-in fixation monitoring required patients to respond to a color change of the central fixation target occurring at random intervals. Target stimuli were presented primarily in the region of the transition zone (identified by a prior visual field test; see details on high-resolution perimetry), and the spatial parameters of customized therapy were determined based on weekly progress and results of monthly tests." Transcranial direct current stimulation: "tDCS was applied using two $5 \times 7 \mathrm{~cm}^{2}$ salinesoaked sponge electrodes connected to a 9-V battery-driven stimulator delivering a constant current of $2 \mathrm{~mA}$ for the entire duration of the training procedure. Following the 10-20 International EEG co-ordinate system, the anode was placed at the occipital pole and the cathode (reference) was positioned at the vertex. Electrodes were then secured using nonlatex rubber straps, and an identical montage was worn by all patients throughout training." Provided by: University eye clinic. Delivery: face-to-face, individual, location University eye clinic (Table 1). Regimen: "We used a contracted VRT regimen lasting 3 months (2 half-hour sessions, separated by a 30-minute rest interval, for $3 \mathrm{~d} / \mathrm{wk}$ )." Tailoring: not stated. Modification: not stated. Adherence: not stated

Group 2: visual restoration therapy + sham transcranial Direct Current Stimulation (VRT + sham) $(n=6$; data available for $n=4$ )

Intervention: computer-based stimulation of the visual field with sham transcranial direct current stimulation, 30-minute sessions twice per day, 3 times per week for 3 months of vision restoration therapy, transcranial direct current stimulation turned on for 30 seconds then ramped down to zero and turned off. Intervention type: restorative. Materials: see above. "Experimental blinding with respect to active or sham transcranial direct current stimulation was implemented according to standard protocol guidelines described previously". Procedures: see above. Provided by: see above. Delivery: see above (Table 1). Regimen: see above. Tailoring: not stated. Modification: not stated. Adherence: not stated 
Plow 2010 (Continued)

Visual field - high-resolution perimetry: position of visual field border and stimulus detection accuracy

Visual field - subjective topograhic measure of perceived visual field deficit

Extended ADL - Veterans Affairs Low Vision-Visual Functional Questionnaire (LV-VFQ)

QoL - Vision Impairment (IVI) profile

Other - independent measure of fixation performance during training and HRP testing

Time points when outcomes were assessed: baseline and at completion of training ( 3 months)

\section{Notes}

\section{Risk of bias}

\begin{tabular}{lll}
\hline Bias & Authors' judgement & Support for judgement \\
\hline $\begin{array}{ll}\text { Allocation concealment } \\
\text { (selection bias) }\end{array}$ & Low risk & "Participants were randomly assigned using a predetermined enrollment se- \\
& & $\begin{array}{l}\text { quence to } 1 \text { of } 2 \text { arms". Method of randomisation not stated. Correspondence } \\
\text { with the author provided the information that "as subjects were admitted, } \\
\text { they were randomly assigned to one of two groups based on an a priori gener- } \\
\text { ated randomization strategy." }\end{array}$ \\
& \\
\hline
\end{tabular}

Blinding (performance Low risk Correspondence with the author stated "the investigators assessing the visubias and detection bias) al field results (primary outcome) were also blinded to patient group assignAll outcomes ment. Once visual field assessment was complete, they were provided with an encrypted copy of the data without any identifying information".

Correspondence with the author stated "Blinding to stimulation (i.e. sham) was maintained by exploiting the inherent properties of tDCS. All patients wore the electrode montage regardless of the group they were relegated to. When the tDCS unit is turned on, current is slowly ramped up until the target current level is reached. During this time, patients will typically report a tingling or itching sensation beneath the surface of the anode electrode (overlying the occipital cortex). This sensation subsides shortly after a couple of minutes of habituation. Thus, in the experimental group, the current remains on but in the sham control group, the current is turned off. In either case, the patient is not aware of this happening. This fact is exploited for the purposes of experimental blinding since patients in the VRT + tDCS group can not perceive sensation of stimulation and neither can those patients who are in the VRT + sham tDCS group."

Incomplete outcome data Low risk (attrition bias)

All outcomes
There were 4 dropouts who were not included in data analysis. Reasons for dropouts were provided, and were even between the groups. The author supplied the following information: "Out of 12 patients who were enrolled into the study, 4 (i.e. 2 from each group), were excluded or could not complete the study. Here are the reasons: VRT + tDCS group: Patient 1 - excluded soon after randomization as she had an unrelated adverse event that excluded her from participation; Patient 2 - excluded from analysis due to technical issues that could not allow us to ascertain whether sufficient tDCS current was being delivered throughout the training period. VRT + sham tDCS group: Patient 1 : did not receive allocated intervention due to onset of medication use that was contraindicated with tDCS; Patient 2 - discontinued due to onset of a medical condition that precluded her from further participation."

\begin{tabular}{ll}
\hline Other bias $\quad$ Low risk $\quad$ No other concerns noted \\
\hline
\end{tabular}


Poggel 2004

\section{Study characteristics}

Methods

Restitutive intervention versus restitutive intervention

Design: prospective RCT

Stratification: no

Randomisation sequence: stated participants were "assigned randomly" but no details given. Correspondence with author did provide any further detail.

Comparisons: 2 groups - visual restoration therapy (VRT) with attentional cueing, VRT without attentional cueing

Allocation concealment: no - "Patients were not told which type of training they received; a double-blind control was not possible owing to staff limitations."

\section{Blinding: no}

Power calculation: no

Intention-to-treat analysis: no. 1 dropout, for whom no data was presented. Stated: "Patient 5 did not participate in the training procedure owing to time constraints and is not listed here."

Other recruitment details: not stated

Patient and public involvement: not stated

Participants

Total study population: 20 recruited (data available for 19)

Withdrawals: 1 ("Patient 5 did not participate in the training procedure owing to time constraints and is not listed here.")

Method of diagnosing VFD: high-resolution perimetry and standard Tuibingen Automated Perimetry

Characteristics of population: participant details are listed in Table 2.

Type and severity of visual problems: participant details are listed in Table 3.

Inclusion criteria: homonymous visual field defects after postgenicular lesions, age 18 to 75 years. Visual field size, assessed by high-resolution campimetry, had to be stable; that is, patients were included only if visual field size increased or decreased by $<2 \%$ over at least 4 weeks before the study started".

Exclusion criteria: optic nerve, retinal or other ophthalmic disorders; mental deficits; impaired attention and neglect; psychiatric disorders; epilepsy and diseases with obvious visual or cognitive effect

Baseline comparison of treatment groups: not stated

This study included patients with visual field defects only (no visual neglect).

Method of diagnosing visual perceptual problems: not stated

Interventions

Group 1: visual restitution therapy (VRT) with attentional cueing $(n=10)$

Intervention: computer-based stimulation of visual field, with cueing

Intervention type: restitution

Materials: computer-based vision restoration therapy (Nova Vision, Magdeburg, Germany). Procedures: a high-resolution computer-based campimetric test (high-resolution perimetry [HRP]; Nova Vision, Magdeburg, Germany) was used to assess visual field size and to determine ARVs.Training stimuli appeared on a dark computer screen, each target increasing in brightness in four steps from dark gray $\left(30 \mathrm{~cd} / \mathrm{m}^{2}\right)$ to bright white $\left(96 \mathrm{~cd} / \mathrm{m}^{2}\right)$ over 2000 milliseconds. Stimulus size, fixation control, mode 
Poggel 2004 (Continued)

of response, and viewing distance were identical to those used for HRP. For vision restoration therapy with attentional cueing, the training stimulus was preceded by a large $\left(12^{\circ} \times 12^{\circ}\right.$ visual angle) dim gray cue frame enclosing a predetermined segment in the upper visual field that included parts of the intact and blind fields as well as ARVs. The frame appeared for 200 milliseconds and was followed at a randomised interval (mean stimulus onset asynchrony: 1000 milliseconds, range 750 to 1250 milliseconds) by a training stimulus presented in the area that had been stimulated by the cue frame (the attention field). In each training session, patients received 500 training stimuli. In the experimental group, approximately one-third of the trials, that is, those where the target was to be presented in the attention field, were preceded by a cue. Targets were presented at random locations within the upper and the lower visual fields. Depending on the percentage of stimuli detected, the duration of each training session was approximately 30 to 35 minutes." Provided by: not stated.Delivery: training completed at home using computer (Table 1). Regimen: "Patients performed the training in six training units, each lasting approximately 1 month. A unit consisted of 56 sessions, with two sessions per day." Tailoring: yes: "Each patient's ARV was determined based on five HRP tests. The training area was then adjusted to the visual field border of that individual." Modification: not stated. Adherence: not stated ("Data from each session were saved on a disk")

Group 2: visual restitution therapy (VRT) with no attentional cueing $(n=9)$

Intervention: computer-based stimulation of visual field

Intervention type: restitution

Materials: see above. Procedures: see above.Provided by: see above. Delivery: see above. (Table 1). Regimen: see above. Tailoring: see above. Modification: see above. Adherence: see above

\begin{tabular}{ll} 
Outcomes & See Table 4 \\
& Change in size of visual field: \\
& Tubinger automated perimetry (TAP) \\
& High resolution perimetry (HRP) \\
& Time points when outcomes were assessed: at the end of each training unit (HRP), and after the 6th \\
training unit (HRP and TAP) & Training and measurement were essentially the same thing. \\
& $\begin{array}{l}\text { Authors referred to Kasten 2001 as proof that control was not needed. They did not address his conclu- } \\
\text { sions on effects of training when recruiting from an already trained group - see Jobke 2009 above. } \\
\text { Outcome data was largely presented for all patients combined (control and experimental groups com- } \\
\text { bined) }\end{array}$ \\
\hline Risk of bias & $\begin{array}{l}\text { Authors' judgement } \\
\text { Bias }\end{array}$ \\
\hline $\begin{array}{l}\text { Allocation concealment } \\
\text { (selection bias) }\end{array}$ & $\begin{array}{l}\text { Unclear risk } \\
\text { control was not possible owing to staff limitations" - the paper did not state } \\
\text { what methods (if any) were used to conceal the allocation from those enrolling } \\
\text { and assigning participants and correspondence with the author did not pro- } \\
\text { vide any further information. }\end{array}$ \\
\hline
\end{tabular}

Blinding (performance bias and detection bias) All outcomes
High risk

\footnotetext{
"Patients were not told which type of training they received; a double-blind control was not possible owing to staff limitations".
} 
Poggel 2004 (Continued)

Incomplete outcome data Unclear risk 1 participant did not participate, none of his data were included in final analy(attrition bias) sis. The co-author was not totally clear on the reason for non-participation, but All outcomes believed it to be another stroke.

Other bias High risk

Researchers had financial interest in intervention being investigated: "BA Sabel and $E$ Kasten are inventors. BA Sabel is a consultant and shareholder of NovaVision Inc, and has equity in excess of USD 10,000".

Rossi 1990

\section{Study characteristics}

Methods

\section{Substitutive intervention versus control, placebo or no intervention}

Design: RCT

Stratification: no

Randomisation sequence: "randomly assigned". Method of randomisation not stated

Comparisons: 2 groups; 15 diopter Fresnel prisms and control (no prisms)

Allocation concealment: no

Blinding: no, as the prism group wore their prisms during testing

Power calculation: no

Intention-to-treat analysis: not stated (not clear if any dropouts)

Other recruitment details: "39 patients with either homonymous heminaopia or unilateral visual neglect were recruited from an inpatient stroke rehabilitation unit".

Patient and public involvement: not stated

Participants

Total study population: 39

Withdrawals: none

Method of diagnosing VFD: tangent screen (inability to reliably detect a $1 \mathrm{~cm}$ red target on tangent screen examination in a homonymous field pattern) and Harrington Flocks visual field screener

Characteristics of population: participant details are listed in Table 2.

Type and severity of visual problems: participant details are listed in Table 3.

Inclusion criteria: homonymous hemianopia or unilateral visual neglect and a diagnosis of stroke based on clinical history, neurological exam and neuroimaging

Exclusion criteria: visual acuity worse than 20/200, unable to comprehend and co-operate with visual field assessment, disabling cardiac, pulmonary or rheumatologic problems

\section{Baseline comparison of treatment groups: yes}

The study included only stroke patients.

This study included patients with visual field defects and/or visual neglect.

Method of diagnosing visual perceptual problems: neglect was confirmed by inability to reliably detect bilateral tachistoscopically presented targets using the Harrington Flocks Visual Screener. 
Rossi 1990 (Continued)

Interventions
Group 1: 15 diopter Fresnel prisms $(n=18)$

Intervention: prisms

Intervention type: substitution

Materials: plastic, press-on Fresnel prisms (stated these are "commercially available"). Procedures: "Plastic press-on Fresnel prisms were trimmed to fit on the inside of the patients's spectacle lenses. Each prism was cut to the shape of a half circle overlaying only the affected hemifield, with the base of the prims toward the affected field". Provided by: not stated (university neurology department), Delivery: face-to-face, individual, location inpatient (Table 1). Regimen: "Patients wore the prisms for all daytime activities. Prism position and cleanliness were checked daily by study personnel. Patients were restricted to ambulation 'with assessance only' for at least 1 day after the fitty of the prisms". Also "participated in a routine stroke rehabilitation program including physical, occupational, and speech therapy ... ADL training and table-top visual perception retraining tasks". Tailoring: no. Modification: no. Adherence: not stated (stated "In practice, most patients tolerated the Fresnel prisms well after a day or two")

Group 2: control $(n=21)$

Intervention: no prisms

Intervention type: control

Materials: NA. Procedures: NA.Provided by: NA.Delivery: NA. Regimen: "participated in a routine stroke rehabilitation program including physical, occupational, and speech therapy ... ADL training and table-top visual perception retraining tasks". Tailoring: NA. Modification: NA. Adherence: NA
See Table 4

Modified Mini Mental Status Examination

Motor free visual perception test

Line bisection task

Line cancellation task

Harrington Flocks Visual Screener

Tangent Screen Examination

Barthel ADL score

Frequency of falls

Time points when outcomes were assessed: baseline, 2 weeks and 4 weeks
1. The length of time that the prisms were worn may vary considerably for different patients, as this was for "all day time activities"

2. States that diagnosis of homonymous hemianopia precludes diagnosis of neglect - this is not current thinking so must question diagnostic criteria especially with respect to neglect

\section{Risk of bias}

\begin{tabular}{lll}
\hline Bias & Authors' judgement & Support for judgement \\
\hline $\begin{array}{l}\text { Allocation concealment } \\
\text { (selection bias) }\end{array}$ & Unclear risk & Patients were "randomly assigned" but methodology not stated. \\
\hline
\end{tabular}


Rossi 1990 (Continued)

\begin{tabular}{|c|c|c|}
\hline $\begin{array}{l}\text { Blinding (performance } \\
\text { bias and detection bias) } \\
\text { All outcomes }\end{array}$ & High risk & $\begin{array}{l}\text { "the study was not performed in a blinded fashion", however for Tangent } \\
\text { Screen Examination "results were plotted onto templates and judged by ob- } \\
\text { server unaware of the patient's group assignment ..." }\end{array}$ \\
\hline
\end{tabular}

\begin{tabular}{|c|c|c|}
\hline $\begin{array}{l}\text { Incomplete outcome data } \\
\text { (attrition bias) } \\
\text { All outcomes }\end{array}$ & Unclear risk & No incomplete data mentioned \\
\hline Other bias & Low risk & No other sources of bias noted \\
\hline
\end{tabular}

Roth 2009

\section{Study characteristics}

Methods Compensative intervention versus restitutive intervention

Design: RCT

\section{Stratification: no}

Randomisation sequence: paper stated "an equal number of patients assigned randomly to either the EST or the FT group"; and correspondence with the author stated that "the patients were randomized according to a pre-existing list".

Comparisons: 2 groups; compensatory "exploratory saccadic training (EST)" and control ("flicker-stimulation training (FT), which is unlikely to affect visual-search behaviour")

\section{Allocation concealment: no}

Blinding: not stated

Power calculation: no

Intention-to-treat analysis: no

Other recruitment details: participants, aged 18 to 80 years, with post-chiasmatic lesions of greater than 6 months duration and visual field defects that are isolated homonymous hemianopias or quadrantanopias. The study included a mixed population (mainly stroke).

Patient and public involvement: not stated

Participants

Total study population: 30 participants recruited (data analysed for 28)

Withdrawals: "Two FT patients droppped out because of illness and insufficient compliance".

Method of diagnosing VFD: not stated.

Characteristics of population: participant details are listed in Table 2.

Type and severity of visual problems: participant details are listed in Table 3.

Inclusion criteria: visual field defects must not cross the vertical midline, but reach within 5 degrees of it and there must be no other visual field defects, or visual acuity deficit.

Exclusion criteria: other visual field defects, visual acuity less than 0.6 (20/33), other diseases of eye or brain, motor impairments hampering computer use, other neurologic impairments (particularly epilepsy or hemineglect)

Baseline comparison of treatment groups: "The groups did not differ regarding age, diagnoses or duration of disease". 
Roth 2009 (Continued)

This study included a mixed population (mainly stroke). Group 1: 15 participants (12 stroke or haemorrhage, 3 other), Group 2: 15 participants (14 stroke or haemorrhage, 1 other)

This study included patients with visual field defects only (no visual neglect).

Method of diagnosing visual perceptual problems: clock drawing and line bisection test

Interventions

Group 1: explorative scanning training $(n=15)$

Intervention: computer-based scanning training

Intervention type: compensation

Materials: laptop. Where can materials be accessed? "A custom software program (Borland Delphi 7.0) was used to generate a random array of digits....". Procedures: random digits were presented with equal distribution in blind and seeing fields: patients had to find these digits with positive feedback provided for a correctly found number. Provided by: not stated. Delivery: face-to-face, individual, location home-based training (Table 1). Regimen: training was performed for 30 minutes, twice per day, 5 days per week for 6 weeks at home, on a laptop set at $30 \mathrm{~cm}$. Tailoring: no. Modification: no. Adherence: protocols were used to attempt to ensure standardisation and patients were instructed to avoid head movements. However, it is not know whether this standardisation and instructions were adhered to. There may, therefore, be some inconsistencies in the delivery of the intervention. Errors in aspects such as laptop position, etc. could impact on the position of the stimuli viewed and subsequently the explorative eye movements.

Group 2: flicker-stimulation training $(n=15)$

Intervention: computer-based training, "designed to stimulate the blind hemifield"

Intervention type: restitution (note - author stated this is 'potential' restitution training)

Materials: laptop. Where can materials be accessed? "Borland Delphi 7.0 was used to generate the flicker stimulus". Procedures: letters flickering at $10 \mathrm{~Hz}$ were presented at 21.8 degrees eccentricity, with proportion 3:1 blind:seeing field. Participant to maintain central fixation but identify peripheral letter: positive feedback given of correctly identified letter. Provided by: not stated. Delivery: "The patients trained at home, using our laboratory's laptops to ensure standard training conditions (screens, fixed viewing distance, and visual-field area trained)" (Table 1). Regimen: training was performed for 30 minutes, twice per day, 5 days per week for 6 weeks at home, on a laptop set at $30 \mathrm{~cm}$. Tailoring: no. Modification: no. Adherence: patients were instructed to fixate. There appears to have been no attempt to control or measure fixation.

Outcomes See Table 4

Digit search task (response time)

Natural search task (response time)

Natural scene exploration and fixation stability (video eye tracker)

Perimetry (Tubinger automated perimeter)

Reading speed

QoL - World Health Organisation questionnaire WHOQOL-BREF

Time points when outcomes were assessed: baseline, post-treatment, follow-up

Notes

Inclusion criteria stated visual field defect with "duration exceeding 6 months". However, 1 patient in group 2 was reported to have a 4-month-old homonymous hemianopia. Possibility of spontaneous recovery. Furthermore, this discrepancy casts doubt on the application of the selection criteria. 
Roth 2009 (Continued)

\begin{tabular}{|c|c|c|}
\hline Bias & Authors' judgement & Support for judgement \\
\hline $\begin{array}{l}\text { Allocation concealment } \\
\text { (selection bias) }\end{array}$ & Unclear risk & $\begin{array}{l}\text { Correspondence with the author stated that "the patients were informed } \\
\text { that probably each method could be effective, one by eye movement training } \\
\text { (EST), the other by visual field stimulation (FT). FT was supposed to be a po- } \\
\text { tential restitution training. Therefore, the patients of both groups performed a } \\
\text { potentially effective training - but with quite different approaches". }\end{array}$ \\
\hline
\end{tabular}

\begin{tabular}{|c|c|c|}
\hline $\begin{array}{l}\text { Blinding (performance } \\
\text { bias and detection bias) } \\
\text { All outcomes }\end{array}$ & Unclear risk & $\begin{array}{l}\text { No details in the paper or by contacting the author of whether or how assessor } \\
\text { was blinded }\end{array}$ \\
\hline $\begin{array}{l}\text { Incomplete outcome data } \\
\text { (attrition bias) } \\
\text { All outcomes }\end{array}$ & High risk & $\begin{array}{l}\text { Stated "two FT (Group 2) patients dropped out because of illness and insuffi- } \\
\text { cient compliance. Finally data from } 15 \text { EST and } 13 \text { FT patients were included". } \\
\text { Data from these participants were included in baseline characteristics, but not } \\
\text { included in final analyses. }\end{array}$ \\
\hline
\end{tabular}

Other bias Low risk No other cause of bias noted

Rowe 2010

\title{
Study characteristics
}

Methods

\author{
Substitutive intervention versus compensative intervention versus control, placebo or no inter- \\ vention
}

Design: "Randomized controlled, multicentre pilot trial"

Stratification: "Randomization lists were generated using block randomization stratified by centre and degree of hemianopia (partial or complete) with treatment allocation ratio of 1:1:1."

Randomisation sequence: "Participants were individually randomized to one of three treatment groups using a secure (24-hour) web-based randomization programme."

Comparisons: 3 groups: Group 1 - Fresnel prisms; Group 2 - visual search training; Group 3 - control (standard care/information only)

Allocation concealment: treatment allocation was disclosed to the patient by the treating clinician: "The local PI (orthoptist) obtained the treatment allocation and subsequently assigned the participant to the treatment arm."

Blinding: outcome assessors for visual field assessment and reading speed were blind to treatment allocation. "due to the nature of the intervention, it is not possible to blind other study personnel or the participant."

Power calculation: no - pilot trial; designed to enable sample size calculation for future trials

Intention-to-treat analysis: "Outcome data were analysed according to the intention-to-treat principle."

Other recruitment details: "Participants were recruited from stroke units based in 15 United Kingdom (UK) National Health Service (NHS) trusts. Potentially eligible participants were identified by stroke research nurses, and screened for inclusion by a local principal investigator (a qualified orthoptist registered with the Health and Care Professions Council, UK). Participants eligible for inclusion, and providing consent, attended for a baseline assessment, which included assessment and documentation of patient demographics, visual signs and symptoms, visual acuity measures, any additional ocular problems, comorbidity, severity of stroke and level of disability". 
Patient and public involvement: protocol stated: "This trial has involved a stroke survivor directly in the development of this protocol (JR) and will liase closely with her for advice and direction throughout the conduct of the trial and in the dissemination process. Involvement of stroke survivors in oversight committees is also planned for this trial".

Participants

Total study population: 87 participants randomised. 71 participants at 26-week follow-up

Withdrawals: 2 "complete withdrawal" ("patients withdrawn from all data analysis and follow-up"). 9 "partial withdrawal" ("patients withdrawn from follow-up"). 5 loss to follow-up

Method of diagnosing VFD: "Stable homonymous hemianopia (partial or complete) induced by recent stroke, defined following WHO guidelines". "The visual field assessment will be conducted by a qualified Orthoptist at baseline and at the 6-week, 12-week and 26-week follow-up visits. An Esterman strategy is to be used for quantitative visual field assessment. This can be performed using either: The Esterman programme on Humphrey or Octopus perimetry; The III4e target on Goldmann with additional checks of static points in the central visual field."

Characteristics of population: participant details are listed in Table 2.

Type and severity of visual problems: participant details are listed in Table 3.

Inclusion criteria: "a. 18 years of age or older; b. best corrected visual acuity of 0.5 or better in each eye at distance; c. stable homonymous hemianopia (partial or complete) induced by recent stroke, defined following WHO guidelines, present over 2 weeks (to exclude rapid recovery cases) but less than 26 weeks prior to randomization; $d$. refractive error within \pm 5 dioptres; e. willing and able to give consent for the study; f. prior to stroke able to read and understand English."

Exclusion criteria: "a. unable to consent due to severe cognitive impairment; b. assessed to have ocular motility impairment and/or visual inattention in addition to the visual field impairment; or c. had pre-existent visual field impairment due to previous stroke."

Baseline comparison of treatment groups: "There were no notable differences at baseline between three arms."

This study included patients with visual field defects only (no visual neglect).

Method of diagnosing visual perceptual problems: "as assessed by the orthoptist"

Interventions

Group 1: prisms $(n=27)$

Intervention: Fresnel prisms (40 prism dioptre strength)

Intervention type: substitution

Materials: "Participants were assessed and given sector Fresnel prisms of 40 prism dioptre strength on their glasses (or plain glasses if not already worn). Separate prism segments were used as a mechanical displacement to expand the upper and lower quadrants." Where can materials be accessed? In the UK: NHS supplies for Fresnel prisms. Procedures: "The participant will be instructed to maintain central fixation through their glasses. They will then be instructed to use head movements to explore their field to the affected side when they become aware of an object of interest through the prism. The first prism will be placed at the participant's first visit; if possible the second prism will also be fitted at this time. However, if the participant is not comfortable with both prisms being fitted at once, the second prism can be placed at a second visit ( 2 weeks later, \pm 1 week) if no adaptation difficulties to the first prism have occurred. If adaption difficulties have occurred the patient can continue with only the first prism and this will be captured on the case report forms." Provided by: orthoptist. Delivery: faceto-face, clinic location (patients could be in or outpatients). (Table 1) Regimen: "The prisms should be worn for a minimum of $2 \mathrm{~h}$ daily from prism affixation until 6-week follow-up visit as a minimum, after this the patient can elect to continue treatment if they wish." Tailoring: no. Modification: no. Adherence: "There were 73 protocol deviations in 58 patients ( $68.2 \%$ overall: $77 \%$ in the Fresnel prisms arm, $93 \%$ in the visual search arm and $34.5 \%$ in the standard care arm). The majority of deviations ( $\mathrm{n}=$ $41,56.2 \%$ ) related to lack of compliance in the intervention arms (e.g. prism not worn a minimum of 2 hours daily for 6 weeks or visual exercises not carried out for 30 minutes daily for 6 weeks). Compliance 
level was similar across the intervention arms. Patients in the Fresnel prisms arm wore the prisms during 27 days on average."

Group 2. scanning training $(n=30)$

Intervention: "visual search training"

Intervention type: compensatory (scanning) training

Materials: "Comprised an A4 landscape card with horizontal and diagonal numbered circles radiating out from a central fixation target." Where can materials be accessed? From author. Procedures: "The participant will be instructed to hold this at a distance of 8 inches from their eyes (to ensure a wide field of vision is utilised), glasses can be worn as required. Participants will be asked to transfer gaze quickly between printed targets on the A4 card. The targets are printed off centre to the right and left sides along the horizontal as well as oblique planes to ensure stimulation of a wide area in the blind and seeing parts of the visual field." Provided by: instructions provided by orthoptist. Training carried out at home by patients. "Participants will be instructed on the scanning exercises following randomisation to ensure their understanding of the procedure of doing this training. In addition, printed instructions will be provided with the visual training target card". Delivery: home (self-adminstered) (Table 1). Regimen: "Participants will be instructed to continually scan between the various targets for 30 min daily from baseline until their 6-week follow-up, after which they can elect to continue treatment if they wish." Tailoring: no. Modification: no. Adherence: "There were 73 protocol deviations in 58 patients (68.2\% overall: $77 \%$ in the Fresnel prisms arm, $93 \%$ in the visual search arm and $34.5 \%$ in the standard care arm). The majority of deviations ( $n=41,56.2 \%)$ related to lack of compliance in the intervention arms (e.g. prism not worn a minimum of 2 hours daily for 6 weeks or visual exercises not carried out for 30 minutes daily for 6 weeks). Compliance level was similar across the intervention arms ... patients in the visual search training arm followed the visual search exercises 28 days on average."

Group 3: standard care $(n=30)$

Intervention: advice only ("all three arms will receive the same information leaflets")

Intervention type: control

Materials: "Participants were given information leaflets from the UK Stroke Association and the UK Royal National Institute for the Blind about visual impairment following stroke." Where can materials be accessed? UK Stroke Association and the UK Royal National Institute for the Blind. Procedures: standard care. Provided by: NA. Delivery: NA (Table 1). Regimen: NA. Tailoring: NA. Modification: NA. Adherence: NA

Outcomes

See Table 4

Visual field assessment

Reading ability (Radner reading test)

Visual function questionnaire (VFQ 25-10)

Rivermead mobility index

Nottingham extended activities of daily living assessment

ED-5Q (a standardised instrument for measuring health outcome)

Short Form-12 (SF-12)

Adverse events

Time points when outcomes were assessed: baseline, 6-week, 12-week, and 26-week follow-up 
Rowe 2010 (Continued)

\begin{tabular}{|c|c|c|}
\hline Bias & Authors' judgement & Support for judgement \\
\hline $\begin{array}{l}\text { Allocation concealment } \\
\text { (selection bias) }\end{array}$ & Low risk & $\begin{array}{l}\text { "Participants were individually randomized to one of three treatment groups } \\
\text { using a secure (24-hour) web-based randomization programme. Randomiza- } \\
\text { tion lists were generated using block randomization stratified by centre and } \\
\text { degree of hemianopia (partial or complete) with treatment allocation ratio of } \\
\text { 1:1:1. The local PI (orthoptist) obtained the treatment allocation and subse- } \\
\text { quently assigned the participant to the treatment arm." }\end{array}$ \\
\hline
\end{tabular}

Blinding (performance Low risk

bias and detection bias)

Participants and clinical personnel unable to be blinded due to the nature of

All outcomes the intervention. Blinded outcome assessors

Incomplete outcome data Low risk

Incomplete data all accounted for. Intention-to-treat analysis (where possible)

(attrition bias)

All outcomes

Other bias Low risk No other cause of bias noted

Schuett 2012

\title{
Study characteristics
}

Methods

\author{
Compensative intervention versus compensative intervention \\ Design: randomised cross-over trial \\ Stratification: no \\ Randomisation sequence: "randomly allocated" \\ Comparisons: 2 groups, Group A (VET followed by RT) and Group B (RT followed by VET) \\ Allocation concealment: not stated \\ Blinding: not stated \\ Power calculation: not stated \\ Intention-to-treat analysis: not stated \\ Other recruitment details: not stated \\ Patient and public involvement: not stated
}

Participants

Total study population: $36:$ Group A: 17/18 stroke and Group B: 17/18 stroke. The study included a mixed population.

\section{Withdrawals: none}

Method of diagnosing VFD: not stated

Characteristics of population: participant details are listed in Table 2.

Type and severity of visual problems: participant details are listed in Table 3.

Inclusion criteria: not stated (although the authors reported that "none of the patients had visual neglect as assessed by tests in accordance with the Behavioural Inattention Test (line bisection, letter and star cancellation, figure and shape copying, drawing from memory; Halligan 1991)." and "All patients were native German speakers and had at least 5 years of education. All patients complained of moder- 

domains".

Exclusion criteria: cerebral visual disorders, including reduced visual acuity $(<0.90$ for near and far binocular vision), impaired spatial contrast sensitivity (Vistech contrast sensitivity test, 1988), visual adaptation, disturbances of the anterior visual pathways or of the oculomotor system, macular disease (according to ophthalmologic examination), aphasia, premorbid reading disorders, pure alexia (vertical word reading test; Zihl 1995; Zihl 2011), impairments of visual-lexical numerical processing (horizontal and vertical number reading; Zihl 1995; Zihl 2011), or verbal memory deficits

Baseline comparison of treatment groups: none ("before treatment, there were no differences between groups either for demographic and clinical variables or for reading and visual exploration performance".) However, more participants with hemianopia in Group A compared with Group B (Table 3)

This study included patients with diagnoses other than stroke.

This study included patients with visual field defects only (i.e no neglect).

Method of diagnosing visual perceptual problems: "Behavioural Inattention Test (line bisection, letter and star cancellation, figure and shape copying, drawing from memory; Halligan 1991)."

Interventions
Group 1: visual exploration training (VET) $(n=18)$

Intervention type: compensation

Intervention: "Visual exploration training: for improving visual exploration, we used standardized versions of the visual search paradigm (parallel and serial search mode)."

Materials: software-based reading and visual exploration training programmes (developed by Zihl 2011); training material was presented using a LCD monitor with a stimulus display.

Where can materials be accessed? not stated (but references provided). Procedures: "Patients were systematically trained to use larger saccadic eye movements to gain a quick complete visual overview as well as to develop and use a more efficient oculomotor visual exploration or scanning strategy that can be flexibly adapted to the visual-spatial structure of the respective scene or environment. Training material consisted of visual search displays extending $50^{\circ}$ horizontally and $42^{\circ}$ vertically. We used different target and distractor letters of varying similarity as stimuli. Stimulus size was $2.5^{\circ}$, and we used the same colours for the training material and the monitor background as in the reading training. Each training trial was composed of the presentation of a visual search display. Patients were instructed to fixate on a cross in the centre of the monitor and to search, after its offset, for a single target letter (e.g. 'T') among distractor letters (e.g. 'O's) as accurately and quickly as possible. In target-present trials, the patient was asked to press the left mouse button, in target-absent trials, the right mouse button. Presentation and, thus, visual search time was unlimited (exhaustive visual search)." Provided by: treatment was administered and supervised by the experimenter. No details about the training or experience of the experimenter.Delivery: not clear (Table 1). Regimen: "An individual training session lasted $\sim 45$ min consisting of 10-15 practice units ( 20 trials each) and short or, if required, longer breaks between units. Training was completed when patients reached a defined criterion (at least $90 \%$ correct responses) for any level of difficulty used. Patients required on average 12 training sessions, which were carried out within 2-3 weeks for each patient. ...Visual exploration training: Group A: 12.3 sessions (SD 3.4)." Tailoring: "In addition to varying letter similarity during the course of training, visual search difficulty was also systematically increased by increasing the visual display size, i.e. the number of stimuli, not the display area (15-20-item displays). This training protocol was adjusted to individual reading performance and training progress. Modification: (see tailoring). Adherence: "Training was completed when patients reached a defined criterion (at least $90 \%$ correct responses) for any level of difficulty used".

Group 2: reading training $(R T)(n=18)$

Intervention type: compensation

Intervention: reading training 


\begin{abstract}
Materials: "The treatment was performed using the software-based reading and visual exploration training programmes as developed by Zihl 2011; training protocol and procedure were similar to our previous studies (Schuett 2008; Zihl 1995; Zihl 2011). Training material was presented using a LCD monitor with a stimulus display extending 50! horizontally and 42! vertically at a viewing distance of 115 $\mathrm{cm}$." Where can materials be accessed? not stated. Procedures: "single words of different lengths, ranging from 3 to 12 letters, were used as training material. Letter and digit size was 2.5, and width subtended $1^{\circ}$; spacing between letters (text material) was $0.4^{\circ}$. We used yellow for the training material and a dark blue for the background. These size and colour specifications have been shown to allow for comfortable reading and oculomotor training (Schuett 2008; Zihl 1995; Zihl 2011). Each training trial was composed of the time-limited presentation of one single word in the centre of the screen. Patients were instructed to perceive each word as a whole before reading it aloud by intentionally shifting their gaze, as quickly as possible, from the screen's centre to the beginning (in cases with left-sided visual field loss) or to the end (in cases with right-sided visual field loss) of each word. This paradigm allows reading-related eye movements to be trained and reinforced by the patient's normal internal visual feedback and feedback given by the experimenter. During the course of training, the length of the presented words was systematically increased from 3- to 13-letter words. When a patient was able to read at least $90 \%$ of the words of a given length correctly, presentation time was reduced from 1000 $\mathrm{ms}$ to $300-400 \mathrm{~ms}$. The final training stage involved the randomized presentation of words of different lengths. By adopting this procedure, patients were forced to make quicker and more efficient saccades in order to perceive and read the whole word before its disappearance. In addition, patients learned to flexibly adjust the size of saccades according to word length". Provided by: treatment was administered and supervised by the experimenter. No details about the training or experience of the experimenter. Delivery: not clear (Table 1). Regimen: "an individual training session lasted $\sim 45 \mathrm{~min}$; it consisted of 10 practice units ( 30 trials each) and short or, if required, longer breaks between units. Training was completed when patients reached a defined criterion (at least $90 \%$ correct responses) for any level of difficulty used. Patients required on average 12 training sessions, which were carried out within 2-3 weeks for each patient ... Group B (12.6 sessions, SD 2.4)." Tailoring: "training protocol was adjusted to individual reading performance and training progress". Modification: not stated. Adherence: "Training was completed when patients reached a defined criterion (at least $90 \%$ correct responses) for any level of difficulty used".
\end{abstract}

\author{
See Table 4 \\ Reading test (reading time and errors) \\ Visual exploration (cancellation task - time and errors) \\ Visual field assessment (Kinetic perimetry using a standard Tubingen perimeter)
}

Time points when outcomes were assessed: this was a cross-over trial. Time points before the cross-over were: $\mathrm{T} 1$, initial assessment; $\mathrm{T} 2$, before treatment; $\mathrm{T} 3$, after the first training component. (Additional time points - after the cross-over were: T4, after the second training component; T5, after a follow-up interval). "Visual field assessment was carried out before and after treatment (T2 and T4)."

Notes

\section{Risk of bias}

\begin{tabular}{lll}
\hline Bias & Authors' judgement & Support for judgement \\
\hline $\begin{array}{l}\text { Allocation concealment } \\
\text { (selection bias) }\end{array}$ & Unclear risk & $\begin{array}{l}\text { Stated "randomly allocated". No further details on method of randomisation } \\
\text { or concealment }\end{array}$ \\
\hline $\begin{array}{l}\text { Blinding (performance } \\
\text { bias and detection bias) } \\
\text { All outcomes }\end{array}$ & Unclear risk & $\begin{array}{l}\text { It was unclear whether there was participant and/or outcome assessor blind- } \\
\text { ing. However the "experimenter" delivered the intervention, and may there- } \\
\text { fore have taken the outcome measures. }\end{array}$ \\
\hline
\end{tabular}

Incomplete outcome data Unclear risk No flow diagram, and no details of recruitment or retention


Schuett 2012 (Continued)

Other bias Low risk No other issues noted

Spitzyna 2007

\section{Study characteristics}

Methods

\section{Compensative intervention versus control, placebo or no intervention}

Design: randomised cross-over trial.

Stratification: "Because of the small number of patients entering the study, we wished to ensure that the two treatment groups did not become unbalanced on a few key variables so patients were allocated using a modified minimization technique where cumulative measures of two factors (text reading speed ( $\leq 90$ or $>90$ wpm) and degrees of sparing of right foveal/parafoveal ( 0 or 2 degrees) vision) were used to minimize the difference between the two groups."

Randomisation sequence: modified minimisation technique: "The weighting used for allocation to the group with the lowest total was one. We describe the minimisation as modified because the first subject was not allocated randomly to either group, but deterministically placed in Group 1."

Comparisons: "Two-armed study with two therapy blocks in each arm: one group practiced reading moving text (MT) that scrolled from right-to-left, daily for two four week blocks (group 1), while the other had sham therapy (spot-the-difference) for the first block and then crossed over to MT for the second."

Allocation concealment: personal communication with authors: "The allocation was concealed from the persons recruiting into the study but not from the tester. The recruiter(s) did not know that the first subject would be placed in group 1 but the tester did".

Blinding: personal communication with authors: "The tester was the first author (a psychologist). She was not blind to the therapy. It was not possible to blind her to this as it was a behavioural therapy and she was 'dispensing' this at each time point."

Power calculation: no

Intention-to-treat analysis: no

Other recruitment details: not stated

Patient and public involvement: not stated

Withdrawals: "three dropped out before completing therapy".

Method of diagnosing VFD: "Perimetry was performed twice, before and after completion of the therapy blocks ( $B$ and T4). Static fields were measured using the automated Humphrey field analyser II (Carl Zeiss Group, California, USA) analysis of the central 10 degrees of vision (central 10-2 threshold test). Dynamic fields were also measured using a Goldmann perimeter (Haag Streit, Köniz, Switzerland) when there were concerns over subject's performance with the automated procedure (a false positive or false negative response rate greater than $15 \%$ ). The procedures for determining the amount of field sparing were as reported previously. In the event of a discrepancy between the static and dynamic fields or preand post-therapy changes, the opinion of the orthoptist who performed the tests (Ms Bronia Unwin) was sought. The precision of the static perimerty is two degrees and all the patients fell into one of two groups, either 0 or 2 degrees spared to the right of fixation."

Characteristics of population: participant details are listed in Table 2.

Type and severity of visual problems: participant details are listed in Table 3. 
Inclusion criteria: not stated, but described as "participants with fixed homonymous right-sided visual field defect that interfered with reading (hemianopic alexia)." "All the patients had a fixed homonymous defect that had been present for at least 3 months".

\section{Exclusion criteria: not stated}

Baseline comparison of treatment groups: some discrepancies between baseline characteristics of groups. Length of time since symptom onset - all participants in Group 1 were over 1 year since onset of symptoms; 4 participants in Group 2 were less than 1 year since onset ( 3 are 6 months or less). Average age at time of symptom onset was 43 years for group 1 (range 5 to 67 years) and 63 years for group 2 (range 39 to 78 years). "There were no differences between the groups on all of the variables" for general neuropsychological assessments.

The study included a mixed population.

This study included patients with visual field defect only (no visual neglect).

Method of diagnosing visual perceptual problems: not stated

Interventions
Group 1: optokinetic nystagmus inducing reading therapy $(n=11)$

Intervention type: compensation

Intervention: horizontal scrolling text from right to left to "induce small-field optokinetic nystagmus"

Materials: "The tapes were made by animating freely available text from a variety of Sherlock Holmes stories (www.citsoft.com/holmes3.html) across a computer screen from right-to-left (i.e. horizontal motion was from the patients' blind field into their seeing field), so-called Times Square presentation. After some minor preparations, such as deleting hyphens and adding a few spaces after each sentence, custom-written software was used to animate the text across the screen at a variable rate. The output from the graphics card was connected to the video-input on a VHS video recorder to produce the tapes. Tape speeds of: $85,105,143,173,205,240$, and 275 wpm were made with the text presented in Times New Roman font, 24-point, black on white, scrolling across the middle of the screen." Where can materials be accessed? not stated. Procedures: participants were instructed to read and try to follow a line of text scrolling horizontally from right to left in the middle of a computer screen at speeds of 85 to 275 words per minute. "Patients were instructed to read the story on the tapes and try to follow it, although no tests of comprehension were made to check this." Provided by: not stated. Delivery: not clear. Patient-led therapy. (Table 1). Regimen: "treatment blocks lasted for 4 weeks each" and participants were asked to record how long they spent on the tasks each day. "The aim was to achieve a minimum of 400 minutes of rehabilitation (20 sessions $x 20$ minutes) over approximately 4 weeks". Tailoring: "patients contacted one of us (G.A.S.) when they required a new (usually faster) tape." Modification: no. Adherence: "There were no differences between the two groups in total time spent on rehabilitation tasks across both treatment blocks in minutes (range), 914 (865-955); 901 (840-1000), t-test, t (10) $0.50, P=0.628 "$.

Group 2: control $(n=11)$

Intervention type: control

Intervention: sham training; "spot the difference"

Materials: "'Spot-the-difference' tests were taken from a children's puzzle booklet; the original cartoons were altered to remove text. The number of differences on each page varied between eight and 12."

Where can materials be accessed? not stated. Procedures: "Patients were instructed to look for as many differences as possible between the two pictures, but were not told how many to expect, completing at least two cartoons over $20 \mathrm{~min}$. Between 40 to 60 examples were selected randomly for each patient (out of a total of the 70 prepared tests), depending on their speed." Provided by: not stated. Delivery: not clear. Patient-led therapy. (Table 1). Regimen: "treatment blocks lasted for 4 weeks each" and participants were asked to record how long they spent on the tasks each day. "The aim was to achieve a minimum of 400 minutes of rehabilitation (20 sessions $x 20$ minutes) over approximately 4 weeks". Tailoring: not stated. Modification: no. Adherence: "There were no differences between the 
Spitzyna 2007 (Continued)

two groups in total time spent on rehabilitation tasks across both treatment blocks in minutes (range),

914 (865-955); 901 (840-1000), t-test, t (10) 0.50, P = 0.628"

See Table 4
Text reading speeds (passages from Neale analysis of reading)
Single word reading speeds (words taken from MRC psycholinguistic battery)
Eye movement characteristics - spatial characteristics of saccadic amplitude, incoming saccade ampli-
tude and landing position
- temporal characteristics
Perimetry - Humphrey field analyser
- Goldmann perimetry
Time points when outcomes were assessed: T1, initial assessment; T2, before treatment; T3, after the
first training component. (Additional time points - after the cross-over were: T4, after the second train-
ing component; T5, after a follow-up interval)

Notes

Did not state whether visual correction using glasses was used during training or testing.

\title{
Risk of bias
}

\begin{tabular}{|c|c|c|}
\hline Bias & Authors' judgement & Support for judgement \\
\hline $\begin{array}{l}\text { Allocation concealment } \\
\text { (selection bias) }\end{array}$ & Low risk & $\begin{array}{l}\text { Modified minimisation technique of sequence generation. Personal communi- } \\
\text { cation with authors: "The allocation was concealed from the persons recruit- } \\
\text { ing into the study but not from the tester. The recruiter(s) did not know that } \\
\text { the first subject would be placed in group } 1 \text { but the tester did". }\end{array}$ \\
\hline $\begin{array}{l}\text { Blinding (performance } \\
\text { bias and detection bias) } \\
\text { All outcomes }\end{array}$ & High risk & $\begin{array}{l}\text { Personal communication with authors: "The tester was the first author (a psy- } \\
\text { chologist). She was not blind to the therapy. It was not possible to blind her to } \\
\text { this as it was a behavioural therapy and she was 'dispensing' this at each time } \\
\text { point." }\end{array}$ \\
\hline $\begin{array}{l}\text { Incomplete outcome data } \\
\text { (attrition bias) } \\
\text { All outcomes }\end{array}$ & High risk & $\begin{array}{l}\text { "Three patients dropped out before completing therapy" (all from group 2) } \\
\text { and "data from these subjects were excluded from analyses" }\end{array}$ \\
\hline Other bias & Low risk & No other potential bias noted \\
\hline
\end{tabular}

\section{Szlyk 2005}

\section{Study characteristics}

Methods

\author{
Substitutive intervention versus substitutive intervention \\ Design: randomised cross-over design \\ Stratification: not stated \\ Randomisation sequence: "randomly assigned" but method not given \\ Comparisons: participants in Group 1 received Gottlieb prism during the first 3-month phase of the \\ study, and participants in Group 2 received Fresnel prisms during the first 3-month phase of the study. \\ Participants then crossed over to receive the other treatment.
}


Szlyk 2005 (Continued)

\author{
Allocation concealment: not stated \\ Blinding: not stated \\ Power calculation: not stated
}

Intention-to-treat analysis: not stated

Other recruitment details: not stated

Patient and public involvement: not stated

Participants

Total study population: 10 participants.

Withdrawals: no information ( 7 participants provided follow-up data at 2 years - 3 could not be contacted)

Method of diagnosing VFD: not stated.

Characteristics of population: participant details are listed in Table 2.

Type and severity of visual problems: participant details are listed in Table 3.

Inclusion criteria: stated "The patients were screened to include patients with only occipital lobe strokes". Participants described as having "Hemianopsia because of cerebral vascular accidents". All included participants were male, but unclear if this was an inclusion criterion.

Exclusion criteria: not stated.

Baseline comparison of treatment groups: yes

The study included a mixed population.

It was assumed that participants did not have neglect (as this is unlikely in occipital lesions).

Method of diagnosing visual perceptual problems: not stated - it was not stated whether the patients may have had visual neglect (although neglect is unlikely in occipital lesions)

Interventions

Group 1: Gottlieb Visual Field Awareness System (VFAS) $(n=5)$

Intervention type: substitution

Intervention: Gottlieb VFAS prism

Materials: 18.5 dioptre Gottlieb VFAS prism

Where can materials be accessed? "Rekindle(R), Stone Mountain, GA, USA". Procedures: 18.5 dioptre Gottlieb VFAS prism drilled into one lens. Positioned just off pupil centre - generally on the same eye as side of field loss, on same side as field loss, base out. Provided by: low-vision specialist for laboratory and outdoor training, kinesiotherapist for on-road training. Delivery: laboratory and out-door training within university grounds, and on-road (driving) training on a road course within a medical centre (Table 1). Regimen: training of $4 \times 2$ to 3 -hour sessions indoors with low vision specialist and $8 \times 2$ hour outdoor sessions behind the wheel. The lenses were then worn for 3 months. Tailoring: not stated. Modification: not stated. Adherence: no information (whether prism was still worn at time of follow-up was recorded as never/occasionally/frequently)

Group 2: Fresnel prisms $(n=5)$

Intervention type: substitution

Intervention: Press-OnTM Fresnel 20 Diopter Prisms

Materials: Press-OnTM Fresnel 20 Diopter Prisms. Where can materials be accessed? "3M Health Care, St. Paul, MN, USA". Procedures: 20 dioptre press-on Fresnel prisms attached to posterior surface of 1 spectacle lens. Positioned just off pupil centre - generally on the same eye as side of field loss, on same 
Szlyk 2005 (Continued)

side as field loss, base out. Provided by: low-vision specialist for laboratory and outdoor training, kinesiotherapist for on-road training. Delivery: laboratory and out-door training within university grounds, and on-road (driving) training on a road course within a medical centre (Table 1). Regimen: training of $4 \times 2$ to 3 hour sessions indoors with low-vision specialist and $8 \times 2$-hour outdoor sessions behind the wheel. The lenses were then worn for 3 months. Tailoring: not stated. Modification: not stated. Adherence: no information (whether prism was still worn at time of follow-up was recorded as never/occasionally/frequently)

\begin{tabular}{ll}
\hline Outcomes & See Table 4 \\
Goldmann visual field & Visual acuity \\
Contrast sensitivity & Lab assessment - indoor functional assessment \\
Outdoor function assessment \\
Driving skills assessment - indoor and on-road \\
Pyschophysical assessment \\
- attentional visual acuity \\
- attentional motion sensitivity \\
Self-report (satisfaction)
\end{tabular}

Time points when outcomes were assessed: before and after each cross-over. Continued use of devices assessed at 2-year follow-up

Notes

1. Data were presented after the cross-over, for both groups combined - no first phase data were available.

2. Stated: "For each assessment task for each individual in the test-retest period, we computed the change in score from the initial baseline testing to the repeat baseline testing. We then averaged these change scores across subjects for each task". For each task If the change from baseline to training exceeded the test-retest change it was scored as 'improved', if it was less than or equal it was scored as 'no change'. The sum of improved tasks across the test battery was then computed.

\section{Risk of bias}

\begin{tabular}{lll}
\hline Bias & Authors' judgement & Support for judgement \\
\hline $\begin{array}{l}\text { Allocation concealment } \\
\text { (selection bias) }\end{array}$ & Unclear risk & $\begin{array}{l}\text { Stated "randomly assigned into one of two experimental groups" but no de- } \\
\text { tails of method provided }\end{array}$ \\
\hline $\begin{array}{l}\text { Blinding (performance } \\
\text { bias and detection bias) } \\
\text { All outcomes }\end{array}$ & Unclear risk & No details of blinding included \\
\hline $\begin{array}{l}\text { Incomplete outcome data } \\
\text { (attrition bias) } \\
\text { All outcomes }\end{array}$ & Unclear risk & $\begin{array}{l}\text { No incomplete data issues apparent, however, scores have been combined so } \\
\text { it is difficult to tell if there are any missing outcomes. }\end{array}$ \\
\hline Other bias & Low risk & No other cause of bias noted \\
\hline
\end{tabular}

$A B / B A$ : refers to order of interventions within cross-over trial, where $A$ and $B$ denote different interventions and $A B$ or $B A$ the order of delivery 
ACS: alternating current stimulation

ADL: activities of daily living

ARV: area of residual vision

AVT: audiovisual exploration training

$\mathrm{cd} / \mathrm{m} 2$ : candela per square meter (standard unit of luminance)

CNS: central nervous system

$\mathrm{CT}$ : computerised tomography

CVA: cerbrovascular accident

EEG: electroencephalogram

EQ-5D:standardised EuroQol health-related quality of life instrument

FIM: Functional Independence Measure

FT: flicker stimulation training

HRP: high resolution perimetry

HVFD: homonymous visual field defect

IH-CST: InSight Hemianopia - Compensatory Scanning Training

IVI: impact of visual impairment

LCD: liquid crystal display (high definition monitor)

LEDs: light emitting diodes

LV-VFQ: Low Vision - Visual Function Questionnaire

MMSE: Mini Mental State Examination

MRC: Medical Research Council

MRI: magnetic resonance imaging

MT: moving text

$\mathrm{n}$ : number

NA: not applicable

NEI-VFQ: National Eye Institute Visual Function Questionnaire

OT: occupational therapy

$\mathrm{PI}$ : principal investigator

QoL: quality of life

$\mathrm{RCT}$ : randomised controlled trial

RT: restitution therapy

SD: standard deviation

SF-12: Short-Form Health Survey

T1/T2/T3/T4/T5: outcome asssessment timepoint 1, 2, 3, 4 or 5

TAP: Tubinger automated perimetry

$\mathrm{TBI}$ : traumatic brain injury

tDCS: transcranial direct current stimulation

TL: tube luminescent

VET: visual exploration training

VFAS: visual field awareness system

VFD: visual field defect

VFQ-25: visual functioning questionnaire

VIS: Visual In Stroke (study name)

VRT: vision restoration therapy

VST: visual stimulation training

WHOQOL-BREF:

wpm: words per minute

Characteristics of excluded studies [ordered by study ID]

Study Reason for exclusion

Akinwuntan 2005

The protocol for this review was to include "any intervention that is specifically targeted at improving the visual field defect, or improving the ability of the participant to cope with the visual field loss". Although this randomised controlled intervention study did measure visual, neurophysical and driving outcomes, the intervention targeted a person's decreased ability to drive, not specifically due to their visual field defect, but by all the "motor, visual, cognitive, and perceptual deficits ... experienced after stroke", and thus was ineligible.

Akinwuntan $2010 \quad$ Not VFD




\begin{tabular}{|c|c|}
\hline Study & Reason for exclusion \\
\hline Akinwuntan 2012 & Not VFD \\
\hline Alber 2015 & Not RCT \\
\hline Beasley 2013 & Not VFD \\
\hline Bowers 2012 & Not RCT \\
\hline Braga 2018 & Not RCT \\
\hline Brandt 2009 & Not RCT \\
\hline Brigui 2014 & Not RCT \\
\hline Cameirao 2012 & Not vision \\
\hline
\end{tabular}

Excluded from updated version because participants were not confirmed to have visual field defects: this study included 33 participants, all of whom had a diagnosis of stroke. The 2011 version stated: "this study did not diagnose visual field defects but instead relied on clinical identification of a 'visual scanning problem'. Visual scanning problems are likely to be due to visual neglect as well as visual field defects, thus we have to assume that the participants in this study had a combination of problems. However, it could be possible that the participants had visual neglect problems but not visual field defects, and vice versa."

Carter 1988

The protocol for this review was to include "any intervention that is specifically targeted at improving the visual field defect, or improving the ability of the participant to cope with the visual field loss". The intervention in this study was cognitive skills retraining and ADL retraining; it included visual scanning training within a large battery of training activities, but this was not specifically targeted at visual field loss.

\begin{tabular}{ll}
\hline Chen 2013 & Not stroke \\
\hline ChiCTR-OON-15006688 & Not RCT \\
\hline Cho 2015 & Not VFD \\
\hline Courtney-Harris 2015 & $\begin{array}{l}\text { Aim of study was validation of a vision screening tool; and outcomes were focussed on level of } \\
\text { agreement between tests. }\end{array}$ \\
\hline Crotty 2009 & Not VFD \\
\hline Cutfield 2011 & Not RCT \\
\hline Dai 2014 & Not RCT \\
\hline Dargie 2012 & Not RCT \\
\hline Davis 2009 & Not vision \\
\hline Fedorov 2010 & Not VFD \\
\hline Ginsberg 2013 & Not VFD \\
\hline
\end{tabular}




\section{Study \\ Reason for exclusion}

Gordon 1985

The method of sequence generation was described as "patients ... were assigned to either experimental or control condition, depending on the rehabilitation service to which the patient was assigned for treatment. All patients were accessed from two comparable inpatient services; experimental and control conditions were alternated every six months between the two services during the time which all patients on a given service were assigned to the same treatment condition". Although this was described as "quasi-random" it did not meet the level of randomisation of sequence generation that was needed for inclusion.

\begin{tabular}{|c|c|}
\hline Hamel 2012 & Not RCT \\
\hline Hazelton 2013 & Not RCT \\
\hline Hollands 2013 & Not VFD \\
\hline Jo 2012 & Visual neglect, not VFD \\
\hline Kang 2009 & Not VFD \\
\hline Kerkhoff 2013 & Visual neglect, not VFD \\
\hline Kerry 2017 & $\begin{array}{l}\text { Focussed on central alexia ("an acquired reading disorder co-occuring with a generalised language } \\
\text { deficit (aphasia)") }\end{array}$ \\
\hline Ko 2011 & Not RCT \\
\hline Lane 2010 & $\begin{array}{l}\text { The method of sequence generation in this study of compensation interventions was stated as " } \\
\text { the first } 23 \text { were assigned to Group A, and the last } 23 \text { to Group B" and thus was non-random. }\end{array}$ \\
\hline Lee 2013a & Visual neglect, not VFD \\
\hline Lee $2013 b$ & Not RCT \\
\hline Loverro 1988 & $\begin{array}{l}\text { The method of sequence generation in this study of bed orientation was stated as "assigned to re- } \\
\text { habilitation hospital beds based on bed availability" and thus was non-random. }\end{array}$ \\
\hline Machner 2012 & Visual neglect, not VFD \\
\hline Mancuso 2012 & Visual neglect, not VFD \\
\hline Markowitz 2010 & $\begin{array}{l}\text { This was a comment on a study: Bergsma DP and Van der Wildt G. British Journal of Ophthalmology } \\
\text { 2010; 94:88-96, which was not a randomised controlled trial. }\end{array}$ \\
\hline NTR5637 & Not RCT \\
\hline Olma 2013 & Not RCT \\
\hline Opolka 2013 & Visual neglect, not VFD \\
\hline Padula 2009 & Not RCT \\
\hline Park 2013 & Not VFD \\
\hline Rosenberg 2011 & Not VFD \\
\hline
\end{tabular}




\begin{tabular}{ll}
\hline Study & Reason for exclusion \\
\hline Sabel 2009 & $\begin{array}{l}\text { This study looked at visual restitution in optic nerve disorder. The consensus of the Advisory Group } \\
\text { for this review was that the review should be limited to post-chiasmal visual field loss only, so this } \\
\text { study was not included. }\end{array}$
\end{tabular}

\begin{tabular}{|c|c|}
\hline Saposnik 2013 & Not VFD \\
\hline Scholomov 2010 & Not RCT \\
\hline Taylor 2011 & Not RCT \\
\hline Teasell 2011 & Visual neglect, not VFD \\
\hline Thurtell 2010 & Not VFD \\
\hline Van Wyk 2011 & Not VFD \\
\hline Van Wyk 2016 & Not VFD (eye movement disorders) \\
\hline Weinberg 1977 & $\begin{array}{l}\text { ***Was an included study in } 2011 \text { version of Cochrane review***} \\
\text { Excluded from updated version because participants were not confirmed to have visual field de- } \\
\text { fects. Weinberg } 1977 \text { and Weinberg } 1979 \text { both included participants with the same inclusion crite- } \\
\text { ria. The } 2009 \text { version stated: "These studies included only people with right-sided cerebrovascu- } \\
\text { lar accident. However, from the limited information available in the published papers, it does ap- } \\
\text { pear that the diagnosis of visual field defect (or visual neglect) was not an inclusion criterion for en- } \\
\text { try to these studies. The authors appear to assume that this patient group will have visual neglect } \\
\text { as they have right-sided brain damage. It is worth noting that in these two studies the participants } \\
\text { were divided into subgroups of 'mild' and 'severe' based on "presence of visual field defect on con- } \\
\text { frontation and performance on visual cancellation", and that we can therefore be confident that } \\
\text { the 'severe' subgroup contained people with visual field defects, while it is not confirmed whether } \\
\text { all the 'mild' subgroup had a visual field defect. Arguably, therefore, the 'severe' subgroups are } \\
\text { more relevant to our review question than the 'mild' subgroups. There was substantial heterogene- } \\
\text { ity when we included the 'mild' subgroups in the analyses. Exploring this heterogeneity using sub- } \\
\text { group analyses found that the 'severe' subgroup had a greater response to the intervention than } \\
\text { the 'mild' subgroup, for all outcomes ... Arguably it was inappropriate to have included the 'mild' } \\
\text { subgroups within any of the analyses, as it is possible that participants in this group did not have a } \\
\text { visual field defect. However, due to the uncertainty we felt it was appropriate to include the 'mild' } \\
\text { subgroup but to further explore the effect of removing them from the analyses." }\end{array}$ \\
\hline
\end{tabular}

Weinberg 1979

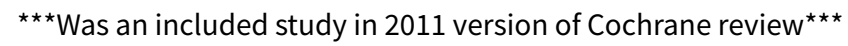

Excluded from updated version because participants were not confirmed to have visual field defects. Weinberg 1977 and Weinberg 1979 both included participants with the same inclusion criteria. The 2009 version stated: "These studies included only people with right-sided cerebrovascular accident. However, from the limited information available in the published papers, it does appear that the diagnosis of visual field defect (or visual neglect) was not an inclusion criterion for entry to these studies. The authors appear to assume that this patient group will have visual neglect as they have right-sided brain damage. It is worth noting that in these two studies the participants were divided into subgroups of 'mild' and 'severe' based on "presence of visual field defect on confrontation and performance on visual cancellation", and that we can therefore be confident that the 'severe' subgroup contained people with visual field defects, while it is not confirmed whether all the 'mild' subgroup had a visual field defect. Arguably, therefore, the 'severe' subgroups are more relevant to our review question than the 'mild' subgroups. There was substantial heterogeneity when we included the 'mild' subgroups in the analyses. Exploring this heterogeneity using subgroup analyses found that the 'severe' subgroup had a greater response to the intervention than the 'mild' subgroup, for all outcomes ... Arguably it was inappropriate to have included the 'mild' subgroups within any of the analyses, as it is possible that participants in this group did not have a 


\section{Study Reason for exclusion}

visual field defect. However, due to the uncertainty we felt it was appropriate to include the 'mild' subgroup but to further explore the effect of removing them from the analyses."

While we were confident that the 'severe' subgroup from this study contained some participants with visual field defects, this was not the focus of this trial, which was focused on participants with right brain damage only. Further, we cannot be certain that all participants in this group had visual field defects (there is a chance that some had severe visual neglect but no visual field defect).

ADL: activities of daily living

$\mathrm{RCT}$ : randomised controlled trial

VFD: visual field defect

\section{Characteristics of studies awaiting classification [ordered by study ID]}

Ghandehari 2011

\begin{tabular}{ll}
\hline Methods & Methods described this as a "prospective, observational study". \\
& Results described as a "randomised controlled trial", and included a study flowchart. \\
& No details of randomisation were provided. \\
\hline Participants & $\begin{array}{l}40 \text { participants: "stroke patients with posterior cerebral artery territory infarction" with "pure } \\
\text { homonymous hemianopia without neglect" }\end{array}$ \\
\hline Interventions & Group 1: Neuroaid (MLC601) \\
& Group 2: Piracetam \\
\hline Outcomes & Visual field (standard perimetry) \\
\hline Notes & Study carried out in Iran during 2009-2010 \\
& Authors emailed in 2015, but no reply \\
\hline
\end{tabular}

Sand 2017

\begin{tabular}{ll}
\hline Methods & $\begin{array}{l}\text { Conference abstract: "Patients were randomised ..." } \\
\text { ClinicalTrials.gov: "observational" study }\end{array}$ \\
\hline Participants & Stroke patients - not clear if VFD was an inclusion criteria \\
\hline Interventions & Experimental: "training with vision teacher with individually adapted training program" \\
& Control: no training \\
\hline Outcomes & Visual field defect \\
& Qisual function \\
Quality of life & National Institute of Health Stroke Scale (NIHSS) \\
\hline
\end{tabular}


Sand 2017 (Continued)

Notes

ClinicalTrials.gov Identifier: NCT02307981

Unclear if this was an RCT or not

NIHSS: National Institute of Health Stroke Scale

$\mathrm{RCT}$ : randomised controlled trial

VFD: visual field defect

Characteristics of ongoing studies [ordered by study ID]

Feldon 2017

\begin{tabular}{ll}
\hline Study name & Visual restoration for hemianopia \\
\hline Methods & RCT
\end{tabular}

Participants

Adults ( 21 to 75 years); lesion in the occipital lobe of the brain (18 to 90 days previously); stable homonymous hemianopia

Interventions

Experimental: training in the blind field: A computer software and chin-rest necessary to perform visual training will be loaned to each participant to use at home. They will perform 1 to 2 daily training sessions in their home, consisting of 200 to 300 trials each. The visual task performed repetitively will involve discriminating the direction of motion of a small cloud of dots located at a predetermined location in the blind field. The computer program will automatically create a record of participant performance during each home training session. They will train daily (about 40 to 60 minutes total), 5 to 7 days per week, for at least 24 weeks.

Control: training in the intact field (as above)

Outcomes Primary outcome measure: 24-2 Humphrey PMD - Change in the perimetric mean deviation (PMD) from 24-2 Humphrey perimetry between baseline and post-training

Starting date March 2018

(Estimated completion: May 2019)

Contact information lisa_blanchard@urmc.rochester.edu

Notes ClinicalTrials.gov Identifier: NCT03350919

\section{Gall 2015}

\begin{tabular}{ll}
\hline Study name & Restoration of vision after stroke (REVIS) \\
\hline Methods & "Randomised" \\
\hline Participants & $\begin{array}{l}\text { Adults aged } 18 \text { to } 75 \text { years; }>6 \text { months post stroke; hemianopia or quadrantopia confirmed by stan- } \\
\text { dard automated perimetry }\end{array}$ \\
\hline Interventions & Experimental: active tDCS (transcranial direct current stimulation) \\
\hline Cutcomes & Primary outcome: improved detection in the visual field, measured using high resolution perimetry \\
& Secondary outcome: change in extent of visual fields using standard automated perimetry \\
\hline \hline
\end{tabular}


Gall 2015 (Continued)

\begin{tabular}{ll} 
Starting date & April 2015 \\
& (study completion: April 2017) \\
\hline Contact information & turgut.tatlisumak@hus.fi \\
\hline Notes & ClinicalTrials.gov Identifier: NCT02405143
\end{tabular}

\section{Hayes 2010}

\begin{tabular}{ll}
\hline Study name & Retraining following hemianopia in acquired brain injury following stroke \\
\hline Methods & Comparison of 2 intensities of scanning training \\
\hline Participants & 20 participants \\
\hline Interventions & Visual scanning training using a light panel \\
\hline Outcomes & Includes quality of life measures and functional vision skills \\
\hline Starting date & ahayes@nvtsystems.com.au \\
\hline Contact information & Unpublished. Recruitment has ended. ACTRN12610000494033 \\
\hline Notes &
\end{tabular}

\section{ISRCTN16023965}

\begin{tabular}{ll}
\hline Study name & Home-training for hemianopia (partial blindness) \\
\hline Methods & RCT (3 groups) \\
\hline Participants & $\begin{array}{l}\text { Adults (aged at least 18) suffering with a nonprogressive visual field defect for at least 3 months } \\
\text { caused by a brain injury }\end{array}$ \\
\hline Interventions & Group 1 (intervention group 1): use the DREX program on a touchscreen tablet \\
& Group 2 (intervention group 2): use the DREX program on a computer \\
& $\begin{array}{l}\text { Group 3 (control group): given their usual care and any treatments given by their doctors or thera- } \\
\text { pists }\end{array}$ \\
\hline Outcomes & "Reading and visual search abilities and also their quality of life" \\
\hline Starting date & June 2015 \\
\hline Contact information & (study completion: December 2017) \\
\hline Notes & azuwan.musa@durham.ac.uk \\
\hline
\end{tabular}


Komm 2009

\begin{tabular}{ll}
\hline Study name & $\begin{array}{l}\text { Rehabilitation outcome in chronic neglect patients with associated visual field loss: results of a } \\
\text { blinded randomized cross-over study }\end{array}$ \\
\hline Methods & Masked randomised cross-over study \\
\hline Participants & Stroke patients with persistent neglect and visual field loss 6 months post-onset \\
\hline Interventions & Computer-aided visual restitution training versus compensatory eye movement training \\
\hline Outcomes & Visual field and neglect measures \\
\hline Starting date & bernhard.sabel@med.ovgu.de \\
\hline Contact information & Currently in press. Results not available for this review \\
\hline Notes &
\end{tabular}

NCT02737930

Study name Fluoxetine for visual recovery after ischemic stroke (FLUORESCE)

\begin{tabular}{ll}
\hline Methods & RCT \\
\hline Participants & MRI-confirmed acute ischaemic stroke resulting in an isolated homonymous visual field loss \\
& Estimated enrolment: 40 participants
\end{tabular}

Interventions Experimental: fluoxetine - $20 \mathrm{mg}$ fluoxetine capsule by mouth once daily for 90 days

Placebo comparator: placebo

\begin{tabular}{ll}
\hline Outcomes & Primary outcome measure: improvement in size of visual field deficit (degrees) \\
Secondary outcome measures: & Improvement in size of visual field deficit (square degrees) \\
Improvement in parametric mean deviation & Functional field score \\
& Visual Function Questionnaire-25 score \\
& Patient Health Questionnaire-9 score \\
& Modified Rankin Scale score \\
& Post-stroke changes in cortical visual representation as measured by functional magnetic reso- \\
nance imaging & Post-stroke changes in retinal nerve fibre layer thickness \\
\hline Starting date & May 2016 \\
\hline (Estimated study completion: June 2020) \\
\hline bontact information
\end{tabular}


NCT02737930 (Continued)

Notes ClinicalTrials.gov identifier: NCT02737930

NCT02886663

\begin{tabular}{|c|c|}
\hline Study name & Visual field restoration in patients with post-stroke homonymous hemianopsia (REVOIR) \\
\hline Methods & Randomised cross-over design \\
\hline \multirow[t]{2}{*}{ Participants } & $\begin{array}{l}\text { Adults, } 3 \text { to } 36 \text { months post-stroke; presence of a homonymous visual field amputation after vascu- } \\
\text { lar retro-chiasmatic lesion of the occipital region (visual cortex alone or with optical radiations or } \\
\text { with other associated occipital areas) }\end{array}$ \\
\hline & Anticipated recruitment: 104 participants \\
\hline \multirow[t]{2}{*}{ Interventions } & $\begin{array}{l}\text { Experimental: immediate rehabilitation ("a stimulus, in the blind field of hemianopsic patients, to } \\
\text { restore the vision of patients with homonymous hemianopsia consecutive to stroke") }\end{array}$ \\
\hline & Control: delayed rehabilitation \\
\hline Starting date & September 2016 \\
\hline Contact information & Isalomon@for.paris \\
\hline Notes & ClinicalTrials.gov Identifier: NCT02886663 \\
\hline
\end{tabular}

DREX: Durham Reading \& Exploration

PMD: perimetric mean deviation

RCT: randomised controlled trial

tDCS: transcranial direct current stimulation

VFD: visual field defect

\section{DATA AND ANALYSES}

\section{Comparison 1. Restitutive interventions versus control, placebo or no intervention}

\begin{tabular}{lllll}
\hline $\begin{array}{l}\text { Outcome or subgroup ti- } \\
\text { tle }\end{array}$ & No. of studies & $\begin{array}{l}\text { No. of partici- } \\
\text { pants }\end{array}$ & Statistical method & Effect size \\
\hline 1.1 Visual field & 1 & 19 & $\begin{array}{l}\text { Mean Difference (IV, Random, 95\% } \\
\text { Cl) }\end{array}$ & $1.02[-1.37,3.41]$ \\
\hline 1.2 Quality of life & 1 & 30 & Odds Ratio (M-H, Random, 95\% Cl) & $13.00[2.07,81.48]$ \\
\hline
\end{tabular}




\begin{tabular}{|c|c|c|c|c|c|c|c|c|c|}
\hline \multirow[b]{3}{*}{ Study or Subgroup } & \multicolumn{9}{|c|}{$\begin{array}{l}\text { Analysis 1.1. Comparison 1: Restitutive interventions versus } \\
\text { control, placebo or no intervention, Outcome 1: Visual field }\end{array}$} \\
\hline & \multicolumn{3}{|c|}{ Experimental } & \multicolumn{3}{|c|}{ Control } & \multirow[b]{2}{*}{ Weight } & \multirow{2}{*}{$\begin{array}{c}\text { Mean Difference } \\
\text { IV, Random, 95\% CI }\end{array}$} & \multirow{2}{*}{$\begin{array}{c}\text { Mean Difference } \\
\text { IV, Random, 95\% CI }\end{array}$} \\
\hline & Mean & SD & Total & Mean & SD & Total & & & \\
\hline Kasten 1998 (1) & 3.94 & 3 & 9 & 2.92 & 2.21 & 10 & $100.0 \%$ & $1.02[-1.37,3.41]$ & - \\
\hline Total $(95 \% \mathrm{CI})$ & & & 9 & & & 10 & $100.0 \%$ & $1.02[-1.37,3.41]$ & \\
\hline \multicolumn{10}{|c|}{ Heterogeneity: Not applicable } \\
\hline \multicolumn{4}{|c|}{ Test for overall effect: $\mathrm{Z}=0.84(\mathrm{P}=0.40)$} & & & & & -10 & $\begin{array}{ll}1 & 1 \\
0 & 5\end{array}$ \\
\hline \multicolumn{4}{|c|}{ Test for subgroup differences: Not applicable } & & & & & Fav & rs control Favours \\
\hline
\end{tabular}

Analysis 1.2. Comparison 1: Restitutive interventions versus control, placebo or no intervention, Outcome 2: Quality of life

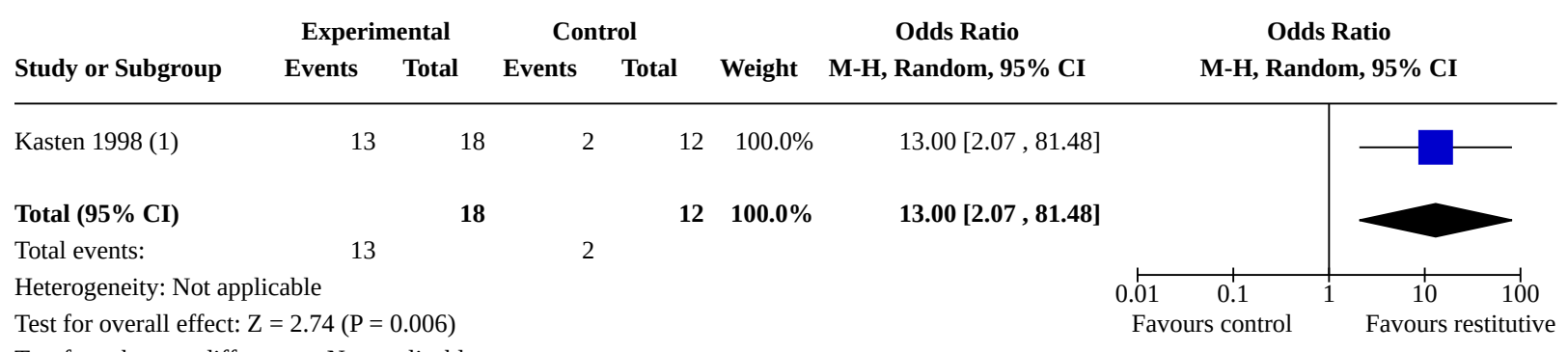

Test for subgroup differences: Not applicable

Footnotes

(1) Dichotomous variable (improve or not improved) - derived from percentage of those who reported subjective improvements of vision

Comparison 2. Compensative interventions versus control, placebo or no intervention

\begin{tabular}{|c|c|c|c|c|}
\hline Outcome or subgroup title & No. of studies & $\begin{array}{l}\text { No. of partici- } \\
\text { pants }\end{array}$ & Statistical method & Effect size \\
\hline 2.1 Visual field & 2 & 95 & $\begin{array}{l}\text { Std. Mean Difference (IV, Ran- } \\
\text { dom, } 95 \% \mathrm{CI} \text { ) }\end{array}$ & $-0.11[-0.92,0.70]$ \\
\hline $\begin{array}{l}\text { 2.1.1 Participants with visual field de- } \\
\text { fects (no visual neglect) }\end{array}$ & 2 & 95 & $\begin{array}{l}\text { Std. Mean Difference (IV, Ran- } \\
\text { dom, } 95 \% \mathrm{Cl} \text { ) }\end{array}$ & $-0.11[-0.92,0.70]$ \\
\hline $\begin{array}{l}\text { 2.1.2 Participants with visual field de- } \\
\text { fects and (possibly) co-existing visual } \\
\text { neglect }\end{array}$ & 0 & 0 & $\begin{array}{l}\text { Std. Mean Difference (IV, Ran- } \\
\text { dom, } 95 \% \mathrm{Cl} \text { ) }\end{array}$ & Not estimable \\
\hline 2.2 Extended activities of daily living & 2 & 87 & $\begin{array}{l}\text { Std. Mean Difference (IV, Ran- } \\
\text { dom, } 95 \% \mathrm{CI} \text { ) }\end{array}$ & $0.49[-0.01,0.99]$ \\
\hline $\begin{array}{l}\text { 2.2.1 Participants with visual field de- } \\
\text { fects (no visual neglect) }\end{array}$ & 2 & 87 & $\begin{array}{l}\text { Std. Mean Difference (IV, Ran- } \\
\text { dom, } 95 \% \mathrm{Cl} \text { ) }\end{array}$ & $0.49[-0.01,0.99]$ \\
\hline $\begin{array}{l}\text { 2.2.2 Participants with visual field de- } \\
\text { fects and (possibly) co-existing visual } \\
\text { neglect }\end{array}$ & 0 & 0 & $\begin{array}{l}\text { Std. Mean Difference (IV, Ran- } \\
\text { dom, } 95 \% \mathrm{Cl} \text { ) }\end{array}$ & Not estimable \\
\hline
\end{tabular}




\begin{tabular}{|c|c|c|c|c|}
\hline Outcome or subgroup title & No. of studies & $\begin{array}{l}\text { No. of partici- } \\
\text { pants }\end{array}$ & Statistical method & Effect size \\
\hline 2.3 Reading & 4 & 162 & $\begin{array}{l}\text { Std. Mean Difference (IV, Ran- } \\
\text { dom, } 95 \% \mathrm{CI} \text { ) }\end{array}$ & $0.26[-0.05,0.58]$ \\
\hline $\begin{array}{l}\text { 2.3.1 Participants with visual field de- } \\
\text { fects (no visual neglect) }\end{array}$ & 3 & 110 & $\begin{array}{l}\text { Std. Mean Difference (IV, Ran- } \\
\text { dom, } 95 \% \mathrm{Cl} \text { ) }\end{array}$ & $0.18[-0.20,0.56]$ \\
\hline $\begin{array}{l}\text { 2.3.2 Participants with visual field de- } \\
\text { fects and (possibly) co-existing visual } \\
\text { neglect }\end{array}$ & 1 & 52 & $\begin{array}{l}\text { Std. Mean Difference (IV, Ran- } \\
\text { dom, } 95 \% \mathrm{Cl} \text { ) }\end{array}$ & $0.45[-0.10,1.00]$ \\
\hline 2.4 Quality of life & 2 & 96 & $\begin{array}{l}\text { Mean Difference (IV, Random, } \\
95 \% \mathrm{Cl} \text { ) }\end{array}$ & $9.36[3.10,15.62]$ \\
\hline $\begin{array}{l}\text { 2.4.1 Participants with visual field de- } \\
\text { fects (no visual neglect) }\end{array}$ & 2 & 96 & $\begin{array}{l}\text { Mean Difference (IV, Random, } \\
95 \% \mathrm{Cl})\end{array}$ & $9.36[3.10,15.62]$ \\
\hline $\begin{array}{l}\text { 2.4.2 Participants with visual field de- } \\
\text { fects and (possibly) co-existing visual } \\
\text { neglect }\end{array}$ & 0 & 0 & $\begin{array}{l}\text { Mean Difference (IV, Random, } \\
95 \% \mathrm{CI} \text { ) }\end{array}$ & Not estimable \\
\hline 2.5 Scanning - cancellation & 2 & 97 & $\begin{array}{l}\text { Std. Mean Difference (IV, Ran- } \\
\text { dom, } 95 \% \mathrm{Cl} \text { ) }\end{array}$ & $-0.01[-0.40,0.39]$ \\
\hline $\begin{array}{l}\text { 2.5.1 Participants with visual field de- } \\
\text { fects (no visual neglect) }\end{array}$ & 1 & 48 & $\begin{array}{l}\text { Std. Mean Difference (IV, Ran- } \\
\text { dom, } 95 \% \mathrm{Cl} \text { ) }\end{array}$ & $0.12[-0.45,0.68]$ \\
\hline $\begin{array}{l}\text { 2.5.2 Participants with visual field de- } \\
\text { fects and (possibly) visual neglect }\end{array}$ & 1 & 49 & $\begin{array}{l}\text { Std. Mean Difference (IV, Ran- } \\
\text { dom, } 95 \% \mathrm{Cl} \text { ) }\end{array}$ & $-0.13[-0.69,0.44]$ \\
\hline 2.6 Adverse events & 2 & 108 & $\begin{array}{l}\text { Odds Ratio (M-H, Random, } \\
95 \% \mathrm{Cl})\end{array}$ & $\begin{array}{l}5.18[0.24 \\
112.57]\end{array}$ \\
\hline
\end{tabular}




\section{Analysis 2.1. Comparison 2: Compensative interventions versus control, placebo or no intervention, Outcome 1: Visual field}

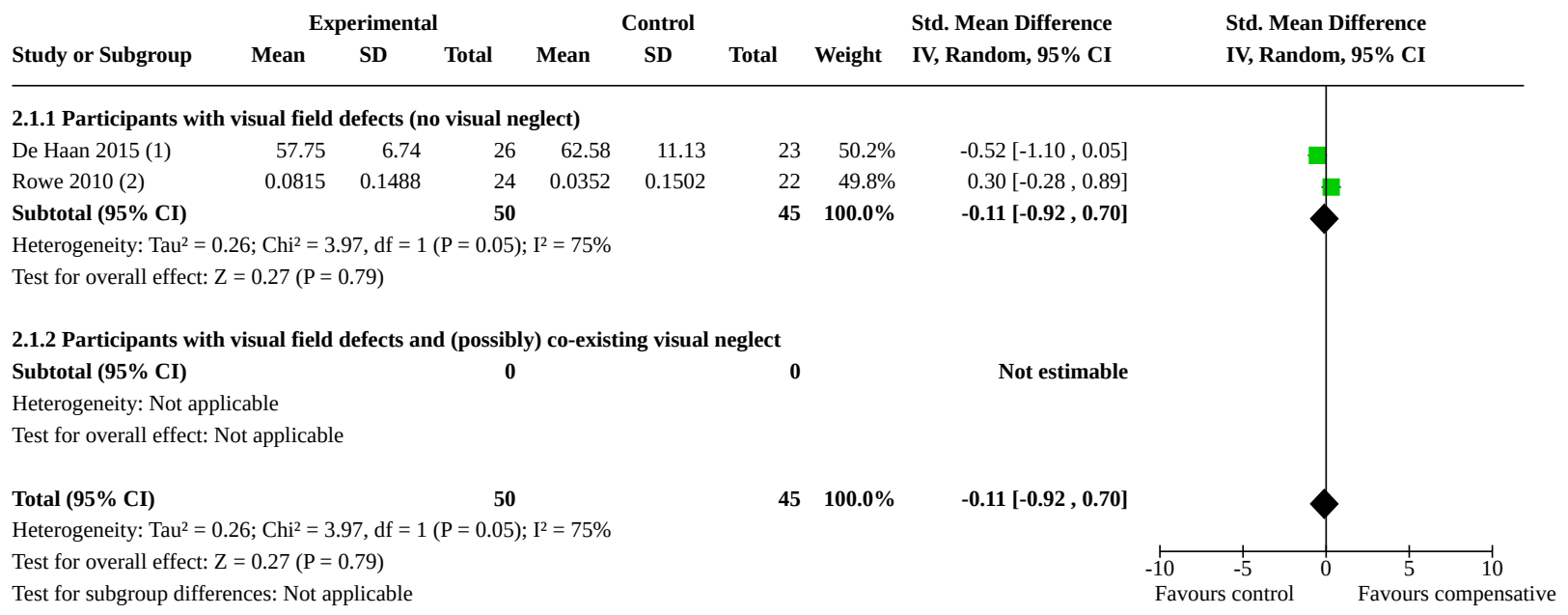

Footnotes

(1) Functional Field Score (NB: Significant difference between training and control group at baseline assessment)

(2) Relative change in visual field area

Analysis 2.2. Comparison 2: Compensative interventions versus control, placebo or no intervention, Outcome 2: Extended activities of daily living

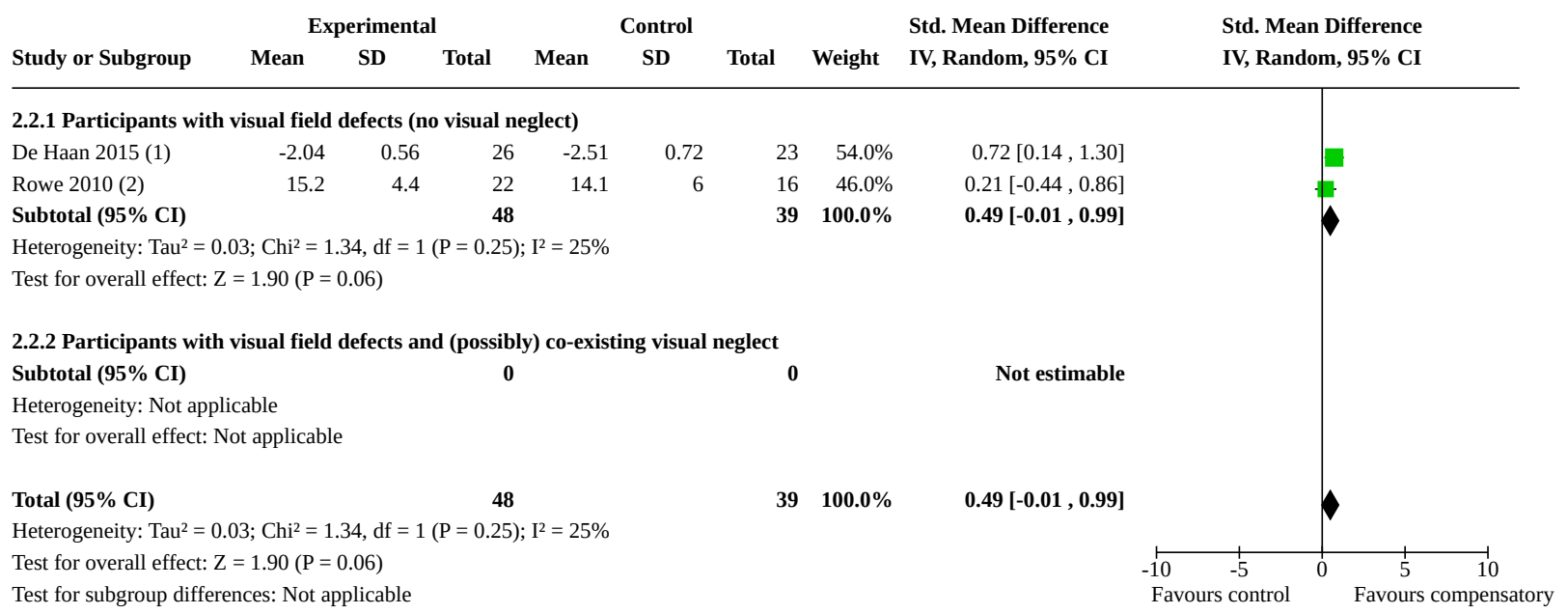

Footnotes

(1) Independent mobility questionnaire (multiplied by -1 as low result indicates positive outcome)

(2) Change in EADL from baseline 


\section{Analysis 2.3. Comparison 2: Compensative interventions} versus control, placebo or no intervention, Outcome 3: Reading

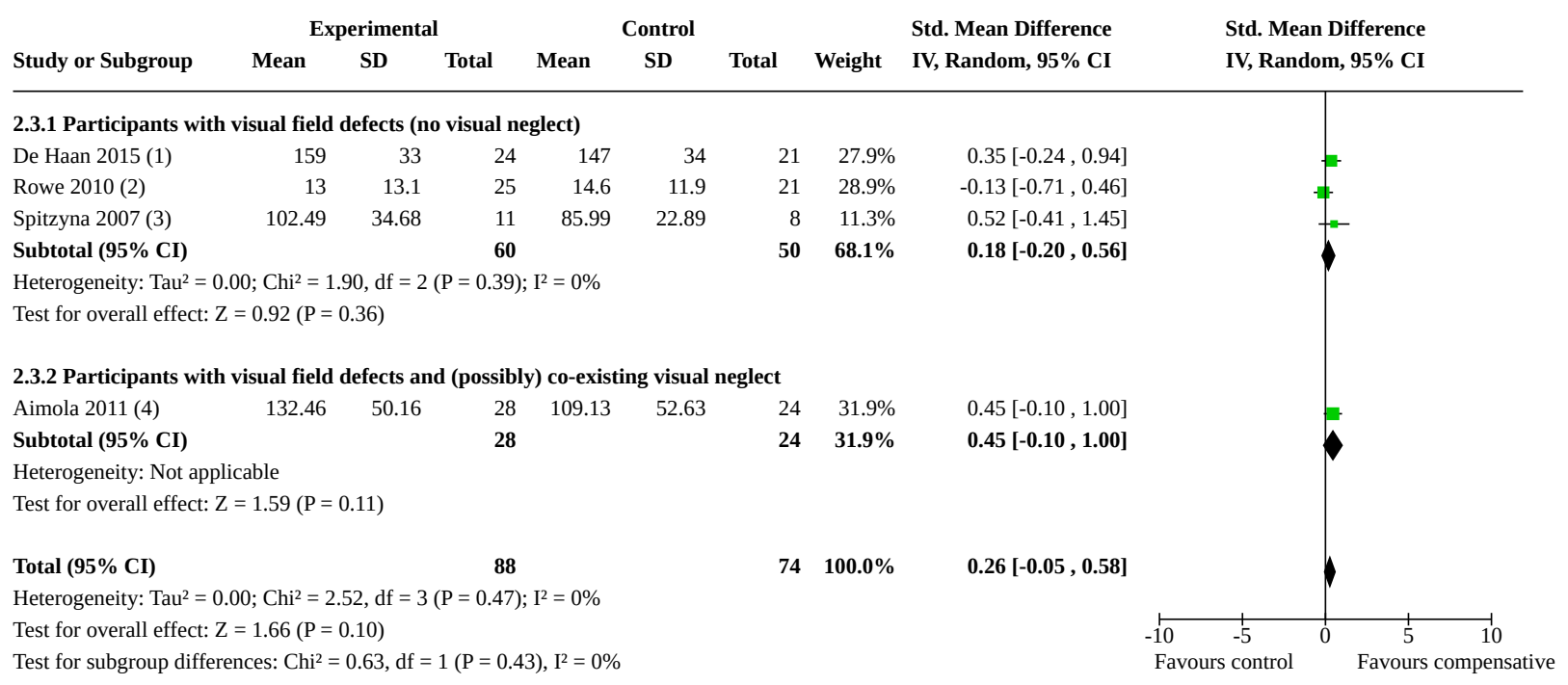

Footnotes

(1) Radner average reading speed (words per minute)

(2) change in Radner reading speed

(3) Reading speed

(4) Mean corrected reading speed (words per minute)

\section{Analysis 2.4. Comparison 2: Compensative interventions versus control, placebo or no intervention, Outcome 4: Quality of life}

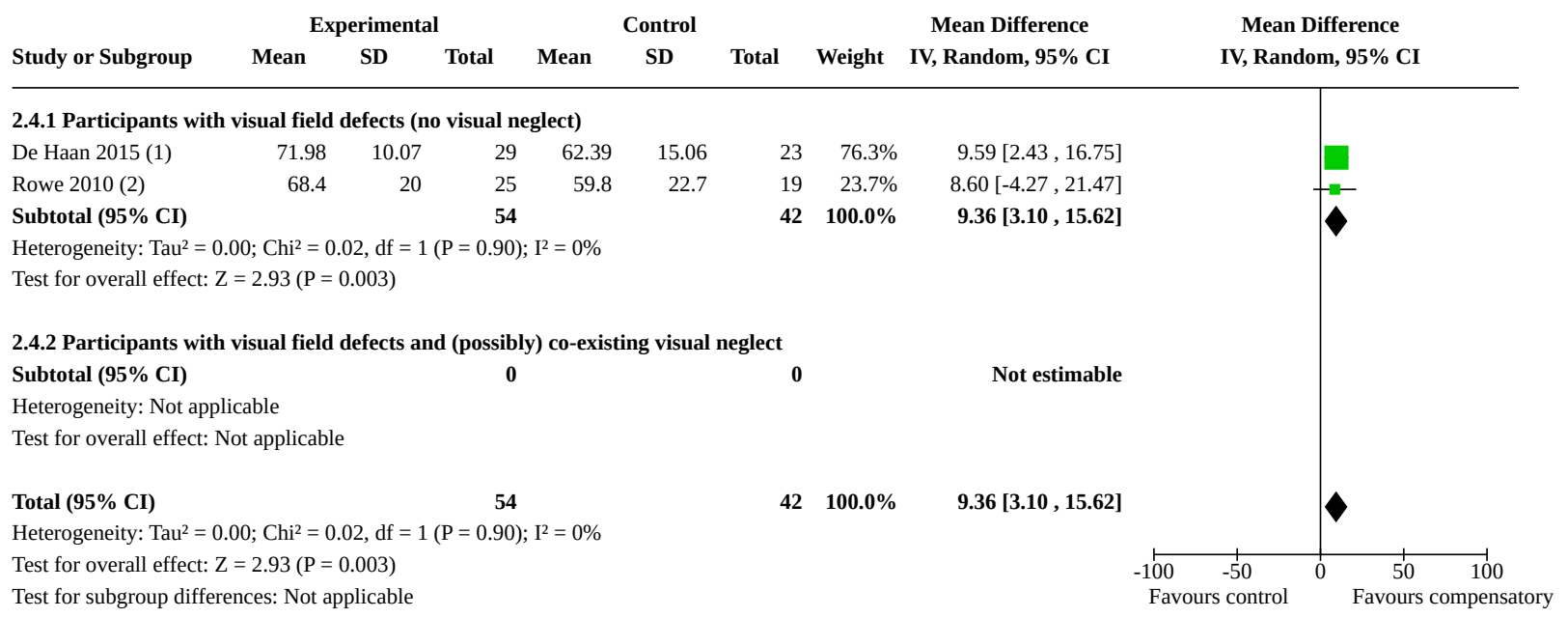

Footnotes

(1) NEI-VFQ-25 total score

(2) VFQ-25 total score 
Analysis 2.5. Comparison 2: Compensative interventions versus control, placebo or no intervention, Outcome 5: Scanning - cancellation

\begin{tabular}{|c|c|c|c|c|c|c|c|c|}
\hline & \multicolumn{3}{|c|}{ Experimental } & \multicolumn{2}{|c|}{ Control } & \multicolumn{2}{|r|}{ Std. Mean Difference } & Std. Mean Difference \\
\hline Study or Subgroup & Mean & SD & Mean & SD & Total & Weight & IV, Random, 95\% CI & IV, Random, 95\% CI \\
\hline
\end{tabular}

2.5.1 Participants with visual field defects (no visual neglect)

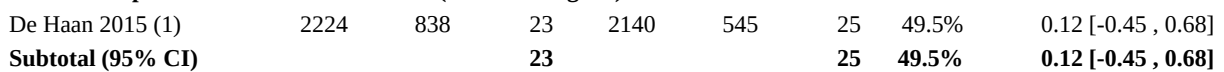

Heterogeneity: Not applicable

Test for overall effect: $\mathrm{Z}=0.41(\mathrm{P}=0.68)$

2.5.2 Participants with visual field defects and (possibly) visual neglect

$\begin{array}{lllllllll}\text { Aimola } 2011(2) & 101 & 53 & 25 & 107 & 40 & 24 & 50.5 \% & -0.13[-0.69,0.44]\end{array}$

Heterogeneity: Not applicable

Test for overall effect: $\mathrm{Z}=0.44(\mathrm{P}=0.66)$

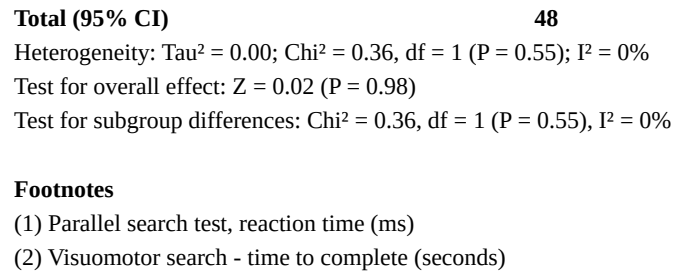

Analysis 2.6. Comparison 2: Compensative interventions versus control, placebo or no intervention, Outcome 6: Adverse events

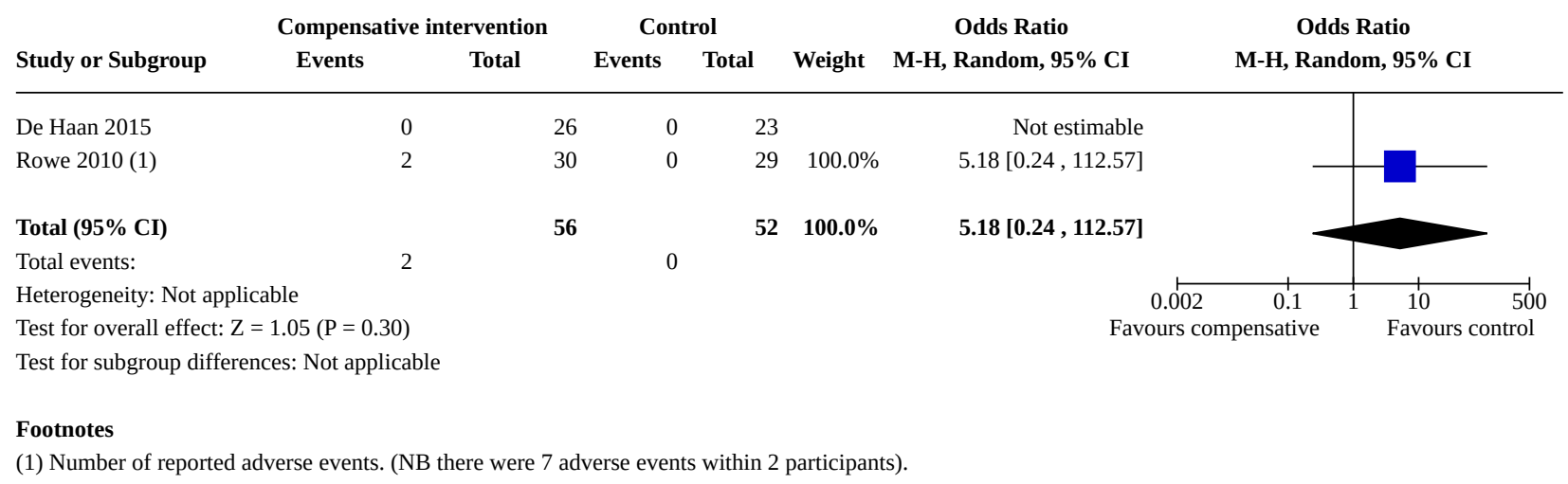

Comparison 3. Substitutive interventions versus control, placebo or no intervention

\begin{tabular}{lllll}
\hline Outcome or subgroup title & No. of studies & $\begin{array}{l}\text { No. of partici- } \\
\text { pants }\end{array}$ & Statistical method & Effect size \\
\hline $\begin{array}{l}\text { 3.1 Functional Activities of Daily Liv- } \\
\text { ing }\end{array}$ & 1 & & $\begin{array}{l}\text { Mean Difference (IV, Random, } \\
95 \% \mathrm{Cl})\end{array}$ & Subtotals only \\
\hline $\begin{array}{l}\text { 3.1.1 Participants not wearning } \\
\text { prisms during assessment }\end{array}$ & 0 & 0 & $\begin{array}{l}\text { Mean Difference (IV, Random, } \\
95 \% \mathrm{Cl})\end{array}$ & Not estimable \\
\hline $\begin{array}{l}\text { 3.1.2 Participants wearing prisms } \\
\text { during assessment }\end{array}$ & 1 & 39 & $\begin{array}{l}\text { Mean Difference (IV, Random, } \\
95 \% \mathrm{Cl})\end{array}$ & $\begin{array}{l}-4.00[-17.86, \\
9.86]\end{array}$ \\
\hline
\end{tabular}




\begin{tabular}{|c|c|c|c|c|}
\hline Outcome or subgroup title & No. of studies & $\begin{array}{l}\text { No. of partici- } \\
\text { pants }\end{array}$ & Statistical method & Effect size \\
\hline 3.2 Visual field & 2 & & $\begin{array}{l}\text { Std. Mean Difference (IV, Ran- } \\
\text { dom, } 95 \% \mathrm{Cl} \text { ) }\end{array}$ & Subtotals only \\
\hline $\begin{array}{l}\text { 3.2.1 Participants not wearing prisms } \\
\text { during assessment }\end{array}$ & 1 & 46 & $\begin{array}{l}\text { Std. Mean Difference (IV, Ran- } \\
\text { dom, } 95 \% \mathrm{Cl} \text { ) }\end{array}$ & $0.12[-0.46,0.70]$ \\
\hline $\begin{array}{l}\text { 3.2.2 Participants wearing prisms } \\
\text { during assessment }\end{array}$ & 1 & 39 & $\begin{array}{l}\text { Std. Mean Difference (IV, Ran- } \\
\text { dom, } 95 \% \mathrm{Cl} \text { ) }\end{array}$ & $1.12[0.44,1.80]$ \\
\hline 3.3 Extended activities of daily living & 2 & & $\begin{array}{l}\text { Std. Mean Difference (IV, Ran- } \\
\text { dom, } 95 \% \mathrm{CI} \text { ) }\end{array}$ & Subtotals only \\
\hline $\begin{array}{l}\text { 3.3.1 Participants not wearing prisms } \\
\text { during assessment }\end{array}$ & 1 & 38 & $\begin{array}{l}\text { Std. Mean Difference (IV, Ran- } \\
\text { dom, } 95 \% \mathrm{CI} \text { ) }\end{array}$ & $0.20[-0.44,0.85]$ \\
\hline $\begin{array}{l}\text { 3.3.2 Participants wearing prisms } \\
\text { during assessment }\end{array}$ & 1 & 61 & $\begin{array}{l}\text { Std. Mean Difference (IV, Ran- } \\
\text { dom, } 95 \% \mathrm{Cl} \text { ) }\end{array}$ & $0.24[-0.26,0.75]$ \\
\hline 3.4 Reading & 1 & & $\begin{array}{l}\text { Mean Difference (IV, Random, } \\
95 \% \mathrm{CI} \text { ) }\end{array}$ & Subtotals only \\
\hline $\begin{array}{l}\text { 3.4.1 Participants not wearing prisms } \\
\text { during assessment }\end{array}$ & 1 & 45 & $\begin{array}{l}\text { Mean Difference (IV, Random, } \\
95 \% \mathrm{CI} \text { ) }\end{array}$ & $\begin{array}{l}2.80[-7.13 \\
12.73]\end{array}$ \\
\hline $\begin{array}{l}\text { 3.4.2 Participants wearing prisms } \\
\text { during assessment }\end{array}$ & 0 & 0 & $\begin{array}{l}\text { Mean Difference (IV, Random, } \\
95 \% \mathrm{CI} \text { ) }\end{array}$ & Not estimable \\
\hline 3.5 Falls & 1 & & $\begin{array}{l}\text { Odds Ratio (M-H, Random, } \\
95 \% \mathrm{Cl})\end{array}$ & Subtotals only \\
\hline $\begin{array}{l}\text { 3.5.1 Participants not wearing prisms } \\
\text { during assessment }\end{array}$ & 0 & 0 & $\begin{array}{l}\text { Odds Ratio (M-H, Random, } \\
95 \% \mathrm{Cl})\end{array}$ & Not estimable \\
\hline $\begin{array}{l}\text { 3.5.2 Participants wearing prisms } \\
\text { during assessment }\end{array}$ & 1 & 39 & $\begin{array}{l}\text { Odds Ratio (M-H, Random, } \\
95 \% \mathrm{Cl})\end{array}$ & $1.21[0.26,5.76]$ \\
\hline 3.6 Quality of life & 1 & & $\begin{array}{l}\text { Mean Difference (IV, Random, } \\
95 \% \mathrm{CI} \text { ) }\end{array}$ & Subtotals only \\
\hline $\begin{array}{l}\text { 3.6.1 Participants not wearing prisms } \\
\text { during assessment }\end{array}$ & 1 & 43 & $\begin{array}{l}\text { Mean Difference (IV, Random, } \\
95 \% \mathrm{CI} \text { ) }\end{array}$ & $\begin{array}{l}8.40[-4.18 \\
20.98]\end{array}$ \\
\hline $\begin{array}{l}\text { 3.6.2 Participants wearing prisms } \\
\text { during assessment }\end{array}$ & 0 & 0 & $\begin{array}{l}\text { Mean Difference (IV, Random, } \\
95 \% \mathrm{CI} \text { ) }\end{array}$ & Not estimable \\
\hline 3.7 Scanning - cancellation & 1 & & $\begin{array}{l}\text { Mean Difference (IV, Random, } \\
95 \% \mathrm{CI} \text { ) }\end{array}$ & Subtotals only \\
\hline $\begin{array}{l}\text { 3.7.1 Participants not wearing prisms } \\
\text { during assessment }\end{array}$ & 0 & 0 & $\begin{array}{l}\text { Mean Difference (IV, Random, } \\
95 \% \mathrm{CI} \text { ) }\end{array}$ & Not estimable \\
\hline $\begin{array}{l}\text { 3.7.2 Participants wearing prisms } \\
\text { during assessment }\end{array}$ & 1 & 39 & $\begin{array}{l}\text { Mean Difference (IV, Random, } \\
95 \% \mathrm{CI} \text { ) }\end{array}$ & $9.80[1.91,17.69]$ \\
\hline
\end{tabular}




\begin{tabular}{lllll}
\hline Outcome or subgroup title & No. of studies & $\begin{array}{l}\text { No. of partici- } \\
\text { pants }\end{array}$ & Statistical method & Effect size \\
\hline 3.8 Adverse events & 1 & 59 & $\begin{array}{l}\text { Odds Ratio (M-H, Random, } \\
95 \% \mathrm{Cl})\end{array}$ & $\begin{array}{l}87.32[4.87, \\
1564.66]\end{array}$ \\
\hline
\end{tabular}

Analysis 3.1. Comparison 3: Substitutive interventions versus control, placebo or no intervention, Outcome 1: Functional Activities of Daily Living

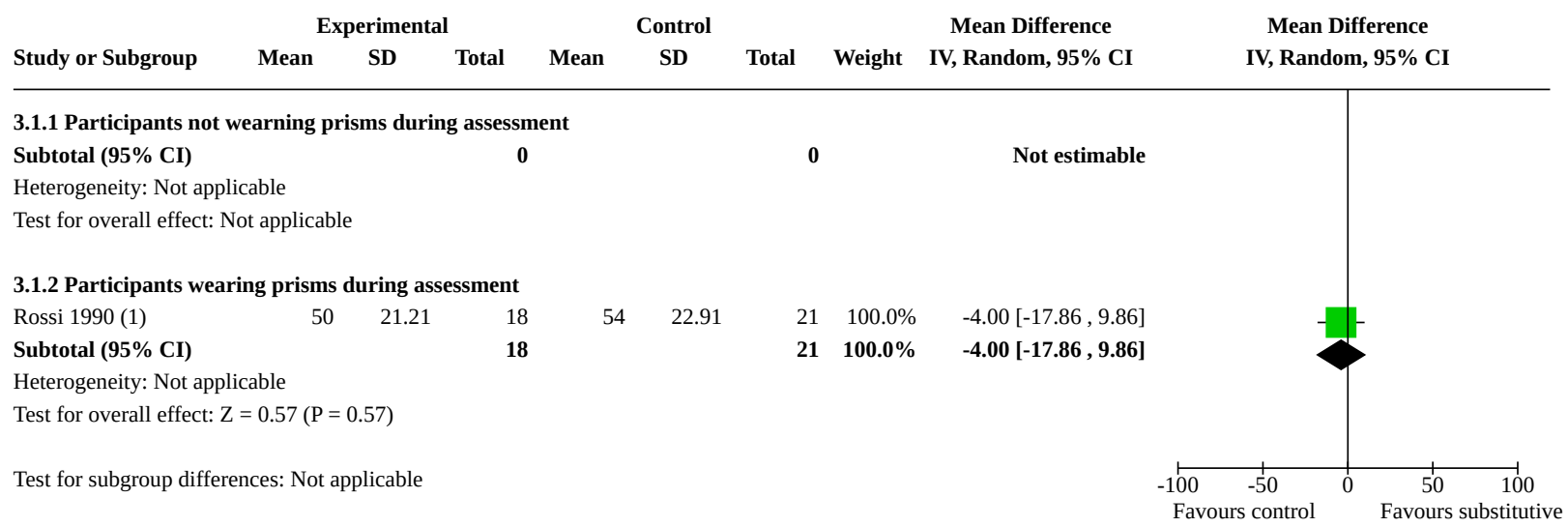

Footnotes

(1) Barthel Index (standard deviations calculated by review authors from reported P value for difference between the groups)

\section{Analysis 3.2. Comparison 3: Substitutive interventions versus control, placebo or no intervention, Outcome 2: Visual field}

\begin{tabular}{|c|c|c|c|c|c|c|c|c|}
\hline & \multicolumn{3}{|c|}{ Experimental } & \multicolumn{2}{|c|}{ Control } & \multirow{2}{*}{\multicolumn{2}{|c|}{ Std. Mean Difference }} & \multirow{2}{*}{$\begin{array}{l}\text { Std. Mean Difference } \\
\text { IV, Random, } 95 \% \text { CI }\end{array}$} \\
\hline Study or Subgroup & Mean & SD & Total & Mean & Total & & & \\
\hline
\end{tabular}

3.2.1 Participants not wearing prisms during assessment

$\begin{array}{lllllllll}\text { Rowe } 2010(1) & 0.0524 & 0.134 & 24 & 0.0352 & 0.1502 & 22 & 100.0 \% & 0.12[-0.46,0.70] \\ \text { Subtotal (95\% CI) } & & & \mathbf{2 4} & & & \mathbf{2 2} & \mathbf{1 0 0 . 0} \% & \mathbf{0 . 1 2}[-\mathbf{- 0 . 4 6 , 0 . 7 0 ]}\end{array}$

Subtotal (95\%

$100.0 \%$

$0.12[-0.46,0.70]$

Heterogeneity: Not applicable

Test for overall effect: $\mathrm{Z}=0.40(\mathrm{P}=0.69)$

\begin{tabular}{|c|c|c|c|c|c|c|c|c|}
\hline Rossi 1990 (2) & -5.8 & 4.24 & 18 & -14.2 & 9.17 & 21 & $100.0 \%$ & $1.12[0.44,1.80]$ \\
\hline Subtotal (95\% CI) & & & 18 & & & 21 & $100.0 \%$ & $1.12[0.44,1.80]$ \\
\hline
\end{tabular}

Heterogeneity: Not applicable

Test for overall effect: $\mathrm{Z}=3.23(\mathrm{P}=0.001)$

Test for subgroup differences: $\mathrm{Chi}^{2}=4.83, \mathrm{df}=1(\mathrm{P}=0.03), \mathrm{I}^{2}=79.3 \%$

Footnotes

(1) Relative change in visual field area

(2) Harrington Flocks Visual Screener error scores - improvement from baseline at 4 weeks. The reported outcome was error scores from the Harrington Flocks Visual Screener, 
Analysis 3.3. Comparison 3: Substitutive interventions versus control, placebo or no intervention, Outcome 3: Extended activities of daily living

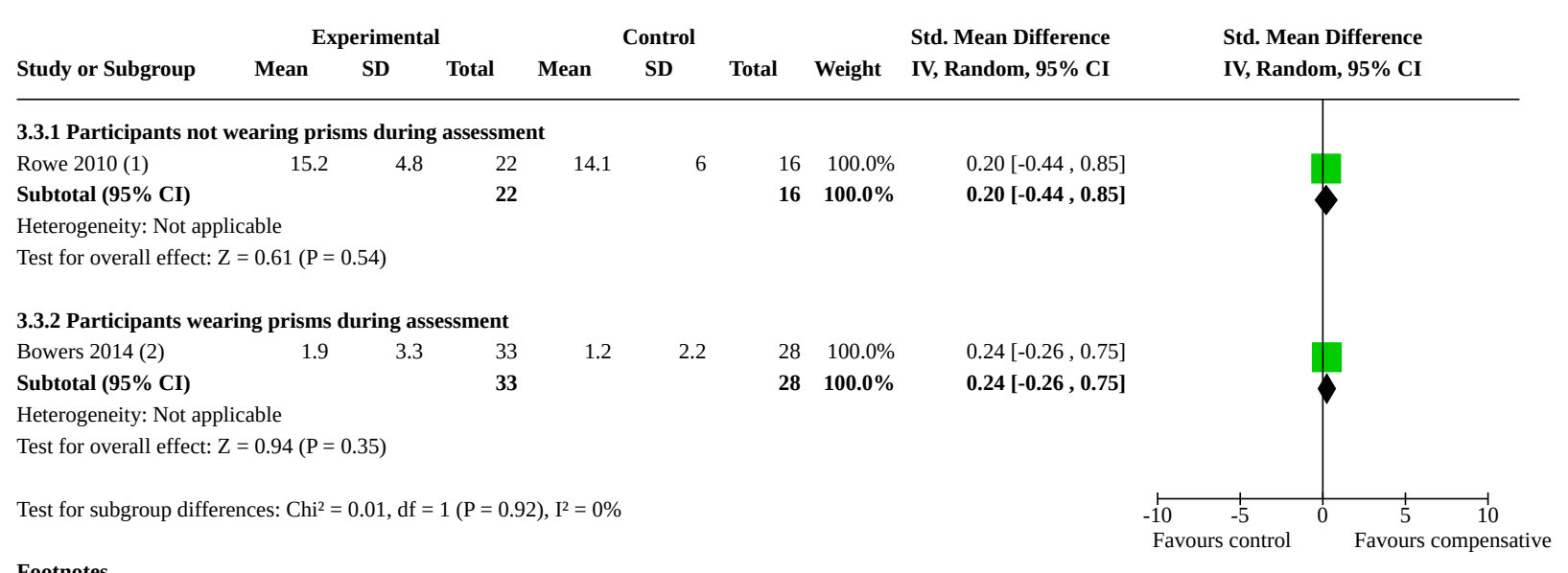

(1) change in EADL from baseline

(2) Mobility improvement scores (in Logits)

Analysis 3.4. Comparison 3: Substitutive interventions versus control, placebo or no intervention, Outcome 4: Reading

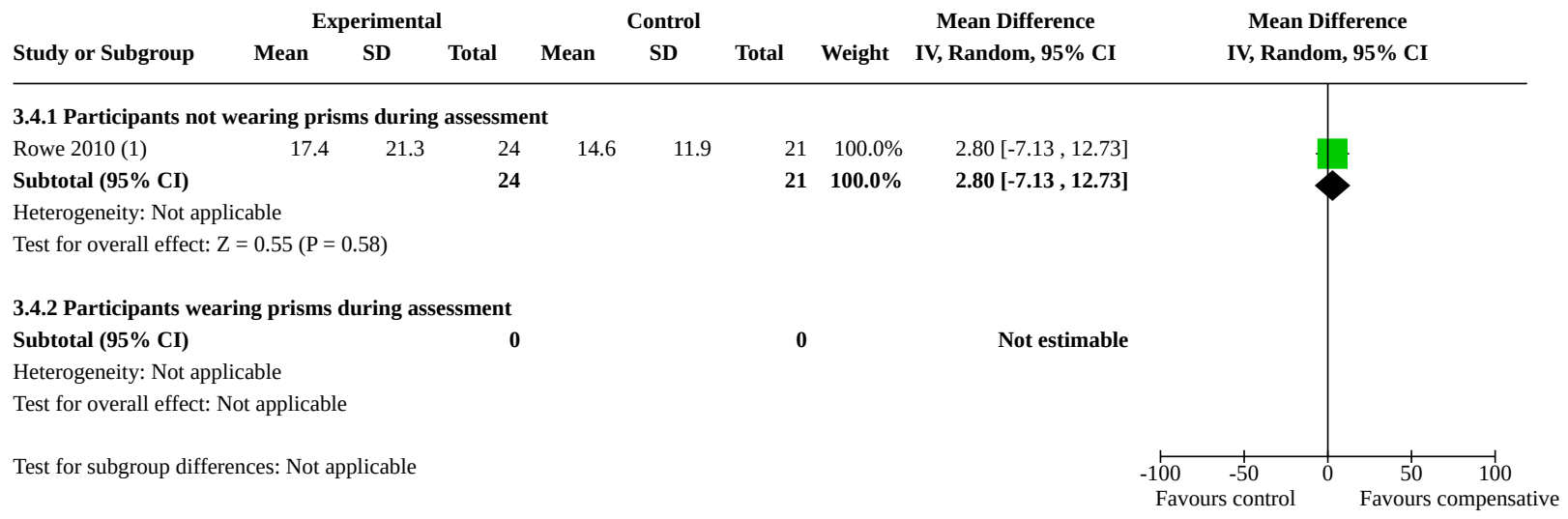

Footnotes

(1) change in reading speed from baseline 
Analysis 3.5. Comparison 3: Substitutive interventions versus control, placebo or no intervention, Outcome 5: Falls

\begin{tabular}{|c|c|c|c|c|c|c|}
\hline \multirow[b]{2}{*}{ Study or Subgroup } & \multicolumn{2}{|c|}{ Experimental } & \multicolumn{2}{|c|}{ Control } & \multicolumn{2}{|r|}{ Odds Ratio } \\
\hline & Events & Total & Events & Total & Weight & M-H, Random, 95\% CI \\
\hline \multicolumn{7}{|c|}{ 3.5.1 Participants not wearing prisms during assessment } \\
\hline Subtotal (95\% CI) & & & & & & Not estimab \\
\hline Total events: & c & & ( & & & \\
\hline
\end{tabular}

Heterogeneity: Not applicable

Test for overall effect: Not applicable

3.5.2 Participants wearing prisms during assessment

$\begin{array}{lllllll}\text { Rossi } 1990(1) & 4 & 18 & 4 & 21 & 100.0 \% & 1.21[0.26,5.76] \\ \text { Subtotal (95\% CI) } & & \mathbf{1 8} & & \mathbf{2 1} & \mathbf{1 0 0 . 0} \% & \mathbf{1 . 2 1}[\mathbf{0 . 2 6}, \mathbf{5 . 7 6}] \\ \text { Total events: } & 4 & & 4 & & & \end{array}$

Total events:

Test for overall effect: $\mathrm{Z}=0.24(\mathrm{P}=0.81)$

Test for subgroup differences: Not applicable

Odds Ratio M-H, Random, 95\% CI

Footnotes

(1) Number of falls

Analysis 3.6. Comparison 3: Substitutive interventions versus control, placebo or no intervention, Outcome 6: Quality of life

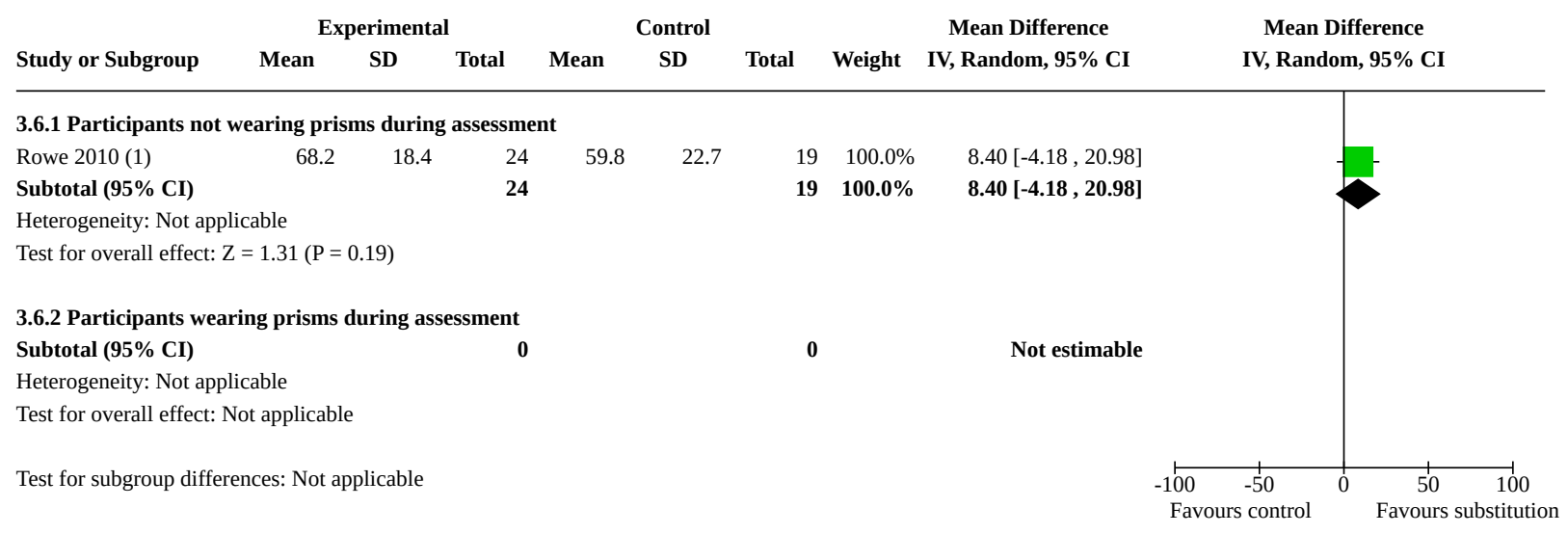

Footnotes

(1) VFQ-25 


\section{Analysis 3.7. Comparison 3: Substitutive interventions versus control,} placebo or no intervention, Outcome 7: Scanning - cancellation

\begin{tabular}{|c|c|c|c|c|c|c|c|c|c|}
\hline \multirow{2}{*}{ Studvor Suboroun } & \multicolumn{3}{|c|}{ Experimental } & \multicolumn{3}{|c|}{ Control } & \multicolumn{2}{|r|}{ Mean Difference } & Mean Difference \\
\hline & Mean & SD & Total & Mean & SD & Total & Weight & IV, Random, 95\% CI & IV, Random, 95\% CI \\
\hline
\end{tabular}

3.7.1 Participants not wearing prisms during assessment

Subtotal (95\% $\mathrm{C}$

Not estimable

Heterogeneity: Not applicable

Test for overall effect: Not applicable

3.7.2 Participants wearing prisms during assessment

$\begin{array}{lllllllll}\text { Rossi } 1990(1) & -12.6 & 12.54 & 18 & -22.4 & 12.54 & 21 & 100.0 \% & 9.80[1.91,17.69]\end{array}$

$\begin{array}{lllll}\text { Subtotal }(95 \% \text { CI) } & 18 & 21 & 100.0 \% & 9.80[1.91,17.69]\end{array}$

Heterogeneity: Not applicable

Test for overall effect: $\mathrm{Z}=2.43(\mathrm{P}=0.01)$

Test for subgroup differences: Not applicable

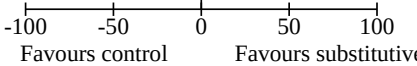

Footnotes

(1) Line cancellation errors. Reported mean baseline measures and the improvements made by the experimental group relative to baseline and the control group, and P values fr

Analysis 3.8. Comparison 3: Substitutive interventions versus control, placebo or no intervention, Outcome 8: Adverse events

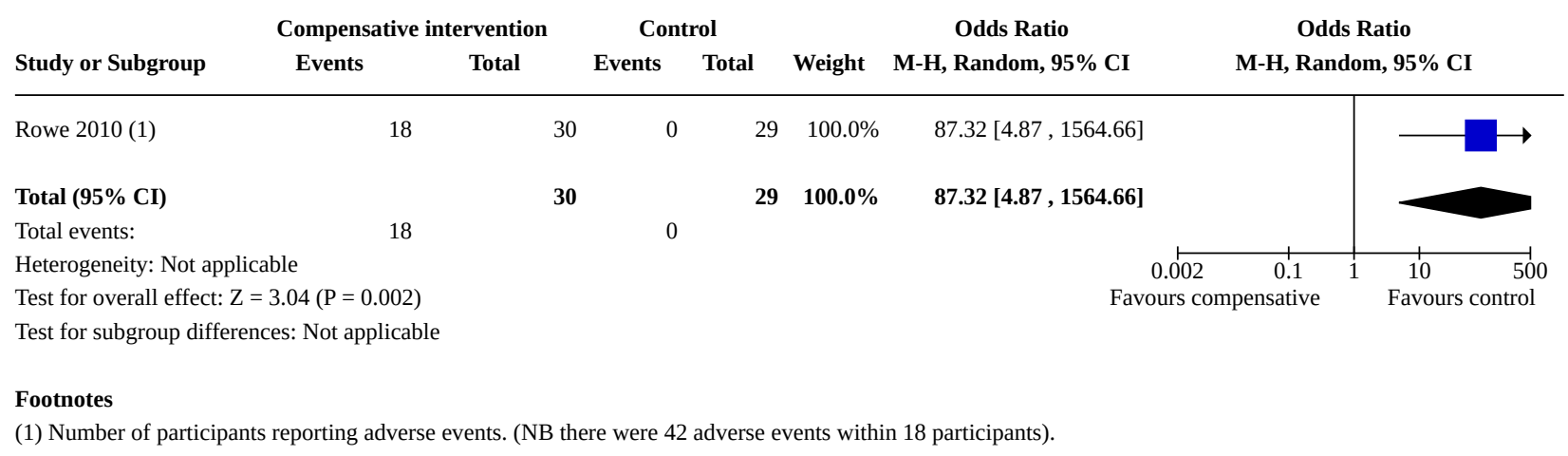

Comparison 4. Assessment or screening versus control, placebo or no intervention

\begin{tabular}{lllll}
\hline $\begin{array}{l}\text { Outcome or sub- } \\
\text { group title }\end{array}$ & No. of studies & $\begin{array}{l}\text { No. of partici- } \\
\text { pants }\end{array}$ & Statistical method & Effect size \\
\hline $4.1 \mathrm{ADL}$ & 1 & 37 & Mean Difference (IV, Random, 95\% Cl) & $-6.97[-23.78,9.84]$ \\
\hline
\end{tabular}


Analysis 4.1. Comparison 4: Assessment or screening versus control, placebo or no intervention, Outcome 1: ADL

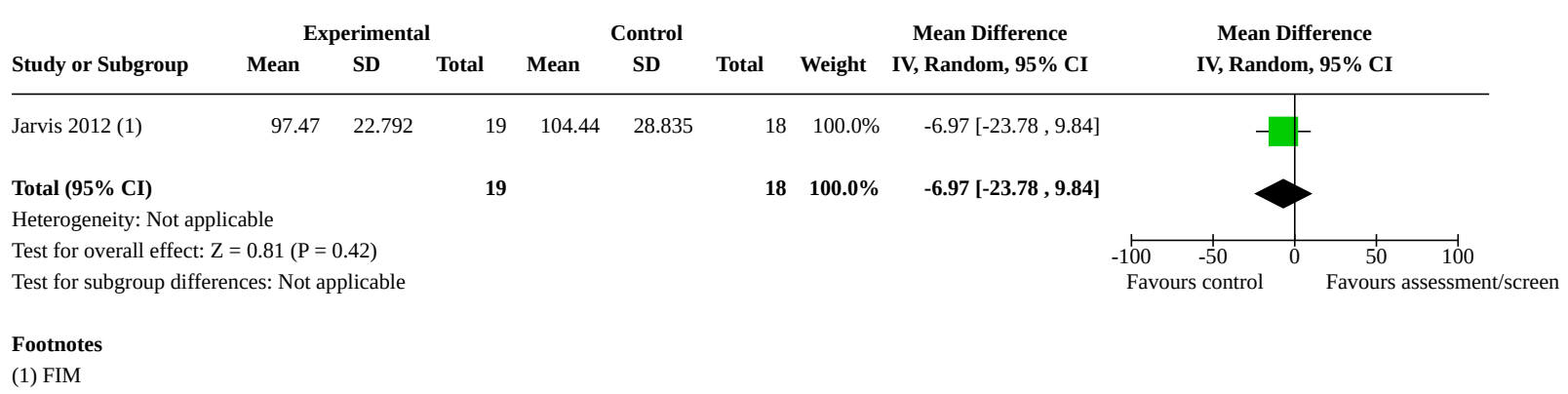

ADDITIONAL TABLES

Table 1. Demographics of included studies: settings of included studies

\begin{tabular}{|c|c|c|c|c|}
\hline Study & Country & Number of centres & Setting for intervention & $\begin{array}{l}\text { Trial registra- } \\
\text { tion }\end{array}$ \\
\hline Aimola 2011 & UK & $\begin{array}{l}\text { Multicentre ("from local } \\
\text { hospitals or as self-refer- } \\
\text { rals") }\end{array}$ & $\begin{array}{l}\text { Community } \\
\text { (participants' own homes) }\end{array}$ & $\begin{array}{l}\text { UK Clinical Re- } \\
\text { search Net- } \\
\text { work Portfolio } \\
\text { (UKCRN, ID 7144) }\end{array}$ \\
\hline Bainbridge 1994 & USA & Single & NS & NS \\
\hline Bowers 2014 & UK, USA & Multicentre (13 study sites) & $\begin{array}{l}\text { University, hospital, private practice for } \\
\text { fitting of prisms } \\
\text { Then use at home (participants' own } \\
\text { homes) }\end{array}$ & $\begin{array}{l}\text { clinicaltrials.gov } \\
\text { NCT00494676 }\end{array}$ \\
\hline De Haan 2015 & Netherlands & $\begin{array}{l}2 \text { ("Royal Dutch Visio and } \\
\text { Bartiméus, the two centers } \\
\text { of expertise for blind and } \\
\text { partially sighted people in } \\
\text { the Netherlands") }\end{array}$ & $\begin{array}{l}\text { Training ... "was provided in Dutch at } \\
\text { nine locations of Royal Dutch Visio and } \\
\text { one location of Bartiméus in the Nether- } \\
\text { lands". } \\
\text { Participants were also given homework } \\
\text { assignments. }\end{array}$ & $\begin{array}{l}\text { ISRCTN Registry } \\
\text { ISRCTN16833414 }\end{array}$ \\
\hline Elshout 2016 & Netherlands & $\begin{array}{l}\text { Unclear ("Patients through- } \\
\text { out the Netherlands could } \\
\text { sign up for our study volun- } \\
\text { tarily by filling in a form on } \\
\text { our website") }\end{array}$ & $\begin{array}{l}\text { Community } \\
\text { (participants' own homes) }\end{array}$ & NS \\
\hline Gall 2013 & Not clear & NS & NS & NS \\
\hline Jarvis 2012 & UK & Single & $\begin{array}{l}\text { Stroke unit, Warring and Halton Hospi- } \\
\text { tals, } \\
\text { NHS Foundation Trust }\end{array}$ & NS \\
\hline Jobke 2009 & Germany & NS & NS & NS \\
\hline Kasten 1998 & Germany & NS & Community & NS \\
\hline
\end{tabular}


Table 1. Demographics of included studies: settings of included studies (Continued)

(participants' own homes)

\begin{tabular}{|c|c|c|c|c|}
\hline Kasten 2007 & Germany & NS & $\begin{array}{l}\text { Community } \\
\text { (participants' own homes) }\end{array}$ & NS \\
\hline Keller 2010 & Germany & Single & Neurological clinic & NS \\
\hline Modden 2012 & Germany & Single & Rehabilitation centre (inpatients) & NS \\
\hline Plow 2010 & USA & Single & $\begin{array}{l}\text { Outpatient } \\
\text { (University clinic) }\end{array}$ & $\begin{array}{l}\text { clinicaltrials.gov } \\
\text { NCT00921427 }\end{array}$ \\
\hline Poggel 2004 & Germany & Single & $\begin{array}{l}\text { Community } \\
\text { (participants' own homes) }\end{array}$ & NS \\
\hline Rossi 1990 & USA & Single & $\begin{array}{l}\text { Rehabilitation } \\
\text { (inpatient) }\end{array}$ & NS \\
\hline Roth 2009 & Germany & NS & $\begin{array}{l}\text { Community } \\
\text { (participants' own homes) }\end{array}$ & NS \\
\hline Rowe 2010 & UK & $\begin{array}{l}\text { Multicentre ("from stroke } \\
\text { units based in } 15 \text { Unit- } \\
\text { ed Kingdom (UK) Nation- } \\
\text { al Health Service (NHS) } \\
\text { trusts") }\end{array}$ & Any (hospital, community) & $\begin{array}{l}\text { Current Con- } \\
\text { trolled Trials } \\
\text { ISRCTN05956042 }\end{array}$ \\
\hline Schuett 2012 & $\begin{array}{l}\text { Unclear. Authors } \\
\text { from Austria, UK } \\
\text { and Germany. } \\
\text { "All participants } \\
\text { were native Ger- } \\
\text { man speakers." }\end{array}$ & NS & NS & NS \\
\hline Spitzyna 2007 & UK & NS & $\begin{array}{l}\text { Community } \\
\text { (participants' own homes) }\end{array}$ & NS \\
\hline Szlyk 2005 & USA & Single; university & Outpatient clinic & NS \\
\hline
\end{tabular}

NHS: National Health Service

NS: not stated

UK: United Kingdom

USA: United States of America 


\begin{tabular}{|c|c|c|c|c|c|c|c|}
\hline Study & $\begin{array}{l}\text { Number of } \\
\text { participants }\end{array}$ & Age & Gender & $\begin{array}{l}\text { Time since stroke/le- } \\
\text { sion }\end{array}$ & $\begin{array}{l}\text { Initial func- } \\
\text { tional ability }\end{array}$ & Type of stroke/lesion & $\begin{array}{l}\text { Side of stroke/ } \\
\text { lesion }\end{array}$ \\
\hline Aimola 2011 & $\begin{array}{l}70 \text { partici- } \\
\text { pants recruit- } \\
\text { ed, } 52 \text { partici- } \\
\text { pants includ- } \\
\text { ed in analyses }\end{array}$ & $\begin{array}{l}\text { Group } 1 \\
\text { Mean } 61.4 \text { years, SD } \\
10.3 \\
\text { Group } 2 \\
\text { Mean } 63.0 \text { years, SD } \\
10.9\end{array}$ & $\begin{array}{l}\text { Group } 1 \\
9 \mathrm{~F} \\
19 \mathrm{M} \\
\text { Group } 2 \\
7 \mathrm{~F} \\
17 \mathrm{M}\end{array}$ & NS & NS & $\begin{array}{l}\text { Group } 1 \\
19 \text { ischaemic stroke } \\
4 \text { haemorrhagic, } \\
4 \text { traumatic brain injury } \\
1 \text { tumour } \\
\text { Group } 2 \\
20 \text { ischaemic stroke } \\
2 \text { haemorrhagic } \\
2 \text { traumatic brain injury } \\
0 \text { tumour }\end{array}$ & $\begin{array}{l}\begin{array}{l}\text { Side of field de- } \\
\text { fect }\end{array} \\
\text { Group } 1 \\
\text { L 15/R } 13 \\
\text { Group } 2 \\
\text { L11/R } 13\end{array}$ \\
\hline $\begin{array}{l}\text { Bainbridge } \\
1994\end{array}$ & 18 & NS & NS & NS & NS & NS & NS \\
\hline Bowers 2014 & $\begin{array}{l}73 \text { ran- } \\
\text { domised; } 67 \\
\text { completed } \\
\text { first phase } \\
\text { (before cross- } \\
\text { over); } 61 \text { com- } \\
\text { pleted second } \\
\text { phase (after } \\
\text { cross-over) }\end{array}$ & $\begin{array}{l}\text { For } 61 \text { participants in- } \\
\text { cluded after the cross- } \\
\text { over: } \\
\text { median } 58 \text { years (range } \\
18 \text { to } 89 \text { ) }\end{array}$ & $\begin{array}{l}\text { For } 61 \text { partic- } \\
\text { ipants includ- } \\
\text { ed after the } \\
\text { cross-over: } \\
\text { M } 40 \\
\text { F } 21\end{array}$ & $\begin{array}{l}\text { For } 61 \text { participants in- } \\
\text { cluded after the cross- } \\
\text { over: } \\
\text { median } 18 \text { months } \\
\text { (range } 3 \text { to } 396 \text { ) }\end{array}$ & $\begin{array}{l}\text { Overall base- } \\
\text { line mobili- } \\
\text { ty difficulty, } \\
\text { for } 61 \text { partici- } \\
\text { pants includ- } \\
\text { ed after the } \\
\text { cross-over: } \\
\text { mean -0.17 } \\
\text { (SD } 2.31 \text { ) log- } \\
\text { its for } n=31 \\
\text { using oblique } \\
\text { prisms } \\
\text { mean -0.06 } \\
\text { (SD } 1.89 \text { ) log- } \\
\text { its for } n=30 \\
\text { using horizon- } \\
\text { tal prisms }\end{array}$ & $\begin{array}{l}\text { For } 61 \text { participants included } \\
\text { after the cross-over: } \\
\text { hemianopia was caused by } \\
\text { stroke for } 47(77 \%)\end{array}$ & $\begin{array}{l}\text { For } 61 \text { partici- } \\
\text { pants included } \\
\text { after the cross- } \\
\text { over: } \\
\text { L hemianopia } \\
39(64 \%)\end{array}$ \\
\hline
\end{tabular}









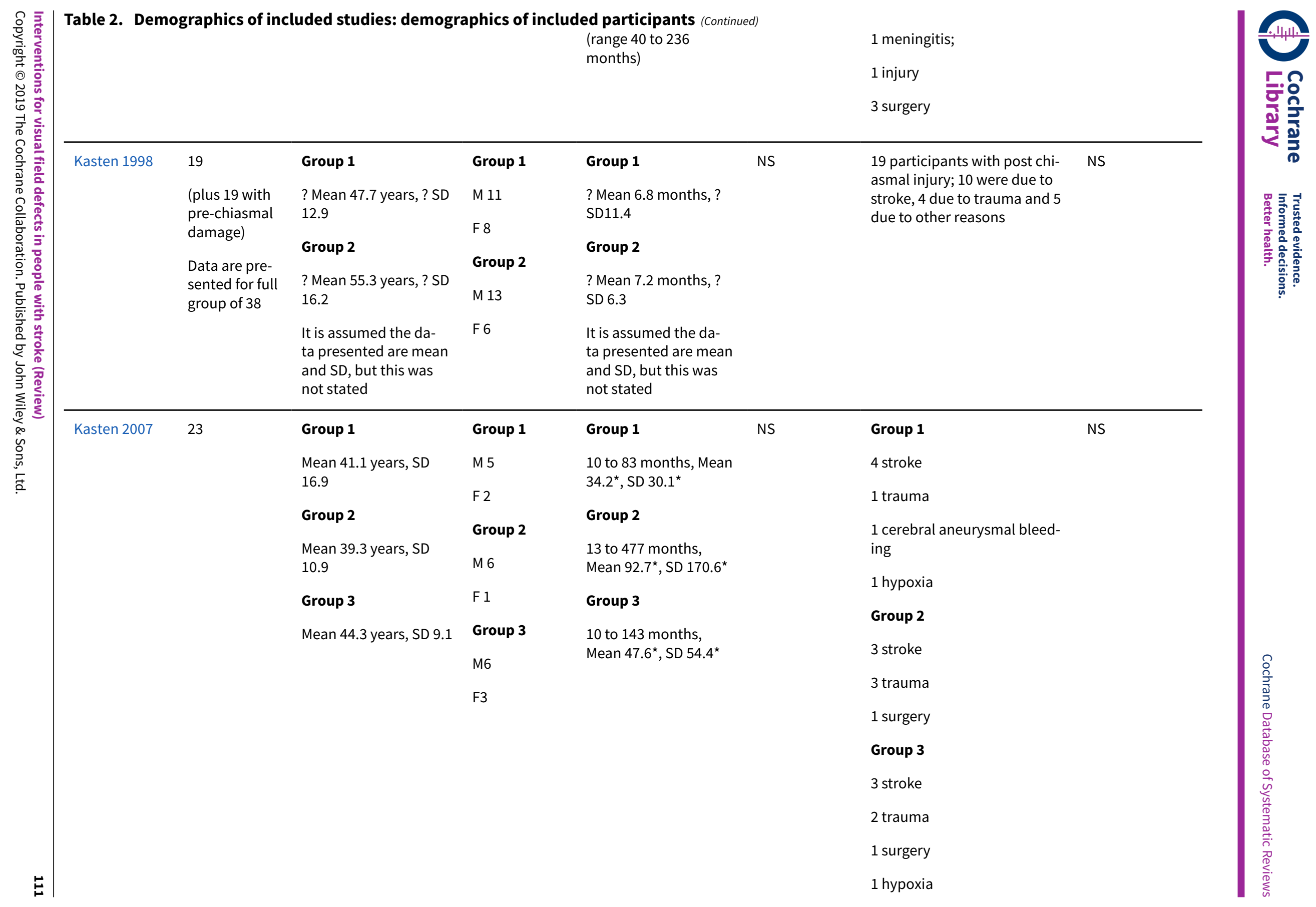




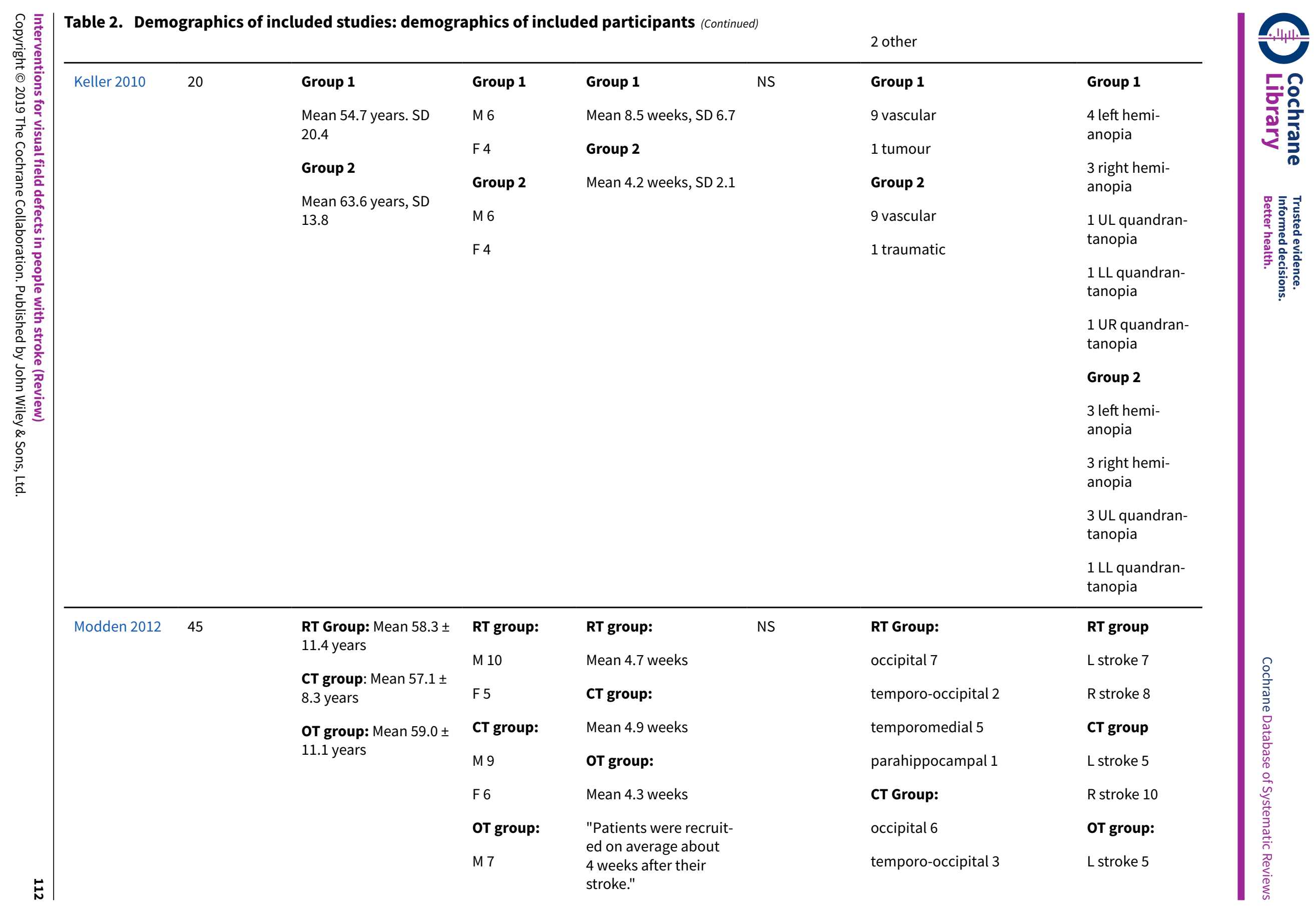




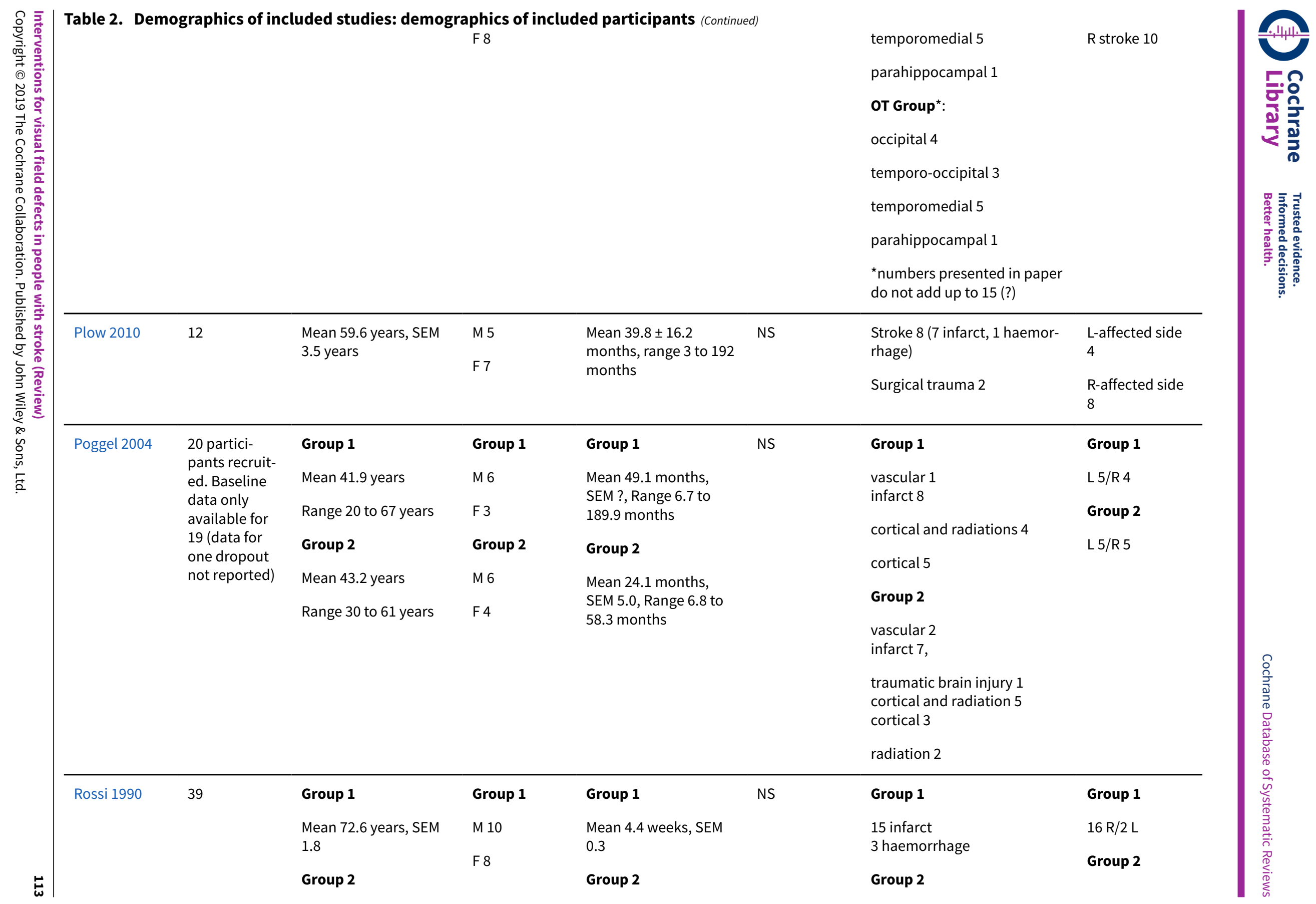




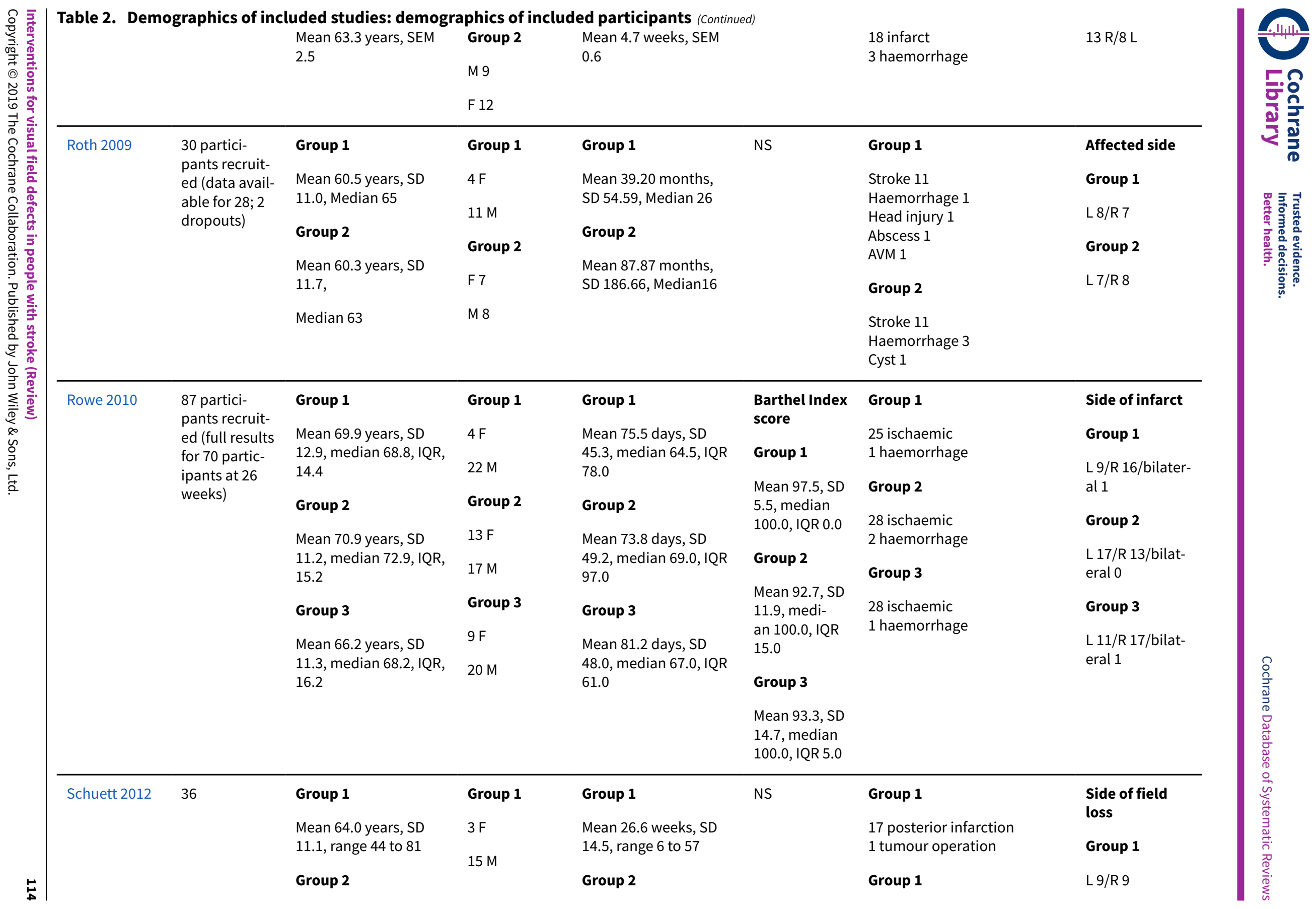








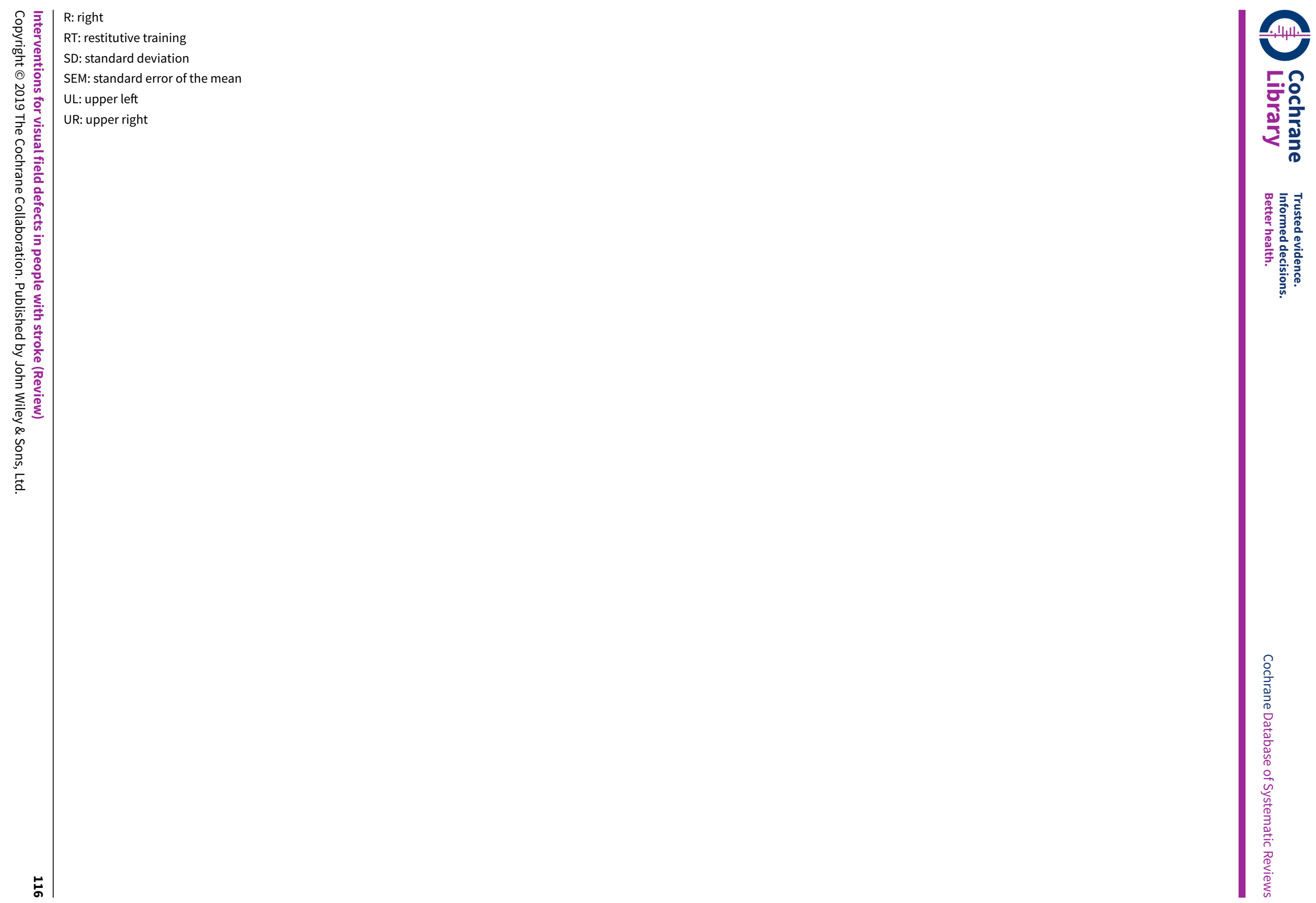
Table 3. Demographics of included studies: visual problems of included participants

\begin{tabular}{|c|c|c|c|c|}
\hline Study & $\begin{array}{l}\text { Methods of visu- } \\
\text { al field assess- } \\
\text { ment }\end{array}$ & Type/extent of field loss & Macular sparing & Presence of neglect? \\
\hline Aimola 2011 & $\begin{array}{l}\text { Unspecified ki- } \\
\text { netic perimeter } \\
\text { Esterman mea- } \\
\text { sures of static su- } \\
\text { perthreshold }\end{array}$ & $\begin{array}{l}\text { Group } 1 \\
\text { Hemianopia 20, quadrantanopia } 8 \\
\text { Group } 2 \\
\text { Hemianopia 20, quadrantanopia } 4\end{array}$ & $\begin{array}{l}\text { Group } 1 \\
\text { Mean } 1.92^{\circ} \text { (SD } \\
1.44) \\
\text { Group } 2 \\
\text { Mean } 2.45^{\circ} \text { (SD } \\
1.85)\end{array}$ & $\begin{array}{l}\text { Yes: stated "Three pa- } \\
\text { tients ( } 2 \text { in the interven- } \\
\text { tion group, } 1 \text { in the con- } \\
\text { trol group) had comor- } \\
\text { bid neglect as confirmed } \\
\text { with the bells test". }\end{array}$ \\
\hline Bainbridge 1994 & $\begin{array}{l}\text { Harrington } \\
\text { Flocks Visual } \\
\text { Screener } \\
\text { Confrontation }\end{array}$ & Not stated & Not stated & $\begin{array}{l}\text { Yes: no details of inclu- } \\
\text { sion criteria or partici- } \\
\text { pants provided, but ob- } \\
\text { jective stated "To study } \\
\text { the effect of ... on visual } \\
\text { neglect or hemianopsia } \\
\text { following stroke". }\end{array}$ \\
\hline
\end{tabular}

\begin{tabular}{|c|c|c|c|c|}
\hline Bowers 2014 & $\begin{array}{l}\text { Goldmann } \\
\text { perimetry }\end{array}$ & Not stated & Not stated & $\begin{array}{l}\text { No: stated "no visual ne- } \\
\text { glect". Visual neglect di- } \\
\text { agnosed with Bells test } \\
\text { and Schenkenberg Line } \\
\text { Bisection Test. }\end{array}$ \\
\hline
\end{tabular}

\begin{tabular}{|c|c|c|c|c|}
\hline De Haan 2015 & $\begin{array}{l}\text { Goldmann } \\
\text { perimetry }\end{array}$ & $\begin{array}{l}\text { Training group } \\
\text { Functional field score } 58 \pm 7.8 \\
\text { Quadrantanopia } 5 \text { (3 lower left, } 1 \text { upper } \\
\text { left, } 1 \text { lower right) } \\
\text { Hemianopia } 21 \\
\text { Control group } \\
\text { Functional field score } 64 \pm 11.4 \\
\text { Quadrantanopia } 5 \text { (3 lower left, } 2 \text { upper } \\
\text { left) } \\
\text { Hemianopia } 18\end{array}$ & Not stated & $\begin{array}{l}\text { No: stated "Neglect was } \\
\text { excluded based on the } \\
\text { Balloons, drawings, Line } \\
\text { Bisection and Rey Com- } \\
\text { plex Figure Test." }\end{array}$ \\
\hline Elshout 2016 & $\begin{array}{l}\text { Goldman } \\
\text { perimetry } \\
\text { Humphrey } \\
\text { perimetry }\end{array}$ & $\begin{array}{l}\text { Right field loss: hemifield 4, incomplete } \\
\text { hemifield 5, quadrant 2, scotoma } 1 \\
\text { Left field loss: hemifield 2, incomplete } \\
\text { hemifield 9, quadrant 1, scotoma } 2 \\
\text { Bilaterial field loss } \\
\text { Incomplete: } 1\end{array}$ & $\begin{array}{l}\text { "All subjects } \\
\text { had macular } \\
\text { sparing of at } \\
\text { least } 2^{\circ "}\end{array}$ & $\begin{array}{l}\text { No: patients with visual } \\
\text { neglect were excluded } \\
\text { (based on line bisection } \\
\text { test) }\end{array}$ \\
\hline Gall 2013 & $\begin{array}{l}\text { Standard auto- } \\
\text { mated perimetry }\end{array}$ & Not stated & Not stated & Not stated \\
\hline Jarvis 2012 & Confrontation & Ocular diagnosis: & Not stated & $\begin{array}{l}\text { Yes: all patients with a } \\
\text { "post-stroke visual im- }\end{array}$ \\
\hline
\end{tabular}


Table 3. Demographics of included studies: visual problems of included participants (Continued)

low vision 30

visual field loss 38

pairment were eligible for inclusion".

eye movement deficit 41

perceptual impairment 24

("Note: patients may have had an isolated visual impairment or combined visual deficits")

\begin{tabular}{|c|c|c|c|c|}
\hline Jobke 2009 & $\begin{array}{l}\text { Standard auto- } \\
\text { mated perimetry } \\
\text { High resolution } \\
\text { perimetry (HRP) }\end{array}$ & $\begin{array}{l}\text { NB: It did not state whether participants } \\
\text { had visual neglect or whether this was di- } \\
\text { agnosed. } \\
\text { Group } 1 \\
2 \text { diffuse, } 2 \text { full homonymous hemianopia, } \\
1 \text { partial homonymous hemianopia, } 1 \text { full } \\
\text { quadrantanopia } \\
2 \text { partial quadrantanopia } \\
\text { Group } 2 \\
4 \text { diffuse, } 2 \text { full homonymous hemianopia, } \\
2 \text { partial homonymous hemianopia, } 1 \text { full } \\
\text { quadrantanopia, } \\
1 \text { partial quadrantanopia }\end{array}$ & $\begin{array}{l}\text { Group } 1 \\
7 \text { sparing, } 1 \text { not } \\
\text { sparing } \\
\text { Group } 2 \\
10 \text { sparing }\end{array}$ & Not stated \\
\hline Kasten 1998 & $\begin{array}{l}\text { Tubinger auto- } \\
\text { mated perimetry } \\
\text { (TAP) } \\
\text { High resolution } \\
\text { perimetry (HRP) }\end{array}$ & $\begin{array}{l}\text { NB: data were presented for full group of } \\
38 \text { participants (including participants in } \\
\text { parallel trial) } \\
\text { Group } 1 \\
\text { TAP } 90^{\circ} \text { - border position, mean } 3.51^{\circ} \text { (de- } \\
\text { grees of visual angle from zero vertical } \\
\text { meridian), SEM } 1.0 \\
\text { TAP } 90^{\circ} \text { - number of misses, mean } 53.0 \text {, } \\
\text { SEM } 9.1 \\
\text { Group } 2 \\
\text { TAP } 90^{\circ} \text { - border position, mean } 3.43^{\circ} \text { (de- } \\
\text { grees of visual angle from zero vertical } \\
\text { meridian), SEM } 0.99 \\
\text { TAP } 90^{\circ} \text { - number of misses, mean } 69.2 \text {, } \\
\text { SEM } 11.2\end{array}$ & Not stated & $\begin{array}{l}\text { No: participants with } \\
\text { neglect were excluded. } \\
\text { Method of diagnosis of } \\
\text { neglect not stated. }\end{array}$ \\
\hline Kasten 2007 & $\begin{array}{l}\text { Tubinger auto- } \\
\text { mated perimetry } \\
\text { (TAP) } \\
\text { High resolution } \\
\text { perimetry (HRP) }\end{array}$ & $\begin{array}{l}\text { TAP } 90^{\circ} \text { (number of blind stimuli positions) } \\
\text { Group } 1 \\
\text { Right eye - mean } 46.6 \text {, SD } 6.9 \text {, left eye - } \\
\text { mean } 43.9 \text {, SD } 3.7\end{array}$ & Not stated & $\begin{array}{l}\text { No: participants with } \\
\text { neglect were excluded. } \\
\text { Method of diagnosis of } \\
\text { neglect not stated }\end{array}$ \\
\hline
\end{tabular}

Group 2 
Table 3. Demographics of included studies: visual problems of included participants (Continued)

Right eye - mean 50.3, SD 8.7, left eye -

mean 43.1, SD 7.6

\section{Group 3}

Right eye - mean 32.9, SD 6.8, left eye -

mean 37.9, SD 7.1

\begin{tabular}{|c|c|c|c|c|}
\hline .Keller 2010 & $\begin{array}{l}\text { Goldmann } \\
\text { perimetry } \\
\text { Goldmann } \\
\text { suprathreshold }\end{array}$ & $\begin{array}{l}\text { Group } 1 \\
4 \text { left hemianopia } \\
3 \text { right hemianopia } \\
1 \text { UL quandrantanopia } \\
1 \text { LL quandrantanopia } \\
1 \text { UR quandrantanopia } \\
\text { Group } 2 \\
3 \text { left hemianopia } \\
3 \text { right hemianopia } \\
3 \text { UL quandrantanopia } \\
1 \text { LL quandrantanopia }\end{array}$ & $\begin{array}{l}\text { Group } 1 \\
6 \text { with } 0^{\circ} \text { macular } \\
\text { sparing } \\
4 \text { with }<5^{\circ} \text { macu- } \\
\text { lar sparing } \\
\text { Group } 2 \\
6 \text { with } 0^{\circ} \text { macular } \\
\text { sparing } \\
4 \text { with }<5^{\circ} \text { macu- } \\
\text { lar sparing }\end{array}$ & $\begin{array}{l}\text { No: participants with ne- } \\
\text { glect were excluded. } 3 \\
\text { neglect tests were used: } \\
\text { "line bisection, Mesulam } \\
\text { test, draw a clock face } \\
\text { test". }\end{array}$ \\
\hline Modden 2012 & $\begin{array}{l}\text { Visual field as- } \\
\text { sessment from } \\
\text { the Test Battery } \\
\text { of Attentional } \\
\text { Performance }\end{array}$ & $\begin{array}{l}\text { RT Group } \\
10 \text { hemianopia } \\
5 \text { quadrantanopia } \\
\text { TAP alertness without cueing, ms; mean } \\
\text { 304.2, SD } 80.8 \\
\text { TAP conjunction search, omissions; mean } \\
\text { 9.1, SD } 9.0 \\
\text { CT Group } \\
\text { 12 hemianopia } \\
3 \text { quadrantanopia } \\
\text { TAP alertness without cueing, ms; mean } \\
383.7 \text {, SD } 205.2 \\
\text { TAP conjunction search, omissions; mean } \\
10.7 \text {, SD } 6.7 \\
\text { OT Group } \\
10 \text { hemianopia } \\
5 \text { quadrantanopia } \\
\text { TAP alertness without cueing, ms; mean } \\
308.1 \text {, SD } 58.6 \\
\text { TAP conjunction search, omissions; mean } \\
10.3 \text {, SD } 5.6\end{array}$ & $\begin{array}{l}\text { RT Group } \\
\text { 3/15 participants } \\
\text { with less than } 2^{\circ} \\
\text { sparing } \\
\text { CT Group } \\
\text { 3/15 participants } \\
\text { with less than } 2^{\circ} \\
\text { sparing plus } 1 \\
\text { participant with } \\
\text { no sparing } \\
\text { OT Group } \\
\text { 3/15 participants } \\
\text { with less than } 2^{\circ} \\
\text { sparing }\end{array}$ & $\begin{array}{l}\text { No: participants with } \\
\text { neglect were excluded. } \\
\text { Method of diagnosis of } \\
\text { neglect not stated. }\end{array}$ \\
\hline
\end{tabular}


Table 3. Demographics of included studies: visual problems of included participants (Continued)

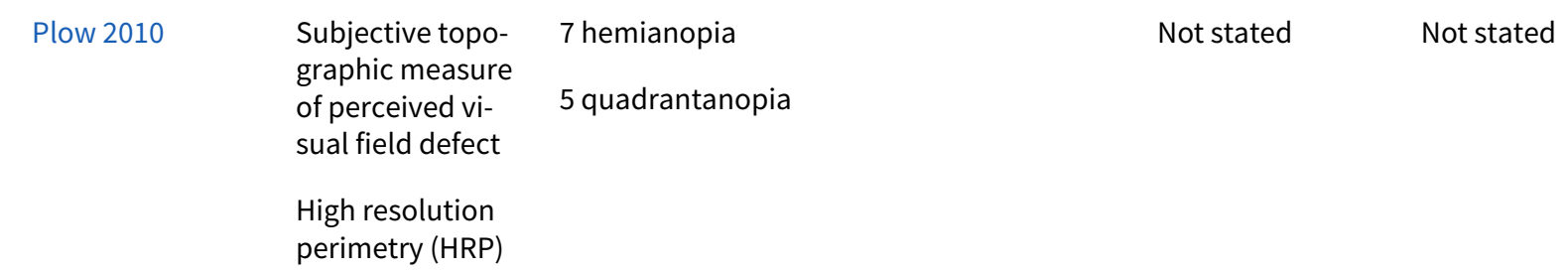

\begin{tabular}{|c|c|c|}
\hline \multirow[t]{3}{*}{ Poggel 2004} & $\begin{array}{l}\text { Tubinger auto- } \\
\text { mated perimetry } \\
\text { (TAP) }\end{array}$ & $\begin{array}{l}\text { Group } 1 \\
\text { Upper attention field (size of area of resid- } \\
\text { ual vision, \%), mean 18.2, SEM } 4.0\end{array}$ \\
\hline & $\begin{array}{l}\text { High resolution } \\
\text { campimetry }\end{array}$ & $\begin{array}{l}\text { Lower probe field (size of area of residual } \\
\text { vision, \%), mean } 21.3, \text { SEM } 3.1\end{array}$ \\
\hline & $\begin{array}{l}\text { High resolution } \\
\text { perimetry (HRP) }\end{array}$ & $\begin{array}{l}\text { Total visual field (size of area of residual vi- } \\
\text { sion, \%), mean } 7.3 \text {, SEM } 1.9\end{array}$ \\
\hline
\end{tabular}

\section{Group 2}

Upper attention field (size of area of residual vision, \%), mean 16.9, SEM 2.4

Not stated

Lower probe field (size of area of residual vision, \%), mean 15.5, SEM 4.0

Total visual field (size of area of residual vision, \%), mean 6.7, SEM 1.3

\begin{tabular}{lll}
\hline Rossi 1990 & $\begin{array}{l}\text { Harrington } \\
\text { Flocks Visual } \\
\text { Screener }\end{array}$ & Group 1 \\
& $\begin{array}{l}\text { Homonymous hemianopia } 12 \\
\text { Tangent screen } \\
\text { measures }\end{array}$ & (Visual neglect 6) \\
& Group 2 \\
& Homonymous hemianopia 15 \\
& & (Visual neglect 6)
\end{tabular}

Not stated

Yes: participants with "homonymous hemianopia or visual neglect were recruited ....". Method of diagnosis of neglect was Harrington Flocks Visual Screener.

39 participants recruited: 27 had homonymous hemianopia; 12 had visual neglect.

\begin{tabular}{|c|c|c|c|c|}
\hline Roth 2009 & $\begin{array}{l}\text { Tubinger auto- } \\
\text { mated perimetry } \\
\text { (TAP) } \\
\text { Scanning laser } \\
\text { ophthalmoscopy }\end{array}$ & $\begin{array}{l}\text { Group } 1 \\
\text { Homonymous hemianopia 12, quadran- } \\
\text { tanopia } 3 \\
\text { Group } 2 \\
\text { Homonymous hemianopia 12, quadran- } \\
\text { tanopia } 3\end{array}$ & Not stated & $\begin{array}{l}\text { No: participants with } \\
\text { neglect were excluded. } \\
\text { Method of diagnosis of } \\
\text { neglect was clock-draw- } \\
\text { ing and line-bisection } \\
\text { tests. }\end{array}$ \\
\hline Rowe 2010 & $\begin{array}{l}\begin{array}{l}\text { Goldmann } \\
\text { perimetry }\end{array} \\
\text { Esterman mea- } \\
\text { sures of static su- } \\
\text { perthreshold }\end{array}$ & $\begin{array}{l}\text { Group } 1 \\
\text { Homonymous hemianopia left partial } 8 \text {, } \\
\text { Homonymous hemianopia right partial } 3 \text {, } \\
\text { Homonymous hemianopia left complete } 9 \text {, } \\
\text { Homonymous hemianopia right complete } \\
6 \\
\text { Group } 2\end{array}$ & Not stated & $\begin{array}{l}\text { No: participants with } \\
\text { neglect were excluded. } \\
\text { Method of diagnosis was } \\
\text { clinical assessment: "as } \\
\text { assessed by the orthop- } \\
\text { tist". }\end{array}$ \\
\hline
\end{tabular}


Table 3. Demographics of included studies: visual problems of included participants (Continued)

Homonymous hemianopia left partial 5 ,

Homonymous hemianopia right partial 9 ,

Homonymous hemianopia left complete 8 ,

Homonymous hemianopia right complete

8

Group 3

Homonymous hemianopia left partial 8 , Homonymous hemianopia right partial 5, Homonymous hemianopia left complete 10 , Homonymous hemianopia right complete 6

\begin{tabular}{lll}
\hline Schuett 2012 & $\begin{array}{l}\text { Tubingen kinetic } \\
\text { perimetry }\end{array}$ & Group 1 \\
& Hemianopia 15, quadranopia 1, paracen- \\
& tral scotoma 2 \\
& Group 2 \\
& Hemianopia 10, quadranopia 4, paracen- \\
& tral scotoma 4
\end{tabular}

\section{Group 1}

Mean $2.3^{\circ}(\mathrm{SD}$

1.4)

Group 2

Mean $2.3^{\circ}(\mathrm{SD}$

1.2)
No: participants with neglect were excluded. Method of diagnosis described as: "as assessed by tests in accordance with the Behavioural Inattention Test (line bisection, letter and star cancellation, figure and shape copying, drawing from memory; Halligan et al, 1991)."

No: only participants with right-sided homonymous hemianopic were included; therefore, presence of neglect was assumed unlikely.

\section{Group 2}

Full homonymous hemianopia 6, lower quadrantanopia 1 , upper quadrantanopia 1

Full homonymous hemianopia 8, partial homonymous hemianopia 1 , lower quadrantanopia 1 , upper quadrantanopia 1
Macular sparing defined as $2^{\circ}$ of sparing

\section{Group 1}

Sparing 5, nonsparing 6

\section{Group 2}

Sparing 3, non sparing 5

\begin{tabular}{|c|c|c|c|c|}
\hline Szlyk 2005 & $\begin{array}{l}\text { Goldmann } \\
\text { perimetry }\end{array}$ & $\begin{array}{l}\text { Group } 1 \\
\text { Goldmann III4e, range } 45.2 \text { to } 125 \text {, mean } \\
59.12^{\star}, \text { SD } 22.07^{\star} \\
\text { Goldmann V4e, range } 48.8 \text { to } 115 \text {, mean } \\
70.56^{\star}, \text { SD } 26.15^{\star} \\
\text { Group } 2 \\
\text { Goldmann III4e, range } 46.8 \text { to } 123.8 \text {, mean } \\
68.0^{\star}, \text { SD } 31.71^{\star} \\
\text { Goldmann V4e, range } 50.67 \text { to } 132 \text {, mean } \\
73.73^{\star} \text {, SD } 33.10^{\star} \\
\text { Figures were calculated for the affected } \\
\text { side only. }\end{array}$ & Not stated & $\begin{array}{l}\text { Not stated; however, al- } \\
\text { though it was not stated } \\
\text { whether the participants } \\
\text { may have had visual ne- } \\
\text { glect, neglect is unlikely } \\
\text { in occipital lesions, and } \\
\text { only participants with oc- } \\
\text { cipital lesions were in- } \\
\text { cluded. }\end{array}$ \\
\hline
\end{tabular}

* Figures calculated from raw data supplied in papers combined: combined etiology 
HRP: high resolution perimetry

LL: lower left

LR: lower right

ms: milliseconds

SD: standard deviation

SEM: standard error of the mean

TAP: Tübingen automated perimeter

UL: upper left

UR: upper right 


\begin{tabular}{|c|c|c|c|c|c|c|c|c|c|c|}
\hline Study & $\begin{array}{l}\text { Functional } \\
\text { ability in } \\
\text { ADL }\end{array}$ & $\begin{array}{l}\text { Visual field } \\
\text { Outcome category } \\
\text { (measure) }\end{array}$ & $\begin{array}{l}\text { Functional } \\
\text { ability in } \\
\text { EADL }\end{array}$ & Reading & Falls & $\begin{array}{l}\text { Quality of } \\
\text { life }\end{array}$ & $\begin{array}{l}\text { Visual } \\
\text { scanning }\end{array}$ & $\begin{array}{l}\text { Adverse } \\
\text { events }\end{array}$ & Other & $\begin{array}{l}\text { Outcomes with } \\
\text { data included } \\
\text { within meta- } \\
\text { analyses }\end{array}$ \\
\hline $\begin{array}{l}\text { Aimola } \\
2011\end{array}$ & & $\begin{array}{l}\text { Kinetic Perimetry } \\
\text { (unspecified kinet- } \\
\text { ic perimeter) } \\
\text { Static Su- } \\
\text { perthreshold } \\
\text { (Esterman mea- } \\
\text { sures of static su- } \\
\text { perthreshold) } \\
\text { (NB not clear if } \\
\text { recorded as out- } \\
\text { come or not; no } \\
\text { results provided } \\
\text { for visual field da- } \\
\text { ta) }\end{array}$ & & $\begin{array}{l}\text { Reading } \\
\text { (correct- } \\
\text { ed reading } \\
\text { speed) }\end{array}$ & & $\begin{array}{l}\text { 1. VFQ } 25 \\
\text { 2. VIQ - Vi- } \\
\text { sual Im- } \\
\text { pairments } \\
\text { question- } \\
\text { naire } \\
\text { 3. Subjec- } \\
\text { tive Rea- } \\
\text { sons ques- } \\
\text { tionnaire }\end{array}$ & $\begin{array}{l}\text { 1. visual } \\
\text { search - } \\
\text { find the } \\
\text { number } \\
\text { (computer } \\
\text {-based) } \\
\text { 2. visuo- } \\
\text { motor } \\
\text { search - } \\
\text { find items } \\
\text { on a shelf }\end{array}$ & & $\begin{array}{l}\text { Tasks simu- } \\
\text { lating ADL - } 1 . \\
\text { driving haz- } \\
\text { ard perception } \\
\text { (mean score per } \\
\text { hazard), 2. ob- } \\
\text { stacle avoid- } \\
\text { ance (comple- } \\
\text { tion time), 3. } \\
\text { visuomotor } \\
\text { search (time) } \\
\text { Attention tasks } \\
\text { - 1. sustained } \\
\text { attention to re- } \\
\text { sponse (mean } \\
\text { percentage er- } \\
\text { ror score), } 2 \text {. } \\
\text { test of everyday } \\
\text { attention }\end{array}$ & $\begin{array}{l}\text { Reading: Analysis } \\
2.3 \\
\text { Visual search: } \\
\text { time to complete } \\
\text { Analysis } 2.5 \\
\text { QoL: data not in- } \\
\text { cluded as only } \\
\text { available for indi- } \\
\text { vidual question- } \\
\text { naire items }\end{array}$ \\
\hline $\begin{array}{l}\text { Bain- } \\
\text { bridge } \\
1994\end{array}$ & & $\begin{array}{l}\text { Gross visual } \\
\text { screening (Har- } \\
\text { rington-Flocks Vi- } \\
\text { sual Field Score) }\end{array}$ & & & & & $\begin{array}{l}\text { Line Can- } \\
\text { cellation } \\
\text { Test }\end{array}$ & & $\begin{array}{l}\text { Motor Free Vi- } \\
\text { sual Perception } \\
\text { Score } \\
\text { Line Bisection } \\
\text { Test }\end{array}$ & $\begin{array}{l}\text { No data includ- } \\
\text { ed in meta-analy- } \\
\text { ses (as no control } \\
\text { group). See Table } \\
5\end{array}$ \\
\hline $\begin{array}{l}\text { Bowers } \\
2014\end{array}$ & & & $\begin{array}{l}\text { Mobility } \\
\text { question- } \\
\text { naire }\end{array}$ & & & & & & $\begin{array}{l}\text { Question: "If } \\
\text { the study were } \\
\text { to end today, } \\
\text { would you } \\
\text { want to contin- } \\
\text { ue with these } \\
\text { prism glasses } \\
\text { (i.e. the prism } \\
\text { glasses worn in } \\
\text { that period)?" }\end{array}$ & $\begin{array}{l}\text { Functional ability } \\
\text { in EADL: Analysis } \\
3.3\end{array}$ \\
\hline
\end{tabular}




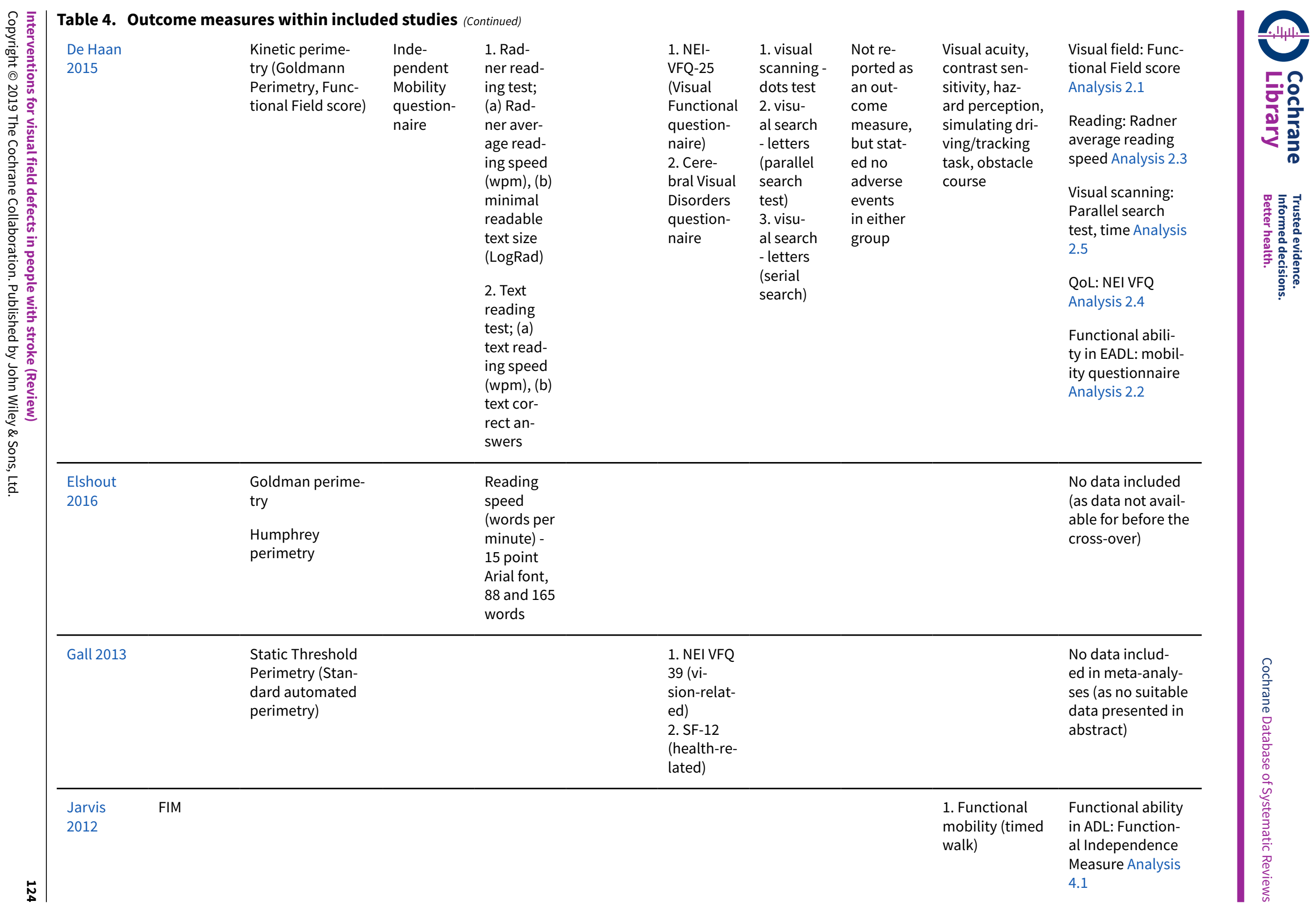




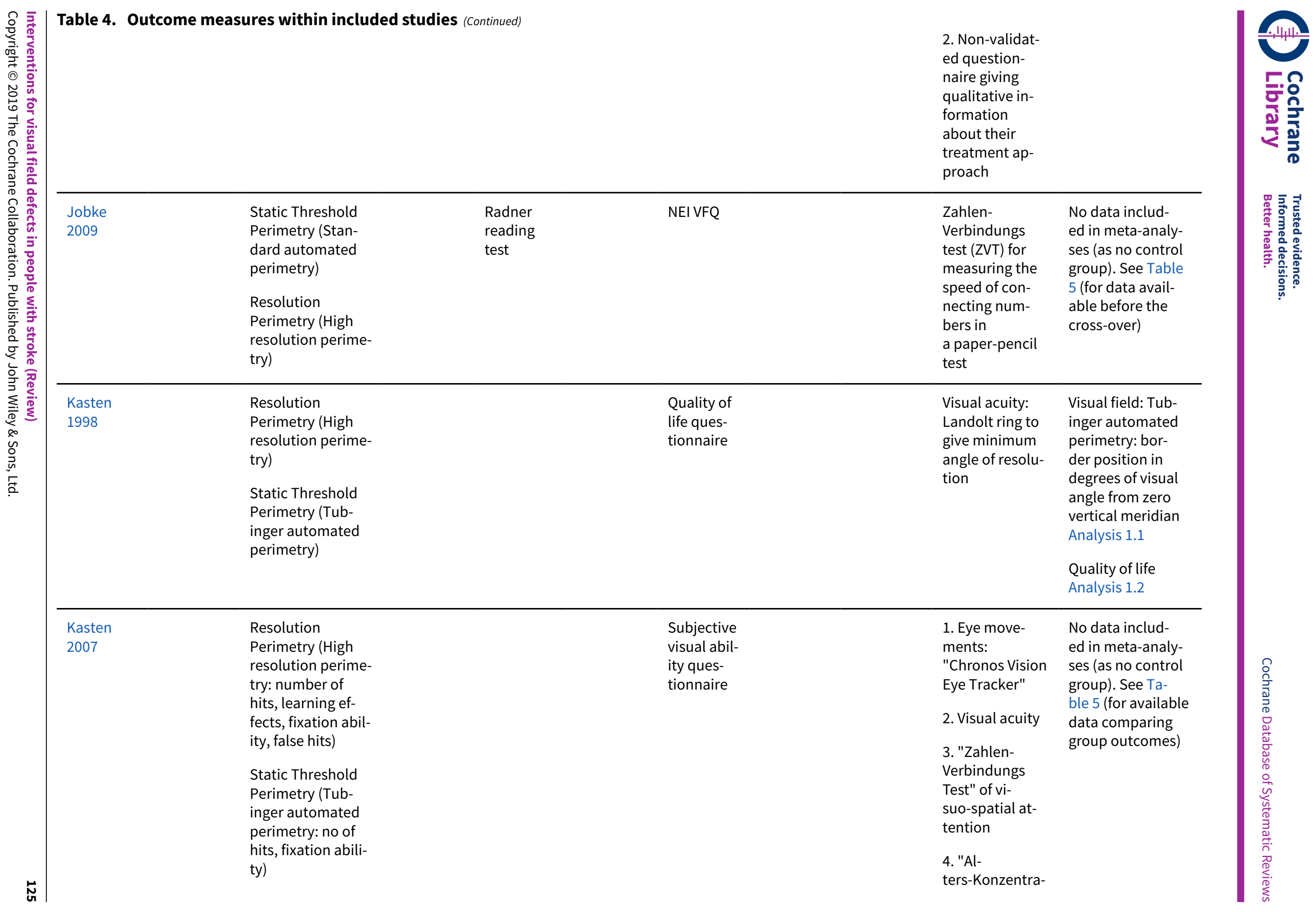




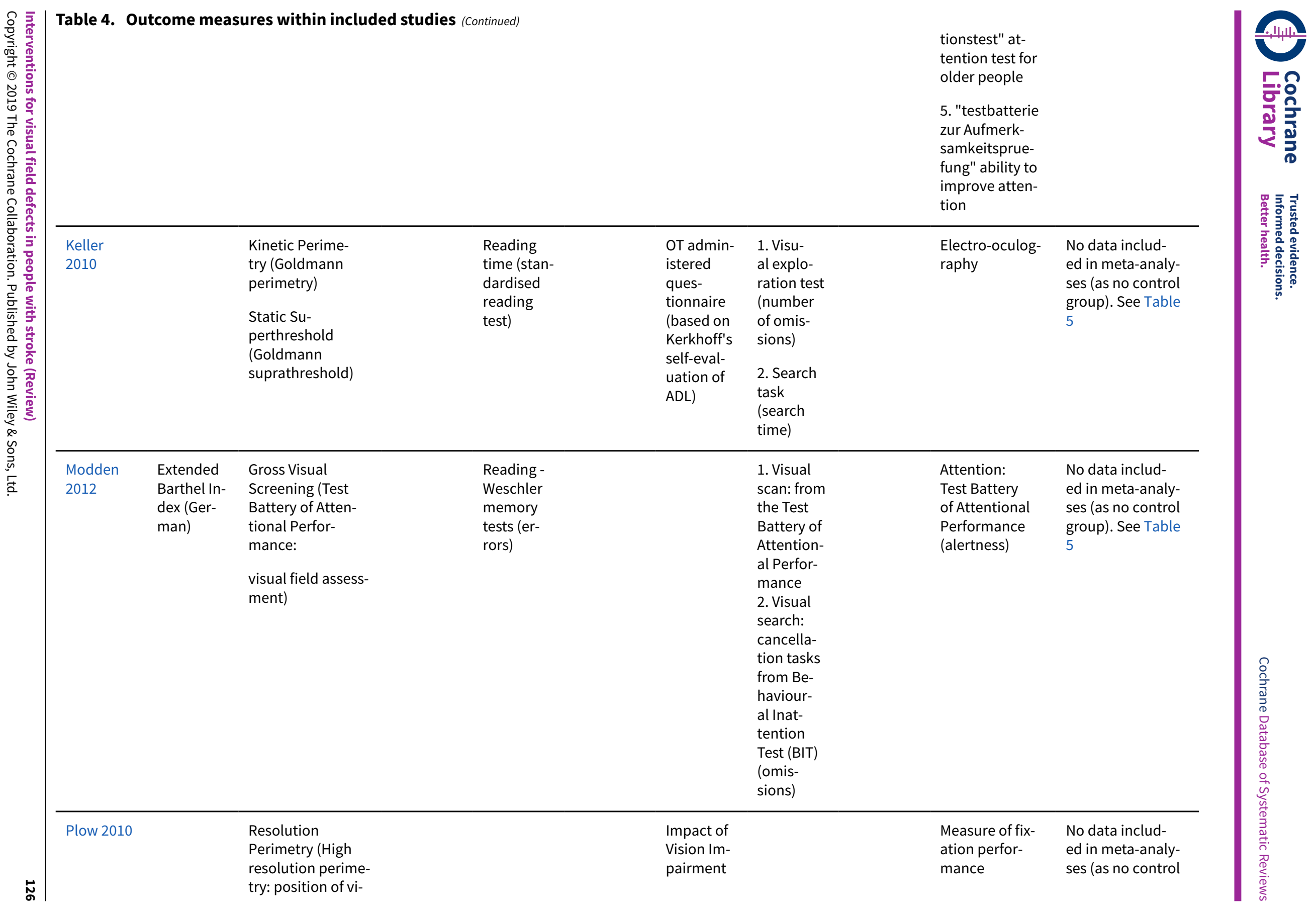


Table 4. Outcome measures within included studies (Continued)

sual field border

(IVI) pro-

tection accuracy)

Low Vi-

Gross Visual

Screening (subjec-

sion-

tive topographic

Function

measure of per-

Question-

ceived visual field

deficit)

naire (LV-

\begin{tabular}{ll}
\hline Poggel & Static Threshold \\
2004 & Perimetry (Tub- \\
& inger automated \\
& perimetry (TAP))
\end{tabular}

No data includ-

ed in meta-analy-

ses (as no control

perimetry (TAP)

group). See Table

Static Su-

perthreshold

(High resolution

campimetry)

\section{Resolution}

Perimetry (High

resolution perime-

try (HRP))

\begin{tabular}{|c|c|c|c|c|c|c|}
\hline Rossi 1990 & $\begin{array}{l}\text { Barthel In- } \\
\text { dex }\end{array}$ & $\begin{array}{l}\text { Gross Visual } \\
\text { Screening (Har- } \\
\text { rington Flocks Vi- } \\
\text { sual Screener) } \\
\text { Static Su- } \\
\text { perthreshold } \\
\text { (Tangent screen } \\
\text { examination) }\end{array}$ & $\begin{array}{l}\text { Number of } \\
\text { falls }\end{array}$ & $\begin{array}{l}\text { Line can- } \\
\text { cellation } \\
\text { task }\end{array}$ & $\begin{array}{l}\text { Modified Mini } \\
\text { Mental Status } \\
\text { Examination, } \\
\text { Motor Free Vi- } \\
\text { sual Perceptual } \\
\text { Test, } \\
\text { Line Bisection } \\
\text { Task }\end{array}$ & $\begin{array}{l}\text { ADL: Barthel In- } \\
\text { dex: Analysis } 3.1 \\
\text { Visual Field: Analy- } \\
\text { sis } 3.2 \\
\text { Falls: number of } \\
\text { falls Analysis } 3.5 \\
\text { Visual scanning: } \\
\text { cancellation } \\
\text { Analysis } 3.7\end{array}$ \\
\hline
\end{tabular}

Reading

QoL:

inger automated

speed

World

1. Digit

perimetry (TAP))

Resolution

ganisa-

sponse

tion ques- time)

tionnaire

WHO-

al search
No data includ ed in meta-analyses (as no control group). See Table 


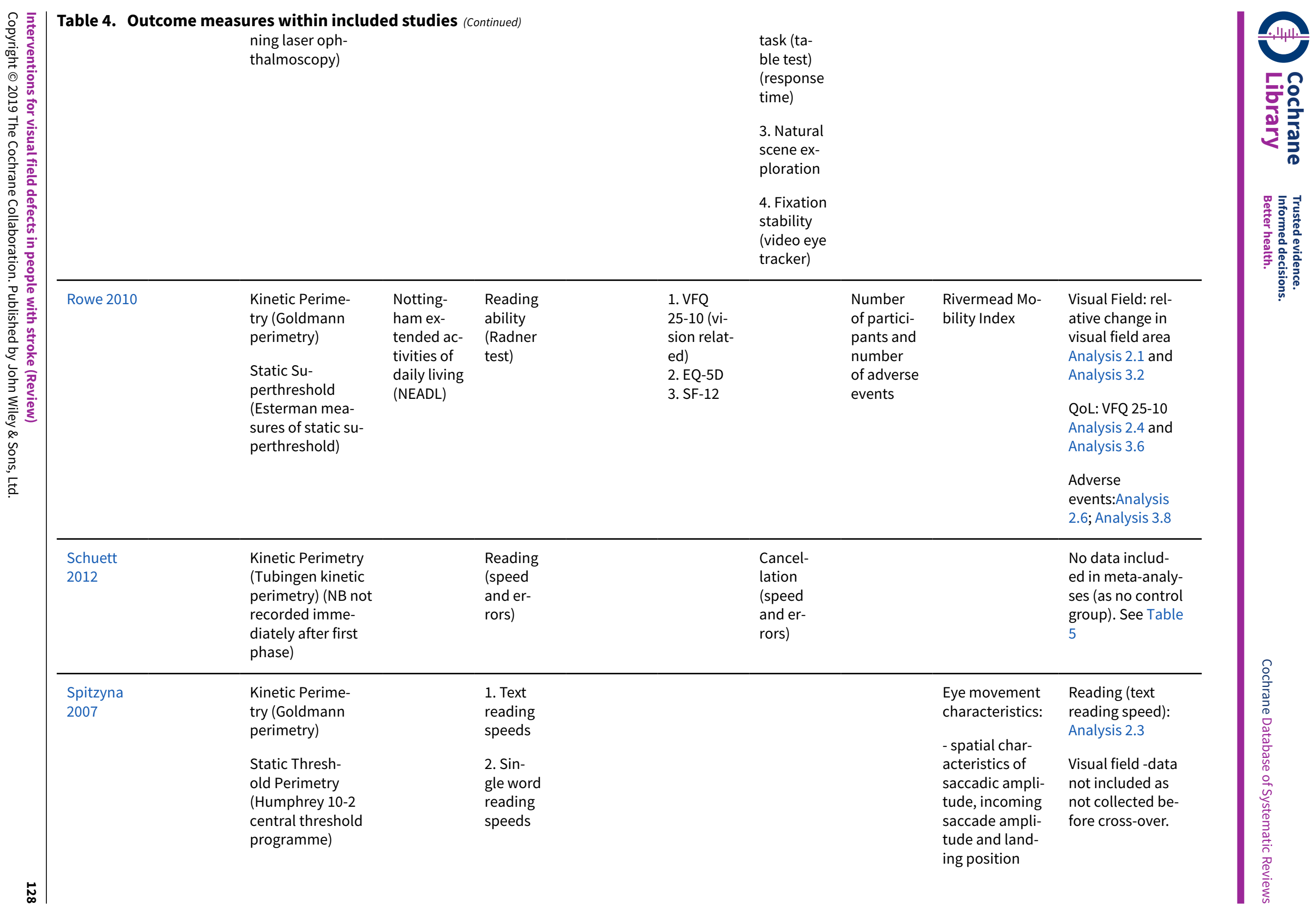




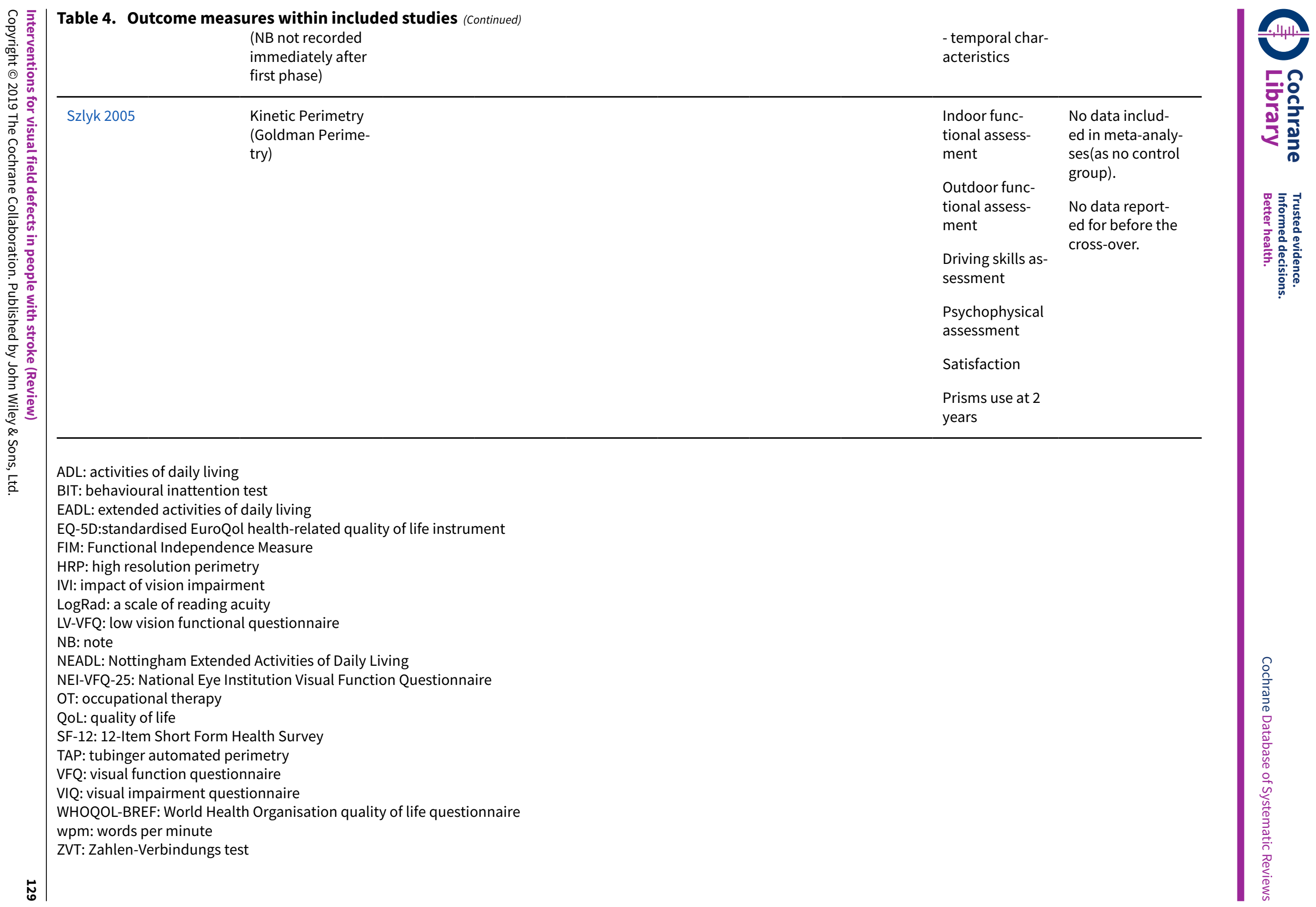


Table 5. Results of studies comparing two similar active interventions (i.e. two interventions from the same category)

\begin{tabular}{|c|c|c|c|c|c|c|}
\hline Study & Interventions & Outcome & $\begin{array}{l}\text { Mean (or } \\
\text { other re- } \\
\text { ported re- } \\
\text { sult if no } \\
\text { mean avail- } \\
\text { able) }\end{array}$ & $\begin{array}{l}\text { Standard } \\
\text { deviation }\end{array}$ & $\begin{array}{l}\text { Number } \\
\text { of partici- } \\
\text { pants }\end{array}$ & Statistical test/results \\
\hline
\end{tabular}

\section{Restitution: one restitution intervention versus another restitution intervention}

\begin{tabular}{|c|c|c|c|c|c|}
\hline \multirow[t]{2}{*}{ Jobke 2009} & Extrastriate VRT & \multirow[t]{2}{*}{$\begin{array}{l}\text { Visual field (high- } \\
\text { resolution perime- } \\
\text { try, HRP) }\end{array}$} & \multirow{2}{*}{$\begin{array}{l}\text { increase from baseline of } \\
5.9 \% \text { (percentage of HRP } \\
\text { hits) } \\
\text { increase from baseline of } \\
2.9 \% \text { (percentage of HRP } \\
\text { hits) }\end{array}$} & \multirow[b]{2}{*}{10} & \multirow{2}{*}{$\begin{array}{l}\text { significant increase: } \mathrm{t}= \\
-5.262, \mathrm{P}=0.0005 \\
\begin{array}{l}\text { significant increase: } \mathrm{t}= \\
-2.373, \mathrm{P}=0.021\end{array}\end{array}$} \\
\hline & Standard VRT & & & & \\
\hline \multirow[t]{3}{*}{$\begin{array}{l}\text { Kasten } \\
2007\end{array}$} & $\begin{array}{l}\text { Parallel co-stimula- } \\
\text { tion }\end{array}$ & \multirow{3}{*}{$\begin{array}{l}\text { Visual field (high- } \\
\text { resolution perime- } \\
\text { try) }\end{array}$} & $\begin{array}{l}\text { increase of } 2.4 \% \text { detected } \\
\text { stimuli }\end{array}$ & 7 & \multirow{3}{*}{$\begin{array}{l}\text { No significant difference } \\
\text { "confirmed by nonpara- } \\
\text { metric Kruskal-Wallis } \\
\text { ANOVA" }\end{array}$} \\
\hline & $\begin{array}{l}\text { Moving co-stimula- } \\
\text { tion }\end{array}$ & & $\begin{array}{l}\text { increase of } 6.5 \% \text { detected } \\
\text { stimuli }\end{array}$ & 7 & \\
\hline & Single stimulus & & $\begin{array}{l}\text { increase of } 3.9 \% \text { detected } \\
\text { stimuli }\end{array}$ & 9 & \\
\hline \multirow[t]{7}{*}{ Plow 2010} & VRT + tDCS & \multirow[t]{2}{*}{$\begin{array}{l}\text { Visual field (high- } \\
\text { resolution perime- } \\
\text { try) }\end{array}$} & $\begin{array}{l}\text { shift from baseline to post- } \\
\text { test from } \\
4.11^{\circ} \pm 1.50^{\circ} \text { to } 8.37^{\circ} \pm 2.29^{\circ} \\
\text { Wilcoxon signed-rank test }= \\
0, \mathrm{P}=0.068\end{array}$ & 4 & \multirow[t]{2}{*}{$\begin{array}{l}\text { Mann-Whitney } U=0, P= \\
0.021 \text { (significantly greater } \\
\text { shift in the visual field bor- } \\
\text { der with VRT + tDCS than } \\
\text { VRT alone) }\end{array}$} \\
\hline & VRT + sham tDCS & & $\begin{array}{l}\text { shift from baseline to post- } \\
\text { test from } 6.33^{\circ} \pm 2.59^{\circ} \text { to } \\
7.03^{\circ} \pm 2.51^{\circ} \text {, Wilcoxon } \\
\text { signed-rank test }=1, P= \\
0.144\end{array}$ & 4 & \\
\hline & VRT + tDCS & \multirow[t]{2}{*}{$\begin{array}{l}\text { Functional ability } \\
\text { in ADL (LV-VFQ) }\end{array}$} & $\begin{array}{l}\text { shift from baseline to post- } \\
\text { test from } 32.25 \\
\pm 5.30 \text { to } 28.25 \pm 5.07 \\
\text { Wilcoxon signed-rank test }= \\
0 ; P=0.068\end{array}$ & 4 & \multirow[t]{2}{*}{$\begin{array}{l}\text { Mann-Whitney } U=5.5 ; P= \\
0.468 \text { (non-significant) }\end{array}$} \\
\hline & VRT + sham tDCS & & $\begin{array}{l}\text { shift from baseline to post- } \\
\text { test from } 28 \pm 2.34 \text { to } 25.25 \\
\pm 1.11 ; \text { Wilcoxon signed- } \\
\text { rank test }=1 ; \mathrm{P}=0.285\end{array}$ & 4 & \\
\hline & VRT + tDCS & \multirow{2}{*}{$\begin{array}{l}\text { Functional abili- } \\
\text { ty in ADL (LV-VFQ) } \\
\text {-6-month fol- } \\
\text { low-up }\end{array}$} & 29.00 & \multirow[t]{2}{*}{5} & \multirow[t]{2}{*}{$\begin{array}{l}\text { Wilcoxon signed-rank test } \\
=4 ; \mathrm{P}=0.343\end{array}$} \\
\hline & VRT + sham tDCS & & 26.80 & & \\
\hline & VRT + tDCS & $\begin{array}{l}\text { Quality of life - 6- } \\
\text { month follow-up }\end{array}$ & 23.20 & 5 & Wilcoxon \\
\hline
\end{tabular}


Table 5. Results of studies comparing two similar active interventions (i.e. two interventions from the same category) (Continued)

\begin{tabular}{|c|c|c|c|c|c|c|}
\hline & VRT + sham tDCS & & 16.8 & 4.62 & & $\begin{array}{l}\text { signed-rank test }=2.5 ; P= \\
0.357\end{array}$ \\
\hline \multirow[t]{2}{*}{$\begin{array}{l}\text { Poggel } \\
2004\end{array}$} & $\begin{array}{l}\text { VRT + attentional } \\
\text { cueing }\end{array}$ & \multirow{2}{*}{$\begin{array}{l}\text { Visual field (high- } \\
\text { resolution perime- } \\
\text { try) - percentage } \\
\text { improvement, at- } \\
\text { tention field }\end{array}$} & 8.3 & SEM 1.5 & 9 & \multirow[t]{2}{*}{$\begin{array}{l}\mathrm{P}=0.001 \text { (in favour of at- } \\
\text { tentional cueing) }\end{array}$} \\
\hline & $\begin{array}{l}\text { VRT with no atten- } \\
\text { tional cueing }\end{array}$ & & 2.9 & SEM 0.8 & 10 & \\
\hline
\end{tabular}

\section{Compensation: one compensation intervention versus another compensation intervention}

\begin{tabular}{|c|c|c|c|c|c|c|}
\hline \multirow[t]{4}{*}{$\begin{array}{l}\text { Schuett } \\
2012\end{array}$} & $\begin{array}{l}\text { Visual exploration } \\
\text { training }\end{array}$ & Reading speed & 105.3 & 33.8 & 18 & \multirow[t]{2}{*}{$\begin{array}{l}\text { Not reported; calculat- } \\
\text { ed as MD - } 19.30 \text { (-43.32 to } \\
\text { 4.72) (see Figure 3) }\end{array}$} \\
\hline & Reading training & & 124.6 & 39.5 & 18 & \\
\hline & $\begin{array}{l}\text { Visual exploration } \\
\text { training }\end{array}$ & \multirow[t]{2}{*}{$\begin{array}{l}\text { Cancellation test } \\
\text { (exploration time) }\end{array}$} & 18.5 & 4.9 & 18 & \multirow[t]{2}{*}{$\begin{array}{l}\text { Not reported; calculat- } \\
\text { ed as MD } 18.30 \text { ( } 14.28 \text { to } \\
22.32 \text { ) (see Figure } 3 \text { ) }\end{array}$} \\
\hline & Reading training & & 36.8 & 7.2 & 18 & \\
\hline \multirow[t]{6}{*}{ Keller 2010} & $\begin{array}{l}\text { Audiovisual ex- } \\
\text { ploration training } \\
\text { (AVT) }\end{array}$ & $\begin{array}{l}\text { Functional abili- } \\
\text { ty in ADL (ADL test } \\
\text { total score) }\end{array}$ & 1.5 & $\begin{array}{l}\text { (SE dis- } \\
\text { played on } \\
\text { graph only) }\end{array}$ & 10 & \multirow[t]{2}{*}{$\begin{array}{l}\text { ANOVA P }=0.036 \text { (in favour } \\
\text { of AVT) }\end{array}$} \\
\hline & $\begin{array}{l}\text { Visual exploration } \\
\text { training }\end{array}$ & & 5.0 & $\begin{array}{l}\text { (SE dis- } \\
\text { played on } \\
\text { graph only) }\end{array}$ & 10 & \\
\hline & $\begin{array}{l}\text { Audiovisual ex- } \\
\text { ploration training } \\
\text { (AVT) }\end{array}$ & \multirow[t]{2}{*}{$\begin{array}{l}\text { Reading time (sec- } \\
\text { onds) }\end{array}$} & 75 & $\begin{array}{l}\text { (SE dis- } \\
\text { played on } \\
\text { graph only) }\end{array}$ & 10 & \multirow[t]{2}{*}{$\begin{array}{l}\text { ANOVA } P=0.03 \text { (in favour } \\
\text { of AVT) }\end{array}$} \\
\hline & $\begin{array}{l}\text { Visual exploration } \\
\text { training }\end{array}$ & & 178 & $\begin{array}{l}\text { (SE dis- } \\
\text { played on } \\
\text { graph only) }\end{array}$ & 10 & \\
\hline & $\begin{array}{l}\text { Audiovisual ex- } \\
\text { ploration training } \\
\text { (AVT) }\end{array}$ & \multirow[t]{2}{*}{$\begin{array}{l}\text { Visual scanning } \\
\text { (percentage hits) }\end{array}$} & 85.3 & $\begin{array}{l}\text { (SE dis- } \\
\text { played on } \\
\text { graph only) }\end{array}$ & 10 & \multirow[t]{2}{*}{$\begin{array}{l}\text { ANOVA P }=0.01 \text { (in favour } \\
\text { of AVT) }\end{array}$} \\
\hline & $\begin{array}{l}\text { Visual exploration } \\
\text { training }\end{array}$ & & 64.1 & $\begin{array}{l}\text { (SE dis- } \\
\text { played on } \\
\text { graph only) }\end{array}$ & 10 & \\
\hline \multirow[t]{3}{*}{$\begin{array}{l}\text { Modden } \\
2012\end{array}$} & $\begin{array}{l}\text { Computer-based } \\
\text { compensation ther- } \\
\text { apy }\end{array}$ & \multirow{2}{*}{$\begin{array}{l}\text { Visual field en- } \\
\text { largement (visual } \\
\text { field assessment } \\
\text { from Test Battery } \\
\text { of Attentional Per- } \\
\text { formance) }\end{array}$} & 2.9 & 4.0 & 15 & $\begin{array}{l}\text { Pre- to post-treatment sig- } \\
\text { nificant field expansion }(P \\
=0.013)\end{array}$ \\
\hline & $\begin{array}{l}\text { Standard occu- } \\
\text { pational therapy } \\
\text { (compensation) }\end{array}$ & & 1.3 & 4.7 & 15 & $\begin{array}{l}\text { Pre- to post-treatment: no } \\
\text { significant field expansion } \\
(P=0.316)\end{array}$ \\
\hline & $\begin{array}{l}\text { Computer-based } \\
\text { compensation ther- } \\
\text { apy (CT) }\end{array}$ & $\begin{array}{l}\text { Functional ability } \\
\text { in ADL (improve- } \\
\text { ment in Extended } \\
\text { Barthel Index) }\end{array}$ & 3.3 & 3.6 & 15 & $\begin{array}{l}\text { "No significant treatment } \\
\text { effects were found when } \\
\text { comparing ... CT/OT". }\end{array}$ \\
\hline
\end{tabular}


Table 5. Results of studies comparing two similar active interventions (i.e. two interventions from the same category) (Continued)

\begin{tabular}{|c|c|c|c|c|c|}
\hline $\begin{array}{l}\text { Standard occupa- } \\
\text { tional therapy (OT) } \\
\text { (compensation) }\end{array}$ & & 1.8 & 2.0 & 15 & \\
\hline $\begin{array}{l}\text { Computer-based } \\
\text { compensation ther- } \\
\text { apy (CT) }\end{array}$ & \multirow{2}{*}{$\begin{array}{l}\text { Reading - Im- } \\
\text { provement in } \\
\text { reading perfor- } \\
\text { mance, reduction } \\
\text { in number of er- } \\
\text { rors (from base- } \\
\text { line) }\end{array}$} & -0.9 & 1.1 & 15 & \multirow[t]{2}{*}{$\begin{array}{l}\text { "Compared with OT"... "CT } \\
\text { did not significantly re- } \\
\text { duce reading errors." }\end{array}$} \\
\hline $\begin{array}{l}\text { Standard occupa- } \\
\text { tional therapy (OT) } \\
\text { (compensation) }\end{array}$ & & -0.7 & 1.0 & 15 & \\
\hline $\begin{array}{l}\text { Computer-based } \\
\text { compensation ther- } \\
\text { apy (CT) }\end{array}$ & \multirow{2}{*}{$\begin{array}{l}\text { Visual scanning - } \\
\text { reduction in num- } \\
\text { ber of omissions } \\
\text { from baseline, } \\
\text { cancellation tasks } \\
\text { of the Test Battery } \\
\text { of Attentional Per- } \\
\text { formance }\end{array}$} & -5.4 & 5.2 & 15 & \multirow[t]{2}{*}{$\begin{array}{l}\text { "Compared with OT"... "CT } \\
\text { did not result in superior } \\
\text { improvements". }\end{array}$} \\
\hline $\begin{array}{l}\text { Standard occupa- } \\
\text { tional therapy (OT) } \\
\text { (compensation) }\end{array}$ & & -2.3 & 5 & 15 & \\
\hline
\end{tabular}

\section{Substitution: one substitution intervention versus another substitution intervention}

\begin{tabular}{|c|c|c|c|c|c|c|}
\hline \multirow[t]{4}{*}{$\begin{array}{l}\text { Bainbridge } \\
1994\end{array}$} & $\begin{array}{l}\text { Full-field Fresnel } \\
\text { Prisms }\end{array}$ & \multirow{2}{*}{$\begin{array}{l}\text { Visual Field (Har- } \\
\text { rington Flocks Vi- } \\
\text { sual Field Score) }\end{array}$} & 2.9 & 2 & 10 & \multirow[t]{2}{*}{$\begin{array}{l}\text { States full-field more im- } \\
\text { proved }\end{array}$} \\
\hline & $\begin{array}{l}\text { Hemi-field Fresnel } \\
\text { Prisms }\end{array}$ & & 7.2 & 3 & 8 & \\
\hline & $\begin{array}{l}\text { Full-field Fresnel } \\
\text { Prisms }\end{array}$ & \multirow{2}{*}{$\begin{array}{l}\text { Scanning (Line } \\
\text { cancellation test } \\
\text { errors) }\end{array}$} & 4.7 & 1.3 & 10 & \multirow{2}{*}{$\begin{array}{l}\mathrm{P}<0.01 \text {, Student's t-test } \\
\text { (in favour of full-field } \\
\text { prisms) }\end{array}$} \\
\hline & $\begin{array}{l}\text { Hemi-field Fresnel } \\
\text { Prisms }\end{array}$ & & 0.3 & 0.6 & 8 & \\
\hline \multirow[t]{2}{*}{ Szlyk 2005} & $\begin{array}{l}18.5 \text { dioptre Got- } \\
\text { tlieb Visual field } \\
\text { awareness system } \\
\text { prisms }\end{array}$ & \multirow[t]{2}{*}{$\begin{array}{l}\text { Visual skills cate- } \\
\text { gory assessment } \\
\text { battery }\end{array}$} & \multirow{2}{*}{\multicolumn{2}{|c|}{$\begin{array}{l}\text { "There was improvement } \\
\text { within all categories with } \\
\text { both of the prism systems } \\
\text { ranging from } 36 \% \text { for mobil- } \\
\text { ity (with the Fresnel prisms) } \\
\text { to } 13 \% \text { for recognition (with } \\
\text { the Gottlieb VFAS)." }\end{array}$}} & \multirow[t]{2}{*}{$\begin{array}{l}10 \text { (data } \\
\text { only avail- } \\
\text { able for af- } \\
\text { ter cross- } \\
\text { over) }\end{array}$} & \multirow{2}{*}{$\begin{array}{l}\text { "There were no statistical } \\
\text { ly significant differences } \\
\text { between improvements } \\
\text { with the Gottlieb VFAS } \\
\text { compared with the } \\
\text { Fresnel prisms." }\end{array}$} \\
\hline & $\begin{array}{l}\text { Press-on TM } 20 \\
\text { Diopter Fresnel } \\
\text { prisms }\end{array}$ & & & & & \\
\hline
\end{tabular}

ADL: activities of daily living

ANOVA: analysis of variance (statistical test of)

AVT: audiovisual exploration training

CT: compensation therapy

HRP: high-resolution perimetry

LV-VFQ: Low Vision Visual Functioning Questionnaire

$M D:$ mean difference

OT: occupational therapy

SE: standard error

SEM: standard error of the mean

tDCS: transcranial direct current stimulation

VFAS: visual field awareness system

VRT: visual restitution therapy 
Table 6. Results of studies comparing two different types of active interventions (i.e. interventions from different categories)

\begin{tabular}{|c|c|c|c|c|c|c|}
\hline Study & Interventions & Outcome & $\begin{array}{l}\text { Mean (or } \\
\text { other re- } \\
\text { ported re- } \\
\text { sult if no } \\
\text { mean avail- } \\
\text { able) }\end{array}$ & $\begin{array}{l}\text { Standard } \\
\text { deviation }\end{array}$ & $\begin{array}{l}\text { Number } \\
\text { of partici- } \\
\text { pants }\end{array}$ & Statistical test/results \\
\hline
\end{tabular}

\section{Compensation intervention versus restitution intervention}

\begin{tabular}{|c|c|c|c|c|c|c|}
\hline \multirow[t]{8}{*}{$\begin{array}{l}\text { Modden } \\
2012\end{array}$} & $\begin{array}{l}\text { Computer-based } \\
\text { restitution therapy }\end{array}$ & \multirow{2}{*}{$\begin{array}{l}\text { Visual field en- } \\
\text { largement (visu- } \\
\text { al field assess- } \\
\text { ment from Test } \\
\text { Battery of Atten- } \\
\text { tional Perfor- } \\
\text { mance) }\end{array}$} & 3.9 & \multicolumn{2}{|l|}{4.9} & \multirow{2}{*}{$\begin{array}{l}\text { Pre- to post-treatment sig- } \\
\text { nificant field expansion }(P= \\
0.003) \\
\text { Pre- to post-treatment sig- } \\
\text { nificant field expansion }(P= \\
0.013)\end{array}$} \\
\hline & $\begin{array}{l}\text { Computer-based } \\
\text { compensation ther- } \\
\text { apy }\end{array}$ & & 2.9 & 4.0 & 15 & \\
\hline & $\begin{array}{l}\text { Computer-based } \\
\text { restitution therapy } \\
\text { (RT) }\end{array}$ & \multirow{2}{*}{$\begin{array}{l}\text { Functional abil- } \\
\text { ity in ADL (im- } \\
\text { provement in Ex- } \\
\text { tended Barthel } \\
\text { Index) }\end{array}$} & 1.5 & 2.8 & 15 & \multirow[t]{2}{*}{$\begin{array}{l}\text { "No significant treatment ef- } \\
\text { fects were found when com- } \\
\text { paring ... RT/CT". }\end{array}$} \\
\hline & $\begin{array}{l}\text { Computer-based } \\
\text { compensation ther- } \\
\text { apy (CT) }\end{array}$ & & 3.3 & 3.6 & 15 & \\
\hline & $\begin{array}{l}\text { Computer-based } \\
\text { restitution therapy } \\
\text { (RT) }\end{array}$ & \multirow{2}{*}{$\begin{array}{l}\text { Reading: im- } \\
\text { provement in } \\
\text { reading perfor- } \\
\text { mance, reduc- } \\
\text { tion in number } \\
\text { of errors (from } \\
\text { baseline) }\end{array}$} & -0.9 & 2.4 & 15 & \multirow[t]{2}{*}{$\begin{array}{l}\text { "There were no differences } \\
\text { between RT and CT." }\end{array}$} \\
\hline & $\begin{array}{l}\text { Computer-based } \\
\text { compensation ther- } \\
\text { apy (CT) }\end{array}$ & & -0.9 & 1.1 & 15 & \\
\hline & $\begin{array}{l}\text { Computer-based } \\
\text { restitution therapy } \\
\text { (RT) }\end{array}$ & \multirow{2}{*}{$\begin{array}{l}\text { Visual scanning: } \\
\text { reduction in } \\
\text { number of omis- } \\
\text { sions from base- } \\
\text { line, cancella- } \\
\text { tion tasks of the } \\
\text { Test Battery of } \\
\text { Attentional Per- } \\
\text { formance }\end{array}$} & -5.3 & 10.5 & 15 & \multirow{2}{*}{$\begin{array}{l}\text { "... the improvement of the } \\
\text { CT compared with the RT } \\
\text { group did not meet the de- } \\
\text { fined significance level af- } \\
\text { ter Bonferroni correction (P } \\
=.023) . "\end{array}$} \\
\hline & $\begin{array}{l}\text { Computer-based } \\
\text { compensation ther- } \\
\text { apy (CT) }\end{array}$ & & -5.4 & 5.2 & 15 & \\
\hline \multirow[t]{3}{*}{ Roth 2009} & $\begin{array}{l}\text { Explorative scan- } \\
\text { ning training (EST) } \\
\text { (compensation) }\end{array}$ & $\begin{array}{l}\text { Visual field: Tub- } \\
\text { ingen automated } \\
\text { perimetry }\end{array}$ & 44.4 & 13.1 & 15 & \multirow{2}{*}{$\begin{array}{l}\text { "Neither the EST group nor } \\
\text { the FT group showed any dif- } \\
\text { ferences in their TAP or SLO } \\
\text { outcomes, quantified as the } \\
\text { total number of stimuli de- } \\
\text { tected in the blind hemifield } \\
\text { (lowest } P=0.204) . "\end{array}$} \\
\hline & $\begin{array}{l}\text { Flicker stimulation } \\
\text { training (FT)(resti- } \\
\text { tution) }\end{array}$ & & 35.7 & 15.2 & 13 & \\
\hline & $\begin{array}{l}\text { Explorative scan- } \\
\text { ning training (EST) } \\
\text { (compensation) }\end{array}$ & $\begin{array}{l}\text { Quality of life } \\
\text { (WHOQOL-BREF) }\end{array}$ & 12.93 & 1.67 & 15 & $\begin{array}{l}\text { "The EST group reported } \\
\text { greater improvements (T2 } \\
\text { minus T1 scores) in the WHO- } \\
\text { QOL social-relationships do- } \\
\text { main ( } t \text { test; } t(20)=2.217, \mathrm{P}=\end{array}$ \\
\hline
\end{tabular}


Table 6. Results of studies comparing two different types of active interventions (i.e. interventions from different categories) (Continued)

\begin{tabular}{|c|c|c|c|c|c|}
\hline $\begin{array}{l}\text { Flicker stimulation } \\
\text { training (FT) (resti- } \\
\text { tution) }\end{array}$ & & 13.23 & 1.3 & 13 & $\begin{array}{l}0.038) " \text { (but no significant dif- } \\
\text { ferences for other domains). }\end{array}$ \\
\hline $\begin{array}{l}\text { Explorative scan- } \\
\text { ning training (EST) } \\
\text { (compensation) }\end{array}$ & $\begin{array}{l}\text { Reading (reading } \\
\text { speed) }\end{array}$ & 99.7 & 34.7 & 15 & \multirow{2}{*}{$\begin{array}{l}\text { "Although the EST and FT } \\
\text { groups differed in their read- } \\
\text { ing speeds at T1, this differ- } \\
\text { ence remained unchanged } \\
\text { [main effect of group, } \mathrm{F}(1,26) \\
=133.074, \mathrm{P}<0.0001 \text {, interac- } \\
\text { tion, } \mathrm{F}<1 \text { ]". }\end{array}$} \\
\hline $\begin{array}{l}\text { Flicker stimulation } \\
\text { training (FT)(resti- } \\
\text { tution) }\end{array}$ & & 140.2 & 20.9 & 13 & \\
\hline
\end{tabular}

\section{Compensation intervention versus substitution intervention}

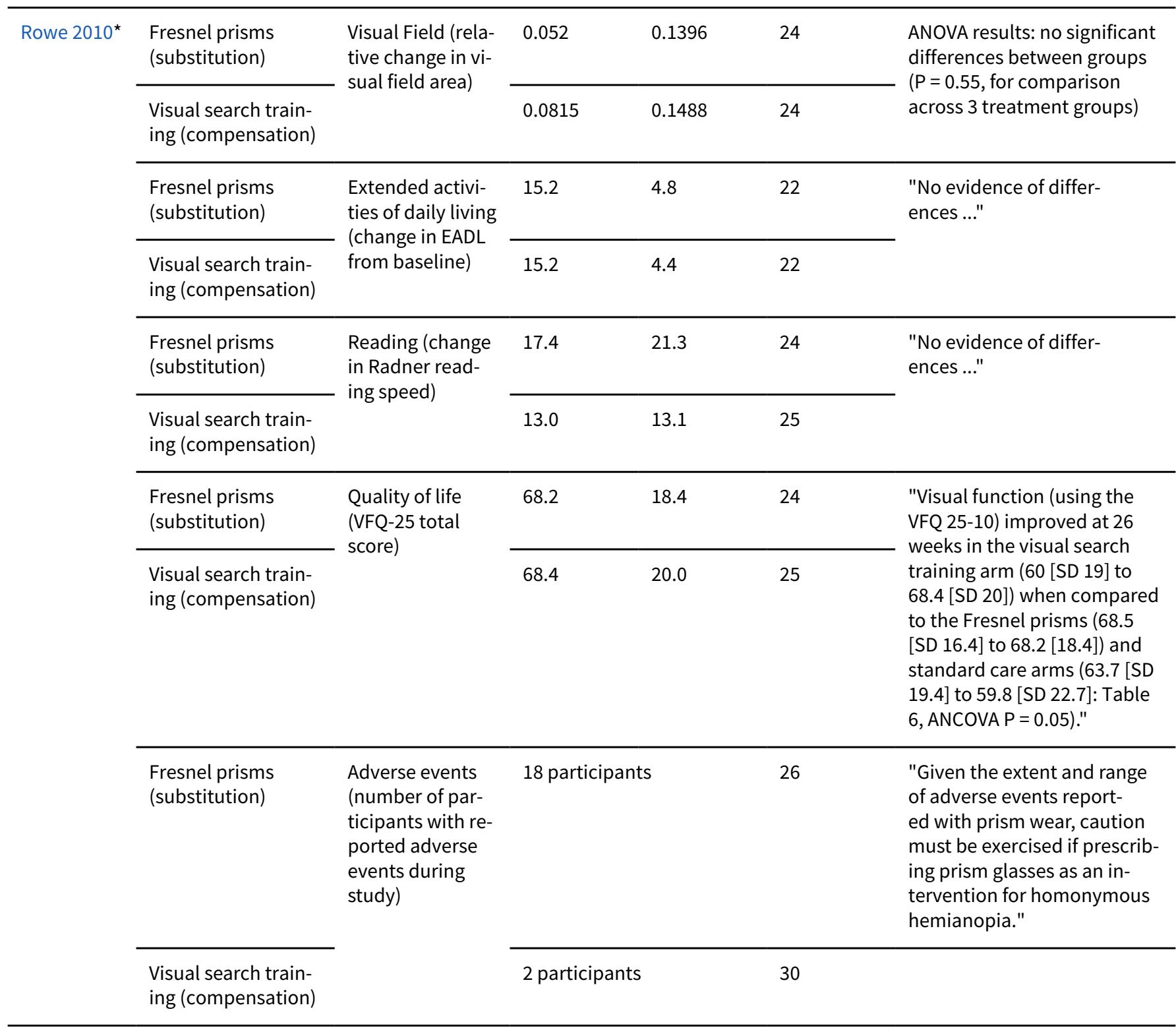

*Rowe 2010 also had a control (standard care) group, and data were included in relevant meta-analyses for compensatory and substitution interventions versus control. 
ADL: activities of daily living

ANCOVA: analysis of covariance (statistical test of)

ANOVA: analysis of variance (statistical test of)

$\mathrm{CT}$ : compensation therapy

EADL: extended activities of daily living

EST: explorative scanning training

FT: flicker stimulation training

RT: restitution therapy

SD: standard deviation

SLO: Scanning Laser Ophthalmoscope

T1: outcome asssessment timepoint 1

T2: outcome assessment timepoint 2

TAP: Tuebingen automated perimetry

VFQ: visual function questionnaire

WHOQOL-BREF: World Health Organization Quality of Life Instrument

\section{AP PEN DICES}

\section{Appendix 1. Cochrane Central Register of Controlled Trials (CENTRAL) Search Strategy}

1. MeSH descriptor Cerebrovascular Disorders, this term only

2. MeSH descriptor Basal Ganglia Cerebrovascular Disease explode all trees

3. MeSH descriptor Brain Ischemia explode all trees

4. MeSH descriptor Carotid Artery Diseases explode all trees

5. MeSH descriptor Intracranial Arterial Diseases explode all trees

6. MeSH descriptor Intracranial Arteriovenous Malformations explode all trees

7. MeSH descriptor Intracranial Embolism and Thrombosis explode all trees

8. MeSH descriptor Intracranial Hemorrhages explode all trees

9. MeSH descriptor Stroke explode all trees

10.MeSH descriptor Brain Infarction explode all trees

11. MeSH descriptor Vasospasm, Intracranial, this term only

12. MeSH descriptor Vertebral Artery Dissection, this term only

13.stroke or poststroke or post-stroke or cerebrovasc* or brain vasc ${ }^{\star}$ or cerebral vasc ${ }^{\star}$ or cva* or apoplex* or SAH

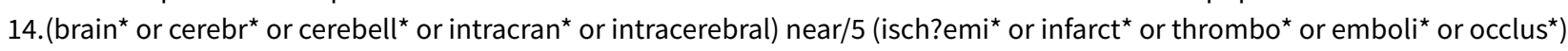

15. (brain ${ }^{\star}$ or cerebr $^{\star}$ or cerebell ${ }^{\star}$ or intracerebral or intracranial or subarachnoid) near $/ 5$ (haemorrhage* or hemorrhage $^{\star}$ or haematoma* $^{\star}$ or hematoma* or bleed*)

16. MeSH descriptor Hemiplegia, this term only

17.MeSH descriptor Paresis explode all trees

18. hemipleg* or hemipar* or paresis or paretic 1735

19. (\#1 OR \#2 OR \#3 OR \#4 OR \#5 OR \#6 OR \#7 OR \#8 OR \#9 OR \#10 OR \#11 OR\#12 OR \#13 OR\#14 OR \#15 OR \#16 OR \#17 OR \#18)

20.MeSH descriptor Eye explode all trees

21. MeSH descriptor Visually Impaired Persons explode all trees

22. MeSH descriptor Ocular Physiological Processes explode all trees

23. MeSH descriptor Diagnostic Techniques, Ophthalmological explode all trees

24.MeSH descriptor Optometry explode all trees

25. MeSH descriptor Orthoptics explode all trees

26. MeSH descriptor Eye Diseases, this term only

27.MeSH descriptor Vision Disorders, this term only

28. MeSH descriptor Eye Manifestations, this term only

29.MeSH descriptor Blindness, this term only

30.MeSH descriptor Diplopia explode all trees

31.MeSH descriptor Vision, Binocular, this term only

32. MeSH descriptor Vision, Monocular, this term only 
33. MeSH descriptor Visual Acuity explode all trees

34.MeSH descriptor Visual Fields, this term only

35. MeSH descriptor Vision, Low, this term only

36. MeSH descriptor Perimetry, this term only

37. MeSH descriptor Ophthalmology, this term only

38. MeSH descriptor Vision Screening, this term only

39. MeSH descriptor Eye Diseases, Hereditary explode all trees

40.MeSH descriptor Eye Hemorrhage explode all trees

41.MeSH descriptor Lacrimal Apparatus Diseases explode all trees

42. MeSH descriptor Lens Diseases explode all trees

43. MeSH descriptor Ocular Hypertension explode all trees

44.MeSH descriptor Ocular Hypotension explode all trees

45. MeSH descriptor Ocular Motility Disorders explode all trees

46. MeSH descriptor Optic Nerve Diseases explode all trees

47. MeSH descriptor Orbital Diseases explode all trees

48. MeSH descriptor Pupil Disorders explode all trees

49. MeSH descriptor Refractive Errors explode all trees

50.MeSH descriptor Retinal Diseases explode all trees

51.MeSH descriptor Blindness, Cortical explode all trees

52. MeSH descriptor Hemianopsia explode all trees

53. MeSH descriptor Vitreoretinopathy, Proliferative explode all trees

54. MeSH descriptor Vitreous Detachment explode all trees

55. MeSH descriptor Scotoma, this term only

56. MeSH descriptor Abducens Nerve, this term only

57. MeSH descriptor Oculomotor Nerve, this term only

58. MeSH descriptor Trochlear Nerve, this term only

59.nystagmus or smooth pursuit or saccades or depth perception or stereopsis or gaze disorder* or retinal or retinopathy or macular degeneration or glaucoma or cataract ${ }^{\star}$ or ophthalmol* or optic nerve

60.intranuclear ophthalmoplegia or parinaud's syndrome or weber's syndrome or skew deviation or conjugate deviation

61.one near/3 half syndrome

62. (visual ${ }^{\star}$ or vision or eye or eyes or eyesight or sight) near/5 (problem ${ }^{\star}$ or disorder ${ }^{\star}$ or impair ${ }^{\star}$ or disabilit ${ }^{\star}$ or loss or disease* or defect ${ }^{\star}$ or manifestation* or screening or test* or examination*)

63.hemianop* or blindness or low vision or refractive errors or vitreoretinopathy or vitreous detachment or scotoma or diplopia or optometr* or ocular or orthoptic*

64.oscillopsia or visual tracking or fresnel prism*

65.III or IV or VI or third or fourth or sixth near/3 nerve palsy

66. (\#20 OR \#21 OR \#22 OR \#23 OR \#24 OR \#25 OR \#26 OR \#27 OR \#28 OR \#29 OR \#30 OR \#31 OR \#32 OR \#33 OR \#34 OR \#35 OR \#36 OR \#37 OR \#38 OR \#39 OR \#40 OR \#41 OR \#42 OR \#43 OR \#44 OR \#45 OR \#46 OR \#47 OR \#48 OR \#49 OR \#50 OR \#51 OR \#52 OR \#53 OR \#54 OR \#55 OR \#56 OR \#57 OR \#58 OR \#59 OR \#60 OR \#61 OR \#62 OR \#63 OR \#64 OR \#65)

67.(\#19 AND \#66)

68. MeSH descriptor Infant explode all trees

69. MeSH descriptor Child explode all trees

70.neonat* or child or children or childhood or juvenile or infan* or toddler

71. MeSH descriptor Neoplasms explode all trees

72. cancer $^{\star}$ or carcinoma ${ }^{\star}$ or tumor ${ }^{\star}$ or tumour ${ }^{\star}$ or neoplasm ${ }^{\star}$

73. (\#68 OR \#69 OR \#70 OR \#71 OR \#72)

74.(\#67 AND NOT \#73)

\section{Appendix 2. MEDLINE (Ovid) Search Strategy}

1. cerebrovascular disorders/or exp basal ganglia cerebrovascular disease/ or exp brain ischemia/ or exp carotid artery diseases/or cerebral small vessel diseases/ or stroke, lacunar/ or exp intracranial arterial diseases/ or exp intracranial arteriovenous malformations/ or exp "intracranial embolism and thrombosis"/ or exp intracranial hemorrhages/or stroke/ or exp brain infarction/or vasospasm, intracranial/ or vertebral artery dissection/

2. (stroke or poststroke or post-stroke or cerebrovasc\$ or brain vasc\$ or cerebral vasc\$ or cva\$ or apoplex\$or SAH).tw. 
3. ((brain\$ or cerebr\$ or cerebell\$ or intracran\$ or intracerebral) adj5 (isch?emi\$ or infarct\$ or thrombo or emboli\$ or occlus\$)).tw.

4. ((brain\$ or cerebr\$ or cerebell\$ or intracerebral or intracranial or subarachnoid) adj5 (haemorrhage\$ or hemorrhage\$ or haematoma\$ or hematoma\$ or bleed\$)).tw.

5. hemiplegia/ or exp paresis/

6. (hemipleg\$ or hemipar\$ or paresis or paretic).tw.

7. 1 or 2 or 3 or 4 or 5 or 6

8. exp eye/

9. exp visually impaired persons/

10. exp ocular physiological processes/ or exp diagnostic techniques, ophthalmological/

11. Optometry/ or Orthoptics/

12. eye diseases/ or vision disorders/ or eye manifestations/ or blindness/ or diplopia/

13. vision, binocular/ or vision, monocular/ or exp visual acuity/ or visual fields/ or vision, low/ or perimetry/or ophthalmology/ or vision screening/

14. exp ocular motility disorders/or exp orbital diseases/or exp pupil disorders/or exp blindness, cortical/or exp hemianopsia/ or scotoma/

15. abducens nerve/ or oculomotor nerve/ or trochlear nerve/

16. (nystagmus or smooth pursuit or saccades or depth perception or stereopsis or gaze disorder\$ or ophthalmol\$ or optic nerve).tw.

17. (intranuclear ophthalmoplegia or parinaud's syndrome or weber's syndrome or skew deviation or conjugate deviation or (one adj3 half syndrome)).tw.

18. ((visual\$ or vision or eye or eyes or eyesight or sight) adj5 (problem\$ or disorder\$ or impair\$ or disabilit\$ or loss or disease\$ or defect \$ or manifestation\$ or screening or test\$ or examination\$)).tw.

19. (hemianop\$ or blindness or low vision or scotoma or diplopia or optometr\$ or ocular or orthoptic\$).tw.

20. (oscillopsia or visual tracking or fresnel prism\$).tw.

21. ((III or IV or VI or third or fourth or sixth) adj3 nerve palsy).tw.

22. or/8-21

23. Randomized Controlled Trials as Topic/

24. random allocation/

25. Controlled Clinical Trials as Topic/

26. control groups/

27. clinical trials as topic/ or clinical trials, phase i as topic/ or clinical trials, phase ii as topic/ or clinical trials, phase iii as topic/ or clinical trials, phase iv as topic/

28. double-blind method/

29. single-blind method/

30. Placebos/

31. placebo effect/

32. cross-over studies/

33. randomized controlled trial.pt.

34. controlled clinical trial.pt.

35. (clinical trial or clinical trial phase i or clinical trial phase ii or clinical trial phase iii or clinical trial phase iv).pt.

36. (random\$ or RCT or RCTs).tw.

37. (controlled adj5 (trial\$ or stud\$)).tw.

38. (clinical\$ adj5 trial\$).tw.

39. ((control or treatment or experiment\$ or intervention) adj5 (group\$ or subject\$ or patient\$)).tw.

40. (quasi-random $\$$ or quasi random $\$$ or pseudo-random $\$$ or pseudo random $\$$ ).tw.

41. ((control or experiment\$ or conservative) adj5 (treatment or therapy or procedure or manage $\$)$ ).tw.

42. ((singl\$ or doubl\$ or tripl\$ or trebl\$) adj5 (blind\$ or mask\$)).tw.

43. (cross-over or cross over or crossover).tw.

44. (placebo\$ or sham).tw.

45. trial.ti.

46. (assign\$ or allocat\$).tw.

47. controls.tw.

48. or/23-47

49. 7 and 22 and 48

50. exp animals/ not humans.sh.

51.49 not 50

52. (neonat\$ or child or children or childhood or juvenile or infant or toddler).ti.

53.51 not 52

\section{Appendix 3. Embase Search Strategy}

1. cerebrovascular disease/ or exp basal ganglion hemorrhage/ or exp brain hematoma/ or exp brain hemorrhage/ or exp brain infarction/ or exp brain ischemia/ or exp carotid artery disease/ or cerebral artery disease/ or exp cerebrovascular accident/ or exp cerebrovascular malformation/ or exp intracranial aneurysm/ or exp occlusive cerebrovascular disease/ or stroke unit/ or stroke patient/ 
2. (stroke or poststroke or post-stroke or cerebrovasc\$ or brain vasc\$ or cerebral vasc\$ or cva $\$$ or apoplex\$ or SAH).tw.

3. ((brain $\$$ or cerebr $\$$ or cerebell\$ or intracran\$ or intracerebral) adj5 (isch?emi\$ or infarct\$ or thrombo $\$$ or emboli\$ or occlus\$)).tw.

4. ((brain $\$$ or cerebr\$ or cerebell\$ or intracerebral or intracranial or subarachnoid) adj5 (haemorrhage\$ or hemorrhage\$ or haematoma\$ or hematoma\$ or bleed\$)).tw.

5. hemiparesis/ or hemiplegia/ or paresis/

6. (hemipleg\$ or hemipar\$ or paresis or paretic).tw.

7. 1 or 2 or 3 or 4 or 5 or 6

8. exp eye/ or exp eye disease/ or exp visual disorder/

9. exp visual system examination/ or eye examination/ or exp vision test/

10. exp ophthalmology/ or orthoptics/or exp visual system/ or exp visual system function/ or depth perception/

11. exp visual aid/

12. abducens nerve/ or oculomotor nerve/ or trochlear nerve/

13. (nystagmus or smooth pursuit or saccades or depth perception or stereopsis or gaze disorder\$ or ophthalmol\$ or optic nerve).tw.

14. (intranuclear ophthalmoplegia or parinaud's syndrome or weber's syndrome or skew deviation or conjugate deviation or (one adj3 half syndrome)).tw.

15. ((visual\$ or vision or eye or eyes or eyesight or sight) adj5 (problem\$ or disorder\$ or impair\$ or disabilit\$ or loss or disease\$ or defect $\$$ or manifestation $\$$ or screening or test $\$$ or examination $\$)$ ).tw.

16. (hemianop\$ or blindness or low vision or scotoma or diplopia or optometr\$ or ocular or orthoptic\$).tw.

17. (oscillopsia or visual tracking or fresnel prism\$).tw.

18. ((III or IV or VI or third or fourth or sixth) adj3 nerve palsy).tw.

19. or/8-18

20. Randomized Controlled Trial/ or "randomized controlled trial (topic)"/

21. Randomization/

22. Controlled clinical trial/ or "controlled clinical trial (topic)"/

23. control group/ or controlled study/

24. clinical trial/ or "clinical trial (topic)"/ or phase $1 \mathrm{clinical}$ trial/ or phase 2 clinical trial/ or phase $3 \mathrm{clinical}$ trial/ or phase $4 \mathrm{clinical}$ trial/

25. Crossover Procedure/

26. Double Blind Procedure/

27. Single Blind Procedure/ or triple blind procedure/

28. placebo/ or placebo effect/

29. (random\$ or RCT or RCTs).tw.

30. (controlled adj5 (trial\$ or stud\$)).tw.

31. (clinical\$ adj5 trial\$).tw.

32. ((control or treatment or experiment\$ or intervention) adj5 (group\$ or subject\$ or patient\$)).tw.

33. (quasi-random $\$$ or quasi random\$ or pseudo-random $\$$ or pseudo random\$).tw.

34. ((control or experiment\$ or conservative) adj5 (treatment or therapy or procedure or manage $\$)$ ).tw.

35. ((singl\$ or doubl\$ or tripl\$ or trebl\$) adj5 (blind\$ or mask\$)).tw.

36. (cross-over or cross over or crossover).tw.

37. (placebo\$ or sham).tw.

38. trial.ti.

39. (assign\$ or allocat\$).tw.

40. controls.tw.

41. or $/ 20-40$

42. 7 and 19 and 41

43. (exp animals/or exp invertebrate/ or animal experiment/ or animal model/or animal tissue/ or animal cell/ or nonhuman/) not (human/ or normal human/ or human cell/)

44.42 not 43

45. (neonat\$ or child or children or childhood or juvenile or infant or toddler).ti.

46. exp Neoplasm/

47. (cancer\$ or carcinoma\$ or tumor\$ or tumour\$ or neoplasm\$).tw.

48. 45 or 46 or 47

49. 44 not 48

\section{Appendix 4. CINAHL Search Strategy}

S1. MH "Cerebrovascular Disorders+" or MH "stroke patients" or MH "stroke units"

S2. TI ( stroke or poststroke or post-stroke or cerebrovasc* or brain vasc ${ }^{*}$ ) or AB ( stroke or poststroke or post-stroke or cerebrovasc ${ }^{*}$ or brain vasc $\left.{ }^{*}\right)$

S3. TI ( brain* or cerebr ${ }^{\star}$ or cerebell* or intracran* or intracerebral ) or AB ( brain* or cerebr* or cerebell ${ }^{\star}$ or intracran $^{\star}$ or intracerebral )

S4. TI ( ischemi ${ }^{\star}$ or ischaemi ${ }^{\star}$ or infarct ${ }^{\star}$ or thrombo* or emboli* or occlus ${ }^{\star}$ ) or AB (ischemi ${ }^{\star}$ or ischaemi ${ }^{\star}$ or infarct ${ }^{\star}$ or thrombo $^{\star}$ or emboli ${ }^{\star}$ or occlus ${ }^{\star}$ )

S5. S3 and S4 
S6. TI ( brain ${ }^{\star}$ or cerebr ${ }^{\star}$ or cerebell ${ }^{\star}$ or intracerebral or intracranial or subarachmoid ) or AB ( brain ${ }^{\star}$ or cerebr $^{\star}$ or cerebell ${ }^{\star}$ or intracerebral or intracranial or subarachnoid )

S7. TI ( haemorrhage* or hemorrhage* or haematoma* or hematoma* or bleed ${ }^{\star}$ ) or AB ( haemorrhage* or hemorrhage* or haematoma* or hematoma* or bleed ${ }^{*}$ )

S8. S6 and S7

S9. MH "Hemiplegia"

S10. TI ( hemipleg* or hemipar* or paresis or paretic) or AB ( hemipleg* or hemipar* or paresis or paretic

$\mathrm{S} 11 . \mathrm{S} 1$ or S2 or S5 or S8 or S9 or S10

S12. MH "Eye+" or MH "Rehabilitation of Vision Impaired+" or MH "Optometry" or MH "Eye Diseases+"

S13. MH "Visual Acuity+" or MH "Perimetry+" or MH "Ophthalmology+" or MH "Vision Screening+" or MH "Ocular Physiology+"

S14. TI (orthoptics or vision, monocular or vision, binocular) or AB ( orthoptics or vision, monocular or vision, binocular )

S15. TI ( vitreous detachment or hemianopsia or hemianopia or quadrantanopia ) or AB ( vitreous detachment or hemianopsia or hemianopia or quadrantanopia )

S16. MH "Abducens Nerve" or MH "oculomotor nerve" or MH "troclear nerve" or MH "optic nerve" or MH "nystagmus, pathologic

S17. TI ( smooth pursuit or saccades or gaze disorder* or retinal or retinopathy or ophthalmol ${ }^{\star}$ ) or AB ( smooth pursuit or saccades or gaze disorder* or retinal or retinopathy or ophthalmol ${ }^{\star}$ )

S18. TI ( hemianop* or blindness or low vision or refractive errors or vitreoretinopathy or vitreous detachment or scotoma or diplopia or optometry ${ }^{\star}$ or ocular or orthoptic ${ }^{\star}$ ) or $A B$ ( hemianop* or blindness or low vision or refractive errors or vitreoretinopathy or vitreous detachment or scotoma or diplopia or optometry ${ }^{\star}$ or ocular or orthoptic $\left.{ }^{\star}\right)$

S19. TI ( oscillopsia or visual tracking or fresnel prism* ) or AB ( oscillopsia or visual tracking or fresnel prism*)

S20. TI ( intranuclear ophthalmoplegia or parinaud's syndrome or weber's syndrome or skew deviation or conjugate deviation ) or $A B$ ( intranuclear ophthalmoplegia or parinaud's syndrome or weber's syndrome or skew deviation or conjugate deviation )

S21. TI ( visual* or vision or eye or eyes or eyesight or sight ) or AB ( visual* or vision or eye or eyes or eyesight or sight)

S22. TI ( problem ${ }^{\star}$ or disorder ${ }^{\star}$ or impair ${ }^{\star}$ or disability ${ }^{\star}$ or loss or disease* or defect ${ }^{\star}$ or manifestation ${ }^{\star}$ or screening or test* or examination $^{\star}$ ) or AB ( problem ${ }^{\star}$ or disorder ${ }^{\star}$ or impair ${ }^{\star}$ or disability ${ }^{\star}$ or loss or disease* or defect* or manifestation $^{\star}$ or screening or test ${ }^{\star}$ or examination ${ }^{\star}$ ) S23. S21 and S22

S24. TI ( third or fourth or sixth ) or AB ( third or fourth or sixth )

$\mathrm{S} 25 . \mathrm{AB}$ nerve palsy or TI nerve palsy

S26. S24 and S25

$\mathrm{S} 27 . \mathrm{S} 12$ or $\mathrm{S} 13$ or $\mathrm{S} 14$ or $\mathrm{S} 15$ or S16 or S17 or S18 or S19 or S20 or S23 or S26

S28. S11 and S27

S29. (MH "Random Assignment") or (MH "Random Sample+")

S30. (MH "Crossover Design") or (MH "Clinical Trials+") or (MH "Comparative Studies")

S31. (MH "Control (Research)") or (MH "Control Group")

S32. (MH "Factorial Design") or (MH "Quasi-Experimental Studies") or (MH "Nonrandomized Trials")

S33. (MH "Placebo Effect") or (MH "Placebos") or (MH "Meta Analysis")

S34. (MH "Community Trials") or (MH "Experimental Studies") or (MH "One-Shot Case Study") or (MH "Pretest-Posttest Design+") or (MH "Solomon Four-Group Design") or (MH "Static Group Comparison") or (MH "Study Design")

S35. (MH "Clinical Research") or (MH "Clinical Nursing Research")

S36. PT clinical trial

S37. PT systematic review

S38. TI random* or AB random*

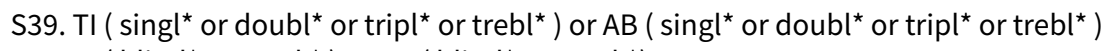

S40. TI ( blind ${ }^{\star}$ or mask* ) or AB ( blind ${ }^{\star}$ or mask ${ }^{\star}$ )

S41. S39 and S40

S42. TI ( crossover or cross-over or placebo* or control ${ }^{\star}$ or factorial or sham ) or AB ( crossover or cross-over or placebo* or control* or factorial or sham )

S43. TI ( clin* or intervention* or compar ${ }^{\star}$ or experiment ${ }^{\star}$ or preventive or therapeutic ) or AB ( clin* or intervention* or compar ${ }^{\star}$ or experiment ${ }^{\star}$ or preventive or therapeutic)

S44. TI trial ${ }^{*}$ or AB trial ${ }^{*}$

S45. S43 and S44

S46. TI ( counterbalance* or multiple baseline* or ABAB design ) or AB ( counterbalance* or multiple baseline* or ABAB design )

S47. TI ( meta analysis* or metaanlaysis or meta-anlaysis or systematic review*) or AB ( meta analysis* or metaanlaysis or meta-anlaysis or systematic review* ${ }^{\star}$ )

$\mathrm{S} 48 . \mathrm{S} 29$ or $\mathrm{S} 30$ or $\mathrm{S} 31$ or S32 or S33 or S34 or S35 or S36 or S37 or S38 or S41 or S42 or S45 or S46 or S47

S49. S28 AND S48

\section{Appendix 5. AMED Search Strategy}

1. cerebrovascular disorders/ or cerebral hemorrhage/ or cerebral infarction/ or cerebral ischemia/ or cerebrovascular accident/ or stroke/

2. (stroke or poststroke or post-stroke or cerebrovasc $\$$ or brain vasc $\$$ or cerebral vasc $\$$ or cva $\$$ or apoplex $\$$ or SAH).tw.

3. ((brain $\$$ or cerebr\$ or cerebell\$ or intracran\$ or intracerebral) adj5 (isch?emi\$ or infarct\$ or thrombo $\$$ or emboli\$ or occlus\$)).tw. 
4. ((brain\$ or cerebr\$ or cerebell\$ or intracerebral or intracranial or subarachnoid) adj5 (haemorrhage\$ or hemorrhage\$ or haematoma\$ or hematoma\$ or bleed\$)).tw.

5. hemiplegia/

6. (hemipleg\$ or hemipar\$ or paresis or paretic).tw.

7. 1 or 2 or 3 or 4 or 5 or 6

8. exp eye/

9. eye disease/ or exp ocular motility disorders/ or exp vision disorders/ or optic nerve/

10. (nystagmus or smooth pursuit or saccades or depth perception or stereopsis or gaze disorder\$ or ophthalmol\$ or optic nerve).tw.

11. (intranuclear ophthalmoplegia or parinaud's syndrome or weber's syndrome or skew deviation or conjugate deviation or (one adj3 half syndrome)).tw.

12. ((visual\$ or vision or eye or eyes or eyesight or sight) adj5 (problem\$ or disorder $\$$ or impair $\$$ or disabilit\$ or loss or disease $\$$ or defect \$ or manifestation $\$$ or screening or test $\$$ or examination\$)).tw.

13. (hemianop\$ or blindness or low vision or scotoma or diplopia or optometr\$ or ocular or orthoptic\$).tw.

14. (oscillopsia or visual tracking or fresnel prism\$).tw.

15. ((III or IV or VI or third or fourth or sixth) adj3 nerve palsy).tw.

16. or/8-15

17. clinical trials/ or randomized controlled trials/ or random allocation/

18. research design/ or comparative study/

19. double blind method/ or single blind method/

20. placebos/

21. (random\$ or RCT or RCTs).tw.

22. (controlled adj5 (trial\$ or stud\$)).tw.

23. (clinical\$ adj5 trial\$).tw.

24. ((control or treatment or experiment\$ or intervention) adj5 (group\$ or subject\$ or patient\$)).tw.

25. (quasi-random $\$$ or quasi random\$ or pseudo-random $\$$ or pseudo random\$).tw.

26. ((control or experiment\$ or conservative) adj5 (treatment or therapy or procedure or manage\$)).tw.

27. ((singl\$ or doubl\$ or tripl\$ or trebl\$) adj5 (blind\$ or mask\$)).tw.

28. (cross-over or cross over or crossover).tw.

29. (placebo\$ or sham).tw.

30. trial.ti.

31. (assign\$ or allocat\$).tw.

32. controls.tw.

33. or/17-32

34.7 and 16 and 33

\section{Appendix 6. PsycINFO Search Strategy}

1. cerebrovascular disorders/ or cerebral hemorrhage/ or exp cerebral ischemia/ or cerebral small vessel disease/ or cerebrovascular accidents/ or subarachnoid hemorrhage/

2. (stroke or poststroke or post-stroke or cerebrovasc\$ or brain vasc\$ or cerebral vasc\$ or cva\$ or apoplex\$ or SAH).tw.

3. ((brain\$ or cerebr\$ or cerebell\$ or intracran\$ or intracerebral) adj5 (isch?emi\$ or infarct $\$$ or thrombo $\$$ or emboli\$ or occlus\$)).tw.

4. ((brain $\$$ or cerebr\$ or cerebell\$ or intracerebral or intracranial or subarachnoid) adj5 (haemorrhage\$ or hemorrhage\$ or haematoma\$ or hematoma\$ or bleed\$)).tw.

5. hemiplegia/ or hemiparesis/

6. (hemipleg\$ or hemipar\$ or paresis or paretic).tw.

7. 1 or 2 or 3 or 4 or 5 or 6

8. exp "eye (anatomy)"/

9. optometry/ or ophthalmology/ or ophthalmologic examination/

10. exp eye disorders/ or exp eye movements/or exp vision disorders/

11. binocular vision/ or monocular vision/ or visual acuity/ or visual field/ or peripheral vision/ or exp depth perception/

12. optic nerve/ or abducens nerve/

13. (nystagmus or smooth pursuit or saccades or depth perception or stereopsis or gaze disorder\$ or ophthalmol\$ or optic nerve).tw.

14. (intranuclear ophthalmoplegia or parinaud's syndrome or weber's syndrome or skew deviation or conjugate deviation or (one adj3 half syndrome)).tw.

15. ((visual\$ or vision or eye or eyes or eyesight or sight) adj5 (problem\$ or disorder\$ or impair\$ or disabilit\$ or loss or disease\$ or defect \$ or manifestation $\$$ or screening or test $\$$ or examination $\$)$ ).tw.

16. (hemianop\$ or blindness or low vision or scotoma or diplopia or optometr\$ or ocular or orthoptic\$).tw.

17. (oscillopsia or visual tracking or fresnel prism\$).tw.

18. ((III or IV or VI or third or fourth or sixth) adj3 nerve palsy).tw.

19. or/8-18

20. clinical trials/ or treatment effectiveness evaluation/ or placebo/

21. (random\$ or RCT or RCTs).tw. 
22. (controlled adj5 (trial\$ or stud\$)).tw.

23. (clinical\$ adj5 trial\$).tw.

24. ((control or treatment or experiment\$ or intervention) adj5 (group\$ or subject\$ or patient\$)).tw.

25. (quasi-random $\$$ or quasi random\$ or pseudo-random $\$$ or pseudo random\$).tw.

26. ((control or experiment\$ or conservative) adj5 (treatment or therapy or procedure or manage\$)).tw.

27. ((singl\$ or doubl\$ or tripl\$ or trebl\$) adj5 (blind\$ or mask\$)).tw.

28. (cross-over or cross over or crossover).tw.

29. (placebo\$ or sham).tw.

30. trial.ti.

31. (assign\$ or allocat\$).tw.

32. controls.tw.

33. or $/ 20-32$

34.7 and 19 and 33

\section{Appendix 7. PQDT Search Strategy}

stroke AND hemianopia

OR

stroke AND "visual field"

OR

cerebrovascular AND hemianopia

$\mathrm{OR}$

cerebrovascular AND "visual field"

\section{Appendix 8. Trials Registers Search Strategies}

\section{US National Institutes of Health Ongoing Trials Register: ClinicalTrials.gov}

(www.clinicaltrials.gov):

( hemianopia OR visual field OR vision defect OR eye diseases) AND ( Brain Infarction OR Intracranial Hemorrhages OR Carotid Artery Diseases OR Brain Ischemia OR Cerebral Hemorrhage OR Cerebrovascular Disorders OR Stroke ) [DISEASE]

\section{World Health Organization International Clinical Trials Registry Platform}

(apps.who.int/trialsearch):

stroke AND hemianopia OR stroke AND visual field

cerebrovascular AND hemianopia OR cerebrovascular AND visual field

WHAT'S NEW

\begin{tabular}{lll}
\hline Date & Event & Description \\
\hline 4 September 2020 & Amended & $\begin{array}{l}\text { Correction to referencing mistake in 'Summary of findings' table } \\
1\end{array}$
\end{tabular}

\section{H I S T ORY}

Protocol first published: Issue 3, 2010

Review first published: Issue 10, 2011 


\begin{tabular}{|c|c|c|}
\hline Date & Event & Description \\
\hline 26 February 2019 & New search has been performed & $\begin{array}{l}\text { Review updated, with searches completed in May } 2018 \text {. The re- } \\
\text { view now includes } 20 \text { studies; previous ( } 2009 \text { ) version includ- } \\
\text { ed } 13 \text { studies. In this updated version, we have excluded three } \\
\text { of the studies from the } 2009 \text {; therefore, this updated version in- } \\
\text { cludes } 10 \text { studies which were included in the previous (2009) ver- } \\
\text { sion and } 10 \text { new studies, with a total of } 547 \text { participants with } \\
\text { stroke. }\end{array}$ \\
\hline 11 October 2018 & $\begin{array}{l}\text { New citation required and conclusions } \\
\text { have changed }\end{array}$ & $\begin{array}{l}\text { The update of this review has led to changes in the conclusions } \\
\text { relating to compensatory interventions (with greater uncertainty } \\
\text { around previous, limited evidence of effectiveness), and has in- } \\
\text { troduced new evidence relating to adverse events (particularly } \\
\text { headache) associated with substitutive interventions. }\end{array}$ \\
\hline
\end{tabular}

\section{CONTRIBUTIONS OF AUTHORS}

For this version: Alex Pollock led the review update, identified relevant studies, provided methodological expertise, extracted data, entered data, carried out analyses, and wrote the final drafts. Pauline Campbell ran searches, contributed to screening of titles, provided methodological expertise, and read and commented on drafts. Christine Hazelton screened titles, identified relevant studies, extracted data, acted as a second review author, provided content expertise, and contributed to final drafts. Fiona Rowe acted as a second review author, provided content expertise, extracted and synthesised data relating to outcome measures, and contributed to final drafts. Sven Jonuscheit and Ashleigh Kernohan applied inclusion criteria to abstracts and full papers, identified relevant studies, extracted data, and read and commented on drafts. Jayne Angilley, Clair Henderson, and Peter Langhorne read and commented on drafts.

For the previous (2009) version: Alex Pollock led this review, provided methodological expertise, acted as a second review author, carried out analyses, and wrote the final drafts. Christine Hazelton ran searches, identified relevant studies, acted as first review author, extracted data, entered data, provided content expertise, and contributed to final drafts. Clair Henderson acted as a second review author for the identification of relevant studies. Baljean Dhillon, Heather Orr, Katrina Livingstone, Frank A Munro, Fiona Rowe, Uma Shahani, Jayne Angilley, and Peter Langhorne provided additional content expertise, read and commented on final drafts, and acted as additional reviewers where there was uncertainty or disagreement. Peter Langhorne also provided additional methodological expertise where there was uncertainty about the methodological design of studies.

\section{DECLARATIONS OF INTEREST}

Alex Pollock was involved in the VISION trial (Rowe 2010), which was funded by the Stroke Association. No other known interest.

Christine Hazelton has carried out non-randomised studies into the effectiveness of a number of scanning training interventions, including the intervention studied by Roth 2009, and is developing further project proposals in this area. No other known interest.

Fiona Rowe was the chief investigator for the VISION trial (Rowe 2010), funded by the Stroke Association. She was a co-investigator for the Jarvis 2012 trial, funded by the University of Liverpool.

Sven Jonuscheit: none known.

Ashleigh Kernohan: none known.

Jayne Angilley: none known.

Clair A Henderson: none known.

Peter Langhorne: none known.

Pauline Campbell: none known.

The work presented here represents the view of the review authors and not necessarily those of the funding bodies. 


\section{SOURCESOF SUPPORT}

\section{Internal sources}

- No sources of support supplied

\section{External sources}

- Royal National Institute of Blind People (RNIB, Scotland), UK RNIB (Scotland) funded the first (2009) version of this review.

- Chief Scientist Office, UK

Alex Pollock and Pauline Campbell are employed by the Nursing, Midwifery and Allied Health Professions Research Unit, which is funded by the Chief Scientist Office in Scotland.

\section{DIFFERENCES BETWEEN PROTOCOLANDREVIEW}

\section{Participants}

In the 2011 version of the review, we included studies that investigated the effectiveness of visual scanning training and techniques even if the population of participants had not been clearly defined as having visual field defects. This decision was made in consultation with a multidisciplinary group of clinicians ( $\mathrm{CH}, \mathrm{JA}, \mathrm{BD}, \mathrm{KL}, \mathrm{PL}, \mathrm{FM}, \mathrm{HO}, \mathrm{FR}, \mathrm{US})$; the decision was that it was clinically relevant and useful to include these studies. It is recognised that, in these studies, the visual scanning problems experienced by participants may have been due to either visual field defects, visual neglect, or a combination of both. The results of these studies were therefore relevant to the population of patients with 'visual scanning' problems, regardless of the physiological cause of the scanning problem. Data from these studies would not be combined with data arising from studies which include a population of patients with visual field defects but not visual neglect. In this update, this decision was reconsidered, and reversed: populations of participants with 'visual scanning problems', but no confirmed visual field defect have been excluded.

\section{Comparisons}

In the 2011 version, we included one additional comparison that we did not outline in the protocol. This was a comparison of compensative intervention versus restitutive interventions. Although not preplanned, discussion amongst the review authors led to the conclusion that this was a clinically relevant comparison and ought to be included in this review. However, for this updated review, we reached consensus that we should adhere to the prestated comparisons, but that we should include a summary of results data from any studies which compared two active interventions (i.e. studies with no control group). This has been added as Table 5 and Table 6 and a narrative synthesis included under Effects of interventions.

\section{Subgroup analyses}

The following subgroup analyses were listed as planned in the protocol and previous versions of this review, but have been removed, as Cochrane guidance recommends restricting the number of subgroup analyses as large numbers can lead to spurious explanations of heterogeneity (Higgins 2011):

- age (under 60 years, 60 years and over);

- gender (men, women);

- side of stroke (left, right, bilateral);

- presence of age-related visual problems (presence, absence);

- presence of eye movement disorders (presence, absence);

- level of motor impairment (mild, moderate, severe);

- level of cognitive impairment (mild, moderate, severe).

\section{Search strategy}

Due to available time and resources for this latest update, and following a detailed consideration of the comprehensiveness of other databases:

- we searched, for the 2011 version of this review, the following databases, but did not search them for this updated version:

* British Nursing Index (searched 1985 to 31 December 2009);

* PsycBITE (Psychological Database for Brain Impairment Treatment Efficacy) at www.psycbite.com (last searched December 2009).

* Trials Central (www.trialscentral.org) (last searched February 2010). 
- for the 2011 version, but not for this updated version, we also:

* searched the references supplied by commercial companies providing interventions aimed at restoration of visual field defect (including NovaVision ${ }^{\circledR}$ );

* performed citation tracking using Web of Science Cited Reference Search for all included studies;

* handsearched proceedings of Association for Research in Vision and Opthalmology (www.arvo.org) (1969 to 2010); these abstracts are now covered by MEDLINE, so were not included in the 2018 handsearching activities.

\section{INDEX TERMS}

\section{Medical Subject Headings (MeSH)}

Quality of Life; Randomized Controlled Trials as Topic; Stroke [ ${ }^{*}$ complications]; Vision Disorders [etiology] [ ${ }^{\star}$ rehabilitation]; Visual Fields

\section{MeSH check words}

Humans 